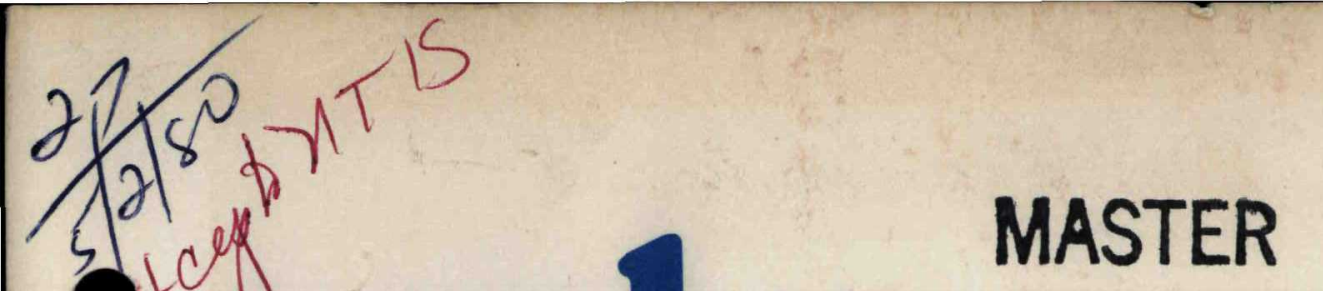

ORNL/SUB-79/13837/2

\title{
STATE OF THE ART REVIEW OF RADIOACTIVE WASTE VOLUME REDUCTION TECHNIQUES FOR COMMERCIAL NUCLEAR POWER PLANTS
}

\author{
Prepared for \\ Oak Ridge National Laboratory \\ Union Carbide Corporation \\ Nuclear Division \\ Under P.O. No. 62B-13837C
}

OPERATED BY

UNION CARBIDE CORPORATION FOR THE UNITED STATES DEPARTMENT OF ENERGY 


\section{Printed in the United States of America. Available from}

National Technical Information Service

U.S. Department of Commerce

5285 Port Royal Road, Springfield, Virginia 22161

NTIS price codes-Printed Copy: A12; Microfiche A01

This report was prepared as an account of work sponsored by an agency of the United States Government. Neither the United States Government nor any agency thereof, nor any of their employees, makes any warranty, express or implied, or assumes any legal liability or responsibility for the accuracy, completeness, or usefulness of any information, apparatus, product, or process disclosed, or represents that its use would not infringe privately owned rights. Reference herein to any specific commercial product, process, or service by trade name, trademark, manufacturer, or otherwise, does not necessarily constitute or imply its endorsement, recommendation, or favoring by the United States Government or any agency thereof. The views and opinions of authors expressed herein do not necessarily state or reflect those of the United States Government or any agency thereof. 


\section{DISCLAIMER}

This report was prepared as an account of work sponsored by an agency of the United States Government. Neither the United States Government nor any agency Thereof, nor any of their employees, makes any warranty, express or implied, or assumes any legal liability or responsibility for the accuracy, completeness, or usefulness of any information, apparatus, product, or process disclosed, or represents that its use would not infringe privately owned rights. Reference herein to any specific commercial product, process, or service by trade name, trademark, manufacturer, or otherwise does not necessarily constitute or imply its endorsement, recommendation, or favoring by the United States Government or any agency thereof. The views and opinions of authors expressed herein do not necessarily state or reflect those of the United States Government or any agency thereof. 


\section{DISCLAIMER}

Portions of this document may be illegible in electronic image products. Images are produced from the best available original document. 


\section{STATE OF THE ART REVIEW OF \\ RADIOACTIVE WASTE VOLUME REDUCTION}

TECHNIQUES FOR COMMERCIAI

NUCLEAR POWER PLANTS

NOTICE This document contains information of a preliminary nature. It is subject to revision or correction and therefore does not represent a final report.

Prepared by

Gilbert/Commonwealth

Engineers/Consultants Reading, PA/Jackson, MD

Under P. 0. No. $62 \mathrm{~B}-13837 \mathrm{C}$

Date Published - Apri1 1980

FOR

OAR RIDGE NATIONAL LABORATORY

Oak Ridge, Tennessee 37830 operated by UNION CARBIDE CORPORATION

for the

DEPARTMENT OF ENERGY

Contract No. W-7405-ENG-26

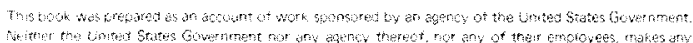

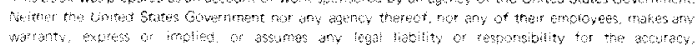

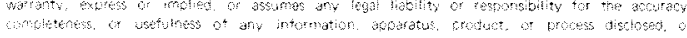

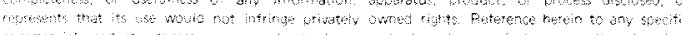


TABLE OF CONTENTS

SECTION NO.

TITLE

PAGE

ABSTRACT

$\mathrm{v}$

$1.0 \quad$ INTRODUCTION $1-1$

1.1 References 1-2

$2.0 \quad$ SUMMARY AND CONCLUSIONS $2-1$

2.1 References $2-3$

3.0 SOURCES OF LOW LEVEL WASTES 3-1

3.1 Wet Wastes 3-1

3.2 Dry Wastes $3-3$

4.0 CHARACTERISTICS OF LOW LEVEL WASTES 4-1

4.1 Wet Wastes 4-1

4.2 Dry Wastes 4-8

4.3 References $\quad 4-9$

5.0 TREATMENT OF LOW LEVEL WASTES 5-1

5.1 Summary of Traditional Liquid Radwaste Processing 5-1
Techniques

5.2 Advanced Volume Reduction Techniques 5-6

5.3 References $5-49$

APPENDIX - TRIP REPORT NO. 1 - ARTISAN INDUSTRIES A-1

TRIP REPORT NO. 2 - CHALK RIVER - AECL A-23

TRIP REPORT NO. 3 - BRUCE GENERATING STATION A-46

TRIP REPORT NO. 4 - TELEDYNE READCO A-54

$\begin{aligned} \text { TRIP REPORT NO. } 5 \text { - GENERAL ELECTRIC/UNITED } & \text { TECHNOLOGIES A-83 }\end{aligned}$

TRIP REPORT NO. 6 - AEROJET ENERGY CONVERSION A-97

TRIP REPORT NO. 7 - PENBERTHY ELECTROMELT A-114

$\begin{array}{ll}\text { OTHER SITE SURVEY MATERIAL } & \mathrm{A}-119\end{array}$

BIBLIOGRAPHY $\quad B-1$ 
4.2 Typical Concentrations of Expected Radioactive Nuclides in Reactor Coolant for BWRs

4.3 Typical Concentrations of Expected Radioactive Nuclides in Laundry Wastes

4.4 Typical Characteristics of PWR Wet Wastes

$4-6$

4.5 Typical Concentrations of Expected Radioactive Nuclides in Reactor Coolant and Secondary Side for PWRs

4.6 Characteristics of Typical Decontamination Waste Solutions

4.7 Characteristics of Typical Dry Waste Material From Commercial Reactors

4.8 Sources of Waste with Significant Amounts of Radioactive Material from Decommissioning the Elk River Nuclear Plant

5.1 Dry Waste Compaction Survey 


\section{LIST OF FIGURES}

NUMBER

TITLE

$\underline{\text { PAGE }}$

5.1 Evaporator/Crystallizer Flow Diagram

$5-8$

5.2 Typical Arrangement of Evaporator/Crystallizer

Equipment

$5-9$

5.3 Sectional View of Typical Evaporator/Crystallizer Installation

5.4 Typical Arrangement of Evaporator/Crystallizer

Equipment

5.5 Long-Tube Vertical Evaporator with External Heater, Forced Circulation, Restriction Device to Prevent Boiling in Tubes, and Distillation Tray Section

5.6 Forced-Circulation Evaporator with External

Horizontal Heater

$5-14$

5.7 Flow Diagram of AECC Fluidized Bed Dryer/Incinerator Using Separate Vessels for Drying and Incinerating

5.8 Fluidized Bed Incinerator Vessel

5.9 Flow Diagram of Fluidized Bed Calciner/Incinerator Using Single Vessel for Calcination and Incinerating

5.10 Typical Horizontal Thin Film Evaporator

5.11 Typical Vertical Thin Film Evaporator

5.12 Flow Diagram for Thin Film Evaporator at FitzPatrick Nuclear Power Station

5.13 Thin Film Evaporator Flow Diagram for WPPSS Nuclear

Projects Nos. 3 \& 5

5.14 Schematic Flowsheet of the Werner-Pfleiderer

Extruder/Evaporator

5.15 Flow Diagram for Bruce Nuclear Power Development

Site Incinerator

5.16 Flow Diagram of Ribbon Blender Volume Reduction System

Flow Diagram of ICRP Volume Reduction System 


$$
\text { LIST OF FIGURES (Cont'd) }
$$

NUMBER

\subsection{8}

5.19

5.20
Flow Diagram of Molten Glass Incinerator

Flow Diagram of JGC Drum Mixer Process

Sectional Views of JGC Drum Mixer
PAGE

$5-45$

$5-47$

$5-48$ 
A review is made of the state of the art of volume reduction techniques for low level liquid and solid radioactive wastes produced as a result of: 1) operation of commercial nuclear power plants, 2) storage of spent fuel in away-from-reactor facilities, and 3) decontamination/decommissioning of commercial nuclear power plants. The types of wastes and their chemical, physical, and radiological characteristics are identified. Methods used by industry for processing radioactive wastes are reviewed and compared to the new techniques for processing and reducing the volume of radioactive wastes. A detailed system description and report on operating experiences follow for each of the new volume reduction techniques. In addition, descriptions of volume reduction methods presently under development are provided. The Appendix records data collected during site surveys of vendor facilities and operating power plants. A Bibliography is provided for each of the various volume reduction techniques discussed in the report. 
SECTION 1.0

INTRODUCTION

This report is a summary of information gathered from site surveys and available literature on the state of the art of volume reduction techniques for low and intermediate level, solid and liquid, radioactive wastes generated in portions of the commercial nuclear fuel cycle. This information will be used by Union Carbide Corporation - Nuclear Division, under contract to Oak Ridge National Laboratory (ORNL), in preparing a broader report on the state of the art of volume reduction and preparation for storage or disposal of low and intermediate level, solid, liquid, and gaseous radioactive wastes generated by both the commercial and government sectors of the nuclear industry.

Currently, more than 2 million $\mathrm{ft}^{3}$ of low level waste from the commercial sector is disposed of each year at licensed burial facilities(1). Much of this waste comes directly from light water reactor (LRW) power plants. While the amount of waste produced at each LWR plant varies greatly, the average volume of waste now being produced in operating LWR plants has been determined to be $1.6 \times 10^{-3} \mathrm{ft}^{3} /$ MWht(2). Based on this figure, a 3,400 MWt plant operating at 80 percent of capacity would ship approximately $38,000 \mathrm{ft}^{3}$ of waste to licensed burial facilities each year. Other estimates of the amount of waste produced by this size plant vary from 7,000 to $70,000 \mathrm{ft}^{3} / \mathrm{yr}(3)$.

In addition to higher operating costs, there are significant sociological and political effects from these large waste volumes. Shipment of these wastes through or near population centers is of increasing concern, despite the exceedingly low threat of any danger to the public. In the few remaining states where commercial burial sites are operated, objections are also being raised by the citizenry about becoming the "dumping grounds" for nuclear wastes from other states. De facto limitations on the quantities of low level waste that can be buried each year at Barnwell, South Carolina have already caused some Midwestern utilities to begin sending their waste to Richland, Washington and Beatty, Nevada, a threefold increase in transportation cost alone. As a result of these problems, many utilities are giving greater 
consideration to long term on-site storage of their radioactive wastes. It is apparent that higher volume reduction must be achieved in radwaste processing. Towards this end, a number of new volume reduction techniques have been developed over the last few years. Much has been written describing these systems and their potential for achieving higher volume reduction factors, but data is needed on actual operating experience to judge their performance and determine what additional steps must be taken to achieve maximum volume reduction.

The scope of work for this project was limited to considering liquid and solid radioactive wastes generated at commercial power plant sites, at spent fuel storage facilities, and as a result of decontamination/decommissioning. Gaseous wastes and solidification products from these volume reduction techniques were considered only as they relate to the volume reduction system. A brief, general description of each type of processing technique is given. Since this report concentrates on commercial facility wastes, DOE experience with these volume reduction techniques is not discussed.

\section{$1.1 \quad$ REFERENCES}

1. P. J. Macbeth, G. Wehmann, B. J. Thames, and D. H. Card, "Evaluation of Alternative Methods for the Disposal of Low-Level Radioactive Wastes", NUREG/CR-0680, July 1979.

2. A. H. Kibbey, H. W. Godbee, and E. L. Compere, "A Review of Solid Radioactive Waste Practices in Light-Water-Cooled Nuclear Reactor Power Plants", NUREG/CR-0144, October 1978.

3. R. B. Briggs, et. a1., "Feasibility of a Nuclear Siting Policy Based on the Expansion of Existing Sites", ORAU/IEA-78-19(R), November 1978. 
SECTION 2.0

SUMMARY AND CONCLUSIONS

The largest source of low and intermediate level wastes is operating, commercial nuclear power plant facilities. These facilities use various process equipment for reducing the volume of wastes depending on their chemical, physical, and radiological characteristics. These wastes are defined in Section 3.0. The main chemical, physical, and radiological characteristics of each category of waste are presented in Section 4.0 . Chemical decontamination solution properties are not well defined, but they are being more frequently used in power plants. Limited information on these decontamination solutions is also given in Section 4.0.

Literature searches and site surveys were conducted for the following volume reduction techniques:

- Forced circulation evaporator/crystallizer

- Fluidized bed calciner/incinerator

- Fluidized bed dryer/incinerator

o Thin film evaporator

- Extruder/evaporator

- Incinerator (conventional type)

- Compactor

- Ribbon blender

- Inert carrier evaporative process

- Molten glass incinerator

- Mixer type evaporative process

For each, a brief description and summary of operating experience are given in Section 5.0. With the exception of the evaporator/crystallizer, all of the processes that can handle liquid wastes can also remove over 99 percent of the free water in these wastes, thus achieving the maximum volume reduction factors possible. However, for all of these systems, practical size limitations 
prevent processing rates from being higher than a few gallons per minute. Thus, each of these techniques (other than evaporator/crystallizers) requires some means of waste preconcentration to maintain a reasonable yearly throughput.

The net system volume reduction factor should be considered in evaluating system effectiveness. This factor includes new waste volumes created by the need to process off-gas or seal water leakage from the system. In general, such considerations will result in a net system volume reduction factor not as high as that for the process equipment alone. Since this net system factor will determine the actual volume of waste shipped or stored, it is the more appropriate factor to use in evaluating the economic and technical merits of the system.

Despite the obvious need for greater volume reduction of power plant wastes and the fact that many of these systems have been commercially available for over five years, the site surveys reveal that only one of these techniques (other than compaction) is currently processing radioactive wastes in a domestic nuclear power station. This technique is incineration, and its use has been restricted to a very small unit at the Yankee Rowe plant not representative of the latest incineration technology. The operating experience sections of this report have had to rely very heavily on data from vendors and independent laboratories because of the lack of commercial installations. For this same reason, there is little discussion in the report on such things as maintenance outages, component failures, and exposures to personnel during operation and maintenance outages. However, within the next five years this situation should change considerably, since many of the systems now being pre-op tested, installed, or procured, will be going on line. At that time, another state of the art survey would be valuable.

Definitions for the terminology in this report follow:

- Low level waste - "radioactive wastes other than those specifically categorized as high-level and transuranic waste, spent fuel, or mine and 
mine tailings". The maximum quantity of long-lived, alpha-emitting transuranic nuclides per gram of low level waste is 10 nanocuries(2).

- Decontamination factor (DF) - the ratio of the concentration of a particular isotope of concern or of gross activity in the feed stream to the concentration in the purified product stream.

- Volume reduction (VR) factor - the radio of the feed volume to the concentrated product volume across a specific piece of equipment, without regard to other factors such as off-gas cleanup.

Costs are an important part of any volume reduction system, since reduction of overall disposal costs is one of the primary objectives of any VR system.

This report does not attempt to determine such costs, because of the difficulty in getting actual comparative costs (i.e., costs that are based on the same waste type, processing criteria, shipping criteria, etc.). Limited cost data from utilities and equipment vendors are presented in the Appendix.

\section{$2.1 \quad \underline{\text { REFERENCES }}$}

1. P. J. Macbeth, G. Wehmann, B. J. Thames, and D. H. Card, "Evaluation of Alternative Methods for the Disposal of Low-Level Radioactive Wastes", NUREG/CR-0680, July 1979.

2. "Regulation of Federal Radioactive Waste Activities", NUREG-0527, September 1979. 
SECTION 3.0

SOURCES OF LOW LEVEL WASTES

\section{$3.1 \quad$ WET WASTES}

Commercial nuclear power plants are the single greatest source of low level liquid radioactive wet wastes in the nuclear fuel cycle. These wastes are usually categorized as either boiling water reactor (BWR) wastes or pressurized water reactor (PWR) wastes. The major difference is the absence of borates in the BWR wastes. With the advent of full flow condensate polishing systems for PWR secondary side water, the similarities between BWR and PWR wastes are increasing. There are a number of different waste streams under each of these headings, but, in all cases, the wastes are aqueous solutions of suspended or dissolved materials. The BWR wet wastes are collected and segregated into one of the following categories:

- High purity waste - equipment drainage

- Medium purity waste - miscellaneous leakage and floor drainage

- Chemical waste - ion exchanger regeneration solutions and laboratory drains

- Detergent wastes - drainage from laundry machines and personnel decontamination stations

- Spent resin - water slurry of depleted bead resin from ion exchangers

- Filter precoat - water slurry of powdered resin, diatomaceous earth, etc., from precoat-type filters 
Similarly, the PWR wet wastes are collected and segregated into one of the following categories:

- Miscellaneous waste - equipment and floor drainage and miscellaneous leakage

- Chemical waste - same as for BWRs

- Secondary system wastes - turbine building floor and equipment drainage, steam generator blowdown, condensate polisher regeneration solutions, etc. (These wastes normally contain little or no radioactivity.)

- Detergent wastes - same as for BWRs.

- Spent resin - same as for BWRs.

- Filter precoat - same as for BWRs.

Another significant source of low level wet waste is the fuel reprocessing facility. At present, fuel from commercial reactors in the United States is not being reprocessed. Should this ever occur, however, low level wet wastes will be produced as a result of equipment and floor drainage, equipment leakage, fuel pool purification, and spent fuel shipping cask washdown. Currently, two of the existing fuel reprocessing plants are used as away-from-reactor (AFR) spent fuel storage facilities (General Electric's Morris, Ilinois plant and Nuclear Fuel Service's West Valley, New York plant). At these plants, the spent fuel storage pools are cleaned continuously with 250 to $300 \mathrm{gpm}$ precoat filters that are backwashed about once a month. These backwash volumes (totaling approximately 2,000 gal per backwash) and small amounts of mild detergent waste from cask washdown operations represent the only significant volumes of wet waste currently being produced at the AFR spent fuel storage facilities. 
Significant volumes of wet waste are also generated as a result of decontamination/decommissioning activities. For example, decontamination of the primary loop at Dresden Unit 1 is expected to produce several hundred thousand gallons of contaminated cleaning solution.

Wet decontamination/decommissioning wastes from BWRs and PWRs or their components are grouped together because the function and materials of construction of the equipment or system being decontaminated and/or decommissioned are more important in determining the type of decommissioning solution to be used than is the type of reactor involved. No simple listing of the categories or types of decontamination solutions can be made. However, different decontamination waste solutions may evolve as a result of cleaning the following four functional categories of components:

- Single items such as a pump, valve, tool, etc.

- A system, such as a reactor coolant recirculation loop.

- A building or portion (walls, floor, etc.).

- Personnel (eyewash, showers, etc.)

The decontamination solution generated will also depend on the reason for decontamination. For instance, if the item is to be reused, a very strong, active decontamination procedure might be used, such as electropolishing or strong chelating agents, etc. If decontamination is only to remove minor, smearable, surface contamination (such as from shipping casks), a mild detergent solution or plain demineralized water may be used.

\section{$3.2 \quad$ DRY WASTES}

Low level dry wastes consist of contaminated tools, piping, equipment, clothing, wood, trash, etc. This type of waste results from LWR power plant operation, AFR spent fuel storage, and decontamination/decommissioning activities. A convenient way of grouping this type of waste is on the basis of processing characteristics, i.e., compactible/noncompactible and combustible/noncombustible. 
SECTION 4.0

CHARACTERISTICS OF LOW LEVEL WASTES

4.1 WET WASTES

These wastes are aqueous solutions of dissolved or suspended material. In most cases, the material in solution is inorganic; however, there are often small amounts of organic material present, such as oil or detergent. The precise composition of most of these waste streams will vary from plant to plant and even for one particular plant from day to day. Thus, the following listings of characteristics for these wastes are typical, average values.

\subsubsection{BWR Wet Wastes}

Physical, chemical, and radiological properties of BWR wet wastes are given in Tables $4.1,4.2$, and 4.3 .

\subsubsection{PWR Wet Wastes}

Physical, chemical, and radiological properties of PWR wet wastes are given in Tables 4.4 and 4.5 .

\subsubsection{Decontamination/Decommissioning Wet Wastes}

A wide variety of decontamination solutions are used in the nuclear industry today. Identifying these waste solutions is complicated, because the exact chemical composition of the decontamination agent is proprietary vendor information. Furthermore, most literature concentrates on the effectiveness of the decontamination procedures, not on the waste solutions produced. Instead of covering all possible types of waste, Table 4.6 provides data on three representative waste solutions, one each for the three main categories of decontamination, i.e., decontamination of a component, decontamination of a complete system, and decontamination of a building. 
TABLE 4.1

TYPICAL CHARACTERISTICS OF BWR WET WASTES (Refs. $1,2,3, \& 6)$

\begin{tabular}{|c|c|c|c|c|c|c|c|c|}
\hline \multicolumn{2}{|c|}{ Characteristic } & $\begin{array}{c}\text { High Purity } \\
\text { Waste }\end{array}$ & $\begin{array}{l}\text { Medium } \\
\text { Purity } \\
\text { Waste }\end{array}$ & $\begin{array}{c}\text { Chemical } \\
\text { Waste }\end{array}$ & $\begin{array}{c}\text { Detergent } \\
\text { Waste } \\
\end{array}$ & $\begin{array}{l}\text { Bead } \\
\text { Resin }\end{array}$ & $\begin{array}{l}\text { Powdered } \\
\text { Resin } \\
\text { Filter } \\
\text { Precoat }\end{array}$ & $\begin{array}{c}\text { Diatomaceous } \\
\text { Earth } \\
\text { Filter } \\
\text { Precoat } \\
\end{array}$ \\
\hline Temperature & $\left({ }^{\circ} \mathrm{F}\right)$ & 70 to 150 & 70 & 170 & 70 to 150 & 70 & 70 & 70 \\
\hline $\mathrm{pH}$ & & 6 to 8 & 6 to 8 & 6 to 8 & 7 to 9 & - & - & - \\
\hline Conductivity & $(\mu \mathrm{mho} / \mathrm{cm})$ & $<10$ & 10 to 1000 & $>10,000$ & - & - & - & - \\
\hline Density & $(\mathrm{gm} / \mathrm{cc})$ & 1.0 & 1.0 & 1.18 & 1.0 & - & - & - \\
\hline Activity ${ }^{b}$ & $(\mu \mathrm{Ci} / \mathrm{cc})$ & $(0.88)(A+M)$ & $(0.001)(A+M)$ & $(40)(A+M)$ & $\begin{array}{c}\text { See } \\
\text { Table } 4.3\end{array}$ & 1 to 10 & 0.1 to 500 & 0.05 \\
\hline Constituents: & & & & & & & & \\
\hline Water & (wt \%) & $>99$ & $>99$ & 75 & 99 & 50 & 50 & 40 \\
\hline 0 il & $(\mathrm{ppm})$ & $\begin{array}{l}\text { trace } \\
\text { anounts }\end{array}$ & $\begin{array}{c}<1 \\
\text { (normally) }\end{array}$ & - & - & - & - & - \\
\hline $\begin{array}{l}\text { Detergent } \\
\text { Suspended }\end{array}$ & $(w t \%)$ & - & - & - & 1 & - & - & - \\
\hline $\begin{array}{l}\text { Solids } \\
\text { Sodium }\end{array}$ & $(\mathrm{ppm})$ & $<10$ & 10 to 100 & 1000 & 1000 & - & 5 & 10 \\
\hline $\begin{array}{l}\text { Sulfate } \\
\text { Sodium }\end{array}$ & (wt. \%) & - & - & 22.9 & - & - & - & - \\
\hline Chloride & (wt. \%) & - & - & 2 & - & - & 5 & - \\
\hline $\begin{array}{l}\text { Bead Res in } \\
\text { Powdered }\end{array}$ & (wt. \%) & - & - & - & - & 50 & - & - \\
\hline $\begin{array}{l}\text { Resin } \\
\text { Diatomaceous }\end{array}$ & $(w t \cdot \%)$ & - & - & - & - & - & 40 & - \\
\hline Earth & (wt \%) & $=$ & - & - & - & - & - & 40 \\
\hline
\end{tabular}

NOTES:

a Characteristics of chemical waste are after concentration by evaporation to solubility limit of solution. For values of $\mathrm{A}$ and $\mathrm{M}$, see Table 4.2 .

For bead resin and filter precoat type waste, water content listed is interstitial water only.

Bead resin is variable mix of anion and cation resin bead.

Powdered resin is variable mix of powdered anion and cation resin bead 
TABLE 4.2

TYPICAL CONCENTRATIONS OF EXPECTED RADIOACTIVE NUCLIDES IN REACTOR COOLANT FOR BWRs (3)

\begin{tabular}{|c|c|c|c|}
\hline Nuclide & $\begin{array}{c}\text { Reactor Coolant } \\
\text { Fission Products } \\
M(\mu \mathrm{C} / \mathrm{cc}) \\
\end{array}$ & Nuclide & $\begin{array}{c}\text { Reactor Coolant } \\
\text { Activation Products } \\
\mathrm{A}(\mu \mathrm{Ci} / \mathrm{cc})\end{array}$ \\
\hline $\begin{array}{l}\mathrm{Sr}-89 \\
\mathrm{Sr}-90 \\
\mathrm{Zr}-95 \\
\mathrm{Nb}-95 \\
\mathrm{Mo}-99 \\
\mathrm{Ru}-103 \\
\mathrm{Ru}-106 \\
\mathrm{Ag}-110 \mathrm{~m} \\
\mathrm{Te}-129 \mathrm{~m} \\
\mathrm{Te}-132 \\
\mathrm{I}-131 \\
\mathrm{Cs}-134 \\
\mathrm{Cs}-136 \\
\mathrm{Cs}-137 \\
\mathrm{Ba}-140 \\
\mathrm{Ce}-141 \\
\mathrm{Ce}-144 \\
\mathrm{Pr}-143 \\
\mathrm{Nd}-141 \\
\mathrm{~Np}-239\end{array}$ & $\begin{array}{l}2.7 \times 10^{-3} \\
2.0 \times 10^{-4} \\
3.5 \times 10^{-5} \\
3.6 \times 10^{-5} \\
2.0 \times 10^{-2} \\
1.7 \times 10^{-5} \\
2.2 \times 10^{-6} \\
6.0 \times 10^{-5} \\
3.4 \times 10^{-5} \\
4.3 \times 10^{-2} \\
1.2 \times 10^{-2} \\
1.4 \times 10^{-4} \\
9.2 \times 10^{-5} \\
2.1 \times 10^{-4} \\
7.8 \times 10^{-3} \\
3.4 \times 10^{-5} \\
3.0 \times 10^{-5} \\
3.3 \times 10^{-5} \\
1.2 \times 10^{-5} \\
2.1 \times 10^{-1}\end{array}$ & $\begin{array}{l}\mathrm{P}-32 \\
\mathrm{Cr}-51 \\
\mathrm{Mn}-54 \\
\mathrm{Co}-58 \\
\mathrm{CO}-60 \\
\mathrm{Fe}-59 \\
\mathrm{Zn}-65\end{array}$ & $\begin{array}{lll}2 & \times 10^{-5} \\
5 & \times & 10^{-4} \\
4 & \times & 10^{-5} \\
5 & \times & 10^{-3} \\
5 & \times & 10^{-4} \\
8 & \times & 10^{-5} \\
2 & \times & 10^{-6}\end{array}$ \\
\hline
\end{tabular}

1. Only isotopes with half-lives $>24 \mathrm{hr}$ are listed.

2. Activity in main steam is $10^{-3}$ times activity in reactor coolant, except that, for halogen, activity in main steam is $10^{-2}$ times activity in reactor coolant. 


$$
4-4
$$

TABLE 4.3

\section{TYPICAL CONCENTRATIONS OF EXPECTED RADIOACTIVE NUCLIDES IN LAUNDRY WASTES (7)}

Nuclide

$$
\begin{aligned}
& \mathrm{Mn}-58 \\
& \mathrm{Co}-58 \\
& \mathrm{Co}-60 \\
& \mathrm{Zr}-95 \\
& \mathrm{Nb}-95 \\
& \mathrm{Ru}-103 \\
& \mathrm{Ru}-106 \\
& \mathrm{Ag}-110 \mathrm{~m} \\
& \mathrm{I}-131 \\
& \mathrm{Cs}-134 \\
& \mathrm{Cs}-137 \\
& \mathrm{Ce}-144
\end{aligned}
$$

Activity ( $\mu \mathrm{Ci} / \mathrm{cc})$

$1.6 \times 10^{-6}$

$6.4 \times 10^{-6}$

$1.4 \times 10^{-5}$

$2.3 \times 10^{-6}$

$3.2 \times 10^{-6}$

$2.3 \times 10^{-7}$

$3.9 \times 10^{-6}$

$7.1 \times 10^{-7}$

$9.7 \times 10^{-7}$

$2.1 \times 10^{-5}$

$3.9 \times 10^{-5}$

$8.0 \times 10^{-6}$

Note:

Only isotopes with half-lives $>24 \mathrm{hr}$ are listed. 
TABLE 4.4

TYPICAL CHARACTERISTICS OF PWR WET WASTES (Refs. 2, 4, \&5)

Miscellaneous Chemical Waste ${ }^{a}$

Temperature $\quad 170^{\circ} \mathrm{F}$

$\mathrm{pH} \quad 2.5$ to 4.0

Boric Acid 12 wt \%

Crud b 0.1 wt $\%$

Activity $(0.2)(\mathrm{R})$

$\underline{S e c o n d a r y}$ Side Condensate Polisher Regenerative Waste ${ }^{a}$

\begin{tabular}{lr} 
Temperature & $170^{\circ} \mathrm{F}$ \\
$\mathrm{pH}$ & $2.5 \mathrm{to} 4.0$ \\
Sodium Sulfate & $14.9 \mathrm{wt} \%$ \\
Ammonium Sulfate & $9.6 \mathrm{wt} \%$ \\
Sodium Chloride & $2.0 \mathrm{wt} \%$ \\
Crud Activity $^{\mathrm{b}}$ & $0.1 \mathrm{wt} \%$ \\
\hline
\end{tabular}

Detergent Wastes - Same as for BWRs.

Bead Resin - Same as for BWRs.

Filter Precoat Backwash - Same as for BWRs.

NOTES:

a Characteristics of miscellaneous chemical waste and secondary side condensate polisher regnerative waste are after concentration by evaporation to solubility limit of solution.

b See Table 4.5 for values of $R$ and $S$. 
TABLE 4.5

TYPICAL CONCENTRATIONS OF EXPECTED RADIOACTIVE NUCLIDES IN REACTOR COOLANT AND SECONDARY SIDE FOR PWRS (7)

\begin{tabular}{|c|c|c|}
\hline Nuclide & $\begin{array}{l}\text { Reactor Coolant } \\
\text { Fission and Activation } \\
R(\mu C i / c c) \\
\end{array}$ & $\begin{array}{l}\text { Secondary Side } \\
\text { Fission and Activation } \\
\text { S }(\mu \mathrm{C} / \mathrm{cc})\end{array}$ \\
\hline $\operatorname{Cr}-51$ & $1.7 \times 10^{-3}$ & $2.2 \times 10^{-7}$ \\
\hline$M n-54$ & $2.7 \times 10^{-4}$ & $5.3 \times 10^{-8}$ \\
\hline $\mathrm{Fe}-55$ & $1.4 \times 10^{-3}$ & $1.8 \times 10^{-7}$ \\
\hline Co-58 & $1.4 \times 10^{-2}$ & $1.9 \times 10^{-6}$ \\
\hline $\mathrm{Fe}-59$ & $8.8 \times 10^{-4}$ & $1.4 \times 10^{-7}$ \\
\hline $\mathrm{Co}-60$ & $1.8 \times 10^{-3}$ & $2.4 \times 10^{-7}$ \\
\hline $\mathrm{Sr}=89$ & $3.1 \times 10^{-4}$ & $5.4 \times 10^{-8}$ \\
\hline $\mathrm{Sr}-90$ & $8.8 \times 10^{-6}$ & $1.3 \times 10^{-9}$ \\
\hline$Y-90$ & $1.1 \times 10^{-6}$ & $7.3 \times 10^{-10}$ \\
\hline$Y-91$ & $5.6 \times 10^{-5}$ & $8.1 \times 10^{-9}$ \\
\hline$I-131$ & $2.4 \times 10^{-1}$ & $3.6 \times 10^{-5}$ \\
\hline $\mathrm{Rb}-86$ & $7.7 \times 10^{-5}$ & $1.2 \times 10^{-8}$ \\
\hline $\mathrm{Cs}-134$ & $2.2 \times 10^{-2}$ & $3.5 \times 10^{-6}$ \\
\hline $\mathrm{Cs}-136$ & $1.2 \times 10^{-2}$ & $1.8 \times 10^{-6}$ \\
\hline $\mathrm{Cs}-137$ & $1.6 \times 10^{-2}$ & $2.4 \times 10^{-6}$ \\
\hline
\end{tabular}

Note:

Only isotopes with half-lives $>24 \mathrm{hr}$ are listed. 
TABLE 4.6

CHARACTERISTICS OF TYPICAL DECONTAMINATION WASTE SOLUTIONS

Component Decon
Temperature
pH
Conductivity
Dow NS-1
Water
Iron Oxide
Cobalt-60
Total Activity

\section{ontamination}

$70^{\circ} \mathrm{F}$

4

$>10^{4}$ umho/cm

7 wt $\%$

93 wt \%

600 to $900 \mathrm{ppm}$

1.4 to $1.6 \mathrm{ppm}$

1.2 to $2.2 \mu \mathrm{Ci} / \mathrm{cc}$

Building Decontamination ${ }^{f}$

\begin{tabular}{ll}
\multicolumn{2}{c}{ System Decontamination } \\
\hline Temperature & $70^{\circ} \mathrm{F}$ \\
pH & 4 \\
Conductivity & $>10^{4} \mu m h o / \mathrm{cm}$ \\
Dow NS-1 & $7 \mathrm{wt} \%$ \\
Water & $93 \mathrm{wt} \%$ \\
Iron Oxide & $1200 \mathrm{ppm}$ \\
Total Activity & $0.4 \mu \mathrm{Ci} / \mathrm{cc}$
\end{tabular}

\begin{tabular}{ll}
\hline Temperature & $70^{\circ} \mathrm{F}$ \\
pH & 5 \\
Radiac Wash & $5 \mathrm{wt} \%$ \\
Crud & $5 \mathrm{wt} \%$ \\
Oil & $2 \mathrm{wt} \%$ \\
Water & $88 \mathrm{wt} \%$ \\
Activity: & \\
$\quad \mathrm{I}-131$ & $0.6 \mu \mathrm{Ci} / \mathrm{cc}$ \\
Ce-134 & $0.4 \mu \mathrm{Ci} / \mathrm{CC}$ \\
Ce- -136 & $0.2 \mu \mathrm{Ci} / \mathrm{CC}$ \\
Ce- 137 & $1.4 \mu \mathrm{Ci} / \mathrm{CC}$ \\
$\mathrm{La}-140$ & $5.2 \mu \mathrm{Ci} / \mathrm{CC}$ \\
$\mathrm{Ba}-140$ & $3.6 \mu \mathrm{Ci} / \mathrm{CC}$
\end{tabular}

NOTES:

a Data for component decontamination is based on decontamination of regeneration heat exchangers at Peach Bottom Units 2 and 3.

b Data for system decontamination is based on test loop set-up for decontamination of Dresden Unit 1 reactor coolant system.

C Dow NS-1 is a proprietary mixture of EDTA, inorganic salts, and organic inhibitors.

d Total activity for component decontamination is based on $50 / 50$ vol mixture of decon. solution and rinse water.

e Total activity for system decontamination is based on $30 / 70$ vol mixture of decon. solution and rinse water.

$f$ Data for building decontamination is based on decontamination of auxiliary building at Three Mile Island Unit 2.

8 Radiac Wash is a mixture of EDTA, mild detergent and other proprietary additives.

h other types of decontamination solutions include:

(1) Turco $4521 \mathrm{~A}-6 \mathrm{wt} \%$ solution of ammonium sulfate and citrate.

(2) Alkaline permanganate $-13 \mathrm{wt} \%$ solution.

(3) Calgon/Narconal soap solution - 1 wt \%.

(4) Phosphoric acid - 75 wt \% solution (used in electropolishing units). 


\subsubsection{Wet Wastes from AFR Spent Fuel Storage Facilities}

Currently, two of the three domestic spent fuel reprocessing plants are serving as AFR spent fuel storage facilities. In both cases, the spent fuel is stored in pools containing demineralized water that is continuously cleaned to maintain the following water quality conditions:

$\begin{array}{ll}\text { Temperature } & 100 \text { to } 125^{\circ} \mathrm{F} \\ \text { pH } & 7 \\ \text { Total dissolved solids } & <0.1 \mathrm{ppm} \\ \text { Chlorides } & <0.5 \mathrm{ppm} \\ \text { Conductivity } & <3 \mu \mathrm{mho} / \mathrm{cm} \\ \text { Activity (primarily } \mathrm{Cs}-137, \mathrm{Cs}-134, & <4 \times 10^{-4} \mu \mathrm{Ci} / \mathrm{ml} \\ \quad \text { Co-58, Co-60, and } \mathrm{Mn}-58) & \end{array}$

This water is continuously cleaned using a septum filter precoated with powdered anion and cation resin. Frequently, this powdered resin will be top-coated with a thin layer of powdered zeolite to improve cesium removal efficiency. The backwash from these filters has the following approximate composition:

$\begin{array}{ll}\text { Temperature } & 70^{\circ} \mathrm{F} \\ \mathrm{pH} & 7 \\ \text { Anion powdered resin } & 20 \mathrm{wt} \% \\ \text { Cation powdered resin } & 20 \mathrm{wt} \% \\ \text { Crud } & 5 \mathrm{wt} \% \\ \text { Free water } & 55 \mathrm{wt} \% \\ \text { Activity (primarily } \mathrm{Cs}-137, \mathrm{Cs}-134, & 1.0 \mu \mathrm{Ci} / \mathrm{gm} \\ \quad \mathrm{Co}-58, \mathrm{Co}-60, \text { and } \mathrm{Mn}-58) & \end{array}$

\section{$4.2 \quad$ DRY WASTES}

Dry waste includes contaminated tools, equipment, piping, clothing, and trash. The nature of this waste varies considerably from plant to plant, making it impractical to attempt development of a generalized description of its 
content. Furthermore, most utilities record only the volume and gross activity level of the dry waste as shipped. Since nearly all domestic utilities are merely compacting this waste or shipping it without any volume reduction, there has not been any incentive in the past to perform a detailed analysis of this waste. However, this situation may soon change as a result of recent pressure from the burial site agreement states to both improve the waste packaging methods and reduce the volume prior to shipment. The need for better analysis of this waste type has already been recognized in Canada, where all such waste is placed in retrievable storage facilities. This puts a premium on volume reducing the waste as much as possible. For this reason, there has been a greater effort to define and categorize the types of dry waste produced at CANDU power plants, from which much of the data in Table 4.7 is derived. Since the characteristics of dry waste are, for the most part, independent of reactor type, this data is also representative of the dry waste produced by LWR plants.

A large amount of dry waste will be produced as a result of nuclear power plant decommissioning activities. Much of this waste will be of the type listed in Table 4.7. There will also be numerous system components to dispose of that will present unique problems because of size, Curie content, and radiation level. Data on decommissioning dry waste from the Elk River Nuclear Plant 22 MWe BWR) is summarized in Table 4.8 .

\subsection{REFERENCES}

1. "Boiling Water Reactor Liquid Radioactive Waste Processing System," ANSI N197-1976.

2. P. Colombo and R. M. Neilson, Jr., "Properties of Radioactive Wastes and Waste Containers," Quarterly Progress Report, Oct-Dec. 1976, BNL-NUREG-50664, June 1977.

3. Perry Nuclear Power Plant, Units 1 and 2, Preliminary Safety Analysis Report, Docket Nos. 50-440 and 50-441. 
TABLE 4.7

CHARACTERISTICS OF TYPICAL DRY WASTE MATERIAL

FROM COMMERCIAL REACTORS (8)

Combustible Waste $^{\text {a }}$

Content - Paper, rags, throw-away protective clothing, wood, etc.

Bulk Density - Varies greatly (usually $>0.5 \mathrm{gm} / \mathrm{cc}$ )

Activity -0.25 to $2.5 \mathrm{mCi} / \mathrm{m}^{3}$

Limitations - no PVC radiation field $<5 \mathrm{mr} / \mathrm{hr}$ on contact

Compactible Waste ${ }^{a}$

Content - Paper, rags, throw-away protective clothing, etc.

Bulk Density - Varies greatly (usually >0.5 gm/cc)

Activity - Varies greatly (typically 0.25 to $2.5 \mathrm{mCi} / \mathrm{m}^{3}$ )

Limitations - Radiation field $<200 \mathrm{mr} / \mathrm{hr}$ on contact

Noncombustible/Noncompactible Waste

Content - Pipe, valves, tools, pump casings, air filters, pipe insulation, scrap metal from machine shop, etc.

Quantity $-272 \mathrm{~m}^{3}$ in 1978

\section{Core Components}

Content - Control rods, poison curtains, in-core chambers, etc.

Activity - Varies greatly (typical values range from $5 \mathrm{Ci} / \mathrm{ft}^{3}$ to $8000 \mathrm{Ci} / \mathrm{ft}^{3}$ )

\section{Cartridge Filter Elements}

Size - Varies (typically $7^{\prime \prime}$ dia. $\times 27^{\prime \prime}$ long)

Weight - Varies (typically 10 to 15 lbs per element)

Radiation Level - Varies (typically 20 to $100 \mathrm{R} / \mathrm{hr}$ on contact)

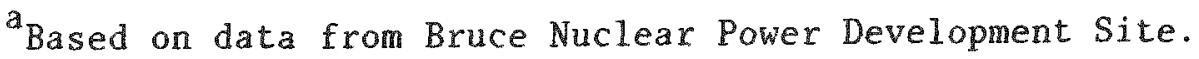


TABLE 4.8

SOURCES OF WASTE WITH SIGNIFICANT AMOUNTS OF

RADIOACTIVE MATERIAL FROM DECOMMISSIONING THE

ELK RIVER NUCLEAR PLANT (9)

Component

Internals

Upper shroud

Lower shroud

Core and shroud plate

Core support stand

Inner thermal shield

Shadow shields

Feedwater distribution ring

Pressure Vessel

Outer Thermal Shield
Inventory (Ci)

770

35

2370

100

3090

2330

75

1110

75

9955
Maximum Contract Radiation Level-(R/hr)

Total

2800

175

8000

150

1000

3000

60

115

1 
4. "Calculation of Releases of Radioactive Material in Gaseous and Liquid Effluents from Boiling Water Reactors," NUREG-0016, April 1976.

5. "Liquid Radioactive Waste Processing System for Pressurized Water Reactor Plants," ANSI N199-1976.

6. Three Mile Island Nuclear Station, Unit 1, Final Safety Analysis Report, Docket No. 50-289.

7. "Calculation of Releases of Radioactive Material in Gaseous and Liquid Effluents from Pressurized Water Reactors," NUREG-0017, April 1976.

8. A. V. Campbel1, R. Kohout, V. R. Slig1, E. F. Jelinski, and A. M. Seabrook, "Volume Reduction of Low Level Radioactive Solid Waste in Ontario Hydro," presented at ANS 9 th Biennial Topical Conference on Reactor Operating Experience, Arlington, Texas, August 1979.

9. "Nuclear Power Waste Technolgoy", edited by A. A. Moghissi, H. W. Godbee, M. S. Ozker, and M. W. Carter, ASME, New York, N.Y., 1978. 
SECTION 5.0

TREATMENT OF LOW LEVEL WASTES

\subsection{SUMMARY OF TRADITIONAL LIQUID RADWASTE PROCESSING TECHNIQUES}

Since the beginning of the commercial nuclear power industry, liquid radioactive wastes have been processed through systems designed to reduce the volumes that had to be buried. By far, most of this waste was treated by filtration and ion-exchange. Often, an evaporator processed liquids that could not be handled economically by ion-exchange. In a few plants, reverse osmosis units were installed to process foaming, detergent wastes, which cannot be handled practically by ion-exchange and are often troublesome for evaporation processes.

Although each of these four common processing techniques do attain some degree of volume reduction, the VR factors are limited by restrictions inherent to the operating principle of the process. Due to these limitations, these processes do not approach the optimum (or maximum) VR factors attainable by the more sophisticated techniques discussed in this section. Therefore, the term "volume reduction techniques" excludes these four, traditional, waste processing methods.

Although filtration, ion-exchange, conventional evaporation, and reverse osmosis are not classified here as "volume reduction techniques", they will be discussed briefly, since these processes often preconcentrate wastes before processing by the more sophisticated "volume reduction techniques". The following subsections briefly describe these traditional processing methods and the experience gained with each. References 1, 2, 3 and 4 contain a more thorough discussion of each. 


\subsubsection{Filtration}

Filtration separates suspended solids from a fluid stream by passage of the fluid through a porous medium which retains most of the solids on or within itself. Many different filters are used for radwaste, including disposable cartridges; metallic, partially cleanable (or non-cleanable) types; precoat types (tubular, flat bed or centrifugal); and metallic, cleanable types (etched disc, etc.). Filter performance criteria usually specifies removal of $90 \mathrm{wt}$ percent or more of all suspended solids 1-5 micron and larger. Disposal or backwashing of the filter elements is required after reaching the maximum allowable differential pressure across the filter elements, which varies from 15 to 100 psid, depending on the type of filter.

It is generally assumed that an insignificant amount of the activity in the liquid is removed by this process and that a more efficient means of activity removal must follow the filtration process. For this reason, it is not possible to calculate a VR factor for a filter operation. Indirectly, filtration increases the overall VR factor by helping to improve the performance of the processing technique that follows it.

\subsubsection{Ion-exchange}

Ion exchange resins are insoluble, high molecular weight polyelectrolytes that exchange ions (normally hydrogen or hydroxyl) for equally charged ions in the surrounding solution. The resins can be anion, cation, or a combination of both. For radwaste service, the latter, often called mixed-bed demineralizers, are most often used because of the variable and often unknown composition of the waste solutions. With the proper ion-exchange resin, effluent qualities of less than $1.0 \mu \mathrm{mho} / \mathrm{cm}$ are easily achieved. However, this method of processing becomes economically less competitive with other processing techniques such as evaporation as the influent conductivity increases. 
Ion-exchange resins can be regenerated for multiple reuse. In radwaste service, however, it is not normally economical to do so, since the regeneration solutions themselves must be processed (usually by evaporation).

Typically, radwaste demineralizer vessels have a bed depth of $3 \mathrm{ft}$ and a flow through the bed of 2 to $8 \mathrm{gpm} / \mathrm{ft}^{2}$ of surface. Internal distribution laterals are provided for uniform flow through the bed, and stainless steel is used for the demineralizer vessel and all internals.

A prefilter is used upstream of the demineralizer vessel to protect the ion-exchange resins against oil fouling or plugging with suspended solids. To avoid thermal degradation of the resins, the influent temperature is kept as low as possible, generally below $140^{\circ} \mathrm{F}$. The resins are degraded by exposure to radiation levels of $10^{8}$ roentgens or above. However, for radwaste service, such radiation levels are not usually encountered.

In some cases, filtration and ion-exchange are simultaneous in a vessel called a filter/demineralizer. This is a standard, back-flushable, precoat filter whose elements are precoated with powdered ion-exchange resins.

The DF values for ion-exchangers are highly dependent on, among other things, the dissolved solids (ionic) concentration of the feed solution. For feed solutions with conductivities in the range of $100 \mu \mathrm{mho} / \mathrm{cm}$, the $\mathrm{DF}$ values range from 10 to 100 for most isotopes. However, since the performance of the ion-exchanger is dependent on the type and quantity of dissolved solids in the feed, volume reduction factors are quite variable and not very meaningful in comparing one feed to another.

\subsubsection{Conventional Evaporation}

Evaporation removes a solvent (water, in the case of radwaste solutions) from its impurities, both dissolved and suspended. Conventional evaporation is widely used in the nuclear industry as a first step in reducing waste volumes and eliminating radioactive nuclides from liquid effluents. Conventional evaporation is restricted by the solubility limit of salts in the waste 
solution or by fouling or foaming substances in the waste. Evaporation can be used on a wide range of waste compositions and concentrations; however, it is most effective on solutions having relatively high concentrations of impurities. As the dissolved solids concentration of the feed is decreased, ion-exchange and reverse osmosis become more economically competitive with evaporation.

Evaporators can be operated in several modes: batch, semibatch, and continuous. In semibatch operation, which is the mode most commonly used in radioactive waste service, the feed is continually added to maintain a constant level in the evaporator until the entire charge reaches a salt concentration suitable for processing in the solid radioactive waste system.

Decontamination factors for radwaste evaporators are normally expressed as feed-to-distillate concentration ratios; however, a parameter more often used by evaporator designers is the unit's maximum separation factor, defined as the bottoms-to-distillate concentration. Evaporator DFs from $10^{5}$ to $10^{6}$ have been attained, however, the maximum DFs normally seen range from $10^{2}$ to $10^{5}$, depending on the isotopes to be removed and the chemical composition of the waste.

The decontamination factor for all evaporators can be reduced by foaming, splashing, entrainment, or volatilization of the solute. Additives can reduce foaming; proper mechanical design (to control flow rate, temperature, etc.) will minimize or eliminate splashing, entrainment, and volatilization. Scaling will also reduce evaporator performance. Prefiltration or pretreatment of feed, proper mechanical design, and periodic cleaning of the tube bundle will minimize scale. Chlorides in the waste feed have often caused corrosion; using corrosion resistant alloys has minimized this problem in newer evaporators.

The volume reduction factor for a conventional evaporator is dependent on the solubility of the salts in the waste feed. For dilute boric acid and sodium sulfate solutions (the two wastes most frequently processed by this method), the volume reduction factors that can be achieved are, on the average, about 
10 and 20, respectively, giving a final salt concentration of 10 to 12 wt

percent for $\mathrm{H}_{3} \mathrm{BO}_{3}$ and 20 to 25 wt percent for $\mathrm{Na}_{2} \mathrm{SO}_{4}$. For miscellaneous dirty radwaste (floor drains, etc.), the VR factors range from 10 to 1,000 .

\subsubsection{Reverse Osmosis}

Reverse osmosis (RO) is a process in which a solvent overcomes the solution's osmotic pressure by applying external pressure to the concentrated solution side of a semipermeable membrane, leaving behind over 95 percent of al1 soluble molecules in the concentrated liquor. Standard recovery rates (ratio of permeate flow-to-feed flow) are in the range of 40 to 60 percent. Waste feed is supplied at pressures as high as 600 psig to overcome the osmotic pressure. In most cases, when the solids concentration approaches about 5 wt percent, the osmotic pressure becomes too high to make further concentration practical. Reverse osmosis units are usually composed of a number of stages such that the permeate from the first stage is the feed to the next stage, etc. For each succeeding stage, the DF is increased by the square of the preceeding stage's DF.

Reverse osmosis membranes are usually constructed of modified cellulose acetate. Configuration of the membranes are either tubular, spiral-wound, or hollow fiber. Prefiltration is required to prevent plugging of the latter two membranes with particulate matter. The temperature of the feed should be kept below $85^{\circ} \mathrm{F}$ and the $\mathrm{pH}$ adjusted to just below neutral to prevent deterioration of the membrane. In continuous service, these membranes can be expected to last for several years.

The DFs for RO units in operating nuclear plants have ranged from 10 to $10^{2}$, depending on influent activity and total solids content.

For feed concentrations in the range of $3,000 \mathrm{ppm}$, volume reduction factors of up to 25 have been achieved while maintaining DF values of 100 for a single pass. 
5.2 ADVANCED VOLUME REDUCTION TECHNIQUES

Since today there is increasing economic incentive and political pressure to reduce the volumes of radioactive waste that must be disposed of, advanced volume reduction techniques are receiving greater attention. In this section, the following improved volume reduction systems now in operation or in the process of being installed will be discussed:

- Forced circulation evaporator/crystallizer

- Fluidized bed dryer/incinerator

- Fluidized bed calciner/incinerator

- Thin film evaporator

- Extruder/evaporator

- Incinerator

- Compactor

This subsection will also cover the following volume reduction concepts that are under development:

- Ribbon blender

- Inert carrier radwaste process

- Molten glass incinerator

- Drum mixer process

\subsubsection{Forced Circulation Evaporator/Crystallizer}

- System Description

Formation of a crystalline solid by evaporation is a common practice in the chemical industry. Crystallization is the controlled precipitation of solids from a saturated, aqueous, salt solution.

Creating a crystalline salt slurry by evaporation without forming salt deposits on the walls of the evaporator vessel and piping requires careful attention in both equipment design and operation. For many 
years, the chemical processing industry has successfully created these salt slurries using forced circulation evaporator/crystallizers, but only recently have they been applied to radioactive waste. According to Perry (Ref. 5), the differences between a forced circulation evaporator used as a standard evaporator versus one used as a crystallizer are subtle, consisting primarily of differences in heat exchanger tube velocities, heat transfer coefficients, feed pretreatment, and instrumentation. A most important consideration is proper design of the piping system used in transporting the crystalline slurry to a storage or solidification system. Generally, a forced circulation evaporator designed for use as a crystallizer could also be used for conventional evaporation, but not vice-versa.

A typical forced circulation evaporator/crystallizer system is shown in Figure 5.1. Typical layouts in a nuclear power plant are shown in Figures 5.2, 5.3, and 5.4. The crystallizer consists of an external tube and shell heat exchanger, vapor body, and recirculation pump. Liquor is withdrawn from the bottom of the vapor body, pumped at a high flow rate through the heat exchanger, and returned to the vapor body, where it flashes to steam. The vapors leave the vapor body and pass through a demister before being condensed in a shell and tube cooler/condenser. The demister can be attached directly to the vapor body or can be a separate vessel. The latter approach is gaining more favor in radwaste service because of improvements in maintenance access by locating the demister in a separate shielded cubicle.

The heat exchanger is designed for submerged tube operation; to prevent boiling in the tubes, a large static head is maintained. Where headroom is insufficient, boiling can be prevented by increasing the backpressure on the heat exchanger through proper design of the piping between the heater and vapor body or by installing a backpressure valve. The operational problems associated with a valve of the required size (16" to 20 " size range for radwaste service) make this latter approach undesirable. 


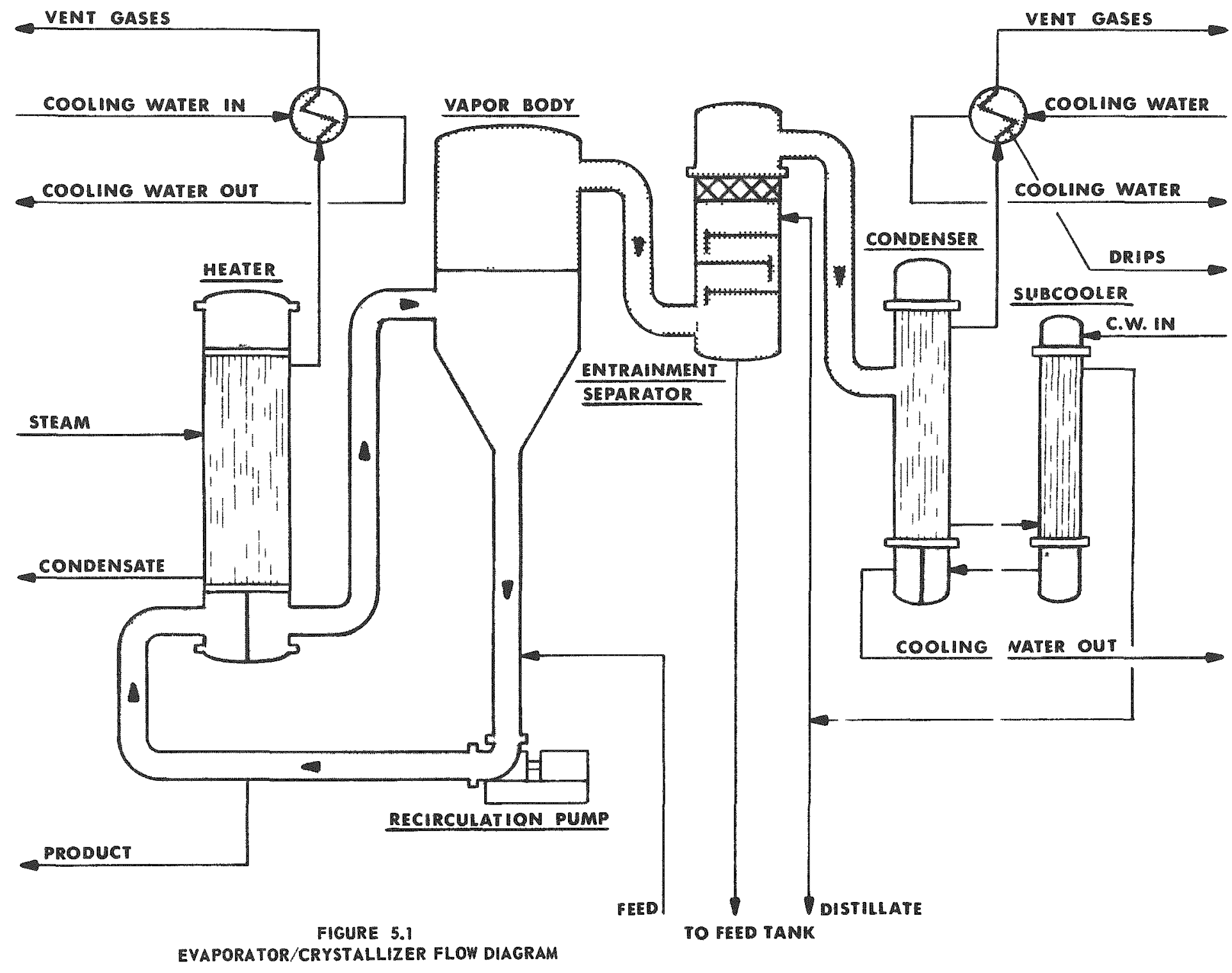




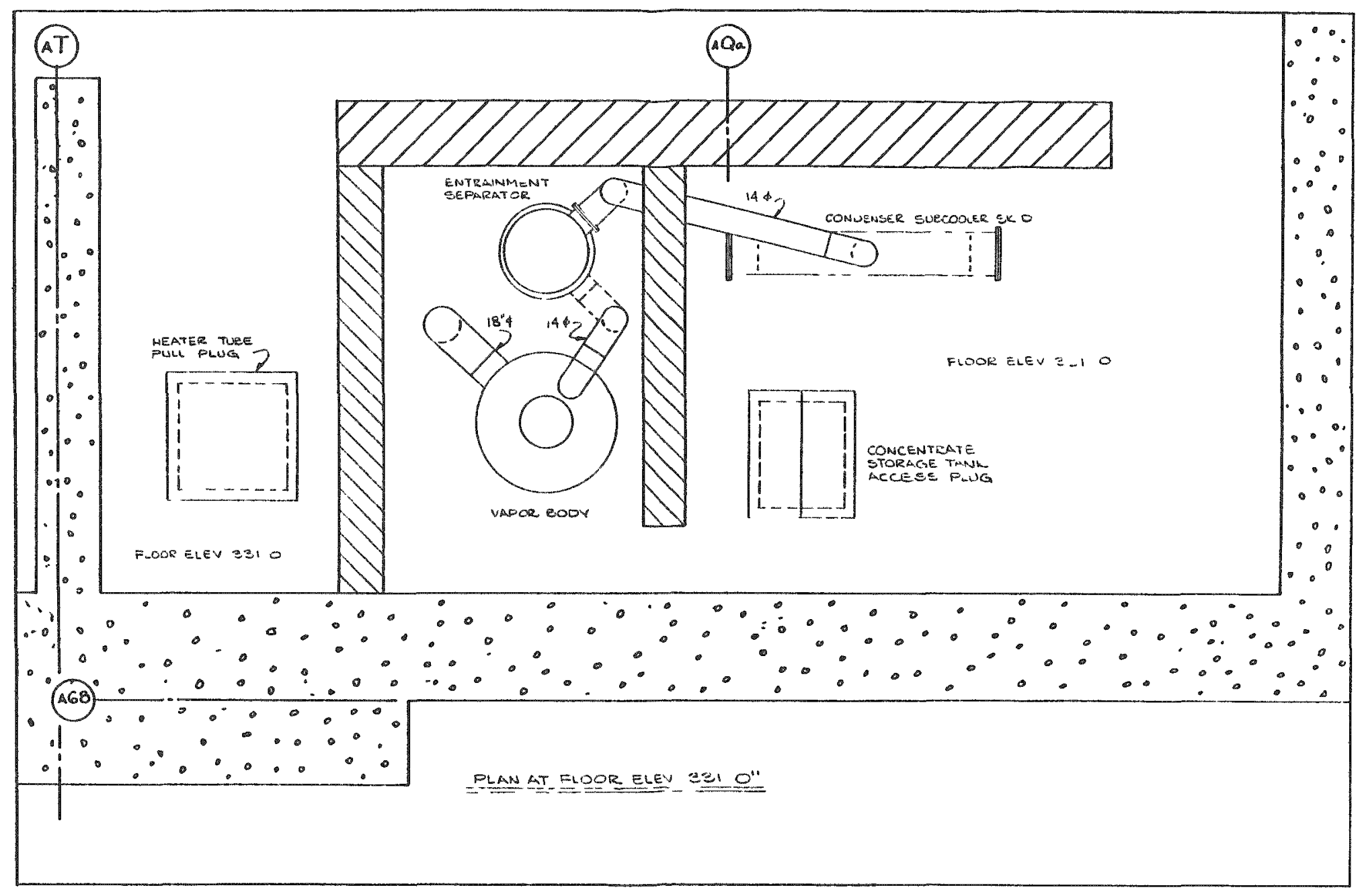

FIGURE 5.2

TYPICAL ARRANGEMENT OF EVAPORATOR/CRYSTALLIZER EQUIPMENT 


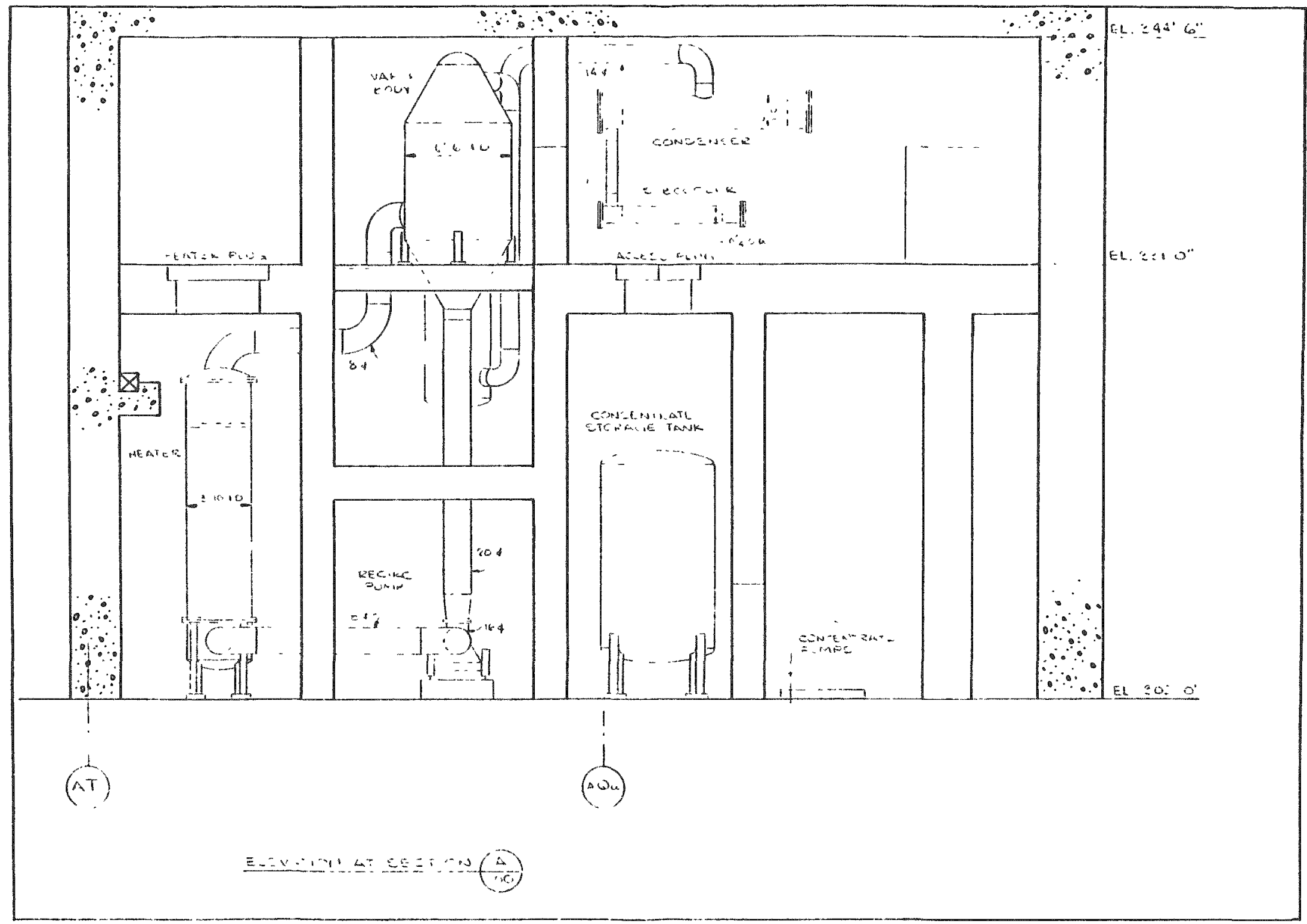




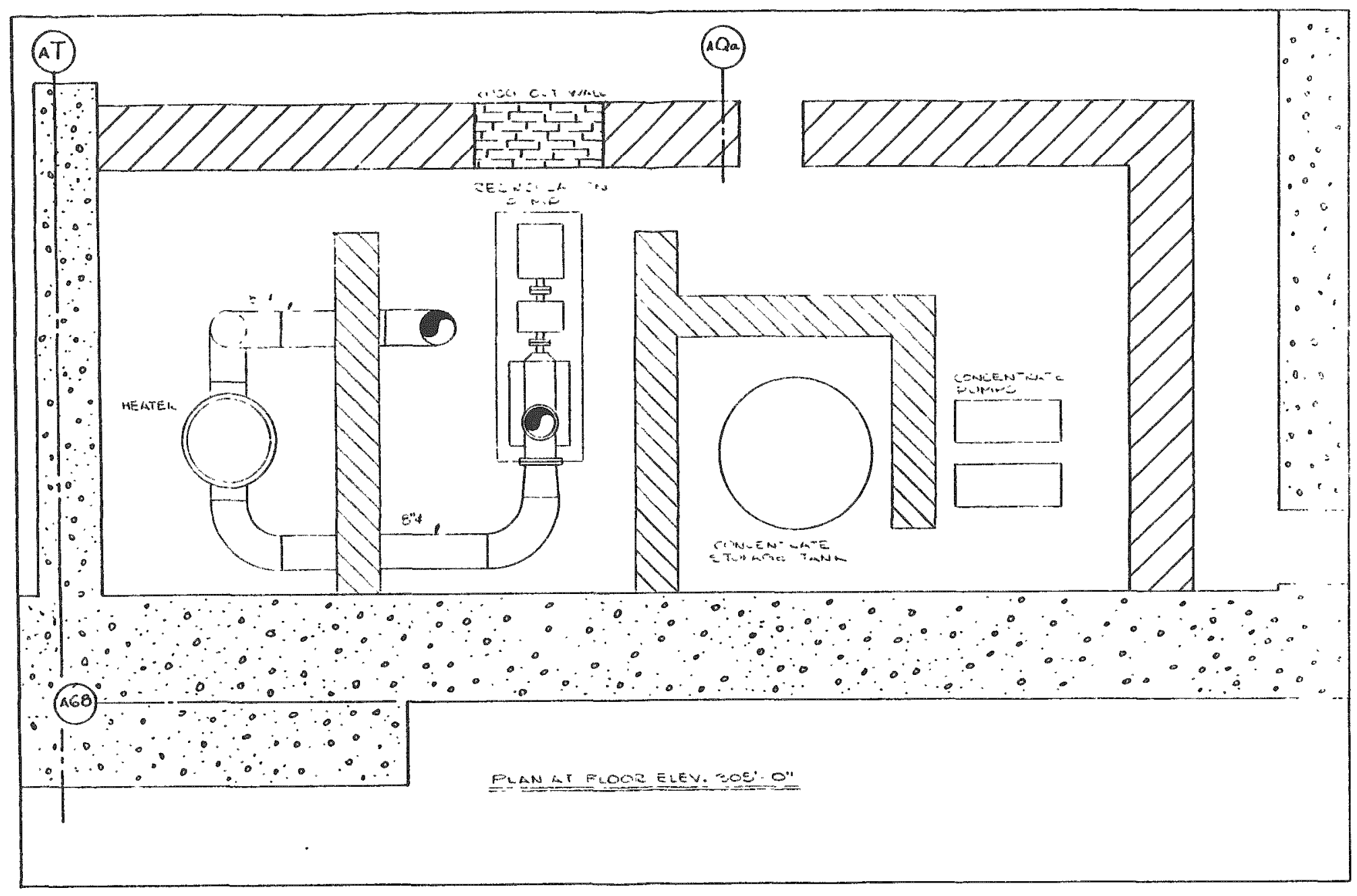


The heat exchanger itself can be either a horizontal or vertical (Figures 5.5 and 5.6), single or multiple pass unit. Where headroom is available, a vertical unit is suggested in the literature rather than a horizontal unit, because crystalline salts would have a greater tendency to settle out in the latter type. There is not a general consensus in the literature on the number of passes the heat exchanger should have. Certainly from a cost standpoint, the multipass types are more attractive due to the reduction in material requirements. From an operational standpoint, a single pass heater reduces the potential for salting-out and solids accumulation because of smoother flow paths entering and exiting the unit and because changes in flow direction are eliminated.

The liquid waste passes through the heater on the tube side at a flow rate of 4 to $12 \mathrm{fps}$. The flow rate should be in the lower part of this range if the evaporator is used as a crystallizer. At these low flow rates, the growth of salt crystals is promoted and erosion of the tubes by the abrasive salt crystals is reduced. The head and net positive suction head requirements for the relatively large capacity recirculation pump (normally a 3,000 to $10,000 \mathrm{gpm}$ pump) are also reduced. The heater tubes themselves are large diameter (normally $2^{\prime \prime}$ ) to allow easy passage of the salt crystals and help achieve the low flow rates required. The salt crystals passing through these tubes at the flow rates mentioned may result in a scouring effect which helps minimize scale build-up in the heater.

A number of forced circulation evaporator/crystallizers have been or are planned to be installed in commercial nuclear power plants. To date, however, there has not been any operating experience with these units. A forced circulation evaporator/crystallizer has been operated successfully at Hanford since 1974 on high level spent fuel reprocessing waste. One forced circulation evaporator has been operated since 1975 at Nine Mile Point nuclear powex plant processing BWR type waste with good success. Some components of the unit are currently being replaced with corrosion 


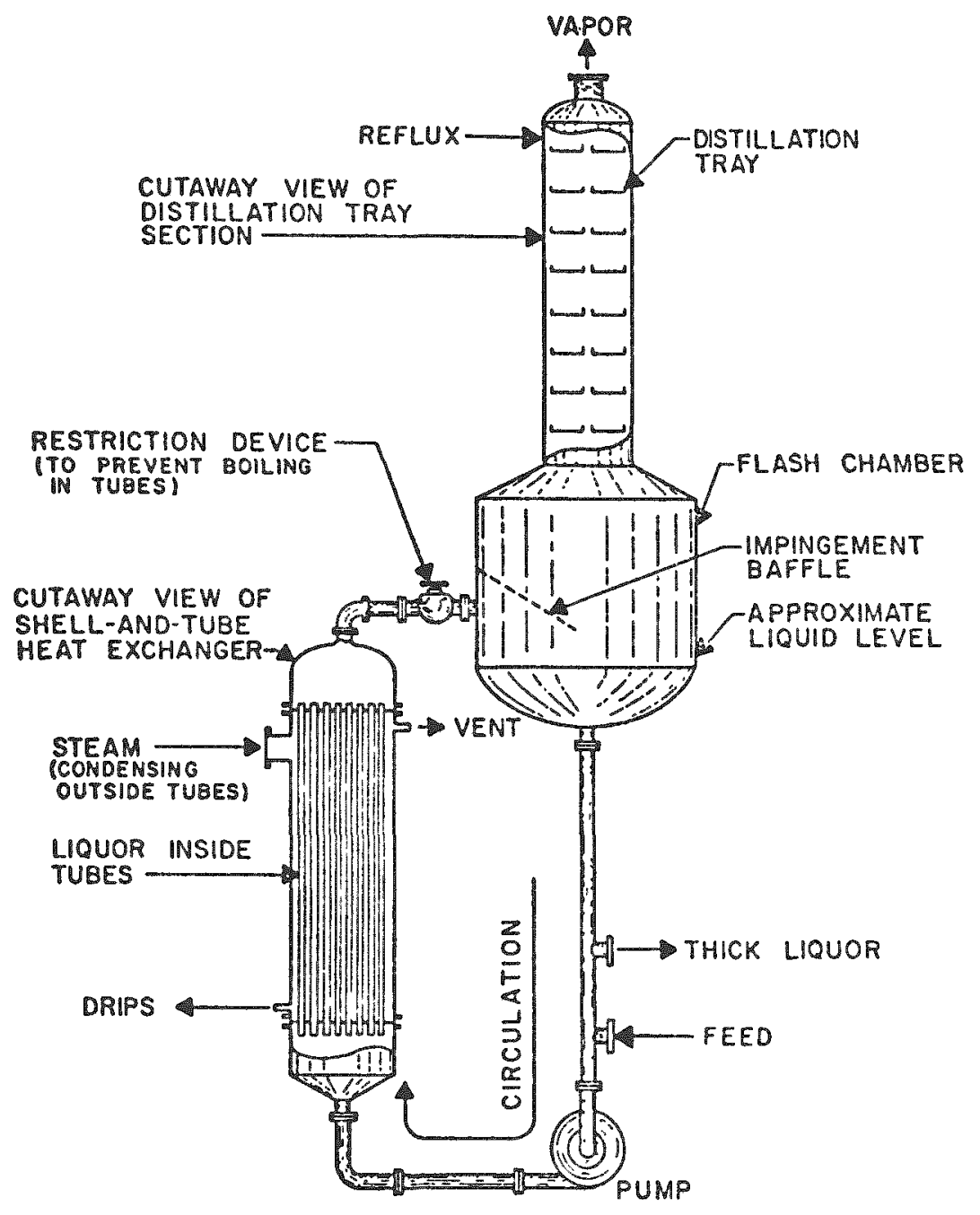

FIGURE 5.5

LONG-TUBE VERTICAL EVAPORATOR WITH EXTERNAL HEATER, FORCED CIRCULATION, RESTRICTION DEVICE TO PREVENT BOILING IN TUBES, AND DISTILLATION TRAY SECTION 


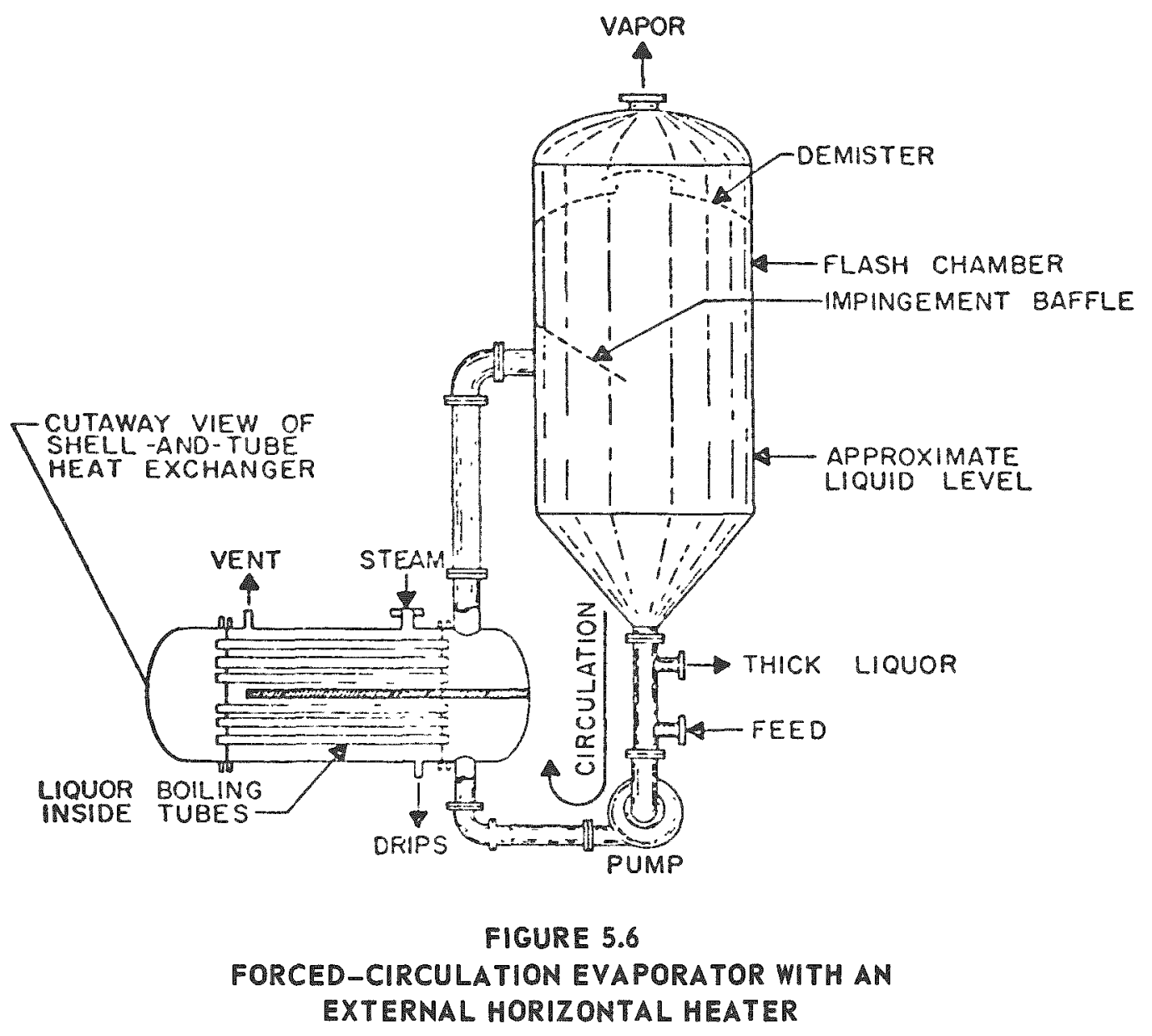


resistant materials because of problems with chloride stress corrosion. While it was running, the unit consistently achieved bottoms concentrations of 20 to 25 wt percent from a 1.5 wt percent $\mathrm{Na}_{2} \mathrm{SO}_{4}$ feed solution. This corresponds to a volume reduction factor of 15 to 20 . The unit has also been used to process floor drains and laundry wastes, achieving volume reduction factors of 100 to 400 . The actual decontamination factors for this evaporator are:

$$
\begin{aligned}
& \text { Regeneration solutions - } 200 \text { (feed-to-distillate) } \\
& \text { Floor drains }
\end{aligned}
$$

These DFs are two orders of magnitude below the design DF of $2 \times 10^{4}$, but several planned modifications may improve them. These modifications and other operating data and descriptive information for the Nine Mile Point evaporator are given in the Appendix.

Using a pilot plant forced circulation evaporator/crystallizer with rated capacity of $250 \mathrm{lb} / \mathrm{hr}$ (distillate), Horton Processing Division (HPD) Inc., has tested numerous nonradioactive solutions, including boric acid, sodium sulfate, ammonium sulfate/sodium sulfate, and simulated floor drainage. The results of some of this work have been reported in the literature ( 7 and 8 ). Additional findings were reported at an industry workshop sponsored jointly by HPD and Stock Equipment Co., in August 1978, a summary of which can be found in the Appendix. Briefly, some of these findings are:

- Neutralized sodium sulfate solutions can be concentrated to 50 wt percent without difficulty. At this concentration, sodium sulfate is a crystalline slurry approximately 20 wt percent above its solubility limit, resulting in a VR factor of 49, assuming a 1.5 wt percent feed solution.

- Boric acid can be concentrated to 50 wt percent without difficulty, if it is properly neutralized. Without this preconditioning, a $50 \mathrm{wt}$ percent solution of boric acid is a crystalline slurry that is 
difficult to handle in instrument lines and transfer piping. By first neutralizing this solution, its solubility is increased substantially, minimizing operational problems.

- With proper pretreatment, ammonium sulfate/sodium sulfate can be concentrated to over 50 wt percent without difficulties with operating interfaces. Carryover of ammonia is a problem that can be avoided by operating at a low $\mathrm{pH}$ or by removal of the ammonia prior to evaporation. The latter approach is recommended by HPD, for which they have developed a proprietary process.

- Simulated floor drains have been taken to a 50 wt percent solution without difficulty if they are combined with sodium sulfate in the crystallizer.

\subsubsection{Fluidized Bed Dryer/Incinerator}

o System Description

Fluidized bed drying of liquid radioactive waste is a process that has been developed by Aerojet Energy Conversion Company (AECC) of Sacramento, California (Figure 5.7). In this process, the liquid waste is sprayed into a vessel containing a starter bed of granular material, such as fine sand, which is fluidized by a preheated stream of air. The bed is further heated by electrical heater elements to an operating temperature of 850 to $900^{\circ} \mathrm{F}$. At this temperature, water in the waste feed is evaporated, leaving a dry, granular salt behind in the bed. Leaving the vessel is a gas stream consisting of water vapor, hot gases, and fine salt particles. A cyclone separates the solid materials from this stream and drops them into a product storage hopper. To maintain a constant bed depth as more waste material is processed, a portion of the bed is periodically removed through a screw conveyor, cooled, and taken to the product storage hopper. 


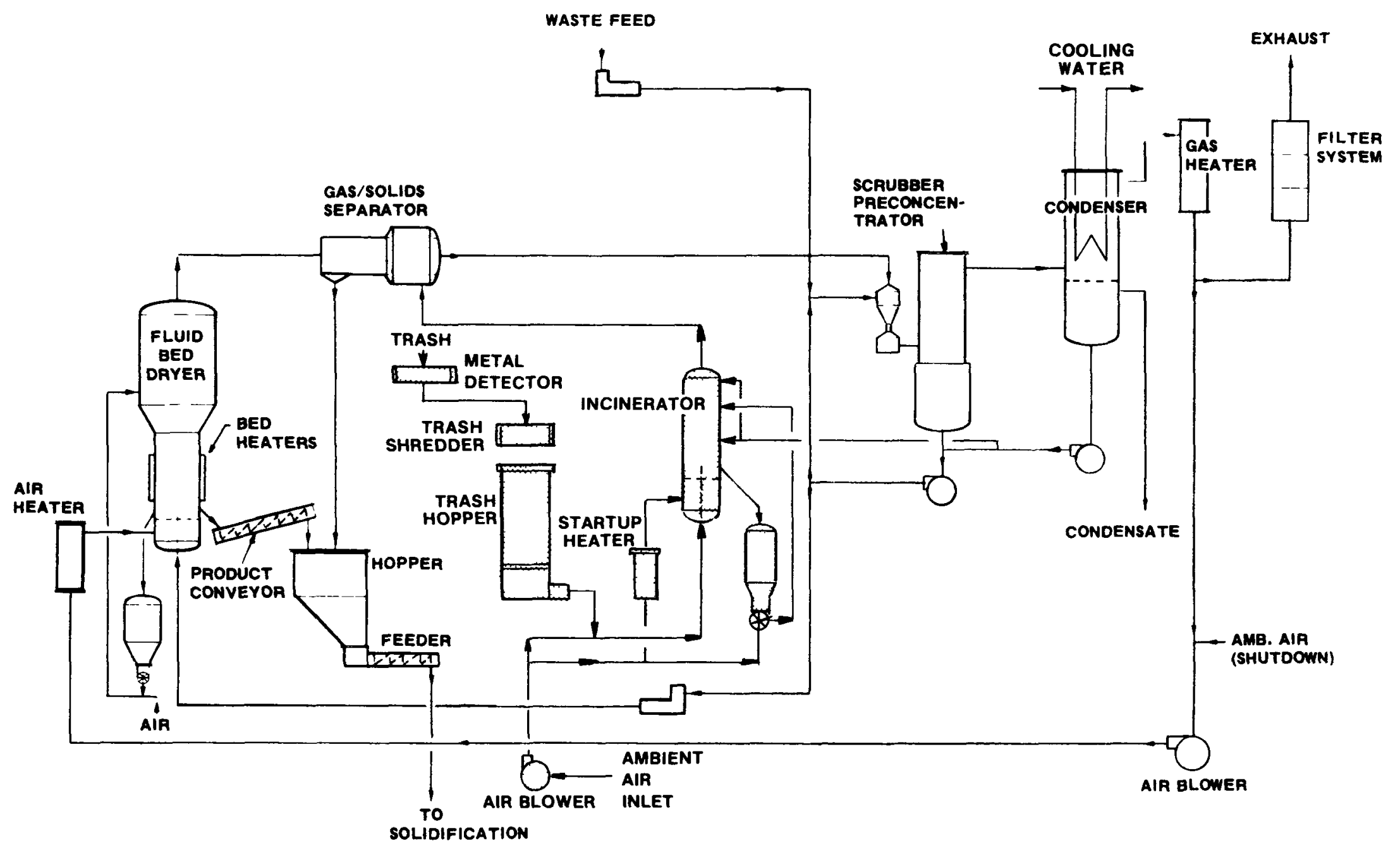

FIGURE 5.7

FLOW DIAGRAM OF FLUIDIZED BED DRYER/INCINERATOR USING SEPARATE VESSELS FOR DRYING AND INCINERATING 
The hot gases leaving the cyclone are taken through a wet scrubber/waste preconcentrator, where the heat in the gas is used to preconcentrate waste feed to the fluidized bed dryer to about $28 \mathrm{wt}$ percent. At the same time, the off-gas is scrubbed of any remaining particulate matter. After leaving the preconcentrator, the off-gas is passed through a condenser, gas heater, and filter system before discharge.

Liquid wastes are processed in the fluid bed dryer. Dry combustible waste and contaminated oil are volume reduced by oxidation in a separate, fluidized bed, incinerator vessel (Figure 5.8). The fluidized bed in the incinerator vessel is an inert material such as sand (instead of the salt from the feed stream in the dryer vessel). The incinerator bed is preheated to $1,000^{\circ} \mathrm{F}$ by an electric preheater in the air supply stream.

Combustible waste passes through a metal detector, is shredded, and blown into the vessel. Combustion of this waste takes place at a temperature of $1,450^{\circ} \mathrm{F}$. The products of this combustion process, both solid and gaseous, are removed as an overhead stream and processed in the off-gas system described previously for the fluid bed dryer. Since no waste material is added to the bed, it is normally not necessary to remove any bed material from the vessel during operation.

- Operating Experience

To date, there has been no operating experience with the fluidized bed dryer/incinerator in commercial nuclear power plants. A full scale prototype unit has been operated successfully by AECC for over 3,500 hours on nonradioactive liquid wastes (such as sodium sulfate and boric acid) and for over 500 hours on liquid waste and trash. This unit can process liquid waste at 20 to $120 \mathrm{gph}$ and dry waste at $100 \mathrm{lb} / \mathrm{hr}$. Several units similar to the AECC prototype system have also been ordered by utility companies, but these units will probably not be operational for another 3 to 5 years. 

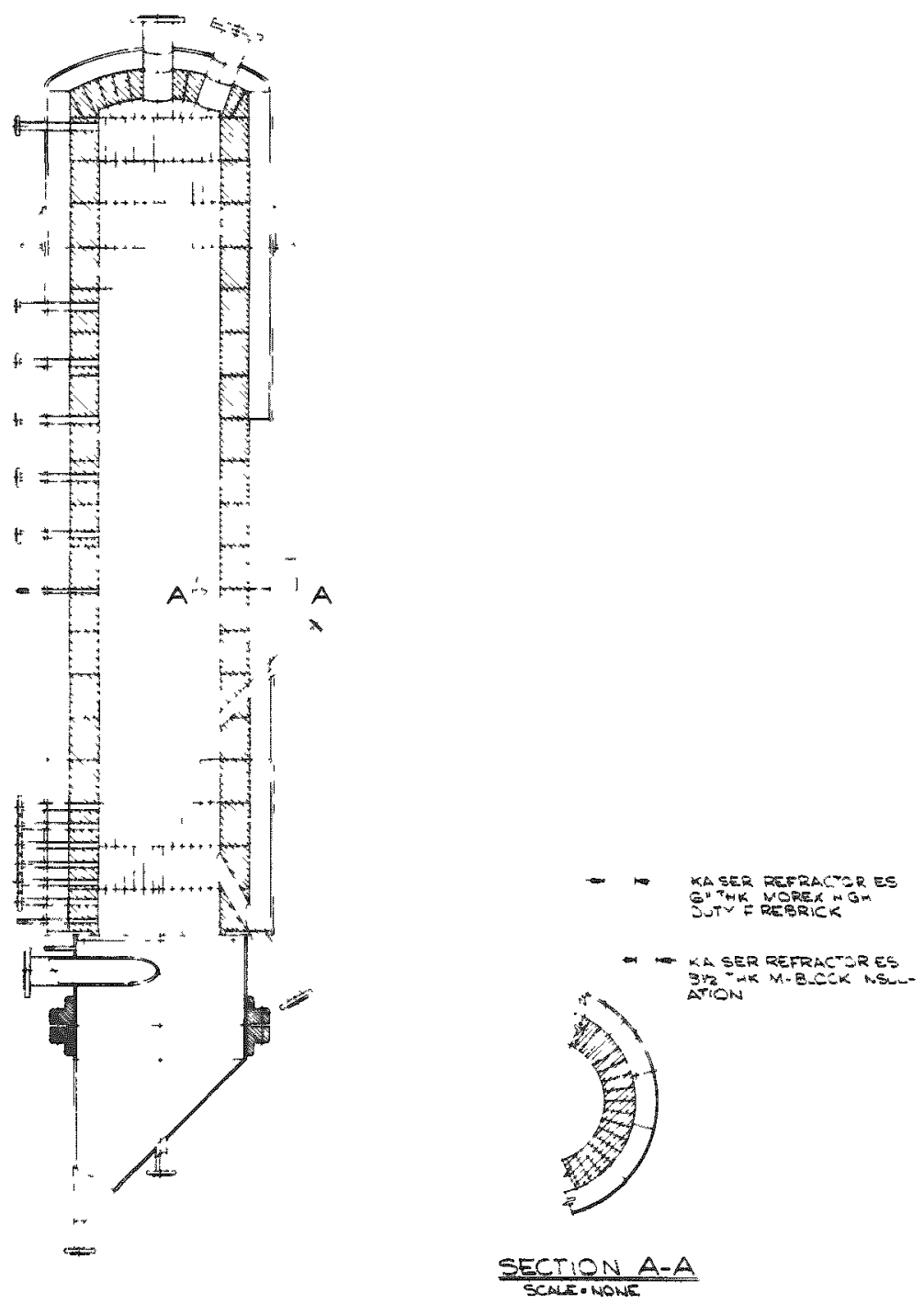

FIGURE 5.8

FLUIDIZED BED INCINERATOR VESSEL 
Based on numerous test runs with the prototype fluidized bed dryer/incinerator, the following volume reduction factors are claimed for this type of equipment:

- Sodium sulfate (20 wt percent feed concentration) - 5

- Boric acid (12 wt percent feed concentration) - 10

- Dry, combustible, uncompacted waste -70

Based on actual operating data from utilities that have used other types of incinerators for radioactive trash, a volume reduction factor of 70 is exceptionally high. This difference could be due to the more complete combustion that the fluidized bed process is said to achieve and/or due to differences in the quality and Btu content of the waste feed.

In 1975, AECC, in conjunction with the NRC, conducted tests on the prototype dryer to determine the decontamination factors for $1-131$. This testing program indicated that 50 percent of all I-131 would leave the dryer vessel with the off-gas. Most of this iodine carryover is subsequently removed in the off-gas cleanup system. The combined decontamination factor of the dryer and off-gas cleanup systems for all forms of I-131 was determined to be $10^{5}$.

\subsubsection{Fluidized Bed Calciner/Incinerator}

- System Description

A fluidized bed calciner/incinerator for volume reducing radioactive liquid wastes and combustible dry wastes is being commercially marketed under a joint venture by Energy, Incorporated and Newport News (Figure 5.9). Calcination is a high temperature process in which aqueous salt solutions, dewatered resins, or combustible dry wastes are burned to form stable, free-flowing, elemental oxides. The calciner offered by Energy, Inc. and Newport News, designated the RWR-1, is similar in operating principle to the fluidized bed dryer discussed in Section 5.2.2. However, for the RWR-1 system, both the liquid wastes and 


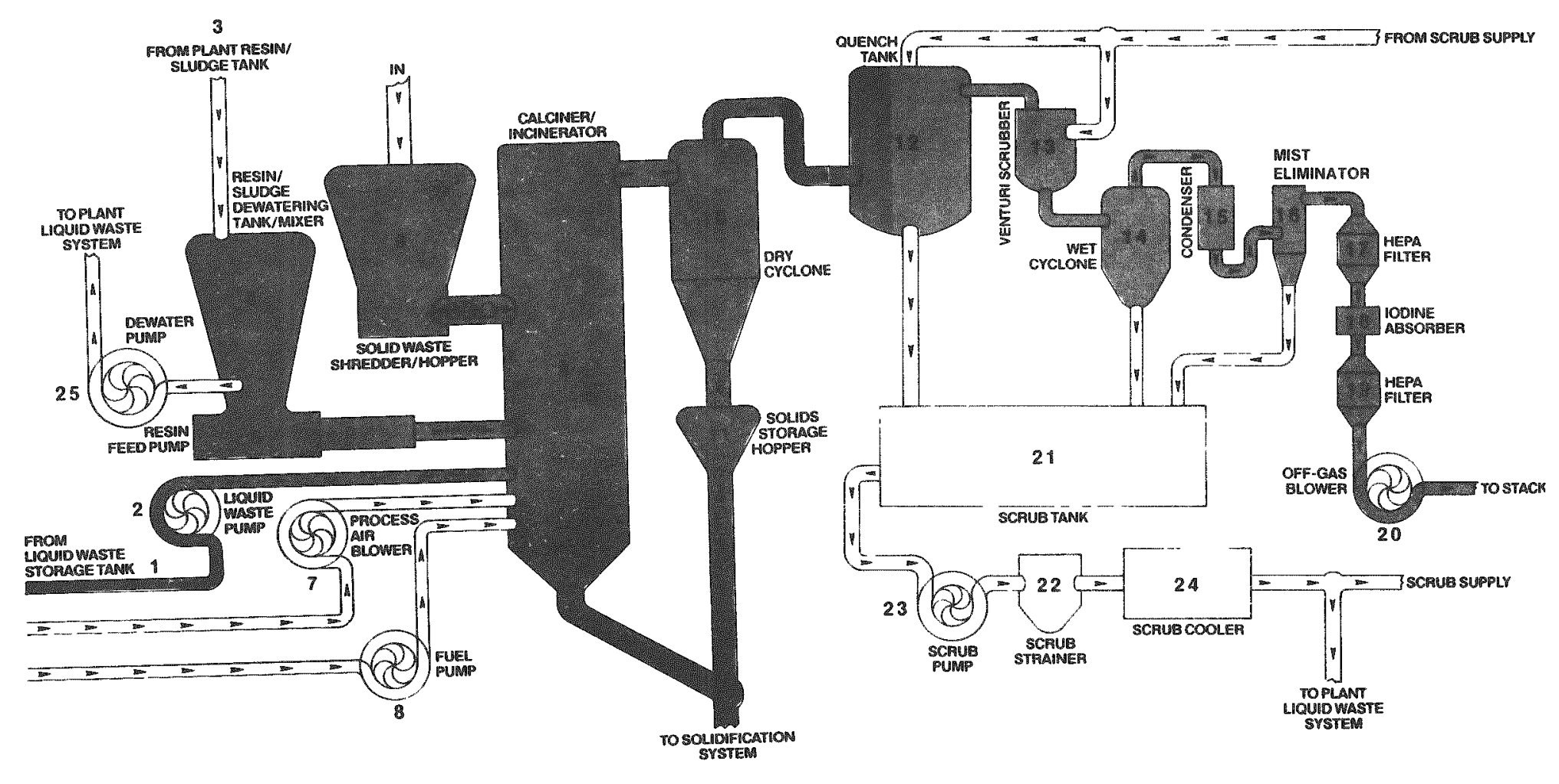

FIGURE 5.9

FLOW DIAGRAM OF FLUIDIZED BED CALCINER/INCINERATOR USING SINGLE VESSEL FOR CALCINATION AND INCINERATING 
dry combustible wastes are processed in one vessel containing an air fluidized bed of inert granular material. The bed is heated by injecting kerosene or a similar heating fuel into the bed. By adding an excess quantity of fluidizing air to the calciner vessel, all of the calcination products formed from both liquid and solid waste feed stocks are removed with the off-gas. These solids are then separated from the off-gas in a dry cyclone and drop by gravity into a product storage hopper. Any remaining particulate matter in the off-gas stream is removed by a quench tank and wet cyclone/wet scrubber system. The off-gas passes through a condenser and demister section to remove residual moisture before passing through HEPA filters and an iodine adsorber prior to discharge.

At present, there is no operating experience with the fluidized bed calciner/incinerator in the commercial nuclear power industry. A unit is planned for installation at the Niagara Mohawk Nine Mile Point Power Plant in the near future. This unit will be capable of handling $200 \mathrm{lbs} / \mathrm{hr}$ of dewatered resin, $140 \mathrm{lbs} / \mathrm{hr}$ of dry, shredded combustible waste, or $40 \mathrm{lbs} / \mathrm{hr}$ of $25 \mathrm{wt}$ percent sodium sulfate solution.

Although there has been no commercial experience with the RWR-1 system, considerable data has been gained on nonradioactive waste in a prototype unit at Energy, Inc's facilities in Idaho Falls, Idaho. A great deal of experience has also been gained in processing high level radioactive waste in a similar type calciner that has been operated at the Idaho National Engineering Laboratory for the past fifteen years. Based on this experience, the following volume reduction factors are expected for the commercial unit:

Sodium sulfate (25 wt percent feed concentration) - 5

Boric acid (12 wt percent feed concentration) - 10

Dewatered bead resin - 20

Dry, shredded, combustible waste -80 


\subsubsection{Thin Film Evaporator}

- Sytem Description

Mechanically agitated, thin film evaporators (TFEs) have been used for many years for processing viscous $(>1,000 \mathrm{cp})$, heat sensitive, or fouling type fluids. Since 1951, TFEs have been used to volume reduce radioactive liquid wastes, mainly at government research institutions and military installations. There are two basic types of TFE design horizontal and vertical (Figures 5.10 and 5.11). Both types have three main components, a tubular vapor body with external heating jacket, a rotor, and a motor drive unit. Various rotor designs are available, but all of these can be put in one of three basic categories, "zero" clearance, fixed clearance, or adjustable clearance.

Due to the relatively high cost and mechanical design difficulties associated with increasing the size of these units, the waste feed to the TFEs should be preconcentrated as much as possible by conventional evaporation, reverse osmosis, or other means. Such preconcentration allows the volume throughput requirements of a nuclear power plant radwaste treatment system to be met by a manageably sized ( 1 to $10 \mathrm{gpm}$ ) TFE.

The basic operating principle is the same in all TFE design variations. Feed enters the vapor body vessel and is thrown against the walls by centrifugal force developed by the rotor. A thin film of liquid is maintained by the rotor blades, which pass through each point of the heated surface over 10 times per second. The heat transferred through the cylinder walls causes vaporization of the thin liquid film. These vapors are removed through the vapor outlet after passing either concurrently or countercurrently to the liquid flow through the spaces between the rotox blades. Carryover material from the existing vapor may be removed in internal or external entrainment separators. The material remaining in the 1 iquid phase is continuously concentrated as it 


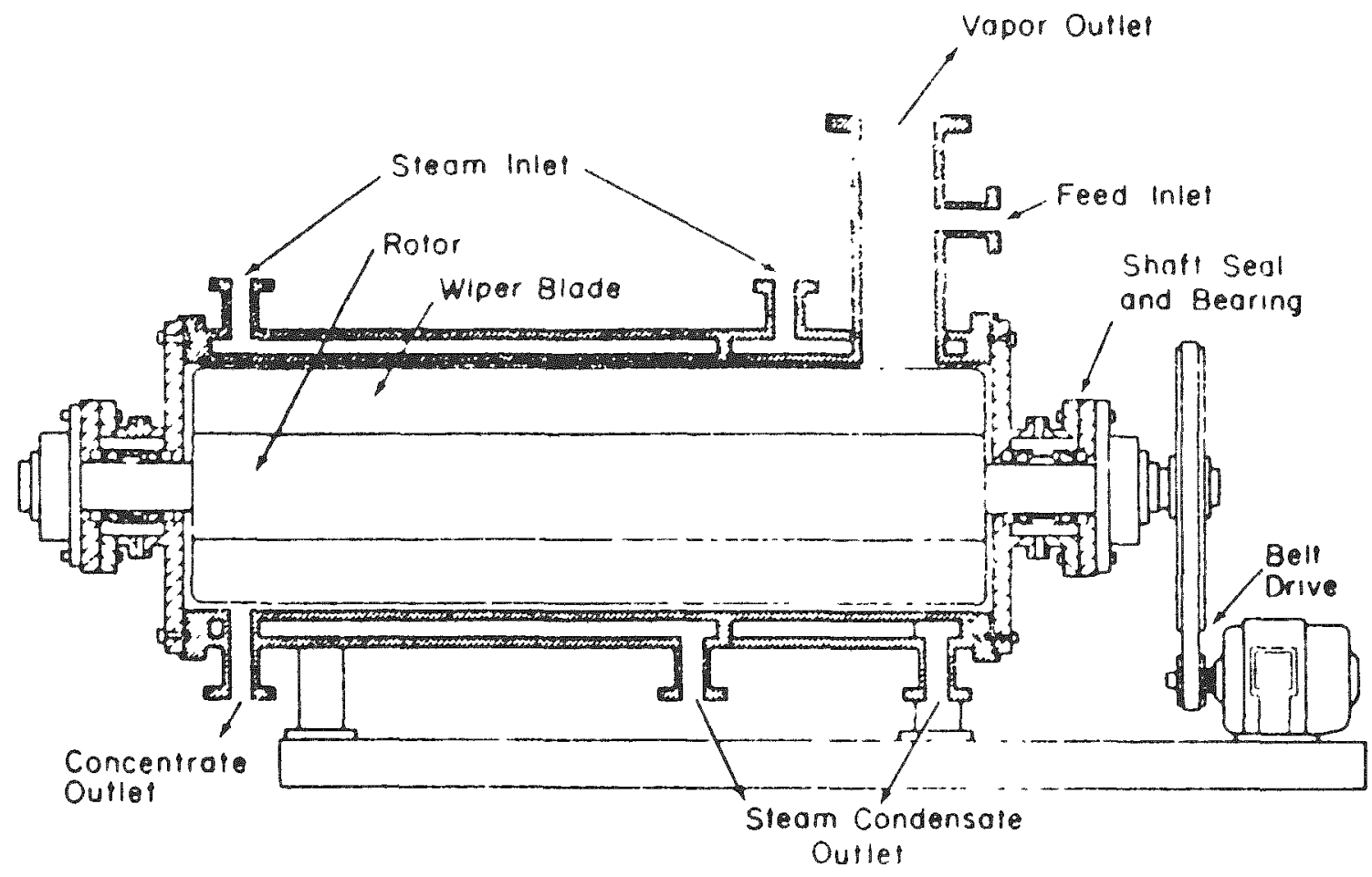

FIGURE 5.10

TYPICAL HORIZONTAL THIN FILM EVAPORATOR 

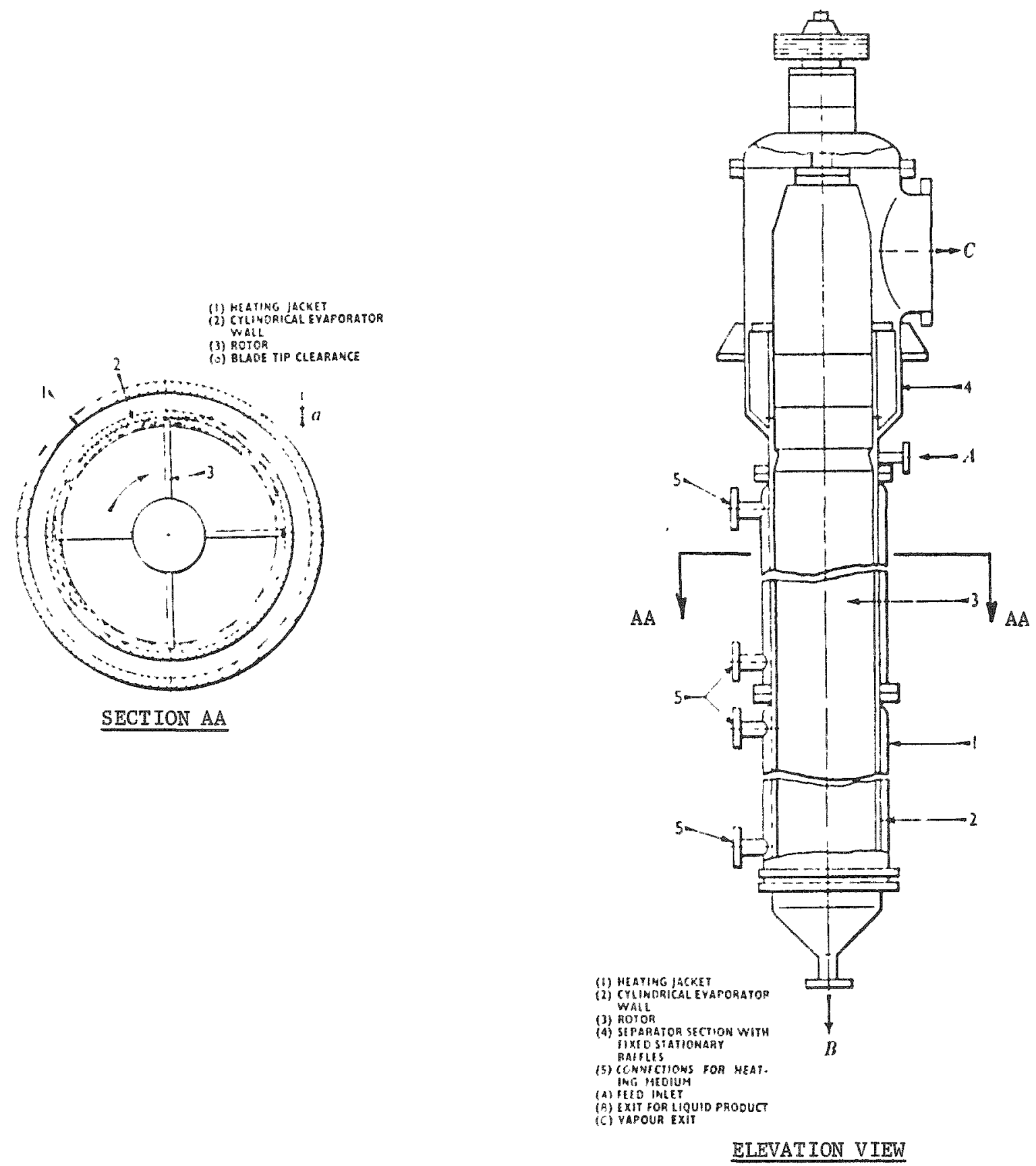

FIGURE 5.11

TYPICAL VERTICAL THIN FILM EVAPORATOR 
gradually flows to the opposite end of the vapor body where it is discharged by gravity through a discharge nozzle and collected in a concentrates storage tank.

Interaction between the rotor blade and wall of the vapor body creates a complex wave front. This turbulent wave action, which is maintained by proper film thickness control, allows heat and mass transfer to occur with minimal boiling. If the film is too thin, it may become too dry causing scale formation. If the film is too thick, nucleate boiling will occur causing increased vapor entrainment. By proper design of rotor blade clearance and careful control of steam supply, the optimum film thickness can be achieved for any fluid conditions.

About 10,000 mechanically agitated TFEs have been installed worldwide since the 1940s, and, since 1951, approximately 50 units have been used to process radioactive wastes (9). As mentioned previously, most of these units have been used at government research facilities or at military installations. Only one TFE has been installed and operated in a commercial nuclear power plant in the United States. This unit (Figure 5.12) was installed at the James A. Fitzpatrick Nuclear Power Plant in Scriba, New York and is described in detail by Rupinskas and Vogt (10). This unit was a $10.8 \mathrm{sq} \mathrm{ft}$, horizontal, tapered TFE designed to concentrate a 25 wt percent BWR sodium sulfate regeneration solution to 60 wt percent for discharge into drums. This corresponds to a VR factor of 3 . Because of various operational difficulties, the unit was operated for only a few hours before its use was discontinued. The unit apparently was able to concentrate the waste feed to the desired level, but unacceptably high levels of feed were entrained in the overhead (as much as 4 percent of the feed solids appeared in the distillate)(10). Reportedly, there were additional problems with the bottoms transfer piping and storage system, which was not adequately designed to handle a slurry with high solids content. 


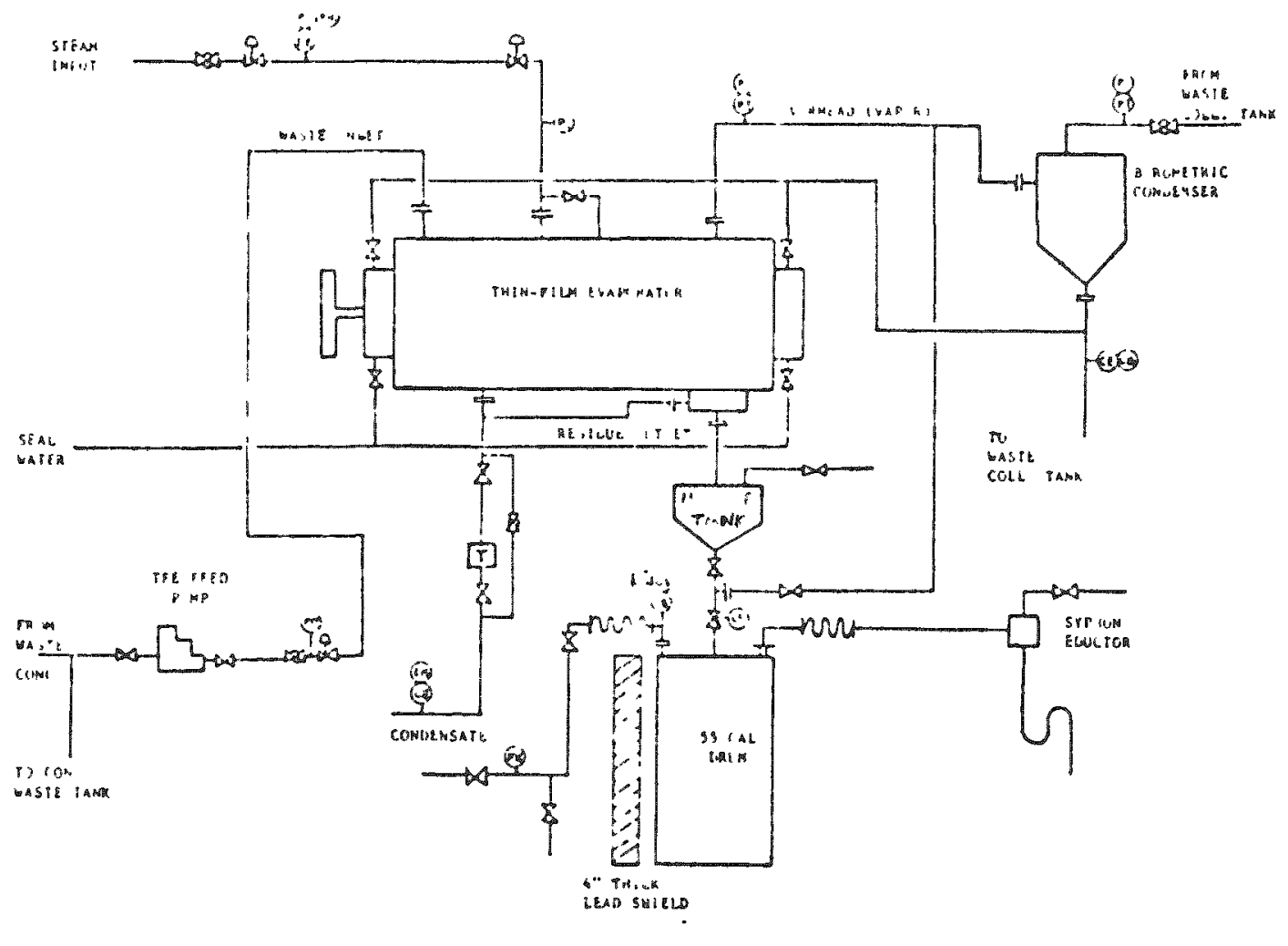

FIGURE 5.12

FLOW DIAGRAM FOR THIN FILM EVAPORATOR AT FITZPATRICK NUCLEAR POWER STATION 
Two other TFEs are being supplied for use in domestic nuclear power plants. These are $100 \mathrm{ft}^{2}, 5 \mathrm{gpm}$, horizontal, fixed clearance units manufactured by Artisan Industries for use at Washington Public Power Supply System (WPPSS) to concentrate various PWR evaporator bottoms streams to 50 wt percent total șolids (Figure 5.13). There are several major differences between this TFE and the one at FitzPatrick that should reduce or eliminate the problems discussed above. Among them are: 1) an external, reflux entrainment separator; 2) a shell and tube vapor condenser; and 3) distillate recycle capability. One of the units was recently tested by the manufacturer before shipment to WPPSS. This test demonstrated that a solids concentration of at least 50 wt percent could be achieved for these waste solutions while maintaining a distillate conductivity of less than $20 \mu \mathrm{mho} / \mathrm{cm}$.

A number of TFE manufacturers maintain pilot plants in which various, simulated, nonradioactive, nuclear power plant waste streams have been concentrated to well over 50 wt percent. The results of one such test on four different detergent waste streams is included in the Appendix. Solids concentrations as high as 98.9 wt percent were achieved in some of these test runs without foaming or carryover of more than $150 \mathrm{ppm}$.

At Chalk River Nuclear Laboratory (CRNL) in Ontario, Canada, a small $5.4 \mathrm{ft}^{2}$ vertical TFE has been tested for a number of years on simulated radioactive and nonradioactive decontamination solutions from the CANDU reactor system. The unit has been tested as a straight evaporator, increasing the concentration of a sodium phosphate feed solution from 10 wt percent to approximately 60 wt percent, corresponding to a VR factor of 5. For this case, the feed/distillate decontamination factor for sodium ions has generally been between $10^{4}$ and $10^{5}$, making an external entraimment separator unnecessary. CRNL has also found that the small. volume of radioactive material in the TFE at any one time allows the radiation levels around the evaporator to be much lower than those in either the feed or concentrate storage systems. Therefore, CRNL feels that shielding the TFE vapor body being installed in the CRNL demonstration waste treatment center will be unnecessary. 
Several years of operating experience have been gained at CRNL and several European facilities in the use of a TFE to volume reduce waste solutions while simultaneously encapsulating them in bitumen. Using the TFE described above, CRNL has successfully solidified both a 5 wt percent sodium phosphate feed solution and 5 wt percent resin slurry feed in bitumen. In the final product, nearly all ( 99.5 percent) the water has been removed and replaced by bitumen. Solidified products containing as much as 45 wt percent salts were achieved without any operational difficulties. Tests were run using straight bitumen and a 40 wt percent water-in-bitumen emulsion, both of which have worked successfully. Because the bitumen emulsion is easier to store and handle, CRNL plans to use it in the demonstration waste treatment center. One drawback to using an emulsion is that the product rate is 20 percent less than that achieved with a straight bitumen feed.

There has been additional commercial experience at Barseback Units 1 and 2 in Sweden, where BWR evaporator bottoms, resins, and filter precoat material have been successfully encapsulated in bitumen using a $10.8 \mathrm{ft}^{2}$ vertical TFE. With 20 wt percent evaporator bottoms as waste feed, this unit has produced a final product containing 40 wt percent salt and less than 1 wt percent water. Using a feed solution of 20 wt percent ground resin or filter precoat material, a product has been obtained with a solids to bitumen weight ratio of $30-$ to- 70 .

\subsubsection{Extruder/Evaporator}

- System Description

The extruder/evaporator is a radwaste volume reduction system developed and marketed by Werner-Pfleiderer Coxporation. A flow diagram of this system is shown in Figure 5.14. The basic component of the system is a twin screw extruder. The screws rotate inside heavy metal, steam jacketed barrels. As processing steam passes through these barrels to heat the waste solutions to above their boiling point, water vapor is driven off through steam domes connected to selected barrels of the 


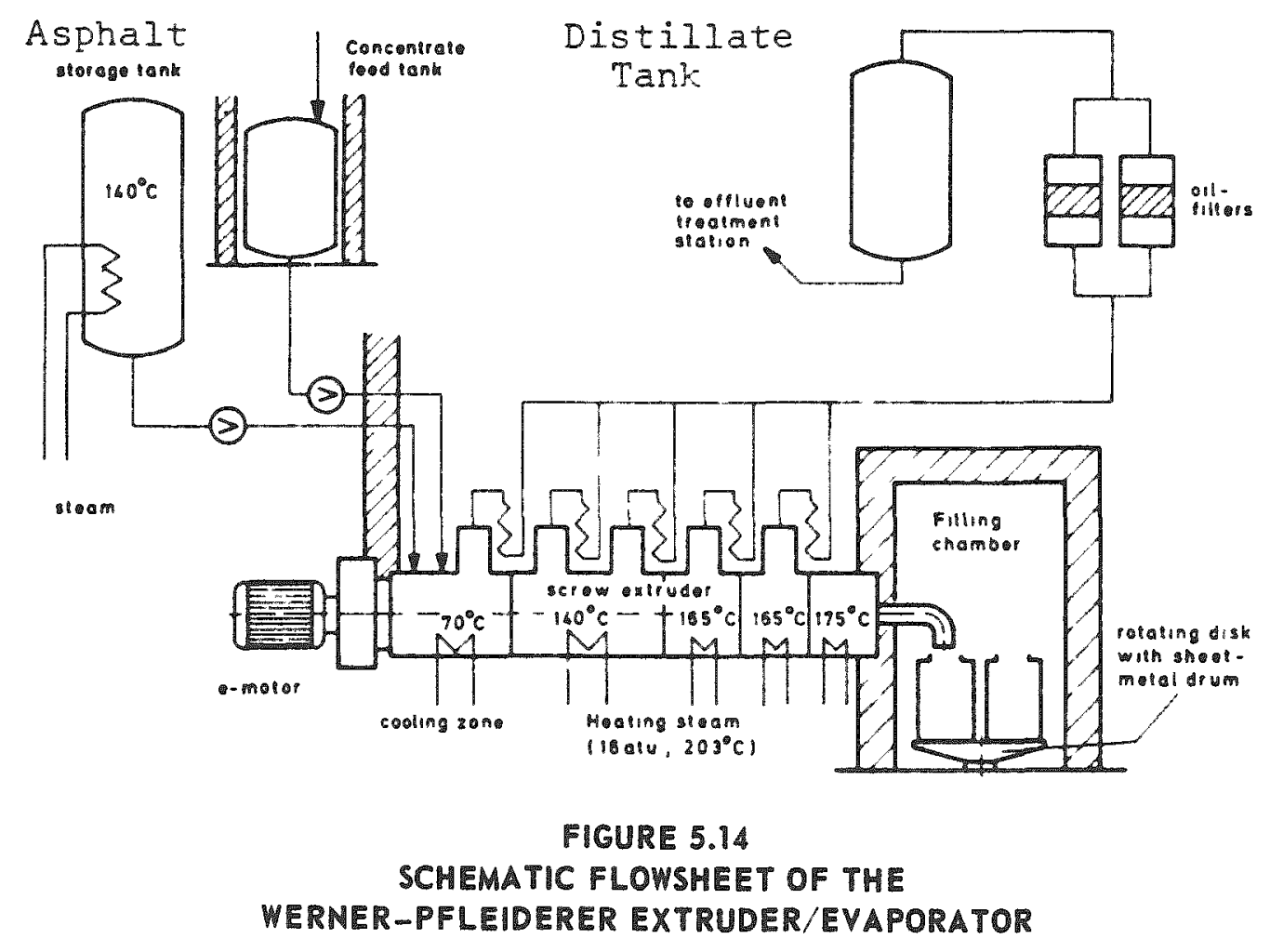


extruder. The dry salt which is left behind is removed from the end of the unit by the action of the rotating screws. Water vapor exiting the steam domes is condensed in a shell and tube cooler/condenser, while noncondensibles are passed through an off-gas cleanup system and released.

The extruder/evaporator could be used exclusively as an evaporator to produce a concentrated salt solution or a completely dry salt. However, for commercial nuclear power plants, where relatively large volumes of liquid radwaste must be processed, it is not economically feasible to build a unit large enough to handle the volume of waste in this manner. Instead, in commercial nuclear plants, the extruder/evaporator is used exclusively as a combined volume reduction/solidification process for waste which has been preconcentrated by some other method. This preconcentrated waste and bitumen are mixed while over 99.5 wt percent of the remaining water in the feed is removed. The end product of dry salt (or resin bead) in bitumen is forced from the end of the unit by the action of the twin screws and drops by gravity into a container for disposal.

There is no operating experience with the extruder/evaporator in the domestic nuclear power industry, although several units have been sold to Consumers Power Company of Michigan for installation in their Palisades and Midland nuclear power plants.

A small, $0.15 \mathrm{~m}^{2}, 4 \mathrm{~kg} \mathrm{H} 20 / \mathrm{hr}$ extruder/evaporator has been tested for several years at CRNL in Canada, using simulated radioactive and nonradioactive, CANDU reactor system wastes. The unit was used successfully to volume reduce and bituminize various wastes, including a 30 wt percent $\mathrm{Na}_{2} \mathrm{SO}_{4}$ regeneration waste solution, a 10 wt percent alkaline peroxide decontamination solution, moist ion-exchange resin, and incinerator ash. In all cases, the end products contained at least 40 wt percent solids and less than 0.5 wt percent water. Distillate quality 
from the unit varied considerably with changes in waste feed, feed rate, barrel temperature profile, and screw rotation rate. For instance, foaming aqueous solutions produced unacceptable distillate quality when processed at more than 75 percent of the extruder's rated capacity. In general, CRNL found that to maintain both a good quality distillate and an acceptable process rate with an entrainment separator, the liquid feed to the unit should have a total solids content of at least 15 wt percent. Under these conditions, the DF values for several different radionuclides processed through the CRNL unit were as follows:

Radionuclide

$$
\begin{aligned}
& \text { Sr }-85 \\
& \mathrm{Cs}-134 \\
& \mathrm{Co}-60
\end{aligned}
$$

\section{Range of DFS}

When processing bead resin or incinerator ash through the extruder, CRNL also found that these wastes had to be dry or suspended in a slurry. When moist ash or resin was fed to the extruder, it became clogged in the throat at the entrance to the unit. Additionally, incinerator ash larger than 0.25 inches in diameter could not be carried from the throat of the unit because of the clearances between the screws and barrel walls.

Successful operating experience has been reported on similar extruder/evaporators processing radioactive wastes at several European research centers and at a commercial nuclear power plant in Borssele, Holland. The unit at Borssele has reportedly been operated for more than 7,500 hours without a maintainance outage(11). Due to the small volume of radioactive waste in the extruder at any one time, the activity level around the unit is low during operation (100 mr/hr range). If the unit is shut down for maintenance, the activity levels can be reduced to the range of $10 \mathrm{mr} / \mathrm{hr}$ by processing a tank of solvent through the unit to take advantage of the self-cleaning action of the rotating screws. 


\subsubsection{Incinerator}

Many different types of incinerators have been used to volume reduce dry combustible radwaste. Methods being studied and tested at DOE facilities are molten salt incineration, stagging pyrolysis, oxidation by acid digestion, and microwave incineration. In this section, "conventional" incineration practices will be discussed. Conventional is refers to incinerators which consist of a simple combustion chamber into which the waste material is charged, along with combustion air and a suitable heating fuel (propane, fuel oil, etc) which provides the initial flame to ignite the waste material.

Only a few incinerators have been installed at commercial nuclear power plants. The largest and most significant of these is a unit now operating for over two years at the Ontario Hydro Bruce Nuclear Power Development Site. A flow diagram for this system is shown in Eigure 5.15. This unit is a "starved air", two stage combustion process in which waste material is burned on a batch basis. A load of approximately $20 \mathrm{~m}^{3}$ of incinerable waste is first loaded into the primary combustion chamber via a conveyor. This chamber is a double-walled vessel with a carbon steel outer wall and stainless steel inner wall. Stainless steel was chosen instead of a refractory lining which might trap excessive radioactivity and be difficult to decontaminate. The waste is ignited by propane burners and pyrolysed with air fed into the chamber through a grating at the bottom. The resultant gases, as well as some fine particulate matter, exit near the top of the primary chamber and enter an afterburner chamber, where, in an excess of air, propane is again used as the ignition source to complete combustion. An induced draft fan draws the flue gases from the afterburner into a shell and tube, air cooled heat exchanger. From there, they are filtered in a baghouse equipped with Nomex bags. After filtration, the gases are monitored and discharged. At the completion of each burn cycle, ashes 


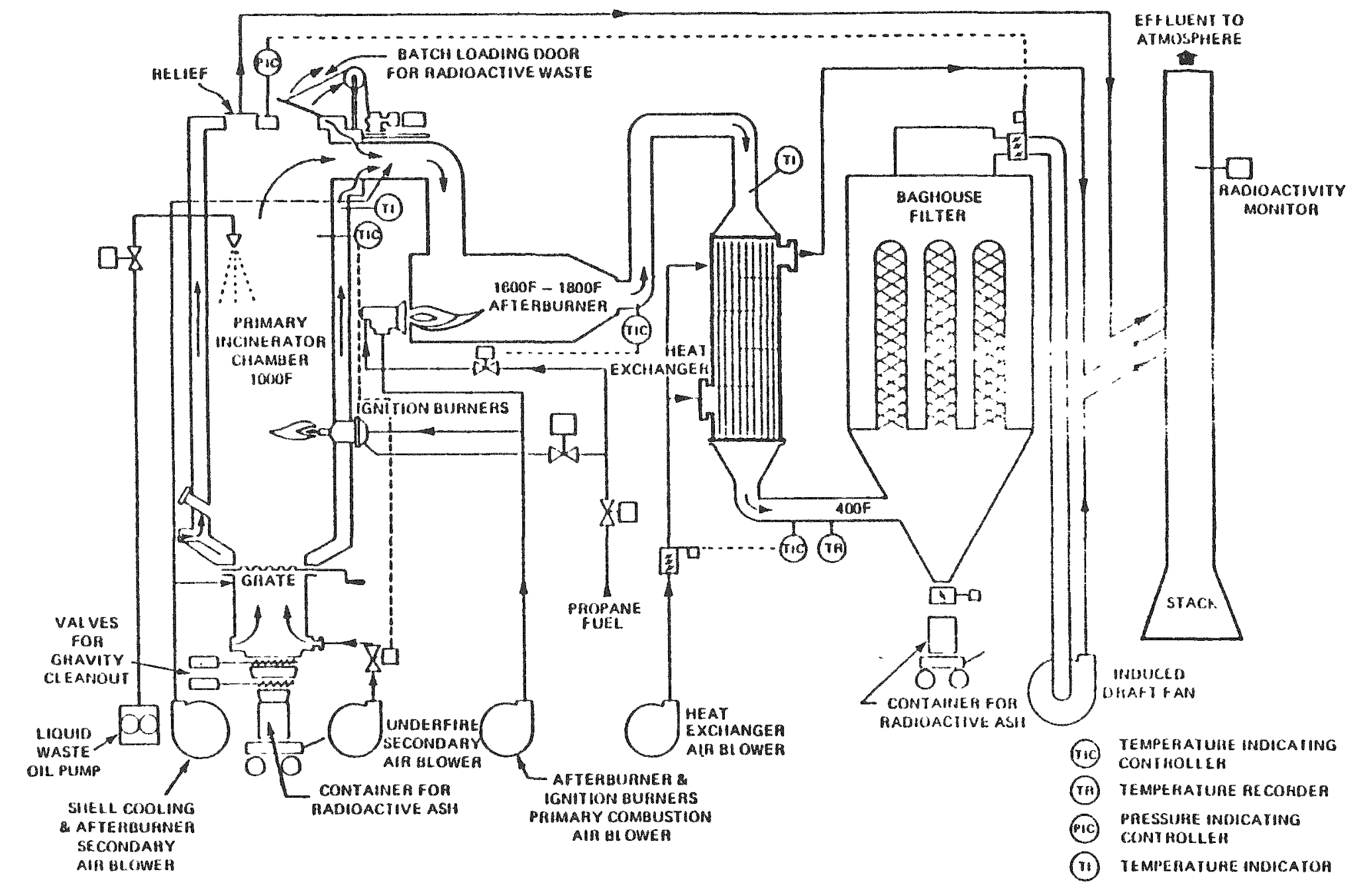


from the primary chamber ace dumped into a $2.5 \mathrm{~m}^{3}$ container located directly below the chamber.

There is considerable operating experience worldwide with radwaste incinerators using conventional techniques. However, this experience has been mainly at research institutions, government laboratories, new fuel processing facilities, and spent fuel reprocessing facilities. These facilities have reportedly operated with varying degrees of success(12). The major problems associated with some have been:

- Containment of gases

- Incomplete combustion

- Material failures

- Criticality control (in cases where U-235 or plutonium are present)

Operating experience with the waste incinerator at Bruce has been reported(12) and is discussed in the Appendix. The unit has been able to attain an average volume reduction factor of 35 with uncompacted, bulk waste feed. However, numerous problems have developed with the unit, including:

- Process control

- Excessive burn cycle time

- Material failures

Radionuclides discharged to the vent stack for the Bruce incinerator have been very low in activity levels. This would indicate that the radiation level of the waste fed to the unit could be increased above the current specification limit of $5 \mathrm{mr} / \mathrm{hr}$ at contact. Radiation levels in the ash and around the equipment have also been low (less than $30 \mathrm{mr} / \mathrm{hr}$ in all cases), indicating that a refractory lined primary chamber could probably be used without increasing radiation doses to unmanageable levels. 
The only incinerator in operation at a commercial nuclear power plant in the United States is at Yankee-Rowe. This is a small, $401 \mathrm{~b} / \mathrm{hr}$ unit with a wet scrubber and deep bed, glass wool filter in the off-gas cleanup system. The unit has reportedly worked very well, although large amounts of plastic must be excluded from the wastes to be incinerated because they hamper complete combustion.

\subsubsection{Compactor}

- System Description

The most common volume reduction system for dry compactible waste (paper, plastics, clothing, bottles, cans, etc.) has been simple drum compactors. In some cases, hydraulic balers or a new type of compactor have been used with good success at several plants.

Drum compactors usually consist of a hydraulically operated ram, a drum support frame, and an air filtration system containing roughing filters and/or HEPA filters. Ram compressive forces range from less than $10,000 \mathrm{lbs}$ up to $30,000 \mathrm{lbs}$, depending on the model.

The baling machines consist of a frame with a rectangular cavity where the waste is compressed by a rectangular ram. On the last stroke of the ram, the ram is held against the compressed waste while wire or strong twine is manually or automatically wrapped around the bale. In some cases, the waste is compacted into a cardboard box, around which the wire or twine is then wrapped. Normally, a filtration system is not built into the baling machine and must be supplied separately. Ram compressive forces of over $50,000 \mathrm{lbs}$ are typical for these machines.

The new device, a CGR box compactor, is similar to a baler, except that it is designed to compact the waste directly into a wooden or metal low specific activity (LSA) box. These boxes measure approximately $7 \mathrm{ft} x$ $4 \mathrm{ft} \times 4 \mathrm{ft}$ (an actual $103 \mathrm{ft}^{3}$ ) and are designed to be stacked two high in a closed tractor trailer with the $7 \mathrm{ft}$ dimension running across the 
width of the trailer. Before the last stroke of the ram during a compaction cycle, the lid of the LSA box is placed between the ram and the filled box. When compressed by the ram against the upper lip of the box, it is nailed into place. In this manner, loss of storage volume due to "spring-back" (common to drum type compactors) is avoided.

- Operating Experience

A telephone survey gathered data on compaction experience from a number of operating nuclear power plants. The data are summarized in Table 5.1. In most cases, standard 55 gallon drum compactors have been used to date. Estimates of the VR factors for these units vary from 2 to 10 . Very few of the plants contacted have done precise calculations of the VR factors actually achieved. At Dresden station, careful measurements were made of the weight of trash compacted into six drums with a standard industrial compactor (ram force of about 10,000 1bs). This same waste was compacted into four drums using a heavy duty compactor with a ram force of $30,000 \mathrm{lbs}$.

At Bruce Station, careful measurement of volume reduction factors using an identical 30,000 $\mathrm{lb}$ machine showed a maximum VR factor of 4 to be obtainable. The compactible nature of the Ontario Hydro waste may be less than average, because they compact only waste that cannot be incinerated. Currently a conversion to a baler is being made for two main reasons:

- More efficient package shape (rectangular versus cylindrical) for storage

- Fewer man-hours required to package a unit volume of waste

\subsubsection{New1y Developed Volume Reduction Systems}

Over the last few years, several new volume reduction techniques have been developed for processing commercial nuclear reactor wastes. Their status 
TABLE 5.1

DRY WASTE COMPACTION SURVEY

\begin{tabular}{|c|c|c|c|}
\hline Plant & Compaction Method & VR Eactor & Notes \\
\hline Arkansas No. 1 & 55821 drum & $\begin{array}{l}6 \text { to } 10 \text { bags } \\
\text { per drum }\end{array}$ & $\begin{array}{l}\text { Bags measure } 65^{\prime \prime} \text { long } \\
\times 30^{\prime \prime} \text { wide; New } \\
\text { compactor mfgd by } \\
\text { NuPac; Ran force is } \\
18,000 \text { lbs }\end{array}$ \\
\hline Salem & 55 gal drum & $\begin{array}{l}3001 \mathrm{~b} \text { to } 500 \mathrm{lb} \\
\text { per drum } \\
\text { (approximated) }\end{array}$ & $\begin{array}{l}\text { Stock Equip. Co. } \\
\text { compactor; Ram force } \\
\text { is } 30,000 \text { Ibs }\end{array}$ \\
\hline Zion & $\begin{array}{l}55 \text { gal drum (two); } \\
\text { Baler }\end{array}$ & $\begin{array}{l}2 \text { (Industrial unit) } \\
3 \text { (Stock unit) } \\
3 \text { (Baler) }\end{array}$ & $\begin{array}{l}\text { Baler develops } \\
150,0001 \mathrm{~b} \text { compressive } \\
\text { force: Bales are } \\
45 \mathrm{ft}^{3}\end{array}$ \\
\hline Indian Pt & 55 gal drum & $\begin{array}{l}7 \text { or } 8 \\
\text { (estimated) }\end{array}$ & $\begin{array}{l}\text { Considering use of } \\
\text { CGR box compactor }\end{array}$ \\
\hline Millstone & $55 \mathrm{gal}$ drum & $3(\operatorname{avg})$ & \\
\hline Pilgrim & Bot compactor & $\begin{array}{l}\text { Ranges from } \\
2-1 / 2 \text { to } 6\end{array}$ & $\begin{array}{l}\text { Ram force is } 1000 \text { lbs; } \\
\text { Box dimensions are } \\
2^{\prime} \times 2^{\prime} \times 18^{\prime \prime}\end{array}$ \\
\hline La Crosse & $55 \mathrm{gal}$ drum & $\begin{array}{l}\text { Ranges from } \\
3 \text { to } 10\end{array}$ & \\
\hline Dresden & 55 gal drum (two) & $\begin{array}{l}202 \mathrm{lb} / \text { drum } \\
\text { (industrial unit); } \\
3031 \mathrm{~b} / \mathrm{drum} \\
\text { (Stock Equip. Co. } \\
\text { unit) }\end{array}$ & \\
\hline Quad Cities & Baler & 10 (estimated) & $\begin{array}{l}\text { Same notes as for } \\
\text { Zion }\end{array}$ \\
\hline Palisades & $55 \mathrm{gal}$ drum & Not reported & \\
\hline Big Rock Pt & 55 gal drum & 3 or 4 (estimated) & \\
\hline FitzPatrick & $\begin{array}{l}55 \text { gal drum; } \\
\text { CGR box compactor }\end{array}$ & $\begin{array}{l}5 \text { or } 6 \text { bags/drum; } \\
130 \text { bags/box (plus } \\
10 \text { pieces of wood) }\end{array}$ & $\begin{array}{l}\text { LSA box measures } 45^{\prime \prime} \\
\times 45^{\prime \prime} \times 85^{\prime \prime} ; \text { Box } \\
\text { compactor compressive } \\
\text { force is } 48,0001 \mathrm{bs}\end{array}$ \\
\hline Bruce & $55 \mathrm{gal}$ drum & 4 (maximum) & $\begin{array}{l}\text { Stock Equip. Co. } \\
\text { compactor; Replacing } \\
\text { compactor with baler }\end{array}$ \\
\hline
\end{tabular}


ranges from preliminary proof-of-principle demonstration to full-scale production units. In this section, four such systems are discussed briefly. All four involve both volume reduction and solidification techniques that have never been tried commercially in the U.S. The NRC may, therefore, choose to categorize any one or all of these systems under the heading of "unanswered safety questions". In this event, a topical report would have to be submitted to the NRC for review and approval before the system could be installed in a new plant or retrofitted to an existing one. To date, no such topical reports have been submitted.

- Ribbon Blender

The ribbon blender shown in Figure 5.16 is a steam-jacketed, horizontal, cylindrical vessel with a close fitting, helical, mixing blade rotating about the central, longitudinal axis. The unit, developed by Teledyne Readco, produces a dry product from all PWR and BWR liquid or slurry wastes. The waste solutions are processed on a batch basis. First, the unit is filled with a predetermined volume of feed stock from which water slowly evaporates as the mixer blade agitates the concentrate. Agitation keeps the product in a loose, free-flowing form as it approaches dryness. At the completion of a batch run, the product is removed from the blender by the action of the helical mixing blades and stored in a product hopper. When sufficient dry product is collected for solidification, it is transported from the storage hopper via a screw conveyor to the feed connection of a heavy-duty, twin screw extruder where it is mixed with the selected solidification agent. The extruder has been used to solidify each of the dried waste streams mentioned above in either cement, urea formaldehyde, bitumen, or polyethylene.

The ribbon blender offers the maximum volume reduction factor available for liquid and slurry wastes except for systems that break wastes down into more elemental compounds (such as incineration of the resins). Test work must still determine whether the feed/distillate decontamination factors for this process are acceptable. Further testing will determine if the relatively thick scale layer that normally forms on the blender 


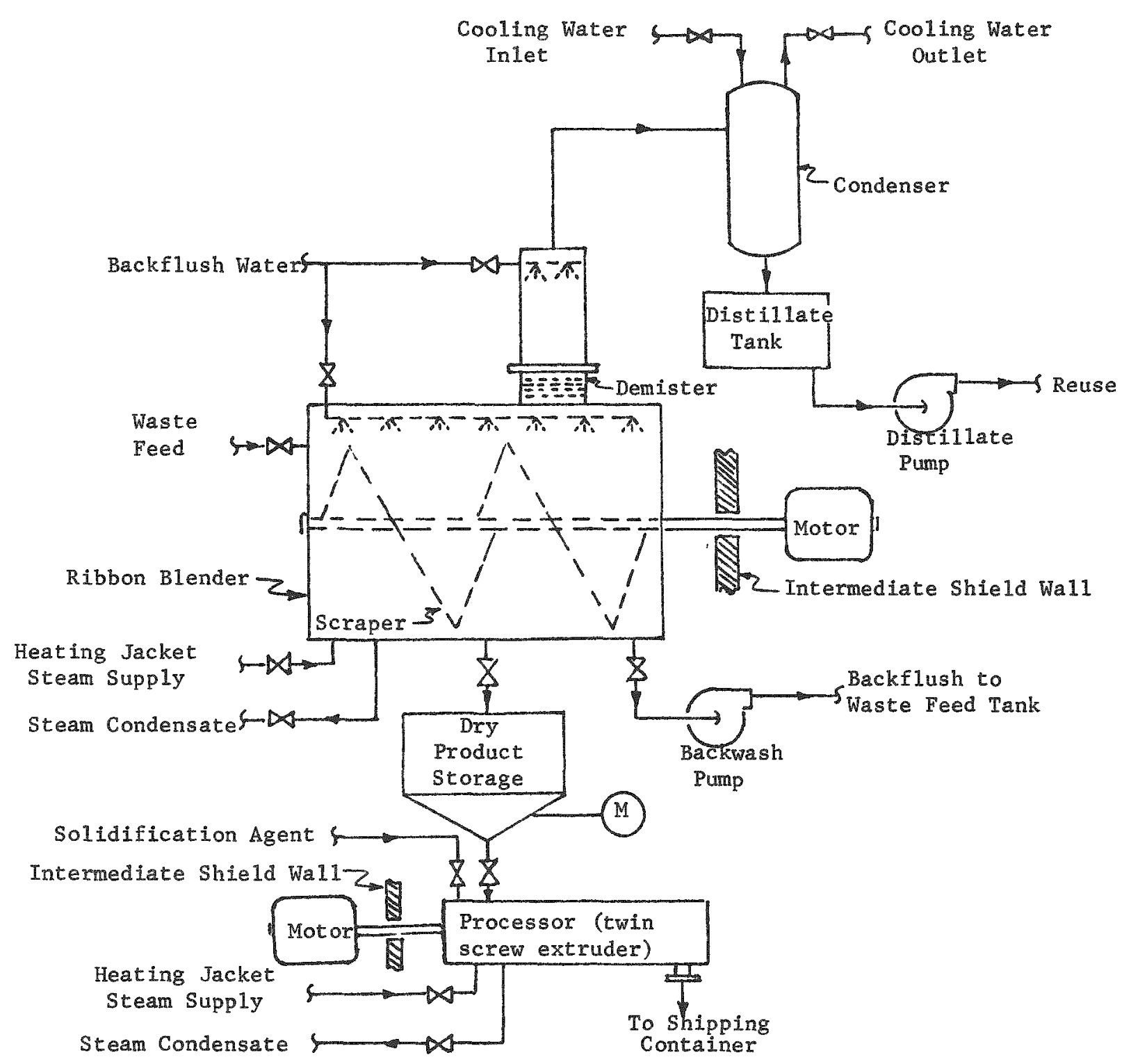

FIGURE 5.16

FLOW DIAGRAM OF RIBBON BLENDER

VOLUME REDUCTION SYSTEM 
walls during operation can be effectively removed prior to maintenance or inspection. If left in the unit, this amount of waste would produce significant radiation levels around the blender.

The ICRP, under development by GE and United Technologies, is an extension of well-developed technology initially used to separate dangerous chemicals such as rocket propellants in a safe environment. The system as shown in Figure 5.17 consists of a simple pot evaporator, an external shell and tube heater, and a large capacity pump which continuously recirculates an inert heat transfer fluid between the heater and pot boiler. The heat transfer fluid in the loop is silicone oil maintained at approximately $300^{\circ} \mathrm{F}$. As the oil is recirculated, a small stream of liquid or slurry waste is continuously pumped into the circuit. A waste flow rate of $120 \mathrm{gph}$ is proposed for a full scale production model. When the waste solution comes in contact with the hot oil, water is driven off as steam, leaving behind a dry, solid product. After a preset concentration of waste product is achieved in the oil, a small stream is bled off to an inline mixer, where an epoxy resin solidification agent is added. The epoxy preferentially mixes with and coats the dry waste product. The epoxy/solids mixture is separated from the silicone oil in a simple gravity type separator, the oil being lighter than the epoxy or waste material. The oil is returned to the main system while the epoxy/solids mixture is pumped out the bottom to an inline static mixer where an epoxy hardener is added. The final product flows at a rate of $20 \mathrm{gph}$ into an open-topped drum where it cools and solidifies.

The ICRP is said to be able to handle all types of liquid and slurry wastes generated at commercial nuclear power plants. It is claimed that the maximum possible volume reduction factor (without going to a system that breaks the waste down into elemental compounds) can be achieved by this method. Although it is being marketed as a combined volume reduction/solidification system, the ICRP can also be used simply to take 


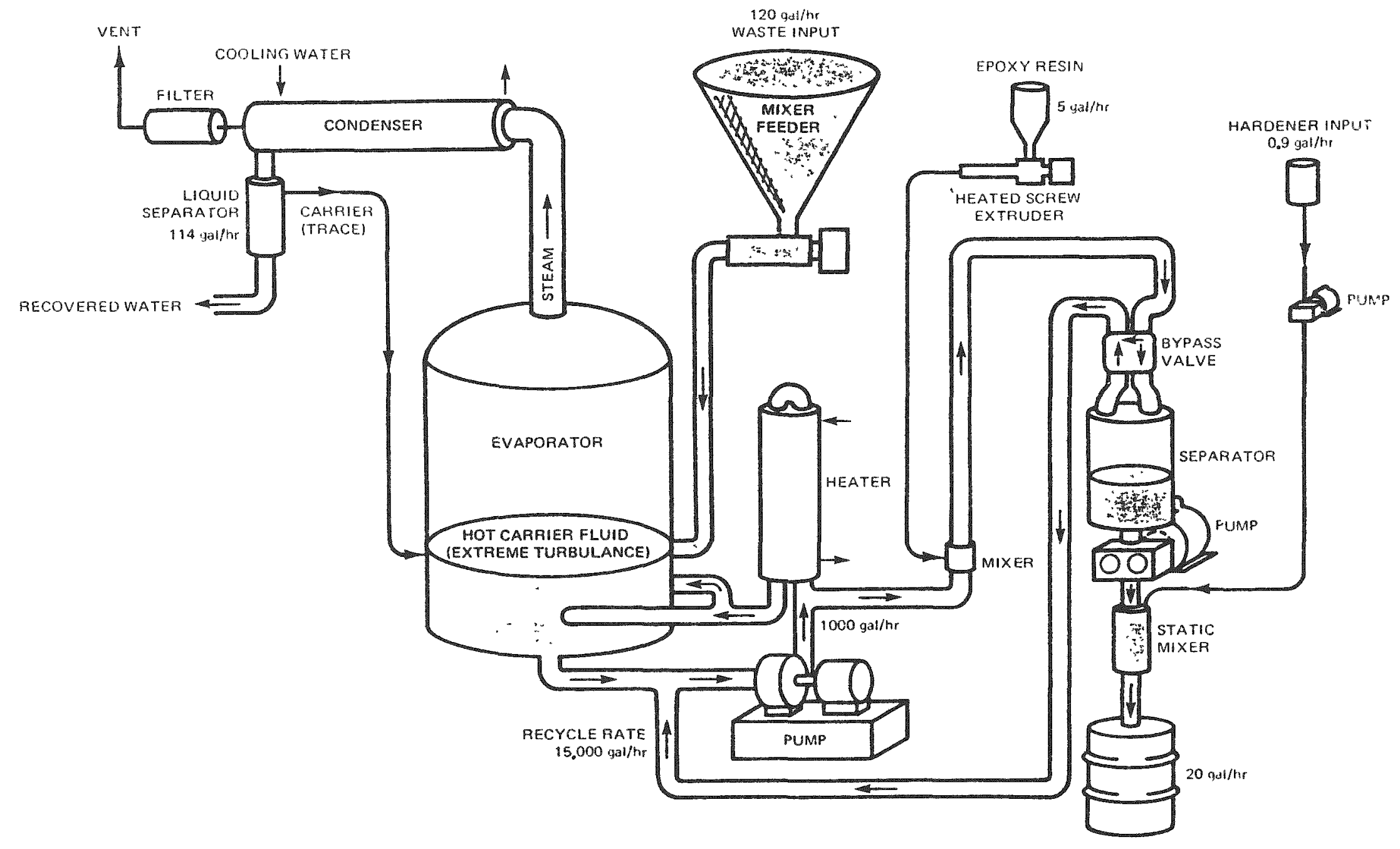


the waste feed to dryness without solidification. Feed/distillate DF values have not yet been determined for radionuclides, but all tests with nonradioactive wastes have resulted to date in distillate of high quality. Concern about possible scaling or epoxy adhereing to the walls of the vessels and piping has led to the use of Teflon linings on most internal surfaces. The durability of this lining in a thermally hot, radioactive environment over long periods of time has not yet been fully demonstrated.

Penberthy Electromelt Company has developed a process for incineration and solidification of combustible material using an electric glass melter or "electromelter". The electromelter, which has been used for over thirty years in the glass industry, is a refractory lined, electric furnace in which a fixed volume of molten glass is maintained at $2,300^{\circ} \mathrm{F}$. Waste is fed into the unit and completely burned as a result of the high temperatures. The ash product mixes with the molten glass. Periodically, when the molten glass/waste mixture reaches a certain level, a small portion is drawn of through a gravity drain line and into a drum where it cools and solidifies. The solidified product is reported to be a very stable, low cost solid with excellent leach resistance properties.

At Penberthy's manufacturing facility in Seattle, Washington, a small electromelter has been used to demonstrate the feasibility of waste incineration/solidification by this method. This test unit is described in greater detail in the Appendix. Currently, a full-scale, prototype of the unit proposed for commercial operation is under construction. This unit, which is sized to process $2,000 \mathrm{lb} / \mathrm{hr}$ of paper waste, or $10 \mathrm{wt}$ percent boric acid solution, is shown in Figure 5.18. According to Penberthy, the unit will also be capable of handling such things as oil, glassware, rubber, plastics, wood, ion-exchange resins, all organic materials, dirt, sand, concrete, nonmetallic filter elements, and filter precoat materials. Sulfate solutions can also be handled, but only in 


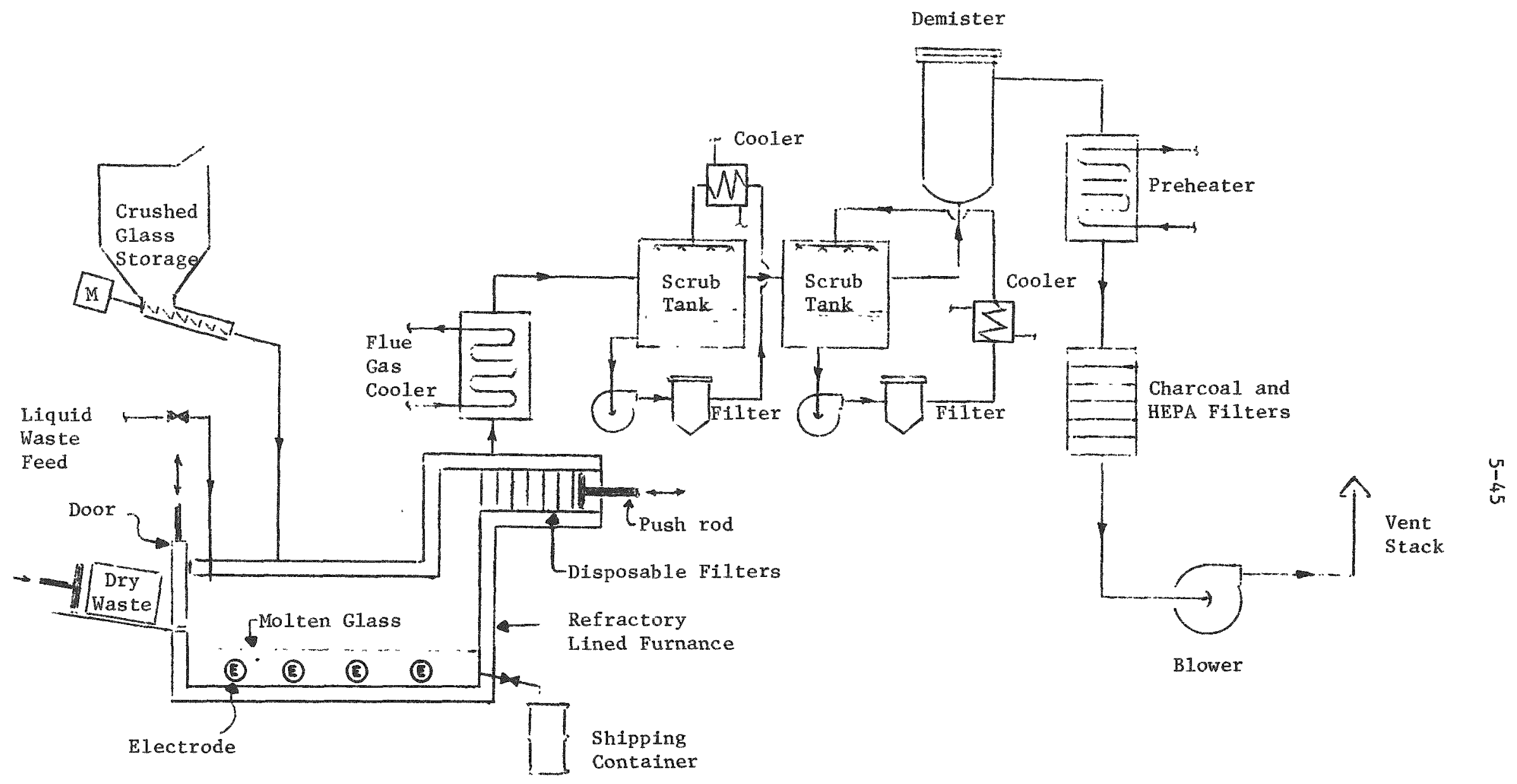

FIGURE 5.18

FLOW DIAGRAM OF MOLTEN GLASS INCINERATOR 
small amounts. Liquid or dry waste is fed into one end of the electromelter and ignited by the high temperature of the molten glass. The temperature of the air space above the molten glass is kept at approximately $2,000^{\circ} \mathrm{F}$ to insure complete combustion of the off-gases . Gases leaving the electromelter are passed through a filter for removal of particulate. They are then routed to a two-stage water spray chamber for removal of sodium and nitric oxides, HCl, etc. From these, the gases are passed through a demister section and reheater before being sent through charcoal and HEPA filters and discharged.

Completion of the prototype incinerator is scheduled for late 1979. Once this unit is in operation, tests can be performed to determine such things as:

- Feed/distillate DF values

- Efficiency of off-gas cleanup system for removal of particulate, iodine, etc.

- Limitations on types and quantities of various feed materials, and

- Required variations in glass composition to yield a satisfactory end product for the different types of waste feed.

The drum mixer process, developed by the Japan Gasoline Company (JGC), evaporates resin slurries or salt solutions to dry products while simultaneously mixing this product with bitumen. The process, as it is now being marketed in the U.S. by Nuclear Power Services, Inc., has been operated successfully with radioactive sludges and evaporator bottoms at the Japan Atomic Energy Research Institute (JAERI) since 1973. A flow diagram of the system is shown in Figure 5.19. The drum mixer, as shown in Figure 5.20, is very similar in construction and operating principle to the ribbon blender discussed previously. The major difference is 


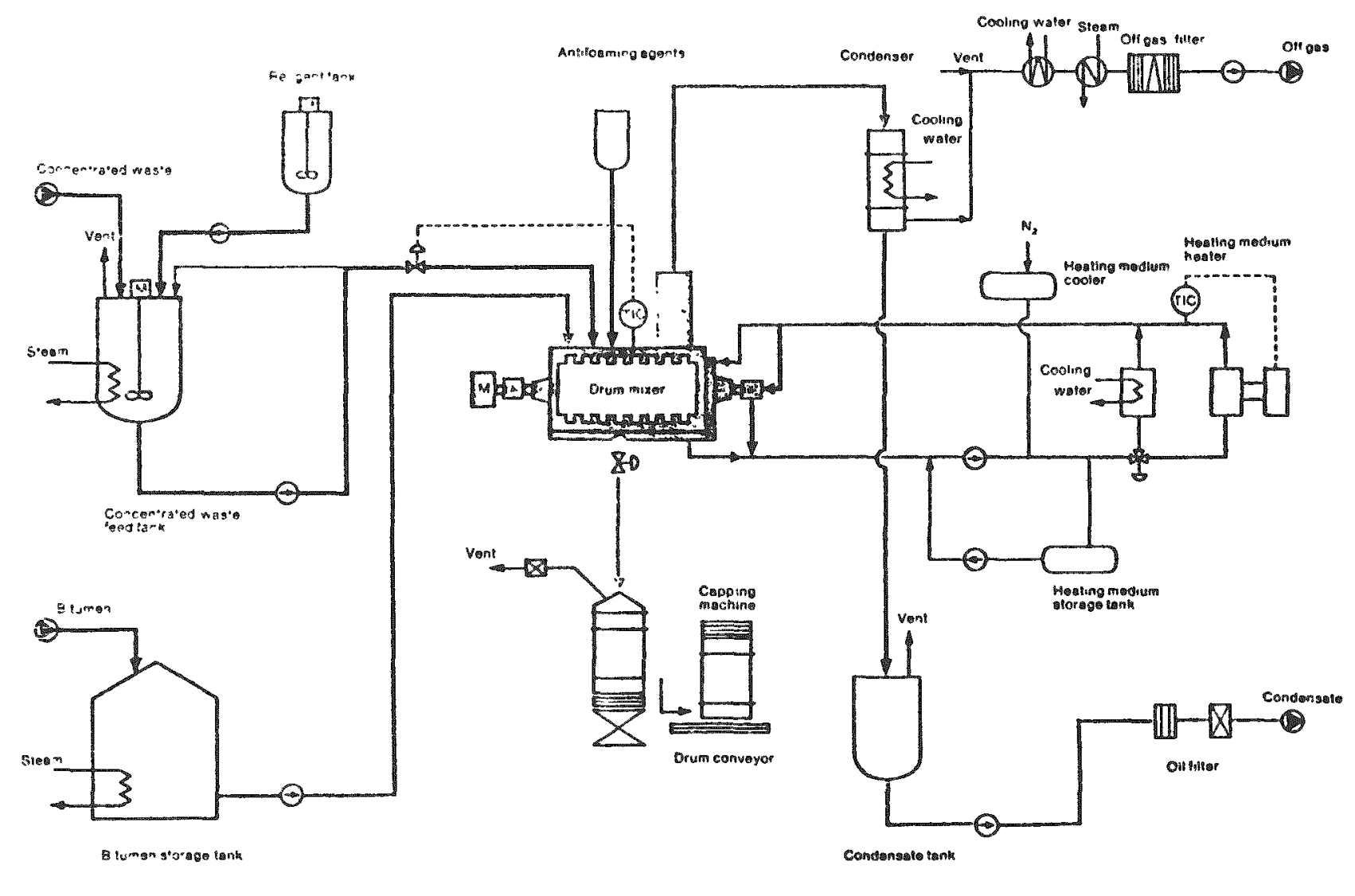

FIGURE 5.19

FLOW DIAGRAM OF DRUM MIXER PROCESS 

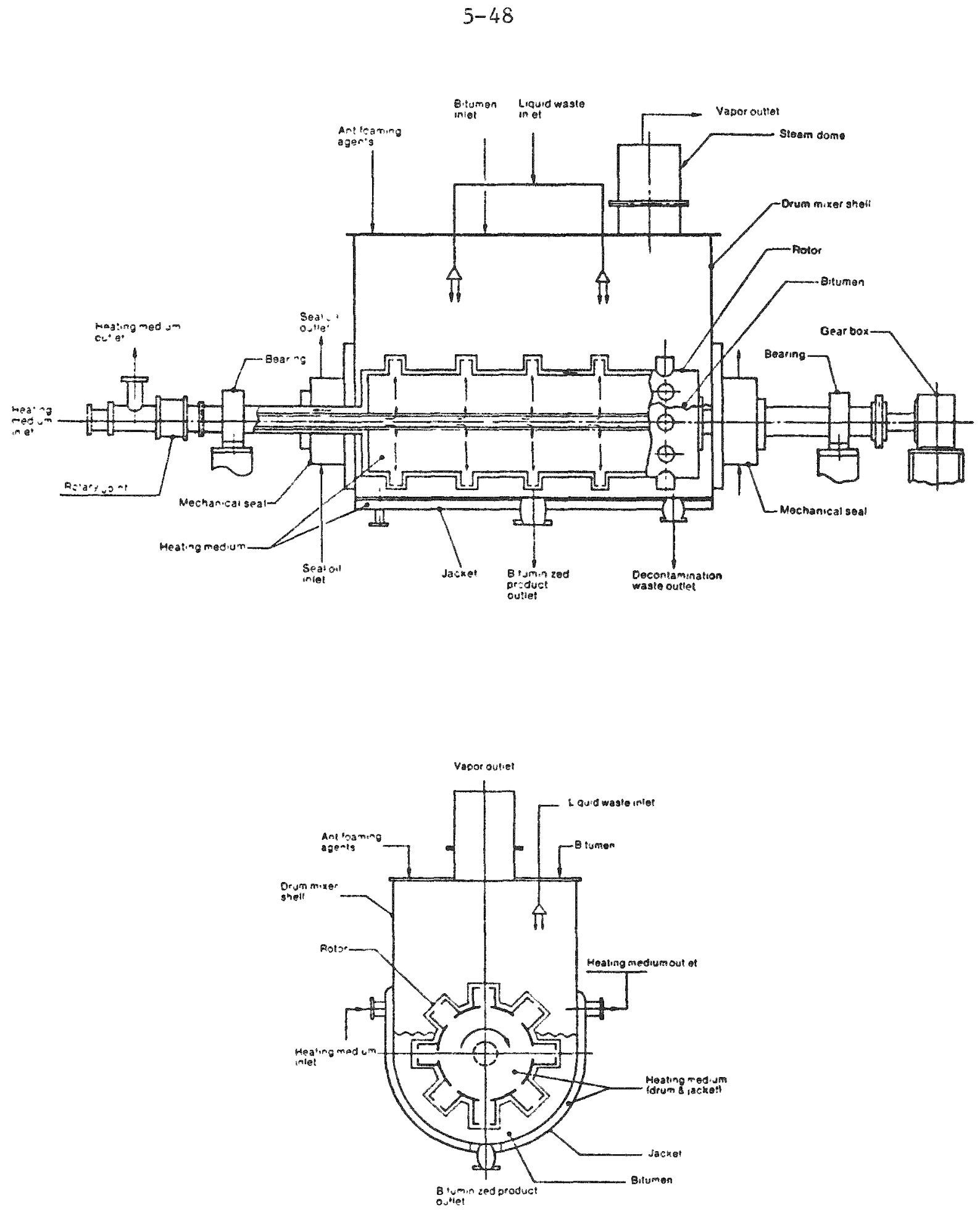

FIGURE 5.20

SECTIONAL VIEWS OF DRUM MIXER 
that, the drum mixer simultaneosly dries and solidifies (in bitumen) the waste material in a single vessel, whereas the ribbon blender only dries the waste. The final product is a mixture of bitumen and dried radsalt, resin bead, or filter sludge that is free of water. Ratios of waste to bitumen are the same as reported earlier for the other bituminization systems. The feed/distillate DFs have normally been greater than $10^{3}$, but oil concentrations in the distillate have been as high as 1,000 ppm, thus requiring an oil filter in the distillate return line. The prototype unit at JAERI has operated without any major mechanical problems since its installation in 1973.

\section{$5.3 \quad$ REFERENCES}

1. K. H. Lin, "Use of Ion Exchange for the Treatment of Liquids in Nuclear Power Plants," ORNL-4792, December 1973.

2. A. H. Kibbey and H. W. Godbee, "The Use of Filtration to Treat Radioactive Liquids in Light-Water-Cooled Nuclear Reactor Power Plants," ORNL/NUREG-41, September 1978.

3. H. W. Godbee, "Use of Evaporation for the Treatment of Liquids in the Nuclear Industry," ORNL 4790, September 1973.

4. J. Markind and T. V. Tran, "A Study of Reverse Osmosis Applicability to Light Water Reactor Radwaste Processing", NUREG/CR-0724, April 1979.

5. J. H. Perry, "Chemical Engineer's Handbook," 4th edition, 1963.

6. D. Anthony and K. Kallfisch, "Evaporator/Crystallizers for Radwaste Service," presented at Symposium on Management of Low Level Radioactive Waste, Georgia Institute of Technology, Atlanta, Georgia, May 1977.

7. P. Cheng, "Operating Experience with Radwaste Evaporators," presented at the ASME Joint Power Generation Conference, September 1977. 
8. P. Cheng, "Crystallization for Radwaste Service," presented at Reactor Radwaste Management Workshop, New Orleans, La., January 1977.

9. H. L. Freese and W. T. Gregory III, "Volume Reduction of Liquid Radioactive Wastes Using Mechanically Agitated Thin-Film Evaporators," presented at the 85 th National Meeting of America Institute of Chemical Engineers, Phila., Pa., June 1978.

10. R. L. Rupinskas and P. M. Vogt, "Thin-Film Evaporators for Processing BWR Liquid Radwaste," presented at the ASME Winter Annual Meeting, New York, N.Y., December $1976(76-$ WA/NE-4).

11. J. E. Stewart and R. Herter, "Solid Radwaste Experience in Europe Using Aspha1t," presented at the ASME-IEEE Joint Power Generation Conference, Portland, Oregon, September 1975 (75-Pwr-21). 
TRIP REPORT NO. 1

ORNL RADWASTE VOLUME REDUCTION STUDY

ARTISAN INDUSTRIES, WALTHAM, MASS./MR. CRAIG ANGELL AUGUST 24, 1979

Artisan Industries (AI) was visited to see the thin film evaporator in their shop for testing prior to shipment to Washington Public Power Supply System (WPPSS). Operating data will not be available for some time, since the unit is not scheduled to be installed at WPPSS for another five to six years. Testing of the unit with nonradioactive, simulated process fluids was completed prior to the visit. Results of these tests are summarized on the attached questionnaire (Exhibit 1). The objective of the shop tests was to demonstrate the unit's ability to produce a bottoms concentration of 50 weight percent for several different waste feed streams with solids concentrations varying from 1 to 30 weight percent. The unit was able to meet this criterion for all waste feed streams. No requirements were placed on the distillate quality during these tests, and no analysis was performed on the distillate. From readings taken with an in-line conductivity monitor used to automatically recycle high conductivity distillate, it was estimated that all distillate was in the range of 10 to $20 \mu m h / \mathrm{cm}^{2}$. The manner in which the bottoms discharge was piped up did not permit a direct measurement of bottoms concentration. The bottoms concentrations were calculated from a materials balance between feed and distillate.

Detailed design information on the WPPSS unit was provided in the form of a process and instrumentation diagram ( $P \& I D)$, process flow diagram, equipment assembly drawings, and plant layout drawings.

Basic design features of the unit are:

- Heat surface area $-100 \mathrm{ft}^{2}$

- Process flow rate -1 to $5 \mathrm{gpm}$

- Maximum desired solids concentration in bottoms - 50 weight percent 
Materials of construction:

- Portions in contact with process liquid and/or vapors - Incoloy 825

- Steam jacket and distillate condenser - Stainless steel

- Drive motor - $75 \mathrm{hp}$

- Steam conditions: $3,200 \mathrm{lb} / \mathrm{hr}, 125 \mathrm{psig}, 350^{\circ} \mathrm{F}$

- Cooling Water - $268 \mathrm{gpm}$

- Blade:

- configuration - straight, fixed

- clearance - 1/16 inch (cold)

- Space envelope (including intermediate building and rotor pull space) - $40 \mathrm{ft} \mathrm{L} \times 22 \mathrm{ft}$ W $20 \mathrm{ft} \mathrm{H}$

- Shaft seals - double mechanical (both ends)

- Flanged end seals - Metal "O" Rings

The WPPSS unit is operated automatically by a microprocessor unit into which information on feedstock composition is fed. AI reported that the horizontal unit has good turn-down capability (down to 20 percent of rated process flow rate).

Since AI has no units operating in commercial nuclear power plants, no information could be given on operating or maintenance experience in this sector. AI reported the following on operation of their units at government facilities.

- Idaho Falls - operating since 1952; vertical $70 \mathrm{ft}^{2}$ unit; no reported difficulties; only known maintenance is replacement of 0 -rings on head flange every three years (no information on seal replacement frequency).

- Puget Sound Naval Base - operating since 1969;20 $\mathrm{ft}^{2}$ unit; no known replacement of shaft or flange seals to date; demister pads replaced once after unit was unintentionally flooded. Contact Robert Benze at Puget Sound for more information on the operation of this unit.

Results of several tests using the AI pilot plant TFE are presented in Exhibits 2 and 3. 


\section{A-3}

Actual operating cost data was not available from AI. Estimated operating cost information, based on 1977 dollars, is attached (Exhibit 4).

Copies of the following reports on thin-film evaporator operation were provided by AI during the plant visit:

- "Wiped-Film Evaporators for Evaporating Alkaline Light Water Reactor Radioactive Wastes," C. B. Goodlet, Savannah River Laboratory, E. I. dePont de Nemours and Co., Aiken, South Carolina. Nuclear Technology Vol. 43 Mid-April 1979.

- "Thin-Film Evaporators for Processing BWR Liquid Radwaste," R. L. Rupinskas, presented at ASME Winter Annual Meeting, New York, N.Y., December 5, 1976, ASME-76-WA/NE-4.

- "Evolution of Radwaste Evaporators in West Germany," H. Mende, H. L. Freeze, presented at ASME-IEEE Joint Power Generation Conference, Long Beach, Calif., Sept. 8, 1977, ASME-77-JPGC-NE-13. 
Artisan Thin Film Evaporator

Radwaste Volume Reduction System Questionnaire

1. Brief description of system (please attach layout dwgs. \& P\&ID, if avallable).

The VRS is consisted of an Artisan $100 \mathrm{sq}$. ft. rototherm-evaporator,

overhead condenser, collecting hopper to accumulate rad waste, and complete

instrumentation and accessories. The system will be operated via a micro-

computer custom designed by Artisan to perform necessary computations and

operate system under ideal conditions.

2. Feedstock Description:

a) Feedstock Designation

$A$

b) Type of Waste

c) Volume per yr. (gal.)

d) Total solids conc. (ppm)

e) Suspended solids (ppm)

f) Conductivity (umho/ cm)

g) $\mathrm{pH}$ :

i) Before adjustment

ii) After adjustment

h) Specific gravity

i) Termerature $\left({ }^{\circ}\right)$

j) SIurry wastes:

i) Solids conc. (vol. i)

ii) Interstitial Water (vol. \%)

iii) Free water above settled sludge (vol.\%)
Decontamin. Inorg. Chem. Floor Drain Detergent

$8000 \mathrm{hr}$

$480,000 \quad 480,000 \quad 480,000$

68,000

$290,000 \quad 225,000 \quad 100,000$

$100-1,000-4000$

$-1-\frac{1,000}{-}-$

$\frac{5-13}{1-1.2}-\frac{3.5-13.0}{1-1.2} \frac{9-11.5}{-60-180}-\frac{1-1.2}{60-180}-\frac{1-1.2}{60-180}-\frac{60-180}{-180}$

$50 \%$

$50 \%$

$50 \% \quad 50 \%$

$50 \%-50 \%$

Exhibit 1 
k) Radionuclide content by major isotopes $(\mathrm{\mu Ci} / \mathrm{mL})$ :

$-\frac{1-131}{\operatorname{Cs}-137}$

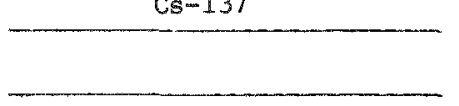
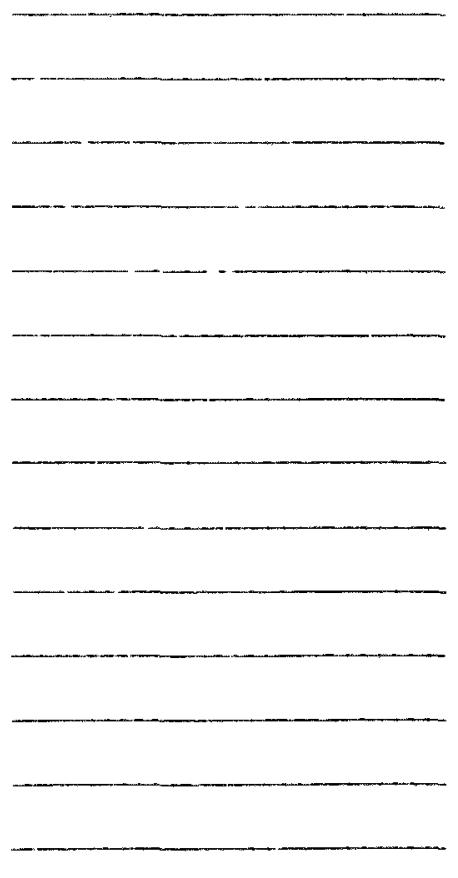

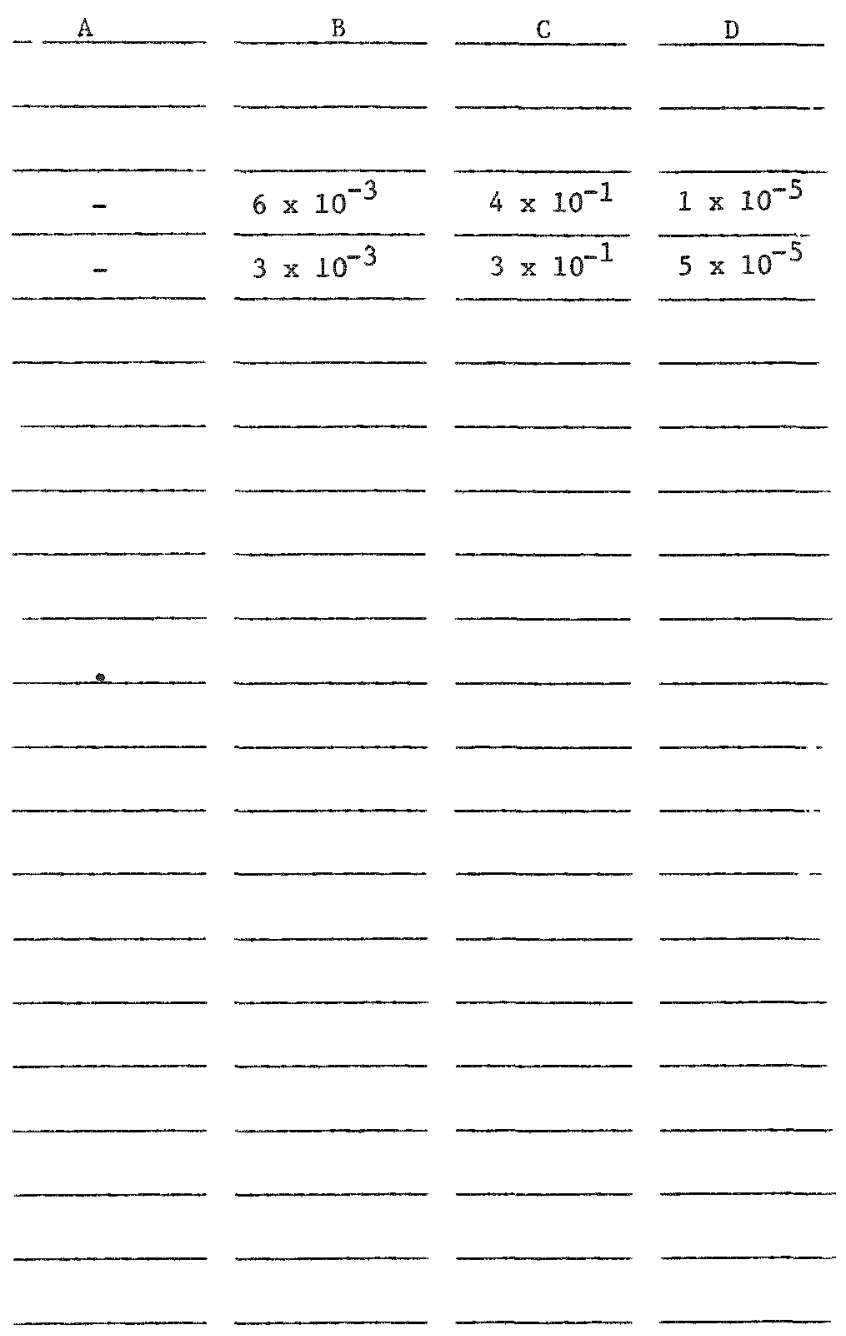

$-2-$

3. Auxiliaries (give pressure, temperature, flow rates, etc.):
a) Stean -
b) Cooling water -
c) Service air -
d) Electric -
e) Other $3,200 \mathrm{pph}$ $268 \mathrm{gpm}$ $20-90$ psig

\begin{tabular}{|c|c|}
\hline $268 \mathrm{gpm}$ & \\
\hline $20-90$ psig & \\
\hline $3 \mathrm{ph}, 460$ volts & $75 \mathrm{hp}+1 \mathrm{hp}$ \\
\hline
\end{tabular}

Exhibit 1 (Cont'd.) 


$$
A-6
$$

4. Operating Data:

a) Feed rate (gpm)

b) Bottoms conc. (wt. \%)

c) Volume reduction factor

(vol. feed/vol. bottoms)

d) Decontamination Factors (feed to distillate):

i) overall

ii) major isotopes:

e) Curie content of bottoms $(\mu \mathrm{Ci} / \mathrm{cc})$

f) Radiation level in bottoms (mr/hr):

1) Surface of container -

ii) One foot from container -
1.0 to 5.0 (5.0 design)

$50 \%$

$5 / 1(\max$. 
5. Operating History:
a) Date unit installation completed -
b) Date unit first operated (with radioactive waste) -
d) Total number of operating hours -

6. Cost Factors:
a) Initial equipment cost -
b) Installation cost
c) Building costs
d) Operating costs ( $\$ / g a 1$. of waste feed)

$\$ 1.2 \times 10^{6}(1975)(2$ units)
i) Personnel
ii) Auxiliaries
iii) Solidification Agent (if integral part of VR system)
iv) Tota 1 
A-8

7. Describe any major operating difficulties experienced with the VR system and what measures were taken to correct them.

No difficulties were encountered in operating the system. On test at Artisan. 
$A-9$

$-6-$

8. List all forced outages, including cause of outage (general maintenance, pump failure, etc.) and duration.

Exhibit 1 (Cont'd.) 


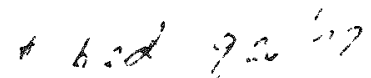

Teat Run $7 / 7 / 79$

\section{BITUMINIZATION OF SODIUM SULFATE}

PROCEDURE: 20 wt $\% \mathrm{Na} \mathrm{SO}_{4}$ was preheated to $220^{\circ} \mathrm{F}$ and fed to an Artisan Rotothem where it as evaporated to drynes. Then $320^{\circ}$ F tar a introduced to the Rototherm thereby encapalating the $\mathrm{NagS} 4$. Variour salt to tar ration were terted wh auccersul encapsulation in all cases. See table below.

MATERIAL: : 1) $\mathrm{Na}_{2} \mathrm{Sn}_{4}$

2) $\operatorname{Tax}$ - AsTM D312-71 type 4 ก.P. $=190+^{\circ}$

\section{RESULTE:}

RUN \#

SOLN. FEED TEMP

TAR FEED TEMP

BOTIOMS TEMP.

PPH SALT

PPH TAR

PQH TOTAL

\% SALT

\section{3}

21.8

\begin{tabular}{l}
$-\quad 318$ \\
\hline
\end{tabular}

197

117

214

60

60

117120

$100 \% 50 \%$
7

220

321

220

60

54

114

$53 \%$
6

220

317

217

60

49

109

$55 \%$
8

4

219

317

208

117

3960

$119 \quad 177$

$66 \%$

$66 \%$

NOTE Ine Square Foot Rototherm war uad.

Feed rate $109.4 \mathrm{pph}$

\% Evaporation 62.3 


\title{
(1) ARTISAN

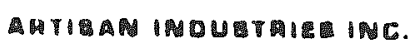

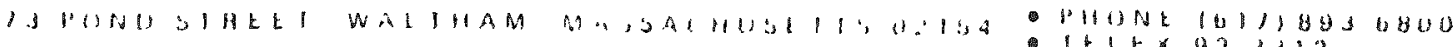
- ItLtazja12

ILit kun $3 / 11 / 7 /$
\end{abstract}

HITUMINIZATIUN UF SODIUM SULEATE

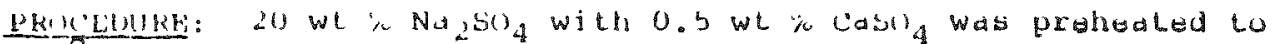
$220^{\circ} \mathrm{F}^{2}$ and fed $\mathrm{l} 3$ a kototherm where it was uvaporatod to dryass. Then $3250 \mathrm{~g}$ a was ted to the rototherm at a conatant rate while

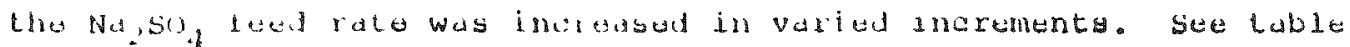
belis for results.

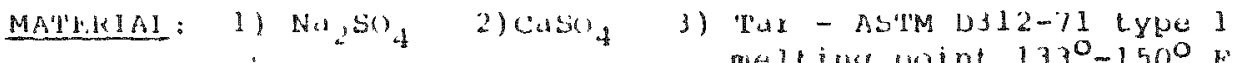

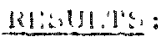

\begin{tabular}{|c|c|c|c|c|c|c|c|}
\hline Rum No. & $\therefore$ & $i$ & 4 & b & 6 & 7 & 8 \\
\hline MIUUIUN LEEI 'ILMML. & $\therefore \therefore$ & 221 & 231 & $2 \therefore 1$ & 220 & 219 & 219 \\
\hline HAK I'HWH 'LEMP'。 & - & 131 & $33:$ & 324 & 325 & $3: 4$ & $12 b$ \\
\hline 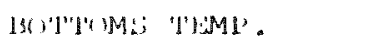 & 259 & $2 y 3$ & 376 & 201 & 234 & 239 & 231 \\
\hline SAl'I ISAK KATHO & $4 / 0$ & $4 / 0$ & $b / 8$ & $10 / 8$ & $10 / 8$ & $24 / b$ & $44 / 1$ \\
\hline sats IN IN In & - & $33 \%$ & $50 \%$ & $35 \%$ & $66 \%$ & $75 \%$ & $85 \%$ \\
\hline
\end{tabular}

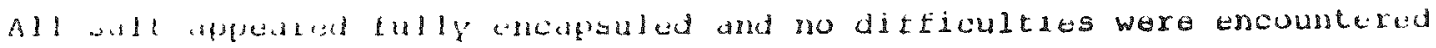
sur tm tun.

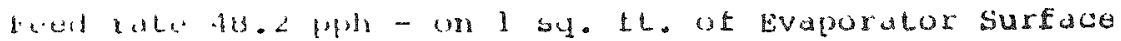

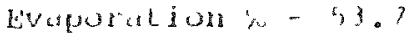




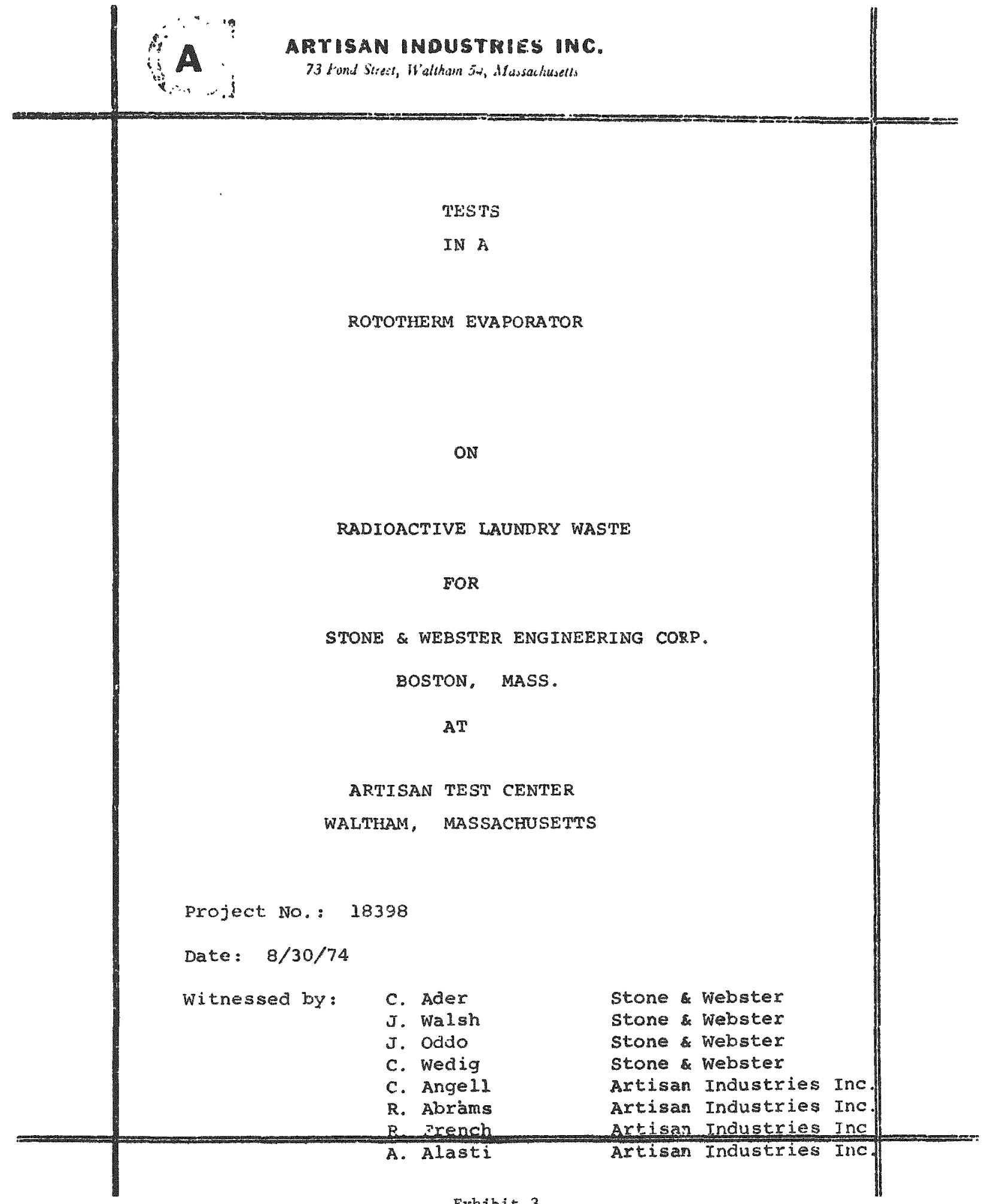

Exhibit 3 


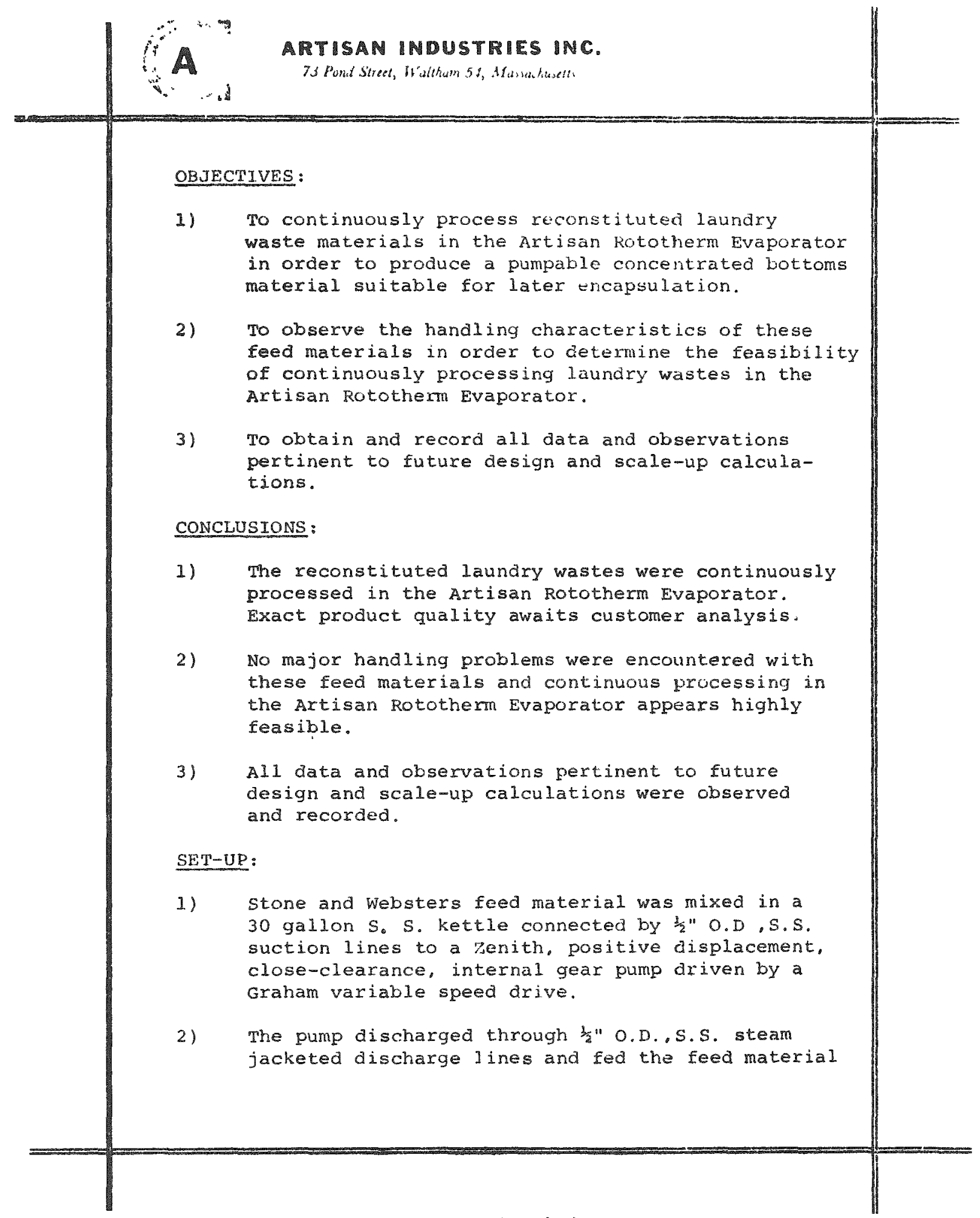

Exhibit 3 (Cont'd.) 


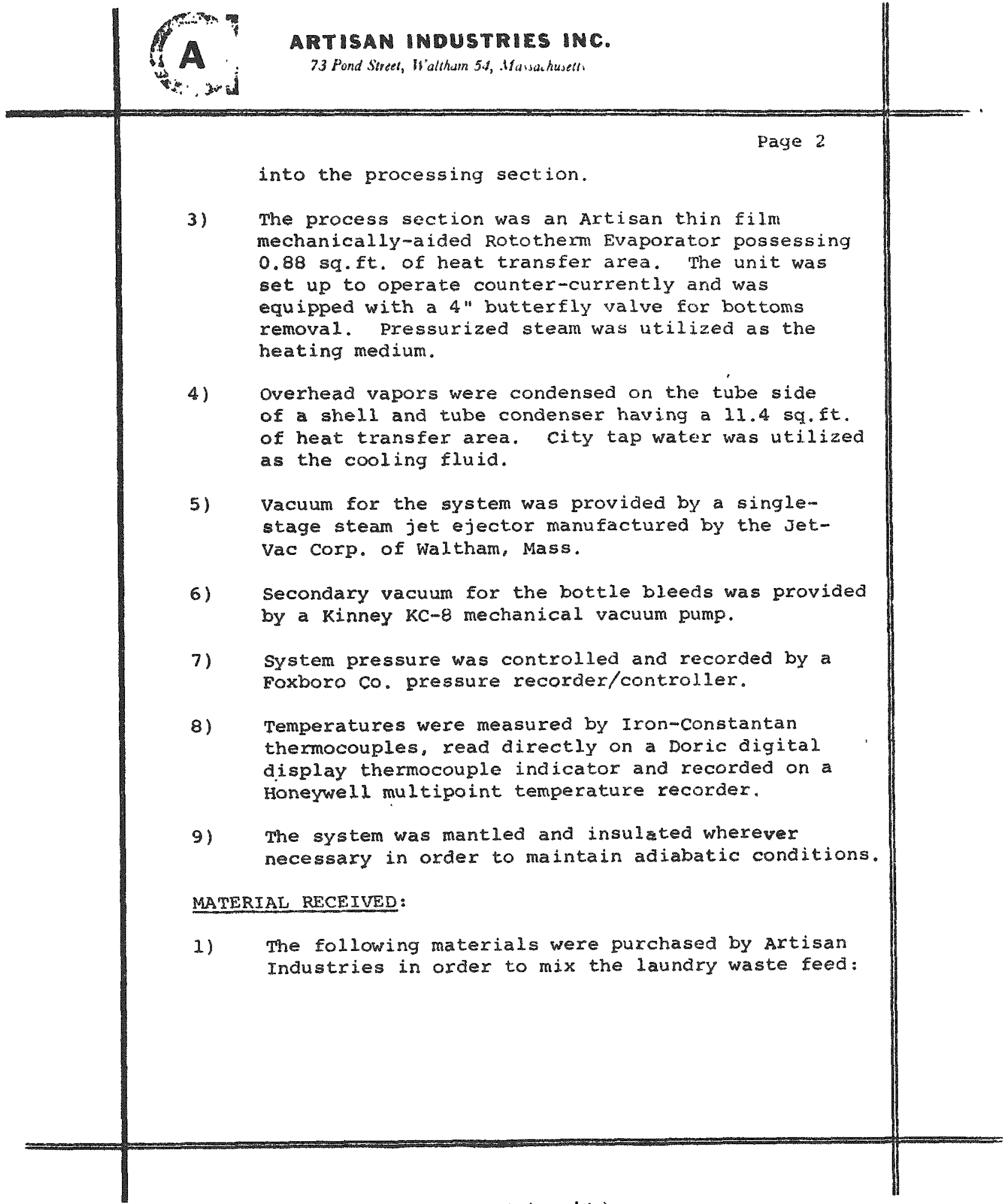

Exhibit 3 (Cont'd.) 


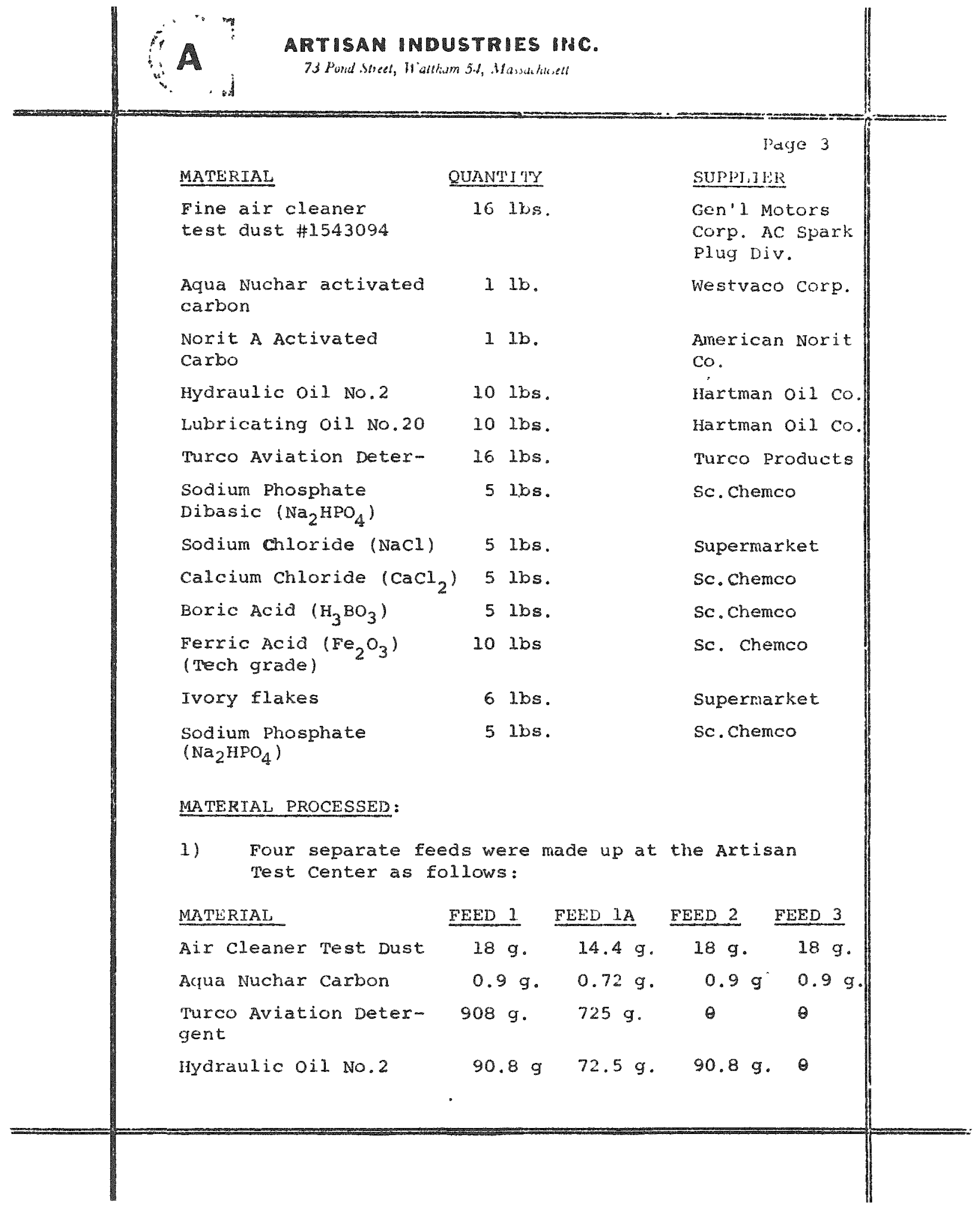

Exhibit 3 (Cont'd.) 


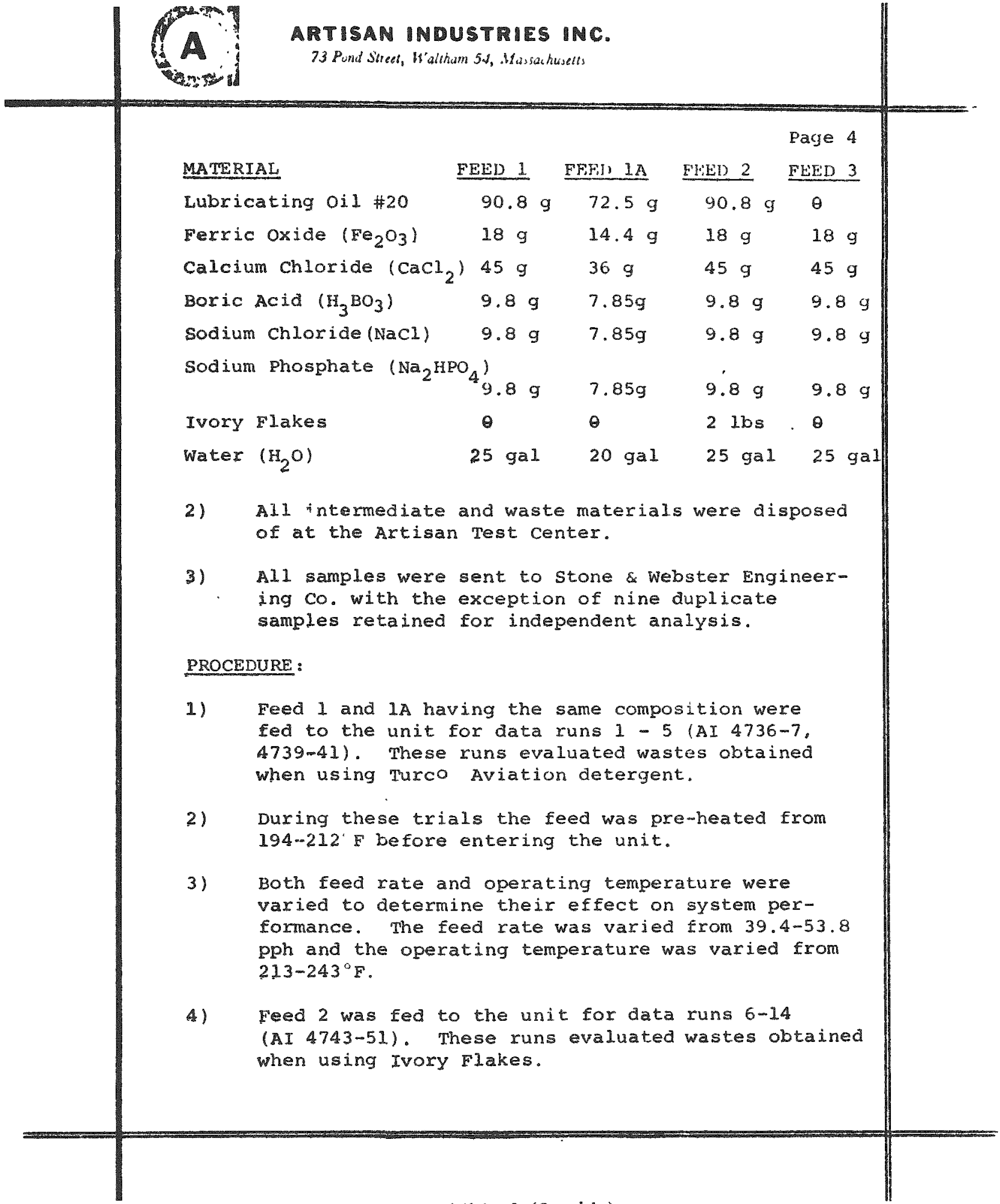

Exhibit 3 (Cont'd.) 
ARTISAN INDUSTRIES INC.

73 Pond Street, Wialthan 5.3, Massuchusels.

5) During these trials the feed was preheated from $209-213^{\circ} \mathrm{F}$.

6) Feed rate, operating temperature and system pressure were the parameters explored while using Feed 2. The feed rate was varied from $28.2-64.5 \mathrm{pph}$, the operating temperature from $212-294^{\prime \prime} \mathrm{F}$ and the system pressure was maintained at either atmospheric or $400 \mathrm{~mm} \mathrm{Hg}$.

7) With both feeds a pair of runs were taken with the only difference being reflux in order to evaluate the effect of this parameter on the performance of the unit.

8) When operating under vacuum, pressure between receiver bottles and the system were equalized before opening to the unit in order not to disturb steady state conditions.

9) Samples of both bottoms and distillate material were taken during each data run for customer analysis.

10) All data and samples were obtained at steady state conditions.

11) Duplicate samples of runs 4 \& (AI 4740,46) were obtained along with a duplicate feed I sample (AI 4735) and were sent to Lapuck Laboratory of Watertown, MA, for C.O.D. analysis of distillates and feed and $\mathrm{A} \%$ solids analysis of the bottoms.

12) Feed 3 was not run.

\section{OBSERVATIONS :}

1) Feed 1 had an appearance very similar to rusty water and foamed on agitation. Feed 2 had the same appearance but was thicker in viscosity being approximately $10 \mathrm{cp}$. This is believed due to the nature of the Ivory Flakes. 


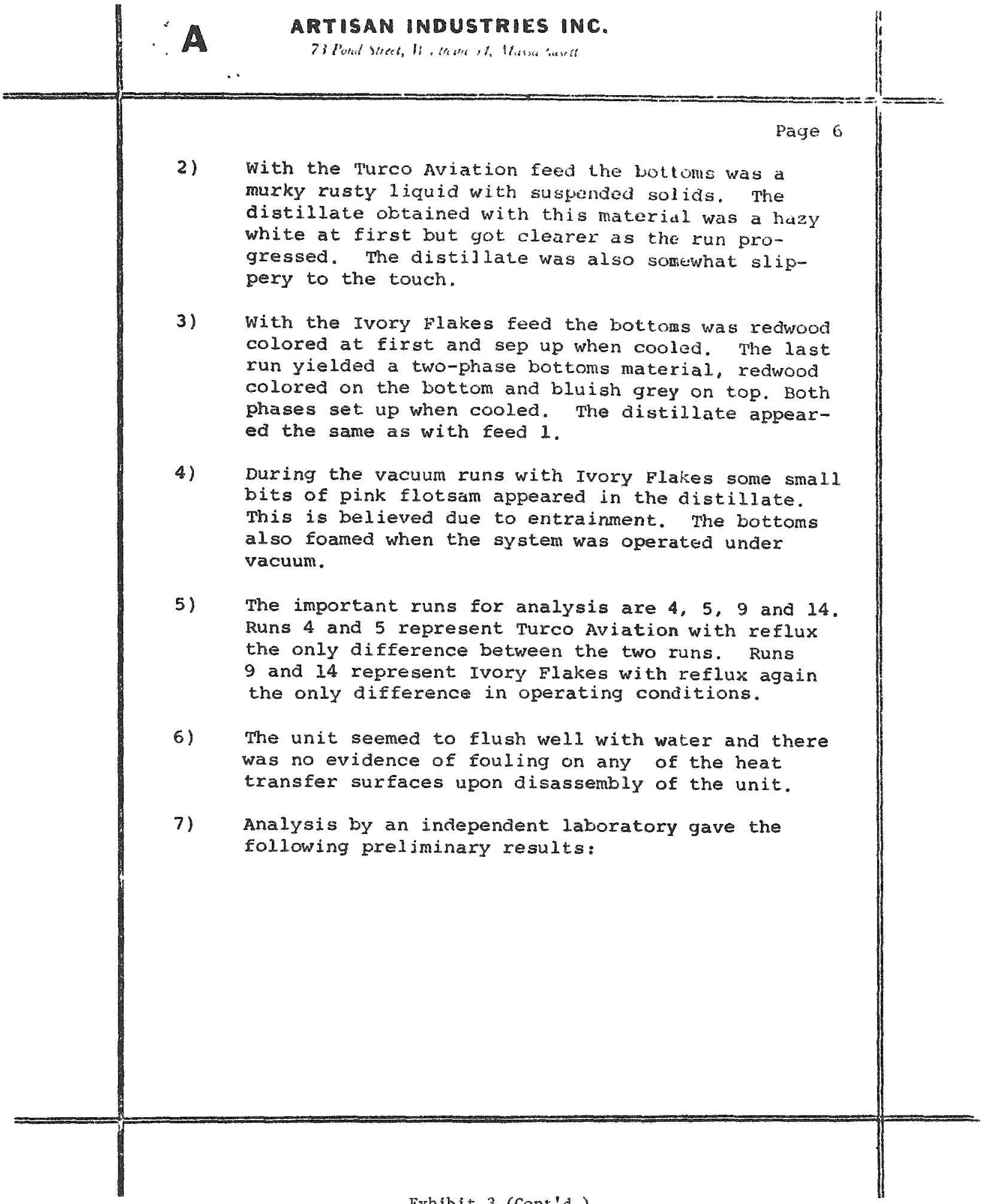




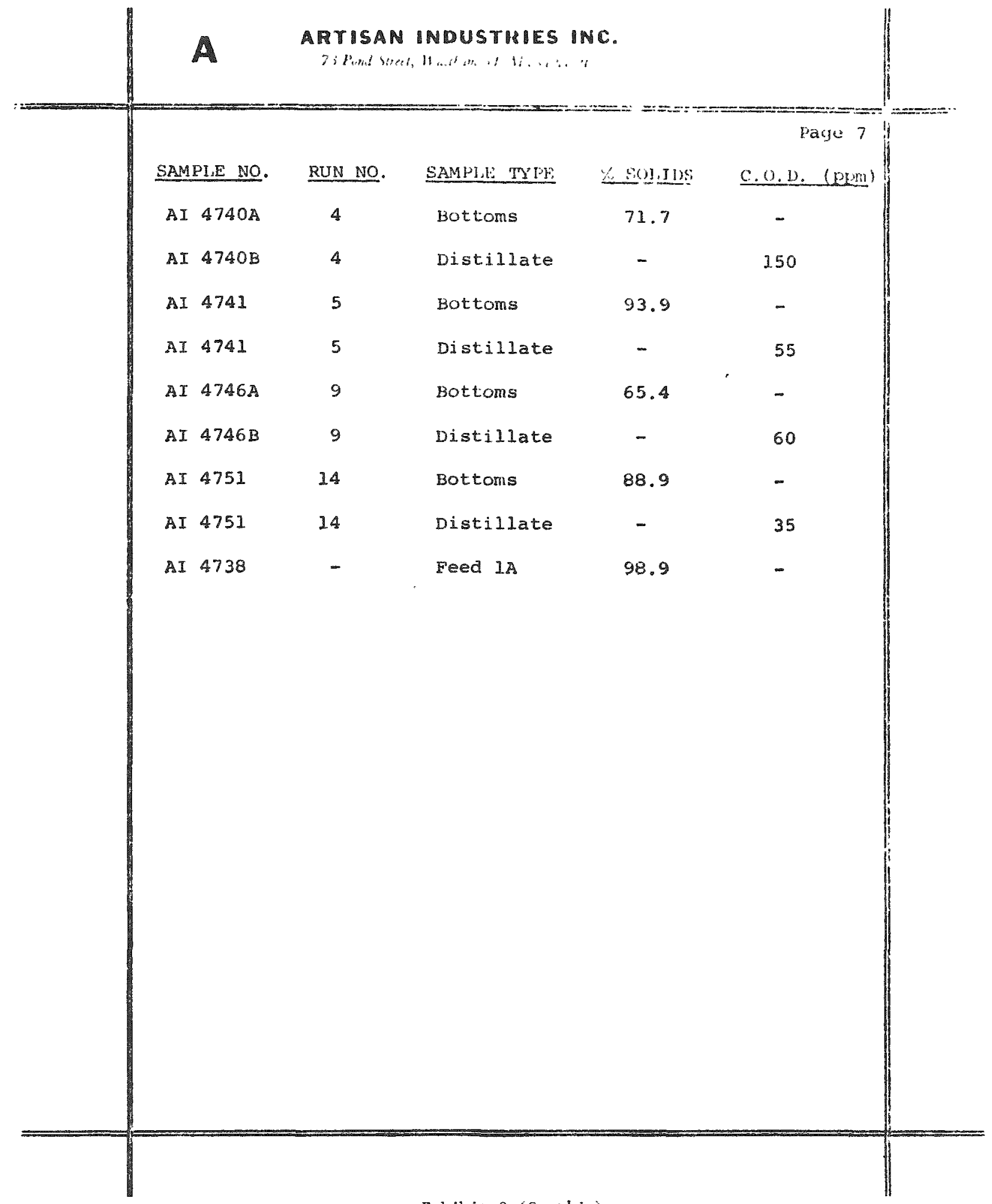

Exhibit 3 (Cont'd.) 
ARTISAN INDUSTRIES INC.

PILOT PLANT DATA SHEET

DATE: 8/30/74 PROJECT NO.: 18393

COMPATY: STONE \& WEBSTER ENGINEERING CO.

\section{MATRRIAL: Radioactive Laundry waste}

\begin{tabular}{|c|c|c|c|c|c|c|c|c|c|c|c|c|c|}
\hline${ }^{\circ} \mathrm{F}$ & 5 & $\mathrm{p}$ & $E \equiv \mathrm{A}$ & $\because \mathrm{U}$ & $\mathrm{R} E$ & & & $\mathrm{rmmHg}$ & $\mathrm{KN}$ & ppin & pph & & \\
\hline PED & $F=95$ & BI:. & VAPOR & Dxs?. & $\begin{array}{l}\text { Ero.stm } \\
\text { IN Jour }\end{array}$ & $\begin{array}{l}\mathrm{Cog}_{2} \mathrm{H}_{2} \\
\mathrm{IN} \mathrm{OOU}\end{array}$ & $\begin{array}{l}\text { FFFLUX } \\
\text { IN/OU? }\end{array}$ & $\begin{array}{l}\text { SYSE. } \\
\text { PRES. }\end{array}$ & $\begin{array}{l}\text { ROTOR } \\
\text { PONER }\end{array}$ & $\begin{array}{l}\text { REFLUX } \\
\text { RATE }\end{array}$ & $\begin{array}{l}\text { FEED } \\
\text { RATE }\end{array}$ & $\%$ FVAP. & 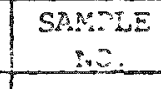 \\
\hline 194 & 203 & 213 & 212 & 70 & $346 / 347$ & $69 / 79$ & $=$ & ATM & 0.3 & $=$ & 48.5 & 95.0 & 4736 \\
\hline 193 & 202 & 225 & 211 & 70 & $348 / 349$ & $69 / 79$ & $=$ & ATM & 0.4 & - & 39.4 & 89.3 & $473^{-}$ \\
\hline 203 & 211 & 218 & 212 & 69 & $348 / 349$ & $69 / 78$ & $70 / 131$ & ATM & 0.4 & 190 & 53.8 & 79.3 & 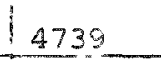 \\
\hline 203 & 211 & 243 & 212 & 69 & $350 / 351$ & $68 / 81$ & $=$ & ATM & 0.4 & - & 44.5 & 96.7 & 6740 \\
\hline 203 & 211 & 228 & 212 & 70 & $849 / 350$ & $68 / 77$ & $70 / 122$ & ATM & 0.4 & 180 & 44.9 & $\varepsilon 1.8$ & 1475 \\
\hline 209 & 214 & 256 & 212 & 70 & $348 / 349$ & $69 / 78$ & 二 & ATM & 0.4 & - & 142.0 & 95.0 & $\therefore 4 \hat{3} 3$ \\
\hline 212 & 218 & 277 & 212 & 70 & $347 / 348$ & $69 / 76$ & $70 / 129$ & ATM & 0.4 & 190 & 138.7 & 94.7 & $59-4=$ \\
\hline 212 & 219 & 244 & 212 & 70 & $344 / 345$ & $68 / 76$ & $70 / 134$ & AIM & 0.4 & 190 & 37.6 & 95.4 & $4-4 E$ \\
\hline 213 & 218 & 269 & 212 & 70 & $345 / 345$ & $68 / 80$ & - & $\mathrm{ATM}$ & 0.5 & - & 52.2 & 95.2 & 4780 \\
\hline 213 & 218 & 280 & 212 & .70 & $348 / 348$ & $68 / 75$ & $70 / 122$ & ATM & 0.5 & 166 & 28.2 & 95.3 & 4747 \\
\hline
\end{tabular}

Rotor speed 1140 RPM throughout trials. 
ARTISAN INDUSTRIES INC.

PILOT PLANT DATA SHEET

DRTE: $8 / 30 / 74$ - PROJECT NO.: 18393

COYPANY: STONE \& WEBSTER ENGINEERING CO.

MATERIAL: Radioactive Laundry waste

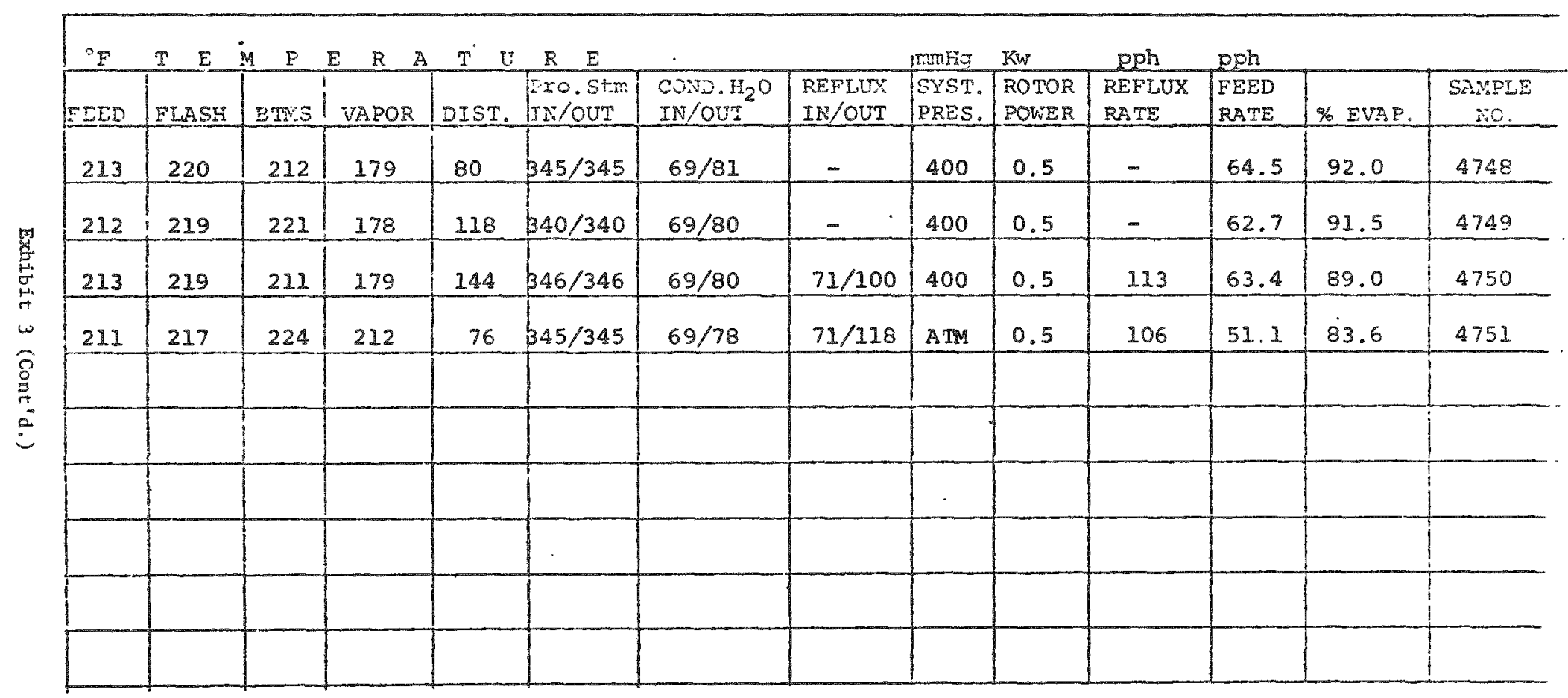


A method to estimate cost per gallon to evaporate water Assume a $20 \mathrm{sq}$. ft. of surface area rototherm E (cost $\$ 53,000$ ) Capacity $20 \mathrm{sq}$. ft. Rototherm E 2 gal/min. evaporation

$$
Q_{E}=M_{\mathrm{H}_{2}} \mathrm{O} \quad A_{\mathrm{H}_{2} \mathrm{O}}=1000 \# / \mathrm{hr} \times 1000=1 \times 10^{6} \mathrm{BTU} / \mathrm{hr} \text {. }
$$

if energy (oil) cost is $\$ 3.00 /$ million BTU

a) Boiler Efficiency $80 \% 3.0 / 8.0=3.75 \$ / \mathrm{mBTU}$

b) Fues 1 preatment \& Labor $25 \% / \mathrm{mBTU}$ based on $8000 \mathrm{hr} / \mathrm{yr}-4.00 \mathrm{~s} / \mathrm{mBTU}=32,500 \mathrm{~s} / \mathrm{yr}$

c) Electrical Energy - $0.75 \mathrm{HP} / \mathrm{kW}$ Net Energy Needed $15 \mathrm{~kW}$ at $3.5 \% / \mathrm{kW}$ $\therefore 15 \times 3.5 \times 8000$ hr year $=4,200 \mathrm{~s} / \mathrm{yr}$

d) Condenser water assuming $30^{\circ} \mathrm{F}$ Rise -

$$
\begin{aligned}
& Q=\mathrm{M} c p \Delta t \\
& \mathrm{M}=\frac{\mathrm{Q}}{\mathrm{cp} \Delta t}=\frac{1 \times 10^{6} \mathrm{BI} \mathrm{IU}^{\prime} / \mathrm{m}}{(1.0)(30) \mathrm{BTU} / \#}=33000 \mathrm{\#} / \mathrm{hr} \mathrm{H} \mathrm{H}_{2} \mathrm{O}
\end{aligned}
$$

or : $4000 \mathrm{gal} / \mathrm{hr}$. dssume cost $35 \% / 1000 \mathrm{gal}$.

$$
\therefore 1406 / \mathrm{hr} \times 8000 \mathrm{hr} .-\quad 11,200 \mathrm{~s} / \mathrm{ur}
$$

e) Deprociation on Equipment $10 \% \quad 5,300 \$$ S/yr

f) Maintenance on Exuioment $4 \% \quad 2.120 \$ / 4 r$ Total -

$$
24,820 \$ / Y x
$$

If add man hrs. at $12.000 \$ /$ hift/yr. $-\frac{4 \text { shifts } x 12,000}{8000}=6.00 \$ / \mathrm{hr}$

$$
\text { or based on } 1000 \# / \mathrm{hr} .-\frac{600}{1000} \approx 0.6 \mathrm{k} / \mathrm{t}
$$

For $8000 \mathrm{hr} / \mathrm{yr} \times 1000 \# / \mathrm{hr} \cdot=\frac{8 \times 10^{6} \# / \mathrm{yr}}{54.820 \mathrm{~s} / \mathrm{yr}}=146 \# \mathrm{H}_{2} \mathrm{O} / \mathrm{s}$

or $1.46 \# / \mathrm{c}$ or $5.76 / \mathrm{gal}$. or $0.68 \% / \#+0.6 \% / \#=1.28 \mathrm{\phi} / \#$

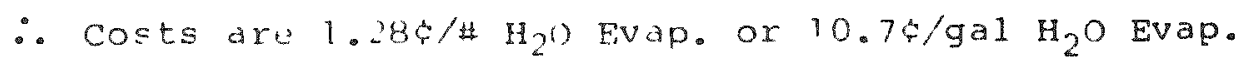
INCREASE by factor of 5 since 1972 


\author{
TRIP REPORT NO. 2 \\ ORNL RADWASTE VOLUME REDUCTION STUDY \\ CHALK RIVER - AECL/DR. DONALD CHARLESWORTH \\ AUGUST 28,1979
}

The AECL Chalk River Nuclear Laboratories were visited to gather information on their low level radwaste management facility. It is now under construction and is to be used as a full scale demonstration of the waste processing techniques presently being tested and evaluated by AECL in smaller, pilot plant setups. Since the demonstration facility is not yet operational, all the data presented here is based on the pilot plant testing programs. Since no cameras were permitted at the facility, the only pictures of the equipment and buildings are those in published reports of the Chalk River program. Copies of the following reports were distributed:

- "Overview of Current Research Related to the Management of Wastes from CANDU Reactors", D. H. Charlesworth, AECL, Chalk River, presented at Canadian Nuclear Association Symposium on Research on Radiological Safety in the Nuclear Fuel Cycle, Toronto, May, 1979.

- "Current Development Programs for the Disposal of Low and Intermediate Level Radioactive Wastes", D. H. Charlesworth, AECL, Chalk River, presented at Canadian Nuclear Association Symposium on the Management of Radioactive Wastes in Canada, Toronto, April, 1978.

- "The Canadian Development Program for Conditioning CANDU Reactor Wastes for Disposal", D. H. Charlesworth, et. al, AECL-6344, July, 1978.

- "Development of Techniques for Radwaste Systems in CANDU Power Station", W. T. Bourns, et. al, AECL-6534, April, 1979.

The demonstration waste processing facility will be capable of handing combustible solid and liquid wastes. The combustible solid waste will be burned in an incinerator and the ash will be mixed with bitumen in either a ribbon blender or extruder/evaporator. At present, the ribbon blender is 
the more likely candrdate for bitumenzing this waste. Liquid wastes will be preconcentrated in a reverse osmosis unit and processed to a dry salt in a thin film evaporator. The method for mixing this waste has not yet been chosen.

CRNL has not conducted any pilot plant testing of waste incineration, although they did have experience with a full scale, refractory brick, single chamber unit 15 years ago. That unit worked well, but reyuired a great deal of maintenance and was difficult to decontaminate. The unit was located some distance from the main laboratory, making operation and maintenance time consuming and custly. It was dismantled primarily for these reasons. The incinerator now being installed in the denonstration facility is a Trecan, starved air type unit similar to the one now operating at Bruce Generating Station. The process rate is one tun per day. It can also handle 10 to 20 gal/day of contaminated oil. The unit is constructed primarily of stainless steel, which CRNL realizes could have corrosion problems when burning polyvinyl chloride (PVC). Rather than changing to a more corrosion resistant material, CRNL has decided to continue using the present materials for most components and to eliminate most PVC from the waste feed. Part of the reason for this approach is to determine any materials problems other than those associated with chlorides.

CRNL noted that one of the major problems with the operating incinerator at Bruce is the periodic occurrence of explosions in the upper portion of the main combustion chamber. This is caused by air inleakage into the unit, which mixes with combustible gases in the chamber and ignites whenever a flames propogates from the afterburner backwards to the main chamber. A counter-balanced relief valve on top of the chamber prevents over-pressurization whenever an explosion occurs. Explosions can be prevented or minimizea by eliminating all sources of air inleakage (loose gaskets, etc.).

The hopper discharge from the incinerator includes a vibratory screening device to separate ash into fine and coarse grade. The fine grade ash (less than $1 / 4$ " diameter) will be bitumenized in a ribbon blender. The size limit 
for fine ash may be increased or decreased, depending on what the ribbon blender can accept. Three types of reverse osmosis (RO) elements have been tested by CRNL. These are:

- Tubular
- Spiral wound
- Hollow fiber

The original flow sheet for the Ro system called for a two stage process using tubular Ro units. The calculated performance data in the attached VR questionnaire form are based on this type of system. The tubular type membranes have the advantage of not plugging when high solids concentrations are present in the feed. However, this type of membrane requires a greater number of elements than a spiral wound membrane, and a still greater number of elements than a hollow fiber membrane for the same process flow rate. Economic studies based on this factor have shown that it would be more cost effective to use spiral wound membranes in the first stage of RO. This approach requires the RO membranes to be preceeded by filtration elements to prevent plugging. CRNL plans to use high efficiency ultra-filtration prefilters for this purpose.

From CRNL's operating experience with Ro units, they have found that for the tubular membranes, the membrane has a tendency to rupture (pull away from the wall of the tube). When the unit is shutdown and drained, they have found that this can be prevented by first draining the inside of the elements and then draining the outer shell.

When the RO units are not being used, they should be kept wet and also chlorinated. CRNL chlorinates their elements about twice weekly. For long periods of inactivity, the elements should be stored in formaldehyde.

The manufacturer of CRNL's RO units claims a life expectancy of two years for their membranes. CRNL has actually run the units for a total of about 100 days without experiencing any deterioration. 
During initial operations, CRNL discovered that the constant start-stop cycling of the Ro units caused separation of the membranes from the tube sheets. This problem was overcome by modifications to strengthen the tube sheet tie rods. Concentrate from the Ro units will be further concentrated and solidified in bitumen using either a thin film evaporator or a Werner-Pfleiderer twin screw extruder/evaporator. Both were found to operate satisfactorily on this waste.

The thin film unit has run very well on foaming type wastes with no drop off in flow rate observed.

CRNL found that the extruder unit could not be operated satisfactorily using feed streams with less than 10 wt. percent solids content. With such waste streams, nucleate boiling caused the bitumen to be stripped from the walls of the extruder, resulting in scale formation on the walls. No such restriction was observed using the thin film evaporator.

The pilot thin film unit tested by CRNL was a vertical unit. There was no buildup of waste on the lower bearing in any of CRNL's test runs with this unit. For the demonstration waste facility, CRNL is soliciting bids on both vertical and horizontal type, $10 \mathrm{sq}$. ft. units.

CRNL found the radiation field around both the thin film evaporator and extruder/evaporator to be minimal. For a waste stream reading $600 \mathrm{mr} / \mathrm{hr}$ on the surface of the feed tanks, the dose rate on the surface of the thin film evaporator was less than $1 \mathrm{mr} / \mathrm{hr}$. For this same waste stream, the core discharge of the evaporator read 30 to $50 \mathrm{mr} / \mathrm{hr}$ while the bottoms collection tank read $1.5 \mathrm{R} / \mathrm{hr}$. Based on this experience, CRNL is not planning to shield the body of the thin film evaporator. CRNL has experimented with both straight bitumen and a bitumen emulsion and found the end product to be comparable. However, because of greater ease with which the emulsion can be handled (no heat tracing and less sophisticated pumps), CRNL plans to use a 
bitumen emulsion in the waste demonstration facility. CRNL has tested the thin film evaporator with both liquid waste feeds and resin slurry feeds. No problems have been experienced with the unit when the feed is a resin slurry. 
AECL Wiped Film Evaporator

Radiste Volume Reduction Systom questionnaire

1. Hief description of system (please attach layout dwgs. \& P\&D, if available).

A $0.5 \mathrm{~m}^{2}$ LUWA wiped film evaporator has been tested as an evaporator for wastes to arise at Cha1k River's Waste Treatment Center. Attached figures

show internals and the experimental arrangement. (Figures are in reports

listed at beginning of Trip Report.)

2. Feedstock Description:

a) Feedstock Designation

b) Type of Waste

c) Tolume per yr. (gal.)

d) Total solids conc. (ppm)

e) Suspended solids (ppm)

f) Conductivity (umo/cm)

ह) $\mathrm{pH}$ :

i) Before adjustment

ii) Aster adjustment

h) Specific gravity

i) Semperature ( $\mathrm{OF}$ )

j) Slurry wastes:

i) Solids conc. (vo1.\%)

ii) Interstitia] Water (vol. :)

iii) Free water above sethled sludge (vol.\%)

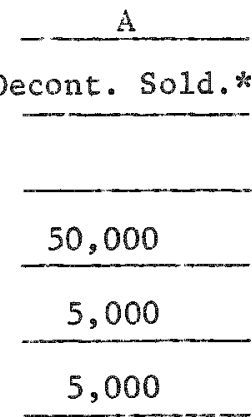

None

pH 6

1.04

77
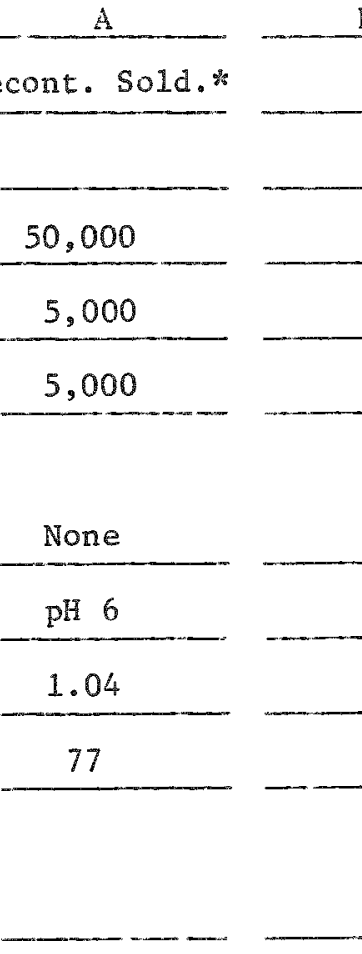

B

C

D
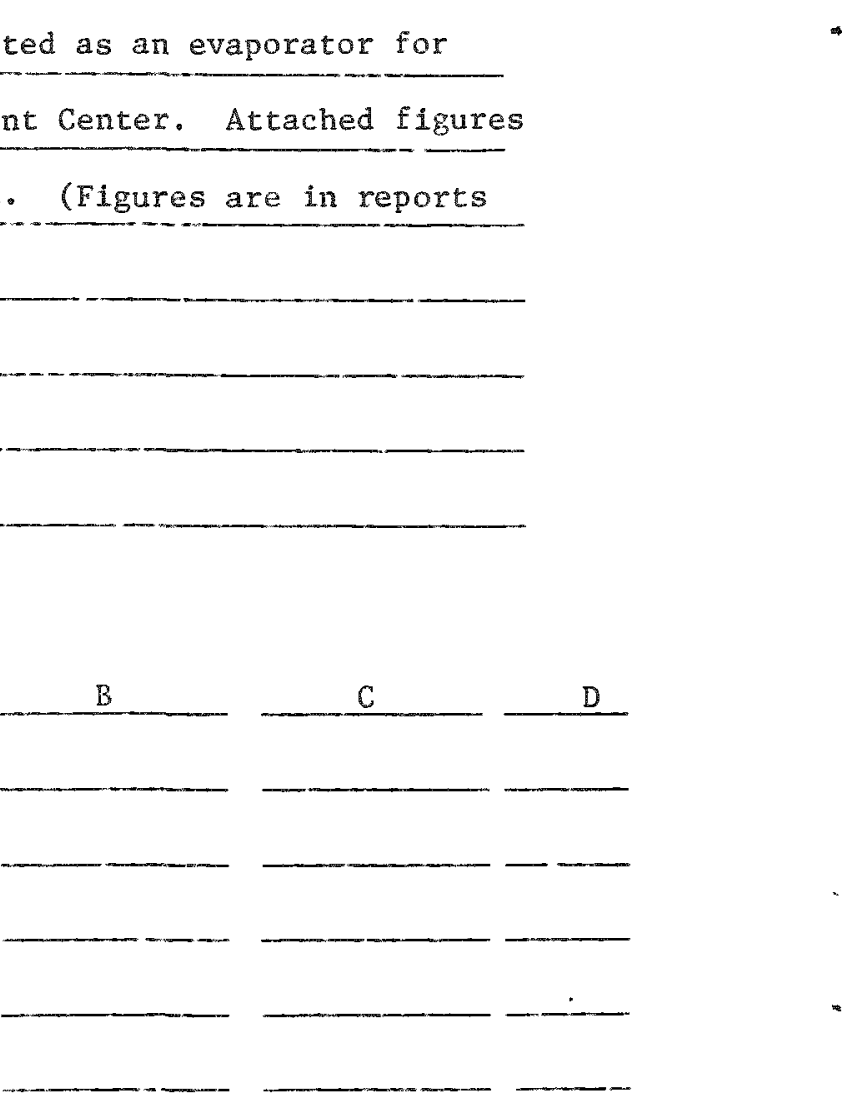

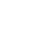

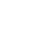

更 
k) Radionuclide content

by major isotopes $(\mu \mathrm{Ci} / \mathrm{ml})$ :

\begin{tabular}{c}
$\frac{C o-60}{C r-51}$ \\
\hline Zr-95 \\
\hline Ce-144 \\
\hline Ce-141 \\
\hline Ru-103 \\
\hline Cs-1340 La-140 \\
Cs-137 \\
Tota1 \\
\hline B- X average \\
\hline
\end{tabular}
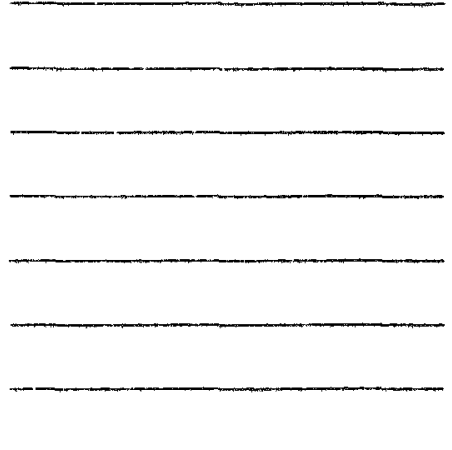

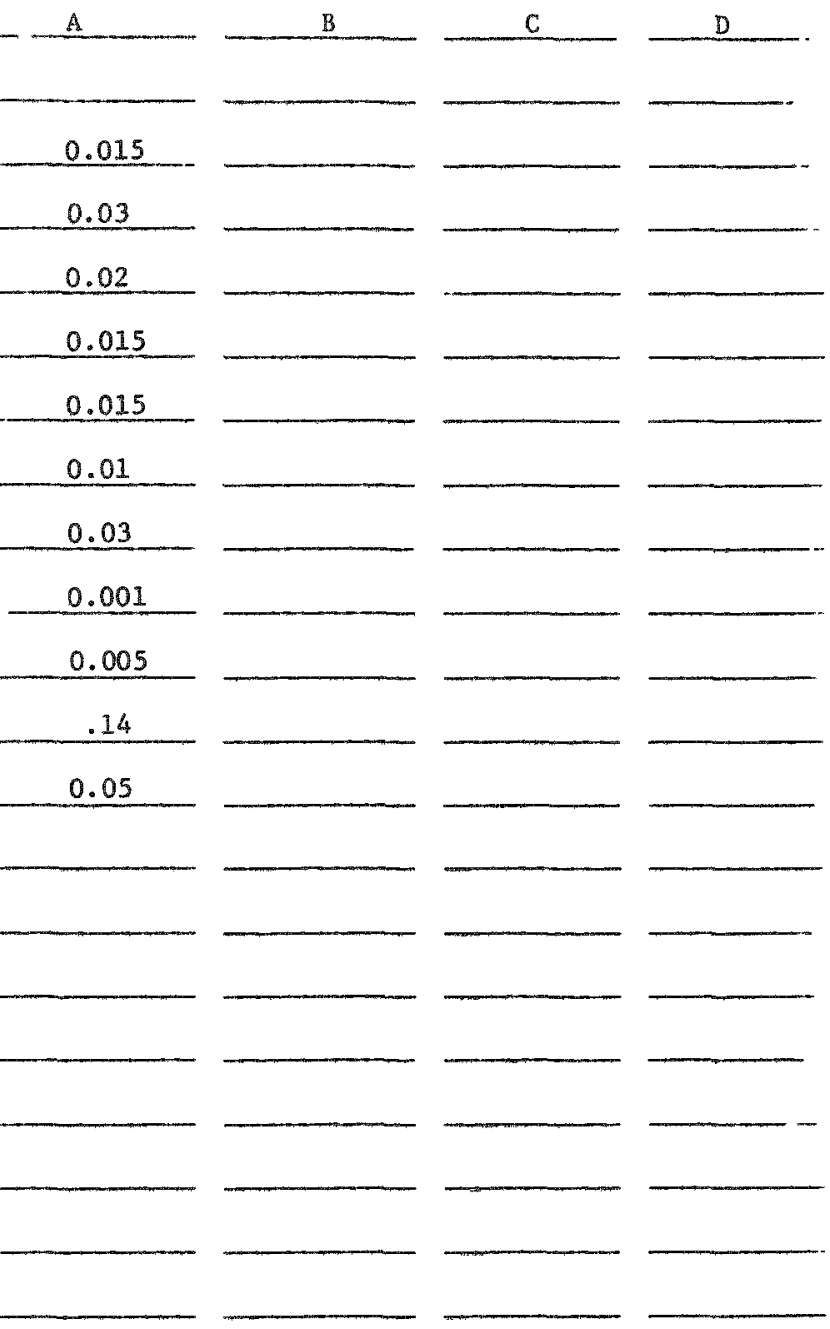

3. Auxiliaries (give pressure, temperature, flow rates, etc.):
a) Steam -
30 to $90 \mathrm{psig}, 230$ to $310^{\circ} \mathrm{F}, 80$ to $400 \mathrm{lb} / \mathrm{h}$
b) Cooling water -
$25 \mathrm{gpm}$
c) Service air -
none
d) Electric -
$575 \mathrm{~V}, 36: 220 \mathrm{~V}, 10 ; 110 \mathrm{~V}, 10$
e) other

Exhibit 5 (Cont'd.) 
4. Operating Data: (for $5.4 \mathrm{ft}^{2}$ pilot plant unit):*
a) Feed rate (gpm)
b) Bottoms conc. (wt.\%)
c) Volume reduction factor
(vol. feed/vol. bottoms)
d) Decontamination Factors (feed to distillate):

\begin{tabular}{l}
$\frac{0.15 \text { to } 0.45}{10 \text { to } 60}$ \\
2 to 12 \\
\hline
\end{tabular}

i) overall

$10^{4}$

ii) major isotopes:

listed on page 2

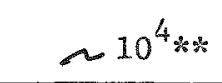

e) Curie content of bottoms $(\mu \mathrm{Ci} / \mathrm{cc})$

\section{5 to 15.0}

f) Radiation level in bottons (mr/hr):
i) Surface of container -
ii) One foot from container -

$\mathrm{N} / \mathrm{A}$

$\mathrm{x}$

*Unit being installed now will be $10 \mathrm{sq}$. ft.

**This is without any external demister section.

$\frac{\mathrm{N} / \mathrm{A}}{\mathrm{X}}$


5. Operating History:
a) Date unit installation completed -
1977
b) Date unit first operated (with radioactive waste) -
1978
d) Total number of operating hours -
400

6. Cost Factors:

a) Initial equipment cost -

$\frac{20,000}{5,000}$

d) Operating costs (\$/gal. of waste feed)

i) Personnel

$\mathrm{N} / \mathrm{A}$

ii) Auxiliaries

$\mathrm{N} / \mathrm{A}$

iii) Solidification Agent (if integral part of VR system)

iv) Total

N/A

$N / A=$ Not Available

Exhibit 5 (Cont'd.) 
A-32

$-j-$

7. Describe any major operating difficulties experienced with the VR system and what measures were taken to correct them.

At low feed rates, there is a tendency for dryout - a11 the heat transfer surface is not uniformly covered. Corrected by increasing the feed flow to wash off the built-up solids. 
8. List all forced outages, including cause of outage (general maintenance, pump failure, etc.) and duration.

Upper bearing seal leak. The seals were replaced within one working day. 


\section{AECL Reverse Osmosis}

Radwaste Volume Reduction Systen Questionnaire

1. 3rief description of system (please attach layout dwgs. \& P\&ID, if available).

Volume reduction of low level aqueous waste from reactor and laboratory

drains and from chemical decontamination of equipment. Tubular reverse

osmosis (R.O.) modules have been scudied entensively and are described

here. U1trafiltration and spiral wound Ro presently under test. Attached

figure shows one layout using tubular Ro. The secondary stage will be

made with tubular Ro nodules, but the primary stage is still to be specified.

- (Figures are in reports listed at beginning of Irip Report.)

$A, B, C$ mixed to give one feed

2. Feedstock Description:
a) Feedstock vesignation
b) Type of vaste
c) Volume per yr. U.S(gal.) (design basis)
d) Total solids cone. (ppm)
e) Suspended solids (ppm)
f) Conductivity (umho/cm)
g) $\mathrm{pH}$ :

i) Before adjustment

ii) After adjustment

h) Specific gravity

i) Temperature (OF)

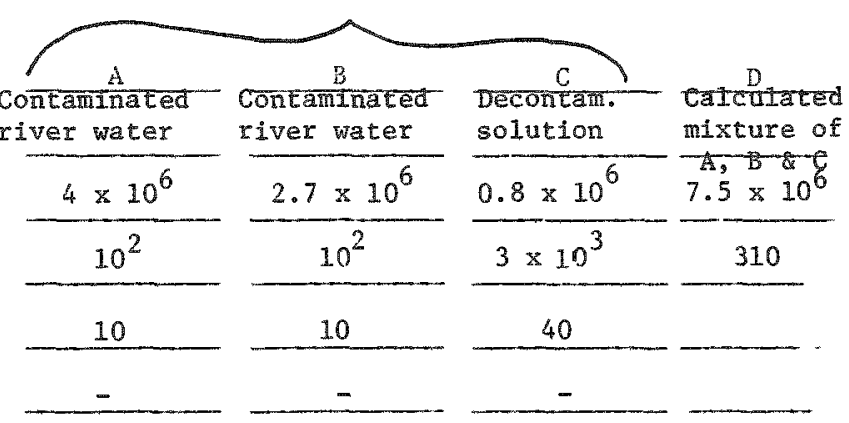

j) Slurry wastes:

i) Solids cone. (vol.

ii) Interstitial water (vol. a)

iii) Free water above settled sludge (vol.\%)

\begin{tabular}{|c|c|c|}
\hline$=$ & $=$ & $5-10$ \\
\hline- & - & 6 \\
\hline 1.0 & 1.0 & - \\
\hline 85 & 85 & 85 \\
\hline
\end{tabular}


$-2-$

k) Radionuclide content by major isotopes $(\mu \mathrm{Ci} / \mathrm{m} \mathrm{I})$ :

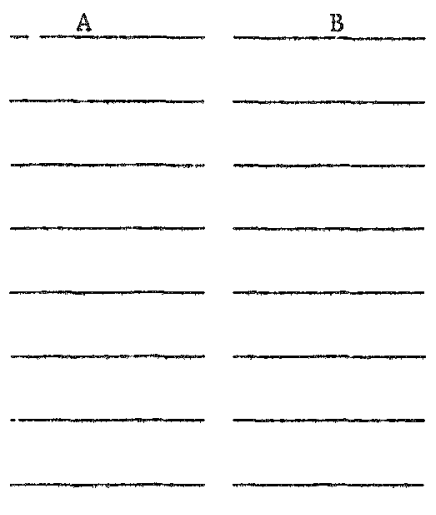

Ru-103

$\mathrm{Ba}-140 \mathrm{La}-140$

$\mathrm{Cs}-134$

Cs -137

Total

Based on average $B \gamma$

3. Auxiliaries (give pressure, temperature, flow rates, etc.):
a) Stean -
b) Cooling water -
c) Service air -
d) Electric -
e) other

none

as necessary to remove pump heat: quantity unmeasured

$\mathrm{C}$

Avg. Value

$\mathrm{Ag} B \mathrm{C}-\cdots$

$1.5 \times 10^{-4}$

3. $\times 10^{-4}$

2. $\times 10^{-4}$

$1.5 \times 10^{-4}$

$1.5 \times 10^{-4}$

1. $\times 10^{-4}$

$3 . \times 10^{-4}$

$0.1 \times 10^{-4}$

$0.5 \times 10^{-4}$

$1.4 \times 10^{-3}$

$\frac{1.4 \times 10^{-3}}{5 \times 10^{-3}}$

$5 \times 10^{-3}$
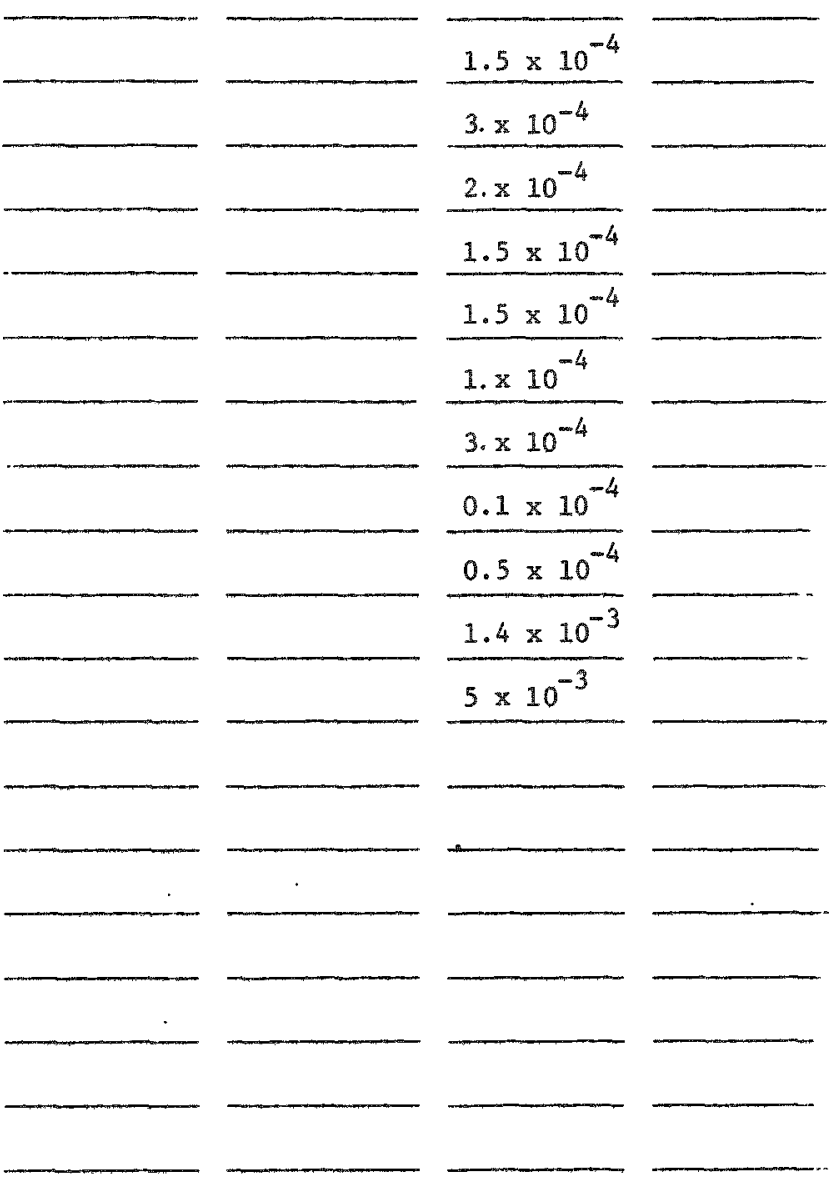

\begin{tabular}{c}
$\frac{C o-60}{C r-51}$ \\
\hline Zr-95 \\
\hline Ce-144 \\
\hline Ce-141 \\
\hline Ru-103 \\
\hline Ba-140 La-140 \\
\hline Cs-134 \\
\hline Total \\
\hline on average B \\
\hline
\end{tabular}

te.):

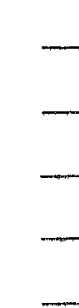

as necessary: for some instruments

as necessary: quantity yet to be specified

none

Exhbit 6 (Cont'd.) 
4. Operating Data:

a) Feed rate (gpm)

b) Bottoms conc. (wt. \%) wt \% total solids

c) Volume reduction factor

(vol. feed/vol. bottons)

d) Decontamination Factors

(feed to distillate):

i) overal1

ii) major isotopes:

$-\mathrm{Cs}-134, \mathrm{Cs}-137, \mathrm{Co}-60, \mathrm{Mn}-54$

Cr-51, Zr-95, Ce-144, Ce-141

Ru-103, La-140

e) Curie content of bottoms $(\mu \mathrm{C} i / c c)$

f) Radiation level in bottoms $(\mathrm{mr} / \mathrm{hr})$ :

i) Surface of container -

ii) One foot from container -
From development work on waste "C" only

Calculated for plant waste " $D$ "

\begin{tabular}{l|c}
0.1 & 15 \\
\hline $3-17$ & 4.5 \\
\hline 25 & 170 \\
\hline $\begin{array}{l}100 \text { on a } \\
\text { single pass }\end{array}$ & \\
\hline $\begin{array}{l}100 \text { on a } \\
\text { single pass }\end{array}$ & \\
\hline single pass & \\
\hline & \\
\hline & \\
\hline & \\
\hline
\end{tabular}

Exhibit 6 (Cont ${ }^{\prime} \mathrm{d}_{\text {.) }}$ 
5. Operating History:
a) Date unit installation completed -
1975
b) Date unit first operated (with radioactive waste) -
1975
d) Total number of operating hours -
up to 100 hours on one $\rightarrow$ module

6. Cost Factors: a) Initial equipment cost - This data yet to

b) Installation cost

c) Building costs

d) Operating costs ( $\$ / g a 1$. of waste feed)

i) Personne1

ii) Auxiliaries

iii) Solidification Agent (if integral part of VR system)

none

iv) Total 
7. Describe any major operating difficulties experienced with the VR system and what measures were taken to correct them.

The major difficulty with the tubular Ro nodules we are using is that the membranes are laid on a dacron cloth and are held against the cloth by the pressure drop during operation. Ends of the membrane tubes are held in place by rings. Apparently, rapid changes in flow and/or pressure eventually cause the membrane to tear at one of the rings. Modules have been strengthened, and this appears to reduce the tearing, but not eliminate it completely.

Fouling of the membranes reduces the permeate flow rate and continuous operating at very high volume reduction factors causes a plating out of salts over the whole system. The volume reduction factor has been reduced and periodic washing used to removing the fouling layer. Fouling is more of a problem with the mixed wastes (Feed "D") than it was with the Decontamination Center waste (Feed " $\mathrm{C}$ "). 
$A-39$

$-6-$

8. List all forced outages, including cause of outage (general maintenance, pump failure, etc.) and duration.

Only development equipment has been run to date. Membrane failure has caused most outages. 
AECL Extruder/Evaporatar

Radwaste Volume Reduction System Questionnaire

1. Brief description of system (please attach layout dwgs. \& P\&ID, if available).

A laboracory model twin-screw extruder purchased from Werner \& Pfleiderer

has been tested as a bituminizer for wastes concentrated in the Waste

Treatment Center. An attached photograph shows the equipment layout.

(Photograph is in reports 1 isted at beginning of Trip Report.)

2. Feedstock Description:
a) Feedstock Designation
b) Type of waste
c) Volute peryr. (gal.)
d) Total solids conc. (ppm)
e) Suspended solids (ppm)
f) Conductivity (umho/cm)
g) $\mathrm{pH}$ :

i) Before adjustment

ii) After adjustment

h) Specific gravity

i) Temperature $(\mathrm{OF})$

j) Slurry wastes:

i) Solids conc. (vo1.\%)

ii) Interstitia1 water (vol. \%)

\begin{tabular}{c}
$\frac{\frac{A}{\text { Decont. }}}{\text { Solutions }}$ \\
$\frac{\text { Waste mixed wi }}{100,000}$ \\
$\frac{10,000}{15,000}$ \\
\hline
\end{tabular}

B

C

volume reduced $300 \times$ by R.0. and evap.

th other feeds to R.O. and vol. of

water above settled sludge (vol.\%)

\begin{tabular}{c}
$\frac{\mathrm{pH} 6}{\text { no adjustment }}$ \\
\hline$\frac{1.1}{77}$ \\
\hline 5 \\
\hline$<1$ \\
\hline
\end{tabular}

95

Exhibit 7 
k) Radionuclide content by major isotopes $(\mu \mathrm{Ci} / \mathrm{ml})$ :
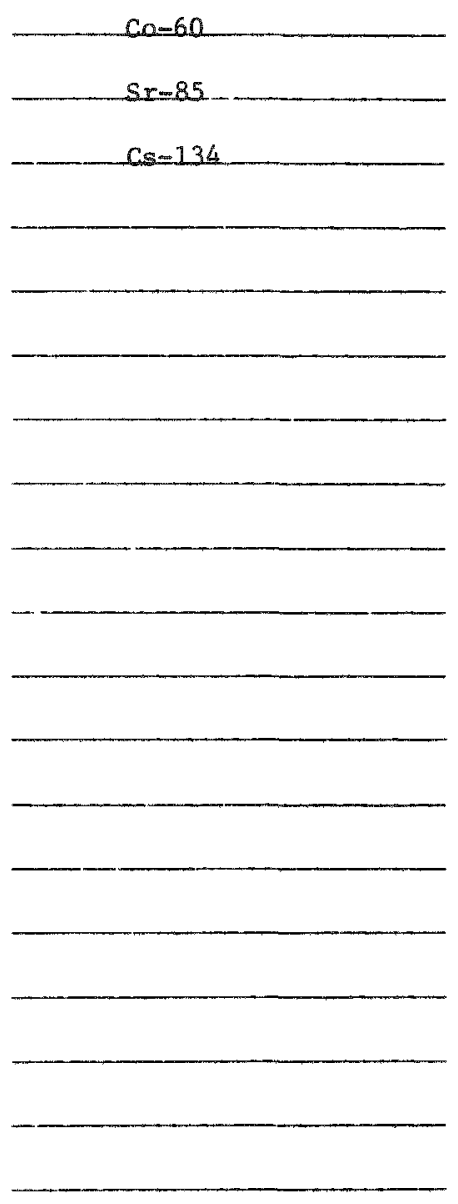

\section{$-2-$}

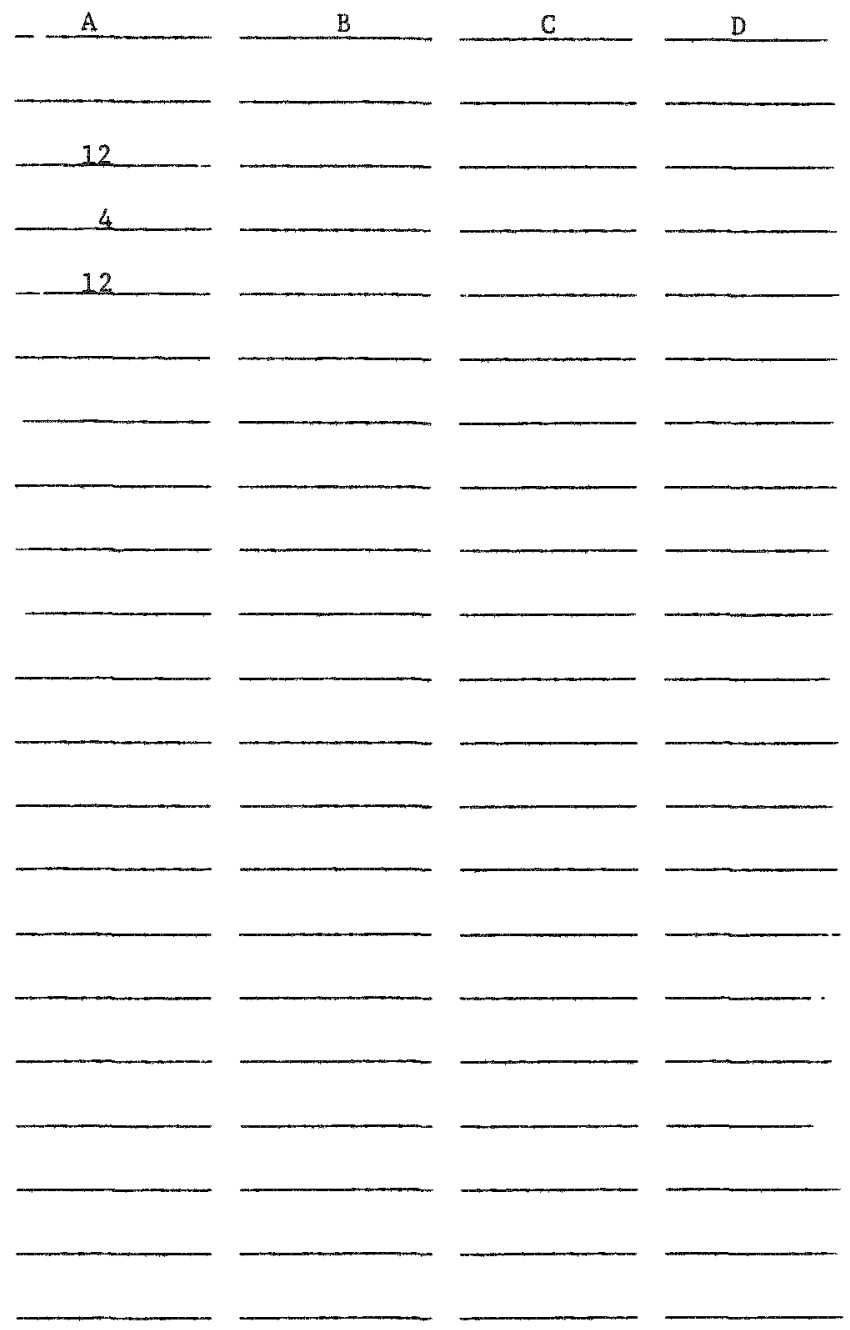

3. Auxiliaries (give pressure, temperature, flow rates, etc.):
a) Steam -
b) Cooling water -
c) Service air -
d) Electric -
e) other

30 to $100 \mathrm{psig}, 130^{\circ} \mathrm{F}$ to $330^{\circ} \mathrm{F}, 20 \mathrm{lb} . / \mathrm{hr}$.

\section{$1 \mathrm{gallon} / \mathrm{minute}$}

not required

$575 \mathrm{~V}, 30 ; 110 \mathrm{~V}, 10$

Exhibit 7 (Cont'd.) 
4. Operating Data:

a) Feed rate ( $\mathrm{gpm})$

0.016

b) Bottoms conc. (wt. \%)

c) Volume reduction factor

(vol. feed/vol. bottoms)

5

d) Decontamination Factors

(feed to distillate):

i) overall

$10^{4}$

ii) major isotopes:

$\frac{\operatorname{co-60}}{\mathrm{S} x-85}$

$\frac{10^{4}}{10^{5}} \frac{10^{4}}{}$

e) Curie content of bottoms (uci/cc)

f) Radiation level in bottoms $(\mathrm{mr} / \mathrm{hr})$ :

*i) Surface of container -

5000

ii) One foot from container -

500

$* 2 R$ on feed container;50 $\mathrm{mr}$ on feed pump; negligible field on extruder. 


\section{A-43}

$-4-$

5. Operating History:
a) Date unit installation completed -
1976
b) Date unit first operated (with radioactive waste) -
1977
d) Total number of operating hours -
850

6. Cost Factors:
a) Initial equipment cost -
b) Installation cost
c) Building costs
d) Operating costs (\$/gal. of waste feed)
i) Personnel
ii) Auxiliaries
iii) Solidification Agent (if integral part of VR system)
iv) Total

$\$ 70,000$

$\$ 10,000$

N/A

$\frac{\$ 70,000}{\$ 10,000}$

N/A - Not Available

Exhibit 7 (Cont'd.) 
$A-44$

$-3-$

7. Describe any major operating difficulties experienced with the VR system and what measures were taken to correct them.

Operating at high inlet temperatures led to foaming of bitumen \& waste. Blockage of the condensers resulted. Derated steam pressure to solve this problem couldn't operate below $10 \%$ feed concentration without cutting back feed rate significantly. 


\section{$A-45$}

$-6-$

8. List all forced outages, including cause of outage (general maintenance, pump failure, etc.) and duration.

None to date.

Even when salt caked out on walls of extruder, unit could pump out salt without any overload torque. No wear observed. Use incinerator ash to clear unit out without any problems. 


\begin{abstract}
A-46
TRIP REPORT NO. 3

ORNL RADWASTE VOLUME REDUCTION STUDY

BRUCE GENERATING STATION INCINERATOR/MR. ARCHIE CAMPBELL
\end{abstract}

AUGUST 29,1979

Ontario Hydro's Bruce Generating Station was visited to see the waste incinerator being used there. The unit is a Trecan, starved air, two chamber unit similar to the one being installed at Chalk River. The unit has been operated for two years, and much of the experience gained during this period was reported in the following paper:

- "Volume Reduction of Low Level Radioactive Solid Waste in Ontario Hydro", A. V. Campbell, R. Kohout, V.R. Sligh, E. F. Jelinski, and A. M. Seabrook, presented at ANS Ninth Biannual Topical Conference on Reactor Operating Experience, Arlington, Texas, August 6 - 8, 1979.

Waste from the power plant is brought to waste collection stations located throughout the plant. At these stations, the waste is segregated into one of three categories:

1. Incinerable

2. Compactible but not incinerable (tin cans, PVC, etc.)

3. Non-processible ( $>200 \mathrm{mr} / \mathrm{hr}$, pipe, etc.)

To remain within radiological release limits, the incinerator was originally limited to burning waste reading $<5 \mathrm{mr} / \mathrm{hr}$ on contact. Ontario Hydro now feels that this limit can be increased. About 90 to 95 percent of Ontario Hydro's waste is below $5 \mathrm{mr} / \mathrm{hr}$.

Because of corrosion problems experienced with the unit, PVC-containing waste is not burned. Several equipment modifications have reduced other corrosion problems substantially. 
When burning wood or other dense material, experience has shown that a cleaner, more complete burn is produced by putting the wood at the bottom of the load. Wet waste is handled by mixing uniformly with the dry waste.

Better control and a more efficient burn would be obtained if waste could be fed into the unit periodically throughout the burn cycle rather than all in one batch at the start. Ontario Hydro is studying the feasibility of doing this with their present incinerator.

On several occasions, there have been explosions in the unit. When this happens, a relief valve on top of the unit opens to prevent over-pressurization. This results in a small volume of gas being discharged without passing through the bag house filters in the off gas system. To date, this has not caused any activity release problems. To reduce the likelihood of explosions, efforts have been made to prevent air inleakage into the upper portion of the incinerator chamber. In addition, at the start of a burn cycle, the upper burners are lighted first to burn off any residual combustible gases in the chamber.

In 1978, approximately 1,850 cubic meters of waste was burned. A portion of this waste came from the Pickering Station located about 180 miles from Bruce Station. This waste volume worked out to an average of one burn per week. After making numerous design improvements, the burn frequency has been increased to two per week.

Ontario also operates an incinerator for nonradioactive waste. It is the same type of unit as the radioactive one, but is lined with refractory brick, and therefore, does not have any PVC problems. The bottom reactor and afterburner of the radioactive incinerator are already refractory lined. There has not been any noticeable buildup of activity in these sections, and consequently, Ontarion Hydro would sexiously consider an all-refractory lined unit if a second radioactive waste incinerator were purchased. Measured dose rates in any portion of the system have been less than $10 \mathrm{mr} / \mathrm{hr}$. The flyash, which is collected in $2.5 \mathrm{~m}^{3}$ containers, measures from 5 to $10 \mathrm{mr} / \mathrm{hr}$ on contact. 
Ontario Hydro Incinerator

Radwaste Volume Recuction System questionnaice

1. Brief description of system (please attach layout dwgs. \& PsID, if available).

Radioactive Waste Incinerator - manufacturer Trecan Ltd., Toronto,

Ontario; batch type controlled air incinerator; capacity $100 \mathrm{~kg} / \mathrm{hr}$

(220 lbs/hr) or $20 \mathrm{~m}^{3} /$ batch; burn cycle length $50-60 \mathrm{hrs}$; dry flue gas

treatment system consisting of partial-air dilution chamber, air cooled,

she11 and tube heat exchanger, and baghouse filtration (NoMEX bags);

induced draft fan (negative pressure system).

2. Feedstock Description:

a) Feedstock Designation

b) Type of Waste

c) Volume per yr.

d) Total solids conc. (ppri)

e) Suspended solids (ppm)

f) Conductivity (umho/ $\mathrm{cm}$ )

g) $\mathrm{pH}$ :

i) Before adjustment

ii) AEter adjustment

h) Specific gravity $\mathrm{kg} / \mathrm{m}^{3}$

i) Temperature (OF)

j) Slurry wastes:

i) Solids conc. (vol. \%)

i1) Interstitial Water (vol. $\%)$

i.ii) Free water above settled sludge (vol.\%)

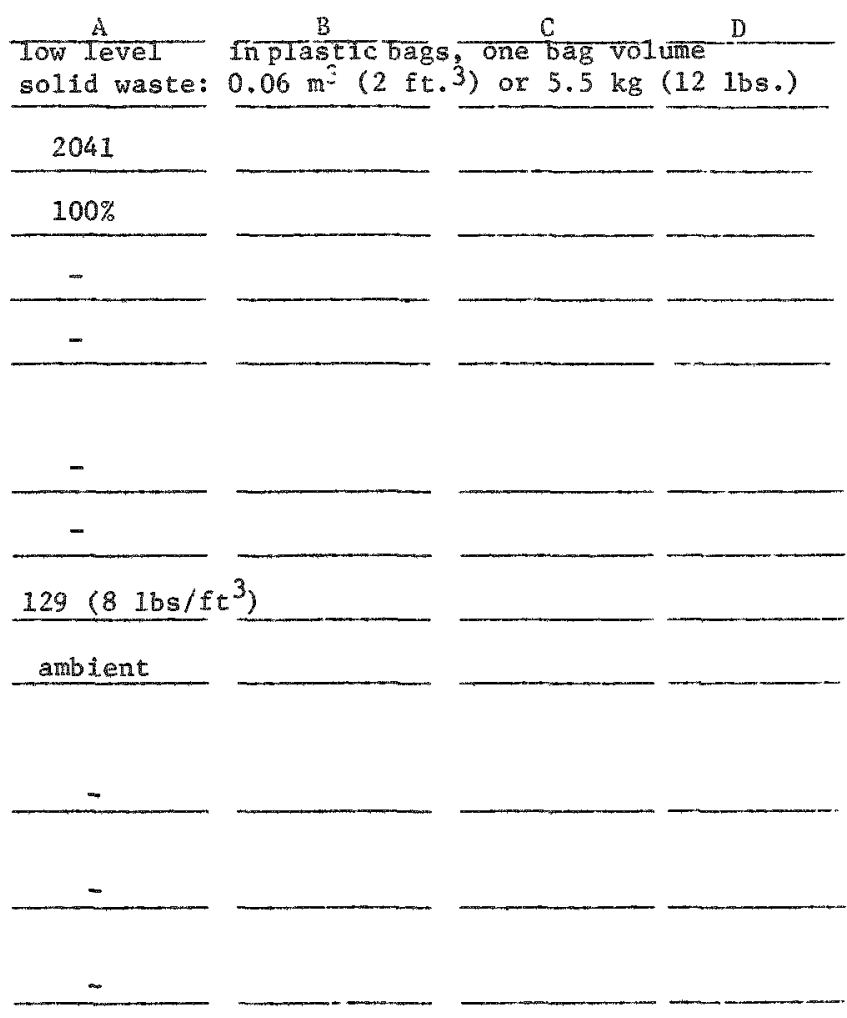


k) Radionuclide content by major isutopes of radioactive waste

$-\frac{\operatorname{ce}-144}{C e-141}$

$\mathrm{Cs}-134$

$\begin{array}{r}\mathrm{RU}-106 \\ \hline \mathrm{Cs}-137 \\ \hline\end{array}$

$\frac{\mathrm{Zr}-95}{\mathrm{Nb}-95}$

$\mathrm{Mn}-54$

$\frac{\mathrm{Co}-60}{\mathrm{Fe}-59}$

average bag

activity at contact
$-2-$

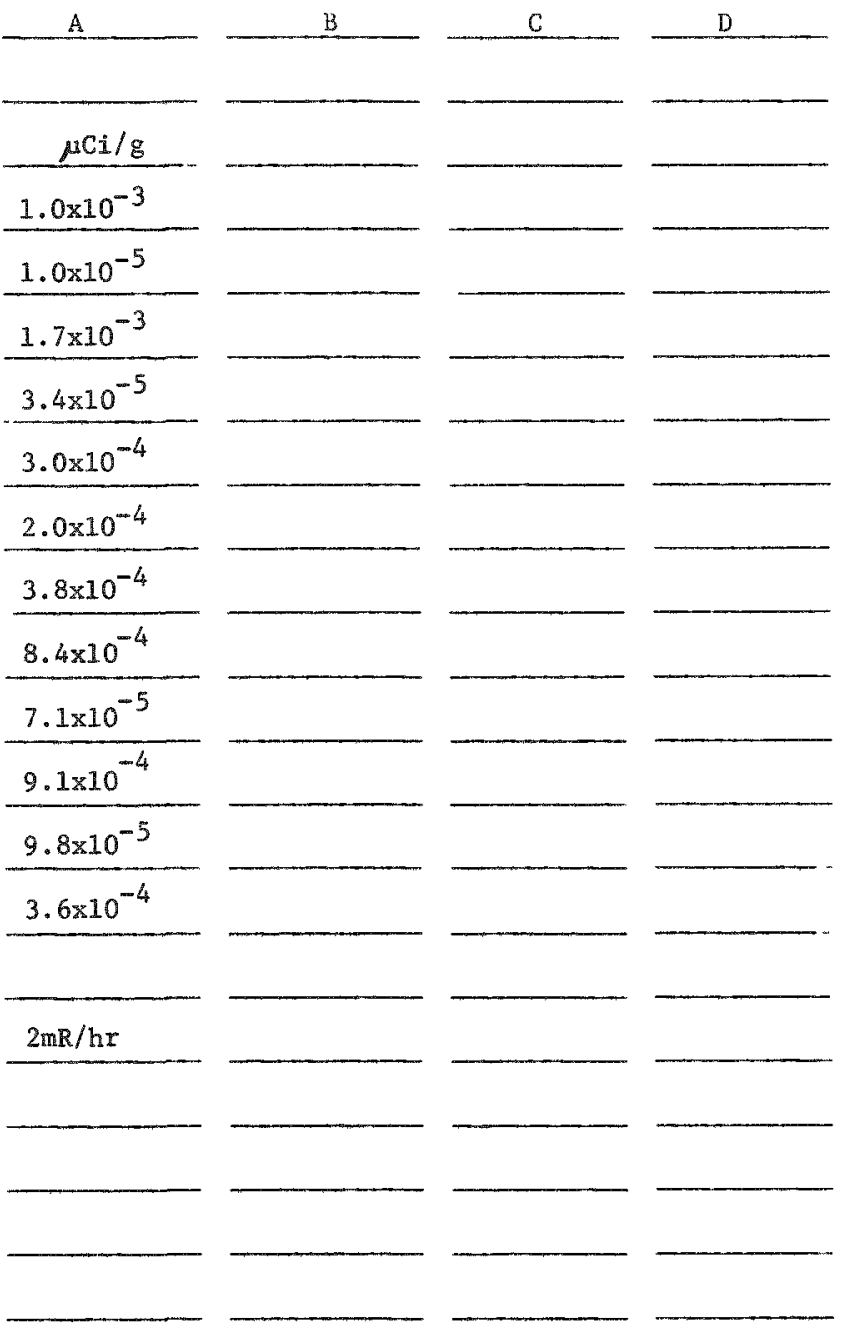

3. Auxiliaries (give pressure, temperature, flow rates, etc.):
a) Steam -
b) Cooling water -
c) Service air -
d) Electric -
e) Other

$\mathrm{N} / \mathrm{A}$

N/A

$\frac{\text { N/A }}{\text { N/A }}$
as required - approx. 100 scfm @ 120 psig
as required - approx. $600 \mathrm{~V} 30$
flue gas: 3000 acfm $@ 204^{\circ} \mathrm{C}$ after $1: 1$ dilution
with air; cooled from $1000^{\circ} \mathrm{C}$ down to $204^{\circ} \mathrm{C}$; total
pressure drop about $12^{\prime \prime}$ WC. $^{\circ}$

Exhibit 8 (Cont'd.) 
4. Operating Data:

a) Feed rate

b) Bottoms conc. (wt. \%)

c) Volume reduction factor (vol. feed/vol. bottoms)

d) Decontamination Factors (feed to off gas ):

i) overall.

ii) major isotopes:

$-\frac{\mathrm{H}^{3}}{\mathrm{I}^{131}}$

Particulate

e) Curie content of bottoms (uci/cc)

f) Radiation level in bottoms $(\mathrm{m} r / \mathrm{hr})$ :
i) Surface of container -
ii) One Erom container - meter

$20 m^{3}$ per batch

$100 \%$ ash

$40: 1$

$10^{5}$

$34.2 \mu \mathrm{CI} / \mathrm{kg}$

up to $30 \mathrm{mR} / \mathrm{hr}$

up to $10 \mathrm{mR} / \mathrm{hr}$ 
5. Operating History:
a) Date unit installation completed -
January 1977
b) Date unit first operated (with radioactive waste) -
May 1977

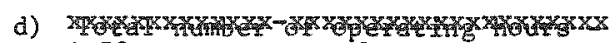 $67 \%$ 1978 incapability factor

b. Cost Factors:

a) Initial equipment cost - including (b)

$1.7 \times 10^{6}$

b) Installation cost

c) Building costs (weighted)

d) Operating costs ( $\$ / \mathrm{m}$ gav. of waste feed for 1978

i) Personnel

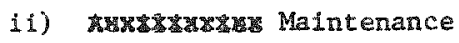

$1.36 \times 10^{6}$

iii)

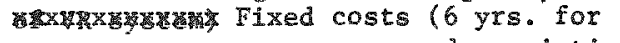

iv) jotal depreciation)

Incinerator Fired Costs

Incinerator Labor - waste handing

Incinerator Labor - system operation

Incinerator Materials - spare parts

Incinerator Purchased Services

Incinerator Maintenance

$\begin{array}{r}482 \\ 219 \\ \hline\end{array}$
344

$1045 \%$

$703 \mathrm{ks}$ (6 yr. depreciation)

$257 \mathrm{ks}$

$463 \mathrm{ks}$ Operating Costs

$135 \mathrm{KS}$

$129 \mathrm{k \$}$

447 KS Maintenance Cost

TOTAL $2134 \mathrm{KS}$

*Includes storage cost 
7. Describe any major operating difficulties experienced with the VR system and what measures were taken to correct them.

(1) Excessive length of burn cycle (50-60 hrs. compared to projected 24 hrs.).

(2) Stress and high temperature corrosion and cracking of the heat exchanger resolved by partial air dilution.

(3) Frequent plugging of the heat exchanger tubes-eliminated by introducing the partial air dilution.

(4) Primary chamber inner liner bulging and buckling - new support brackets.

(5) Slag formation on primary chamber grate - a better design will eliminate that problem.

(6) Carryover of particulate matter and volatiles-secondary chamber to fully oxidize the particulates is undersized; will be modified.

(7) Uncontrollable ingress of external air into primary chamber - partially eliminated by better seals.

(8) Frequent blinding ( $\mathrm{plugging}$ ) of bag filters - process optimization to be implemented; $1 . e$. bigger afterburner.

(9) Manual operating mode, resulting in extensive manpower requirement.

(10) Maintenance areas not easily accessible; difficult component isolation and removal.

(11) Vertical Fiight conveyor - bags jaming.

(12) Slide valves jamming.

(13) Pressure transients in primary chamber - burn procedure pertaining to light-off and control of under fire air have been optimized.

(14) Metering of ash into $200 \mathrm{~L}$ drums - solved by using large $2.5 \mathrm{~m}^{3}$ containers. 
8. List all forced outages, including cause of outage (general maintenance, pump failure, etc.) and duration.

Heat Exchanger

Period from Oct. 77 to June 1979

- one outage frequency of 2 weeks on every 6 burns to clean heat exchanger minor repairs to tube and tubesheet welds average 2 to 3 day outage

- one outage frequency of 3 months of every 30 burns to replace the heat exchanger tube sheet average 2 week outage

- The entire tube bundle was replaced in October 1978

- The heat exchanger was modified to include 1:1 air dilution in June 1979.

Period from June 1979 to present

- outage every 10 burns for inspection and cleaning of heat exchanger

- outage period $\simeq 1$ day

Primary Chamber

- Supports modified in May 1978

- Grate and refractory replaced in August 1979

Other Unreliable Equipment - High Random Failures

- Conveyor

- Stack monitors

- Bag house 


\begin{abstract}
A-54
TRIP REPORT NO. 4

ORNL RADWASTE VOLUME REDUCTION STUDY

TELEDYNE READCO RIBBON BLENDER/MR. KURT BRENNAN
\end{abstract}

AUGUST 31,1979

Teledyne Readco's manufacturing facility in York, Pennsylvania was visited to witness a demonstration of the ribbon blender volume reduction system. The ribbon blender is a steam jacketed, horizontal, cylindrical vessel with a close-fitting helical mixing blade rotating about the central, longitudinal axis of the vessel. The unit works on a batch basis. The liquid or slurry to be concentrated is feed into the blender until the vessel is full. The mixing blade is then used to agitate the liquor as the water is evaporated. After all of the water has been driven off, an isolation valve is opened on the discharge line located on the underside of the vessel midway along the cylinder wall. The mixing blade, which is a left-handed helix in one half of the vessel and a right-hand helix in the other half, pushes the dry salt towards the central discharge point, where the product can be transferred from the storage hopper to either a shipping container or to a solidification system. In the demonstration facility, the product was fed to a heavy duty, twin screw extruder processor also manufactured by Readco. This device, which can be equipped with a steam jacket if required, is capable of mixing the dried product with any number of solidification agents, including cement, prolyethylene, bitumen, and urea formaldehyde.

The ribbon blender used in the pilot plant is a three $\mathrm{ft}^{3}$ unit. The proposed unit for radwaste service is a $100 \mathrm{ft}^{3}$ unit (a P\&ID and outline drawing of this unit is presented on Exhibits 12 and 14). Although the $100 \mathrm{ft}^{3}$ blender has not been tested with radwaste material, many similar sized models have been used for a number of years in other fields such as the food and petrochemical industries.

The processing rate of the blender will vary considerably, depending on the size of the unit and the waste being processed. The pilot plant unit processes waste at a rate of about 10 to $30 \mathrm{lb} / \mathrm{hr} / \mathrm{ft}^{3}$. The larger production 
model will operate at a lower rate than this since the surface area per unit volume in the larger unit is only about 30 percent of that in the smaller pilot unit. It is estimated that the production size unit will take about 10 hours to process $100 \mathrm{ft}^{3}$ of $25 \mathrm{wt}$. percent $\mathrm{Na}_{2} \mathrm{SO}_{4}$ solution. This translates to a process rate of 5 to $10 \mathrm{lb} / \mathrm{hr} / \mathrm{ft}^{3}$.

The performance test was conducted using a feed solution consisting of $251 \mathrm{~b}$. of $\mathrm{Na}_{2} \mathrm{SO}_{4}, 75 \mathrm{lb}$. of water, $2 \mathrm{lb}$. of bead resin, and $3 \mathrm{lb}$. of iron oxide (rust). It took approximately three hours to bring this solution to a dry salt. At the end of the trial run, the salt flowed freely out the discharge, however, there was a substantial buildup of scale that remained on the walls of the vessel because of a one-quarter inch clearance between the mixing blade and vessel wall. Smaller clearances were initially tried, but it was found that below $1 / 4$ in., noise and vibration began to develop in the unit. Because of the nature of the blender evaporation process, there does not appear to be any easy way of avoiding this buildup. After a long period of operation, the scale (in the case of $\mathrm{Na}_{2} \mathrm{SO}_{4}$ ) gets hard and brittle and breaks away from the walls of the vessel in small chunks. A suitable solvent would have to be injected into the vessel to dissolve and flush away any residual scale before working on the unit (the motor drive is separated from the vessel by a shield wall to facilitate maintenance on this item).

During a batch run, the evaporation rate of the unit drops off markedly near the end of the run, adding significantly to the process run time. This would be expected as a result of the reduction in heat transfer rate caused by scale buildups and changes in the heat transfer characteristic of the waste as the percentage of water is reduced.

During a number of earlier test runs, the energy input to the mixer motor was monitored. For all of these runs, only slight, if any, increase in motor horsepower was observed as the liquor density increased.

No data was available on DF values for the unit. However, for waste such as the $\mathrm{Na}_{2} \mathrm{SO}_{4}$ solution described above, distillate quality typically is in the range of $50 \mu \mathrm{mho} / \mathrm{cm}^{2}$. A wire mesh demister section in the vapor outlet line is used to minimize carryover. 
Readco has not found it necessary to adjust the pH of the waste feed stream except in cases where it is needed to make the product compatible with whatever solidification agent is being used. Normally, very little maintenance is expected to be required for the blender vessel itself. The shaft seals at either end of the main blade will be mechanical type. Since the shaft rotates at a very low speed $(100 \mathrm{rpm})$ and since the operating pressure in the vessel is also very low (near atmospheric) few problems should be encountered with either the shaft seals or bearings.

After evaporating the $\mathrm{Na}_{2} \mathrm{SO}_{4}$ solution in the ribbon blender, Readco demonstrated how the product would be solidified using the Readco twin screw extruder processor. The solidification agent used in this demonstration was polyethylene. Smal1, $1 / 8$ inch diameter polyethylene beads were first fed into the processor through a bin located above the processor. These were melted using a steam jacket around the processor to bring the temperature up to $330^{\circ} \mathrm{F}$. Once a steady stream of paste like polyethylene began flowing from the discharge end of the processor, the dried waste product was fed into the unit through a separate bin feeder. The end product, after cooling, was an excellent, monolithic solid material. The waste feed to the processor had in it large chunks (roughly 1 inch square by $1 / 4$ inch thick) of the brittle $\mathrm{Na}_{2} \mathrm{SO}_{4}$ scale described before. These chunks were thoroughly ground up by the processor into particles with an average size of $1 / 16$ inch diameter or less. It was noticed that some of these particles were on the surface of the solidified product, and it would be expected that being on the surface they might not be coated completely with polyethylene. This could cause some reduction in the leach resistance of the final product, although no leach tests had been run or are planned at this time to confirm this.

The processing rate of the pilot plant extruder was 10 to $100 \mathrm{lb} / \mathrm{min}$. (waste and solidification agent mixture). This is the same size unit proposed for use with the $100 \mathrm{ft}^{3}$ ribbon blender. 
The processor is a heavy duty unit which Readco has manufactured for many years and found to be a low maintenance item. After the demonstration run, the top of the processor was removed to inspect the two screws. No polyethylene or waste material was found on the screws themselves or on the walls of the extruder. 
Readco Ribbon Blender

Radwaste Volume Reduction System Questionnaire

1. Brief description of system (please attach layout dwgs. \& P\&ID, if available).

The Teledyne Readco system recelves all liquid \& slurry wastes from a

power plant. The waste is purped into evaporator blender where the waste

is dried into a powder. The dry radwaste is stored in a hopper then fed

to the continuous mixer thru a screw conveyor. In the continuous mixer,

the dry radwaste is mixed with a solidification agent and is discharged

into a disposable container.

2. Feedstock Description:
a) Feedstock Designation
b) Type of Waste
c) Volume per yr. (gal.)
d) Total solids conc. (ppm)
e) Suspended solids (ppm)
f) Conductivity (umho/ cm)
g) $\mathrm{pH}$ :

i) Before adjustment

i1) After adjustment

h) Specific gravity

i) Temperature $\left({ }^{\circ}\right)$

$\frac{\mathrm{A}}{\begin{array}{c}\text { Sodium } \\ \text { sulfate }\end{array}}$

B

Boric acid

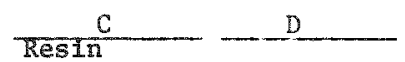

130,000

$2.5 \times 10^{5}$

$2.5 \times 10^{5}$

$\frac{135,000}{1.3 \times 10^{5}} \frac{1.3 \times 10^{5}}{1}$

Slurry

20,000

$5.0 \times 10^{5}$

$2.5 \times 10^{5}$
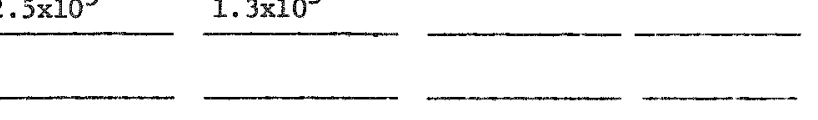

10.7

2.5

10.7

$\overline{76.5 / 1 b / c u . f t^{3} 641 \mathrm{~b} / \mathrm{cu} . \mathrm{ft}} \mathrm{3}^{3} \overline{53 \mathrm{1b} / \mathrm{cu} . \mathrm{ft} \text {. }^{3}}$

14070

j) Slurry wastes:

i) Solids conc. (vol. \%)

ii) Interstitial Water (vol. \%)

iii) Free water above settled sludge (vol.\%) 
k) Radionuclide content by major isotopes ( $\mu \mathrm{Ci} / \mathrm{ml})$ :

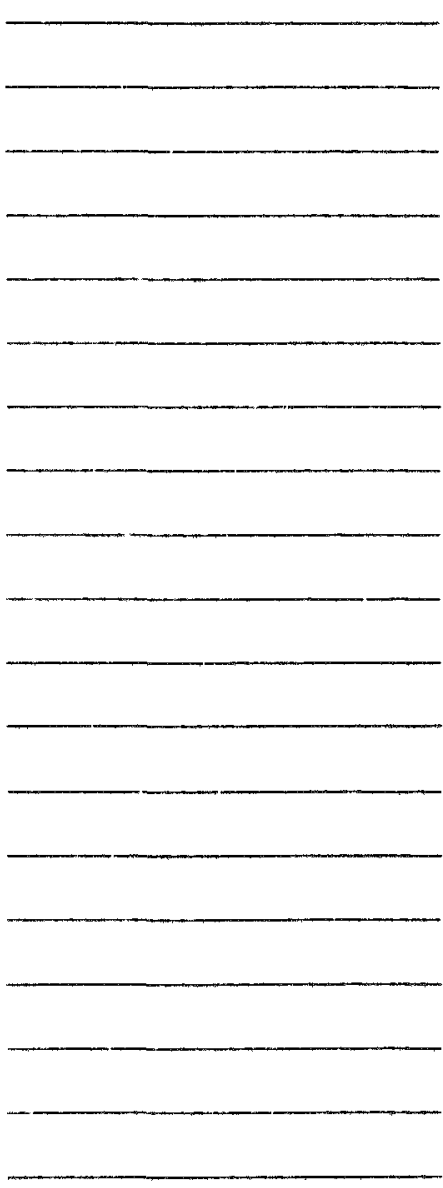

$-2-$
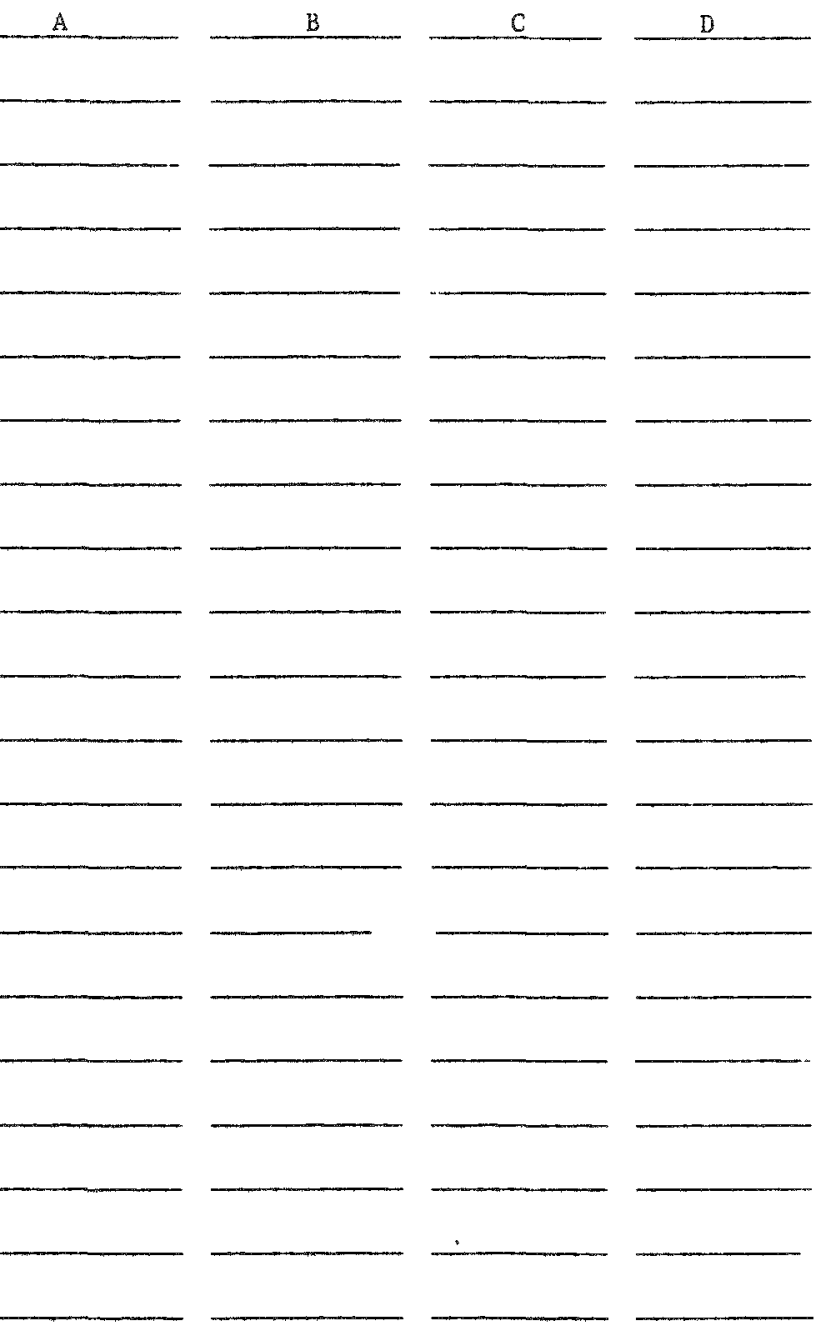

3. Auxiliaries (give pressure, temperature, flow rates, etc.):
a) Steam -
b) Cooling water -
c) Service air -
d) Electric -
e) other

100 psig $330^{\circ} \mathrm{F}$

$150 \mathrm{lb} / \mathrm{min} .50^{\circ} \mathrm{F}$

$150 \mathrm{kw}$ 
4. Operating Data:

a) Feed rate $(\mathrm{gpm})$

1.25

b) Bottoms conc. (wt. \%)

$100 \%$

c) Volume reduction factor (vol. feed/vol. botcons)

$\frac{1.25}{100 \%}$

d) Decontamination Factors (feed to distillate):

i) overall

ii) major isotopes:

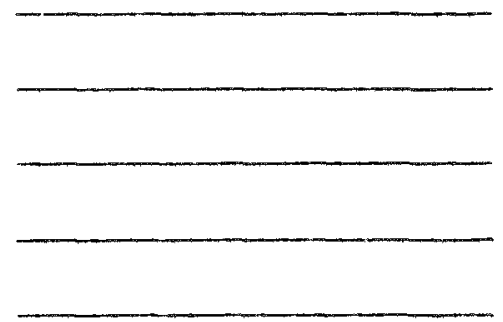

e) Curie content of bottons $(\mu \mathrm{Ci} / \mathrm{cc})$

f) Radiation level in bottoms (mr/hr):

i) Surface of container -

ii) One foot from container - 
5. Operating History:

a) Date unit installation completed -

b) Date unit first operated (with radioactive waste) -

d) Total number of operating hours -

6. Cost Factors:

a) Initial equipment cost -

b) Installation cost

c) Building costs

d) Operating costs ( $\$ / g a 1$. of waste feed)

i) Personnel

ii) Auxiliaries

iii) Solidification Agent (if integral part of VR system)

iv) Total 
7. Describe any major operating difficulties experienced with the VR system and what measures were taken to correct them.

We had a problem with boric acid solutions foaming. This was solved by adding enough of the right kind of anti-foaming agent.

Trying to neutralize the waste pH before drying created a few problems. The neutralizers decreased the evaporation rate and made the scale inside the evaporation blender much harder.

Now we neutralize the waste after it has been dried and it has to be neutralized only when cement is used to solidify the waste. 
$A-63$

$-6-$

8. List all forced outages, including cause of outage (general maintenance, pump failure, etc.) and duration. 


\section{BLENDER EVAPORATOR}

General Construction

The Blender-Evaporator is a cylincicical vessel equipped with a close-fitting agicator which is rotated by means of an electric motor. The cylindrical portion of the vessel is equipped with a heating jacket. All necessary inlets and outlets and connections for various instru ientation are supplied with this vessel. The unit is rree-standing. It is used for evaporating the liquid radioactive waste to a free-flowing, essentially dry state.

\section{Materials of Construction}

Materials of construction for all parts of the BlenderEvaporator, which could come in contact with the radioactive waste, are constructed of Inconel 625. This material is used to allow the processing of ary conceivable waste generated in a nuclear power statjon. The external jacket of the unit is constructed of flange quality steel conforming to all spocifications of tre ASME Code for Unfired Pressure Vessels. Supports, stiffening rings, ctc., are constructed of comon structural steel shapes. All wold metal used in the construction of the unit is certified wold metal material compatible with the joints to be made, all strictly in accordance with ASME Code for Unfired Pressure Vessels.

\section{Size}

Internal dimensions of the unit are $42 "$ in diameter by 120 "long. Total overall length is 150". Overall width is $48^{\prime \prime}$. Height is 60". These dimensions do not include the electric drive motor and gear reducer as these components are located outside the urocessing area. Total capacity of the vessel is approximately $750 \mathrm{U}$. S. gallons.

\section{Vessel Construction}

The vessel is a cylindrical vessel comprising approximately $270^{\circ}$ of arc on the cylindrical section with straight sections above the cylindrical section. The uirt is constructed with one end completely welded in place. The opposite end is a flanged and bolted connection in order to allow insertion and removal, if necessary, of the agitator. The bolted joint is gasketed; and during lhe assembly phase, the bolted 
BLENDER EVAPORATOR

Vessel Construction (Continued)

joint is sealed by means of a 1/4" fillst weld on the interior of the vessel to preclude leakage through the gasketed joint.

All the curved surfaces of the vessel are covered with a jacket for the use of 100 Psig steam. The entire jacket is designed, constructed, tested and certified in accordance with the ASME Code for Unfired Pressure Vessels, Section VIII. All welding on any part of the vessel is in accordance with the ASME Pressure vessel Code, Section IX.

Top of the vessel is fitted with a gasketed cover which is bolted in place. Cover is equipped with various ports for the removal of steam, insertion of monitoring instruments for control of the system, introduction of the feed of material to the vessel, and also introduction of chemical treatment and other necessary additives to the system.

The interior of the vessel, both the curved surfaces, and end surfaces, are completely machined to insure closefitting assembly with the agitator.

\section{Agitator}

The agitator for the Blender-Evaporator is a rwodified fabricated heavy duty Sigma arm. This unit is machined on its outside diameter and on the enus to insure a close fit with the machined section of the Blender-Evaporator vessel. This agitator is mounted in anti-friction type bearings, which are outboard of the mixing chamber. The unit is designed to wipe the walls of the vessel to insure maximum heat transfer at all stages of evaporation. It is further designed to promote complete discharge of the dried material by forwarding it to the center of the vessel where the discharge valve is located.

\section{Seals}

The vessel is equipped with packing glands and stuffing boxes where the agitator shaft enters tho mixing vessel. These glands are equipped with lantern rings for the introduction of flushing water for cleaning the packing chamber.

\section{Discharge}

Discharge of the dried material is by means of a

4" diameter ball-type valve installed on the vessel body

in such a fashion that the dead space between the agitator

Exhibit 10 (Cont'd.) 
BLENDFR EVAPORATOR

Discharge (Continued)

and the valve is kept to an absolute minimum. There is an additional 2" diameter ball valve installed in the bottom of the vessel for use when de-contaminating the vessel. This unit wild be lischarging slurry or solution of decontamination material. Both valves are remote operating type valves.

\section{Drive}

The drive arrangement for this Blender-Evaporator consists of an electric drive motor of 40 horsepower, 1750 RPM, which is airect coupled to a helical gear reducer by mears of a fluid type coupling. The gear reducer is, in turn, coupled to a jack shaft which extends throuyh a barrier wall; and is, in turn, coupled to the agitator shaft. Couplings used in this jack shaft are flexible-type couplings to allow for slight misalignrent. This type of drive arrangement ailows for the motor and gear reducer to be installed outside of the operating area so that any required mantenance can be performed without any exposure to personnel. The drive provides an agitator speed of 25 RPM. Currert characteristic.; of the drive motor are suitable for installation in the particular operating plant.

\section{Decontamination system}

A series of sprays are installed at the top of the Blender-Evaporator vessel for decontamination purposes. These sprays would be used should maintenance be required on the unit, to remove the scale buildup on the operating surfaces of the unit and reduce the radiation exposure to the maintenance wolkers. This spray assembly rotates in order to contact 311 parts of the Blender.

The decontamination system is used only if maintenance is required. It is not necessary to decontaminate between batches, as all scale forned during a drying cycie is rumoved when the next batch is purped into the mixer. 
RADIOACTIVE WASTE FEED PUMI

A radwaste feed pump is provided with the system to take a suction on the plant radioactive waste storage tanks, and to pump the material from the storago tanks to the Evaporator Blender.

This unit is a positive displacement rotary type pump constructed of 316 stainless steel for all metallic parts.

The drive for this pump is arranged to be installed outside the opcrating area to provide for easy access for any maintenance that is required on the drive arrangement. This pump is capable of handing solutions and slurries of any type radioactive waste that might be found in a nuclear power station.

\section{CHEMICAL ADDITIVE SYSTEM}

\section{General}

Chemical Additive system consists of a storace tank for chemical additives, and a positive displacement pump to take a suction from the chemical storaye tanx, and. pump the material to the Evaporator-Elencier.

Some wastes require $\mathrm{pH}$ adjustment, and this would be accomplished by means of a Chemical Additive System, using either sodium hydroxide or calcium hydroxide slurries for the $\mathrm{pH}$ adjustment.

The tank, and all associated piping and pump, to be constructed of stainless steel. Type 304 . Fil welding of the pipe and the tank would be done in accordance with the ASME Unfired Code for Pressure Vessels. The tank will be equipped with a top entering type agitator for preparing the necessary solutions and/or slurries required for the chemical adjustment of the waste prior to evaporation. This Chemical Additive system would be located outsilie a radioactive area.

\section{ADDITIVE ADDITION SYSTEM}

An Additive Addition System is provided similar to the shemical Additive system, although this system would be considerably smaller in both the tank size and the feed pump size. 


\section{ADDITIVE ADDITION SYSTEM (Continuas)}

This unit would be used for addrig antz-foam agents, if necessary, prior to the evaporation in the Evaporator Blender. The tank and the piping would all be constructed of 304 stainless steel, and all weling would be in accordance with the ASME Code for unfired Pressure Vessels, Section IX. This tank would also bu eruipped with a top entering type mixer for preparing the anti-foan solutions.

\section{FLUSHING SYSTEM}

A Flushing system is provided for the entire system, Which consists of a foed pump which takes suction from plant water and provides pressure zo all sections of the system, which could conceivably contain radioactive waste at any point.

This system is constructed completely of 304 stainless steel piping. The pump is constructid of 304 stainless steel. Piping provides for the delivery of this flush water to the spray manifold of the Evaporator Blender. the packing glards of both the blender and the continuous mixer. (If cement or urea formaldehyde is the solidification agent of choice). It is aiso used for flushing the de-mister and all applicable waste lines ind pumps.

\section{DE-MISTER}

A de-mister is provided to decontaminate the stean produced from the Blender-Evaporator. This unit is over-sized to provide a de-contamination factor o $10,000: 1$ for the steam on its way to the condenser.

This de-mister consists of a tank, which is itited with various sizes of fine wire mesh which collects the droplets in the steam and returns them to the Evaporitor-Blender.

This unit is located in a separate oporating area so that maintenance can be performed on $j t$ after decontamination by using the flushing system without orterirg the operating area of the Evaporator ilorder.

\section{Materials of Construction}

Unit is constructed of 316 stainiess steel. Mll welding of the unit is done in accordance vith AS:1E Code ior Unfire.? Pressure Vessels, Section IX. 


\section{DEMISTER}

Materials of Construction (Continued)

A spray system is provided at the top and the bottom of the de-mister section. Provisions are made in the design of the de-mister vessel to allow easy removal of the de-mister stection should it becone defective.

\section{CONDENSER}

A Condenser is provided for condensirg the steam evolving from the Blender-Evaporator. This Condenser is a shell and tube type condenser with water inside the tubes and the vapor on the outside of the tubes. The unit is oversized to insure positive condensation of all vapor generated from the unit. The unit is sized to provide condensing capacity for 150: of the maximum steam evolution rate in the blender.

All material of construction of the Condenser is 304 stainless steel.

Entire unit is built in accordance with FS:E code for Unfired Pressure Vessels, Section VIII.

\section{CONDENSATE TANK}

A 500 gallon tank is provided for collection of the condensate from the Blender-Evaporator. This tank is constructed of 304 stainless steel in accordance with ASME Code for Unfired Pressure Vessels, Section VIII and IX.

The unit is fitted with all necessary openirus for providing the instrumentation necessary for measuring the amount of condensate received, the electrical conductivity thereof, and the radioactivity thereof, etc.

A condensate pump is provided from this tank to transport the finished condensate to whatever destination is applicable in accordance with the operation instructions of the unit.

\section{DRY RADWASTE HOPPER SYSTEM}

The Dry Radwaste Hopper system consists of a receiving ropper to receive the dried radioactive waste from the Evaporator-Blender, to store the material until solidification through the Continuous Solidification 111 xex system, and to provide for accurate feeding of this waste at a continuous controlled rate to the Continuous Solidification Mixer system.

Exhibit 10 (Cont'd.) 
DRY RADWASTE HOPPER SYSTEM (COntinue.)

General

The Dry Radwaste Hopper consists of a cylindrical cone bottom hopper, situated directly bentath the aischarce valve of the Evaporator-Blender, and connected thereto by means of dust-tight connections.

This unit is constructed of 304 stainloss stoel for all contact parts, and all welaing is done in accordance with ASME Code for Unfired Pressure Vessels, Section IX.

The cone bottom is a steup angle to prevent any possibility of bridging of this material.

The actual sizing of this hopper will depend upon the operating parameters of the solidification system. However. a minimum size would he approximatel: 50 cubic feet. Additional storage capacity can be provided.

Suitable connection poirts are installed on the hopper for instrumentation to provide for level stucing duvices.

\section{FEED CONVEYOR}

Feed conveyor is situated at the bottom outlet of the cone section of the Radwaste Hopper. This is also constructed of 304 stainless steel for ali contact parts.

This conveyor consists of a screw type conveyor for providing movement of the dried waste from the Radwaste Hopper to the Solidification Mixe. at a controlled rate.

Entire system is completely enclosed to prevent the leakage of dust at any point.

The screw shaft is provided with packing glands and stuffing boxes where they enter and leave the screw conveyor section. Flanged connections are provided between the Hopper and the Fecd Conveyor, and also between the Continuous solidification Mizer and thes outlot of the Feed Conveyor.

The drive for the Feed Conveyor is provided by means of a variable speed D.C. drive located on the other sida of a barrier wall so that maintonancs can be performed without exposure of personnel. 
General

The Continuous Mixer is used for mixing the dried waste with a suitable solidification agent just prior to packaging. The unit consists of a twin shaft, co-rotating, self-cleaning continuous-type mixer capable of mixing the dried waste with any conceivable form of solidification ayent.

\section{Materials of Construction}

Materials of construction for all contact parts of the Continuous Mixer is 316 stainless steel. The unit is jacketed for the circulation of temperatura controlling media so that the versatility of the use of any solidification agent is maintained. This jacket is constructed of flange quality steel in accordance with ASME for Unfired Pressure Vessels. Supports, stiffening rings, etc., are constructed of common structural steel shapes. All weld netal used in the construction of the unit is certified weld metal material compatible with the joints to be made, all strictly in accordance with ASIIE code for Unfired Pressure Vessels.

Size

The unit has twin co-rotating $5^{\prime \prime}$ diameter rotors, each of which are 36" long inside the mixing chamber. Overall dimensions are 8 feet long, 2 feet wide and 2 feet high.

\section{Vessel Construction}

The vessel is constructed in 3 pieces; a top half of the barrel, bottom half of the barrel, and two end plates. These units are bolted together with o-ring seals at all joints to preclude any leakage of the radioactive material.

The unit is equipped with inlet ports for ary waste and the solidification agent. In the case of cement being used for the solidification agent, the cement and a dry waste would be acmitted through an 8-1/2" $x$ 5" opening in the top half of the barrel, and the water would be admitted through a $3 / 4 "$ connection on the bottom half of the barrel. Another $3 / 4 "$ conilection is provided for flushing operations.

$$
\text { Exhibit } 10 \text { (Cont'd.) }
$$




\section{CONTINUOUS MIXER}

Vessel Construction (Continued)

In the case of bitumen or urea formaldahyde, or other plastic materials for solidification agents, these would all be pumped in through the bottom half of the barrel at various locations necessary for currect operation of the system. The interior of the mixer is complutely machined to insure close fitting assembly with the agitator.

\section{Agitator}

Agitator consists of twin co-rotating agitators made up of a multiple number of paddles and screws. The goometry of the paddles and screws is such that the aujacent paddles wipe each other clean every revolution; thereby eliminating any dead spaces in the mixer. This provides for a very easily cleaned interior of the mixer.

\section{Seals}

The vessel is equipped with packing glands and stuffing boxes where the agitator shaft enters the mixing vessel. These glands are equipped with lantern rings for the introduction of flushing agent for cleaning the packing chamber.

\section{Discharge}

Discharge of the mixer is from the bottom, at the end opposite the feed erd, through a 4" flanged connection. Discharge arrangement is custom built to coinoct to a compatible system for filling waste containers that are used at the particular installation.

\section{Drive}

The drive arrangement for this continuous mixer consists of an electric drive notor of $7-1 / 2$ horsopower, designed to drive the mixer at 100 RPM. It is lirect coupled to a helical gear reducer by means of a flexible type coupling. The gear recucer is, in turn, coupled to a jack shaft which extends through a barrier wall, and is. in turn, coupled to the agitator shafts. 
SOLIDIFICATION AGENT SYSTEM

Gereral

The Solidification Agent Handing System will dupend upon the particular agent to be used for solidification of the dried material.

A. Urea Formaldehyde - If urea formaldohyde is used, 2 tanks are provided for proparing the urea formaldehyde solution and the catalyst solution. These tanks are provided with suitable positive displacement purups for pumping this material into the Continuous Solidification Mixer. This type equipment has been used in nuclear power plants in the past to a great extent.

B. Cement - If Portland cement is to be used for the solidification of the dried radioactive vaste. a cement hopper for receiving incoming cement will be provided with a variable speed screw conveyor to transport the materiai from the Hopper system to the inlet of the continuous Processor. This entire cement system, feeding into the continuous solidification Mixer, will be dust-tight construction. This system is adequately described in other topical roports concerning the use of cement.

C. Bitumen - If bitumen is used for the solidification agent, a heated storage tank of bitumen will be provided for receiving incoming bitumen. A positive displacement rotary fesd pump, also jacketod with associated jacketed lines, will be provided to transport the asphalt in the desired ratio to the waste into tre Continuous solidjfication Mixcr. This type of system is also adequately described in previous topical reports.

D. Other Types of Solidification Agents - Other types of solidification agents, such as other polymers. can easily be handled by this system. The type system to be installed would be similar to the urea formaldehyde system, but might consist of $x$ many as 3 separate ingredients. M.1 necessary tanks and pumps wruld be provided for this type of system in accordance with the chemical and physical material of the solidification agent jrvolved. 


\section{CONTROL PANEL}

A control panel is supplied with the system, which is arranged to provide all the necessary interlocking and redundant type controls as explaincd in the following operation of the radwaste system.

This control panel has a graphic display for case of operators understanding of the system. This giaphic display incorporates indicating lights to keep the operator informed as to the process operation scquences. It also contains all the indicating ard record.ng instruments so that the operator is fully aware of the coridtion of the system at all times. It is fluther cquipped with alarms to warn the operator of any malfunction or anticipated malfunction of any portion of the system.

Total control panel is built to NEMA 12 construction suitable for location near the actual operatirg areas. 
TELEDYNE READCO

RADWASTE VOLUME REDUCTION AND SULIDIFICATION S:STEM

\section{OPERATION}

\section{A. LOADING}

Waste from the waste storage tank is pumped into the evaporator blender by means of the waste feed pump. This pump is a positive displaccment pump which is controlled by means of timer to allow adjustment of the amount of waste charged.

An ultra-sonic level detector mounted in the top of the evaporator blender acts to override the timer controls should the level in the evaporator blender become too high. A second ultrasonic level detector set for a slightly higher level than the first will sound an alarm and cut off all power to the system should the level rise that high.

The loading cycle will not start if either of the two discharge valves on the evaporator blender are not fully closed. After the loading cycle starts. neither of the discharge valves will open until the material is fully dried.

The loading cycle also cannot operate unless the condensate receiver has been discharged and has sufficient capacity to contain all the condensate which will be produced by the new batch.

\section{B. TREATING}

After the end of the loading cycle, the $\mathrm{pH}$ is measured. If necessary, depending upon the waste to be treated, the $\mathrm{pH}$ is adjusted by means of adding caustic soda solution by means of the chemical feed pump and associated pH adjustment controls.

If necessary, depending upon the type waste, other treatments, such as anti-foam agents, are added at this time.

\section{EVAPORATING/DRYING}

After any required treatment of the waste is completed, steam is admitted to the jacket of the evaporator blender for evaporation and arying the wasto material.

Exhibit 10 (Cont'd, ) 
Page 2

\section{EVAPORATING/DRYING (Continued)}

The pressure, and hence the temperature of the steam, can be adjusted to provide any desired temperature. For most wastes, full 100 psig steam is used. In some instances, lower temperatures are used to preclude thermal degradation of the particular waste in the evaporator blender.

As the evaporation and drying proceeds, the steam generated is passed thru a denister to remove entrained material. The dry steam is condensed in the dewatering condenser. The condensate formed is then arained to the condensate receiver.

Pressures and temperatures are monitored constantly in the evaporator blender, between the demister and the condenser and in the condensate line. Evaluation, by the control system of these values, produces information regarding actual pressure in the system, temperature levels and pressure arops. The control system will shut down the steam to the evaporator blender if the pressure becomes too high in the evaporation chamber. $\pi$ high pressure drop across the demister or condenser will be indicated to the operator; and if these values exceed $a$ predetermined value, the main stean will be shut down until remedial action is taken.

The condensate level in the condensate tank is constantly monitored, and the flow of the condensate to the tank is also measured. Dryness of the waste in the evaporator blender is determined by the cessation of flow of condensate to the condensate tank. However, the discharge valve of the evaporator blender cannot be opened even at this point unless a predetermined amount of condensate has heen collected. This feature precludes the possibility of the waste being considered dry due to cessation of condensate flow which might be caused by pluggage of any line between the evaporator blender and the condenser. This situation would also be indicated by the fressure monitors mentioned earlier.

Remote viewing of the waste in the evaporator blender by means of TV cameras could also be used as a final check on the dryness.

Exhibit 10 (Cont'd.) 
Page 3

C. EVAPORATING/DRYING (Continued)

Temperature of the dry waste will increase as it comes to dryness, and this is another indication it can be dumped for final solidification processing.

The various indications of dryness are all interlocked via the control panel to preclule opening the discharge valve prior to actual completion of the arying step.

The dewatering condensate is also monitored for electrical conductivity at all times as a reans of assessing the proper operation of the total system.

The level of the condensate from the heating steam is continuously monitored and adjusted for maximum heat transfer. This condensate is ruturned to the plant condensate system.

D. DRY WASTE STORAGE

After all systems indicate the waste is dried, the main discharge valve can be opened and the waste discharged to the Dry liaste Hupper. Discharge can only be accomplished if the level indicators confirm that this Hopper can accept the full charge. The dried waste is now reajy for processing thru the solidification system. The dry waste hopper is sized to receive enough dry waste so that the solidification system can run at convenient and economically feasible intervals. This sizing depends upon the anticipated type and amounts of wastes to be processed for a given plant, with appropriate safety factors.

\section{E. SOLIDIFICATION SYSTE:A}

The Solidification system is designed to process the dried waste with any desired solidification agent. The system, with the nucussary axiljary oquipment. is compatible with all solidification ayents such as urea formaldehyde, bitumen, cement and various plastics. The waste is Fed at a desired constant rate to the continuous mixer by means of a variable speed screw conveyor. 
1. Urea Formaldehyde

If urea formaldehyde is usod, the urea formaldehyde solution is pumped into the continuous processor at the fred end, and the catalyst is pumped near the discharge end.

\section{Portland Cement}

If portland cement is used, the cement is fed by means of a variable speed screw conveyor fron storage, while water from the condensate receiver is proportioned by means of a positive aisplaconent pump.

3. Bitumen

If bitumen is usea, a jacketed positive displacement pur arrancament is used to proportion the bitumen to the continuous processor in the desires amount.

In all cases, the control system does not allow any of the feeders or pumps to operate unless the mixer is running. Further, the dry waste feeder cannot operate unless the solidification acgent is actually being fed to the mixer. The solidifrcation agent is also allowed to run for a short perlod of tirn after the waste feeder is stopped to irsure removal of all waste material from the mixer, thus purging the continuous processor.

\section{F. CLEANING}

During operation of the evaporator blender, some scale is formed in this unit. When the rext batch of material is pumped into the evaporator blender, this scale is redissolved and presents no problems. However, if access to the unit is requirld or desired, this scale should be removed. I: such a case, a spray header is available for wash lown purposes. This spray header is designed to provide complete cleaning of all parts of the cvanurator blender. The material accumulated in the craporator blendur after wash down is discharged throwgh a separate liquid clean out valve, thru steam jacketod lines, and returned to the radwaste storaje tanks to be reprocessed with the next batch of waste. 
Page 5

F. CLEANING (Continued)

All other sections of the system, which conceivably could become contaminated, are equipe d with flushing connections. This flush water can be recirculated either to the radwaste collection and evaporation system for concentrating, or sent to the radwaste storage system for subsequent reprocessing thru the evaporator blender.

G. DEWATERING CONDENSATE

Depending upon the electrical conductivity and/or radioactivity of the condensate, the system provides for:

1. Return of the condensate for reuse in the plant.

2. Polishing of the condensate thru the plant denumeralizers.

3. Use of some of the condensate for mixing with cement for solidification.

4. Return of the condensate to the radwaste collection system for concentration thru the radwaste evaporators.

5. Discharge.

H. OPTIONS

1. If the solidification media chosen is compatible with water. (such as portland Cement or urea formaldehyde) a bypass line could be installed to bring the waste directly to the continuous processor for mixing with such agent if, for some reason, the volume reduction system were inoperable. This would allow operation of a portion of the system so that waste could be processed without volume reduction in an emergency situation.

Exhibit 10 (Cont'd.) 
100 Gallons 258 Solution

(Evaporator Bottoms)........... i3.3 0.051

With Cement $1.25 / 1.0 \ldots \ldots \ldots \ldots \ldots 20.0 \ldots 20.07 \%$

V.R. + Asphalt $50 / 50 \ldots \ldots \ldots \ldots 2.30 .0039$

V.R. + Cement + Water $60 / 20 / 20 \ldots 3.6 \quad 0.014$

VOLUME REDUCTION RATIOS

Present Cement Method/V.R. + Asphait
$20 / 2 \cdot 3$
$=$
8.7

Present Cement MethoG/V.R. + Cerent

$20 / 3.6=5.6$

BORIC ACID

100 Gallons 138 Solution

(Evaporator Eottoms............ $13.3 \quad 0.118$

with Cement 1.25/1.0.......... 18.3

V.R. + Asphalt $50 / 50 \ldots \ldots \ldots \ldots \ldots$ 2.9. $2.94 \quad 0.026$

V.R. + Cement + water $50 / 25 / 25 \ldots 2.06 \quad 0.018$

VOLUME REDUCTIO: RATIOS

Present Cement Method/V.R. + Aschalt

$13.3 / 2.94=6.2$

Present Cement Bethod/V.R. + Cemont

$18.3 / 2.05=8.9$

RESI:YS

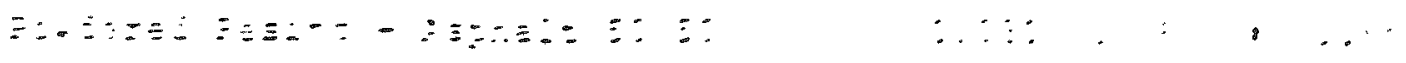

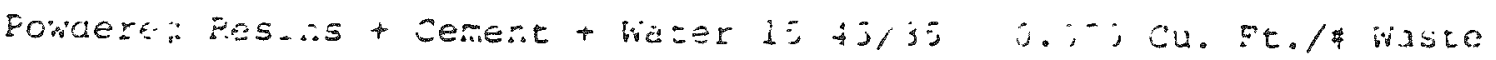

Exhibit 11 


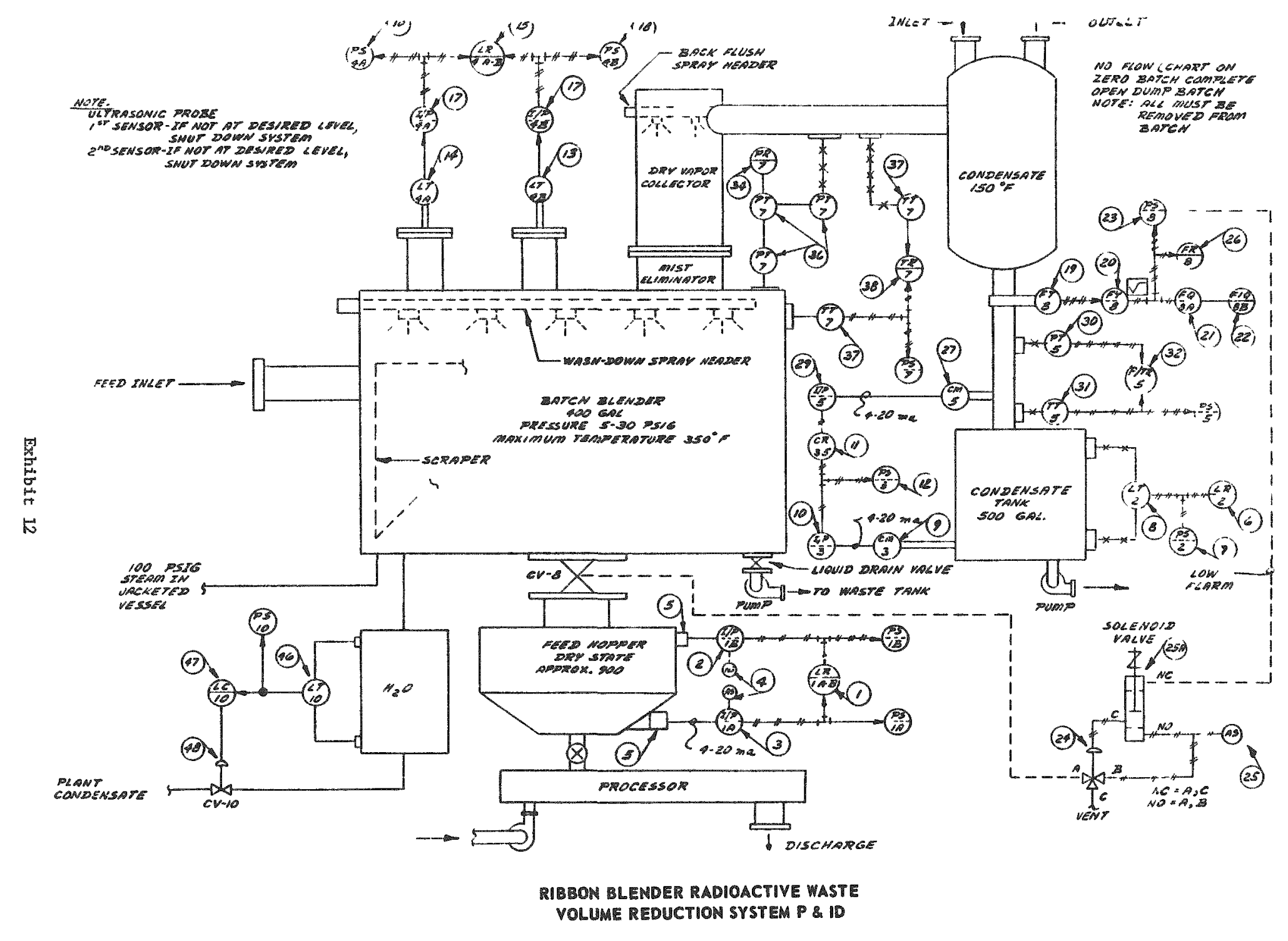


1

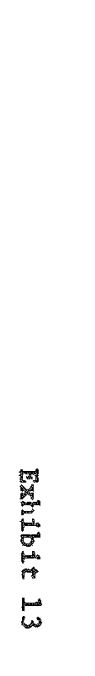

依

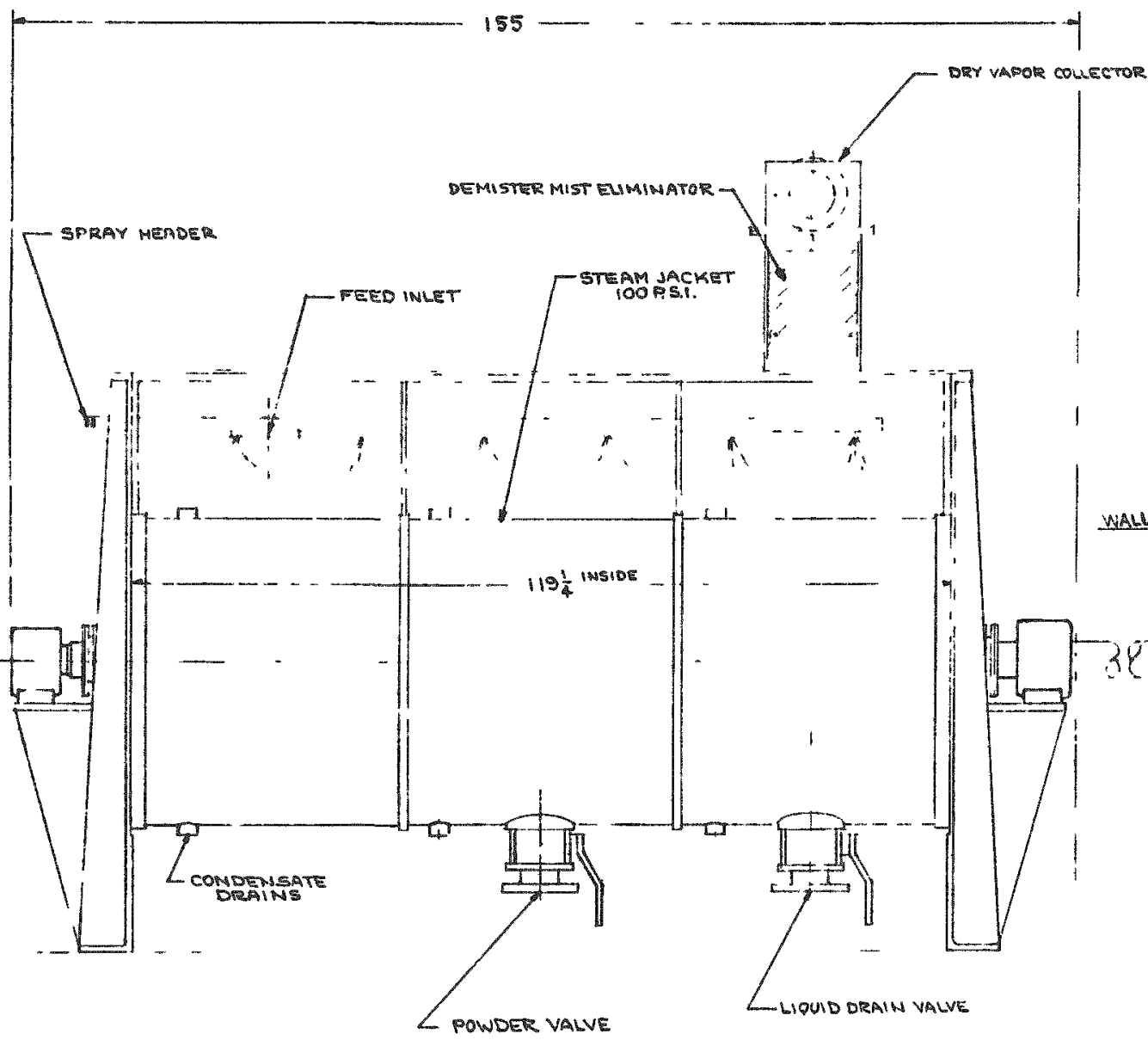

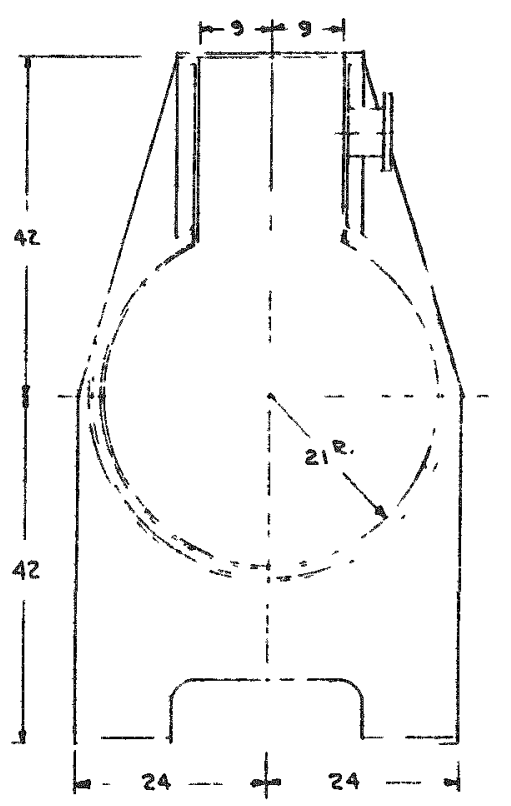

$100 \mathrm{CU} . F T$. RIBBON BLENDER 
TRIP REPORT NO. 5

ORNL RADWASTE VOLUME REDUCTION STUDY

GENERAL ELECTRIC/UNITED TECHNOLOGIES, SAN JOSE, CALIF./MR. T. GREEN

SEPTEMBER 5, 1979

A visit was made to the facilities of United Technologies in San Jose, California to gather information on the Inert Carrier Radwaste Process (ICRP) being developed jointly by General Electric and United Technologies Corporation (UTC). In their laboratory, UTC has been testing a 1/10th production scale unit of the ICRP on a pilot plant basis. The unit was not seen in operation because it was partially disassembled for several modifications being made. Cameras were not permitted at the facilities, and consequently, it was not possible to photograph the equipment.

A detailed description of the system is presented in Exhibit 14. Basically, the system consists of a tube and shell heat exchanger and simple pot type evaporator vessel connected in a closed loop with a recirculation pump. Contained within this loop is an inert carrier fluid, which, in UTC's case, is silicone oil. The oil is heated to approximately $300^{\circ} \mathrm{F}$ as it is circulated and a small stream of waste (either liquid or resin slurry) is added (at $12 \mathrm{gph}$ in the pilot unit and $120 \mathrm{gph}$ in the proposed production scale unit). At this temperature, the water contained in the waste stream is flashed off and recollected in a separate steam condenser. Trace amounts of silicone carried along with the distillate are separated from the condensed water in a simple gravity type oil/water separator and returned to the evaporator vessel. The dried salt or resin remains in the silicone oil. After a set concentration of salt or resin is reached, a small side stream of oil/salt mixture is drawn off to maintain equilibrium as more waste is added. This small side stream is pumped through an inline mixer where an epoxy resin solidification agent is added. The epoxy resin preferentially mixes with and coats the dry salt waste and this mixture is then separated from the silicone oil in another simple gravity type separator. The oil is returned from the separator to the evaporator and the waste/epoxy mixture is pumped into a drum. As this mixture is being pumped, a hardener for the epoxy is added through an inline static mixer. The end product fills the drum at a rate of $20 \mathrm{gph}$. 
The ICRP is not a new process. It has been used extensively in the liquid rocket propellent industry to separate highly explosive chemicals safely. It. is also used in the explosive industry for handling chemicals such as nitroglycerin.

Carryover of silicone with the distillate has been measured at less than 0.1 percent. About $3 \mathrm{ppb}$ of silicone is expected to be dissolved in the distillate and another $50 \mathrm{ppm}$ will be suspended. At present, it is felt that this amount will not be of concern in the distillate discharge. If it were, a dynamic type separator could be used to easily remove most of this (at present, only a static, gravity-type separator is proposed). In tests with sodium sulfate solutions, no traces of $\mathrm{Na}_{2} \mathrm{SO}_{4}$ were found in the distillate.

A total of 56 different types of waste have been successfully tested in the pilot plant, including laundry waste, sodium sulfate, resin slurries, oily waste and many different laboratory chemical wastes. For detergent wastes, the silicone acts as an excellent defoaming agent (silicone is often used in commercial defoaming agents).

The epoxy used has been an excellent solidification agent. Samples of a very hard block of sodium sulfate and resin bead solidified in this epoxy are available. The epoxy used is a commercial grade, non-copolymer type available from many companies. UTC has been using Shell 828 to 1004 Series epoxy resins in their test program at a cost of about $\$ .80$ to $\$ 1.00$ per pound. The epoxy is solid at room temperature and is fed into the silicone/waste stream through a heated screw extruder. Epoxies that are liquid at room temperature could also be used. A catalyst is not needed for this epoxy, only a hardener. The hardener must also be heated slightly above room temperature to become a pumpable liquid. After the hardener is added, the product takes 3 hours to set.

If desired, the process can be run without injecting a solidification agent, resulting in a dry salt or resin as the end product. 
The radiation resistance of the Shell series of epoxy resins is in the range of $10^{8} \mathrm{R}$, which is more than adequate for most commercial power plant wastes. Leach tests run on the end product have shown that the leach rate is less than 1 percent of that of cement.

For some waste types, the volume after solidification is actually less than dewatered feed waste before solidification in the epoxy. In one case, a sample of powdered resin occupied a volume of $75 \mathrm{cc}$ before and $50 \mathrm{cc}$ after solidification. The reduction in this case is due to shrinkage of the resin and filling of air void space with epoxy.

To prevent waste salt or epoxy from sticking to any parts of the system, the entire internal surface of the piping system, heat exchangers and evaporator are coated with Teflon. At the radiation levels expected, UTC does not feel there will be a problem with using this material. A pipe fitting removed from the system after many hours of operation showed no signs of material buildup on the walls. All metal parts will be constructed of 316 stainless steel.

Present plans call for the full scale system to be marketed in shop fabricated modules with space for shielding between active and non-active components, as well as between radioactive and non-radioactive components. GE/UTC expects to be able to provide a full scale system by $1980-81$. 


\section{INERT CARRIER RADWASTE PROCESS}

For The Volume Reduction and

Solidification of Radioactive Waste

System Description, Development Status

and Basic Economics

May 1979

by

\section{CHEMICAL SYSTEMS DIVISION NU!"}

Exhibit 14 


\section{SUMMARY}

In cooperation with the General Electric Company (GE), the Chemical Systems Division (CSD) of United Technologies Corportion has developed and demonstrated the operational feasibility of a process to reduce the volume and solidify low level radioactive wastes. This Inert Carrier Radwaste Process (ICRP) evaporates all of the water (or other low temperature volatiles) in the waste by mixing a small stream of cold waste into a large stream of hot inert fluid under highly turbulent flow. The water flash evaporates, is recovered as condensate, and returned to the system or discharged. The dried residue is coated in suspension with a small quantity of high-melting epoxy resin and separated as a castable solid for disposal. The product cures to form a rock-like, nonflammable solid that is highly resistant to leaching and mechanical failure.

The final volume of the solidified ICRP product from boiling water reactor (BWR) waste, which is typically 20 to $25 \%$ sodium sulfate, is approximately $1 / 10$ th of the volume produced by solidifying the same waste in cement. Similarly, the ICRP product from pressurized water reactor (PWR) waste, which is typically $12 \%$ boric acid, is approximately $1 / 14$ th the volume of the waste solidified with cement. The amount of resin used is only enough required to provide a thin coating over the dry particles and fill the voids to produce a castable product.

Development of the ICRP is being investigated on a pilot plant basis of approxmately 1/10th production scale or at liquid feed rates of 0.1 to 0.2 gpm. Design and cost data are under development for full-scale plant construction with capacities of 60 to $120 \mathrm{gph}$ of liquid or 250 to $500 \mathrm{lb} / \mathrm{hr}$ of solid wastes. The best available data indicates that of these two plants will cost in the order of $\$ 1$ to 2 million. Either plant can be constructed in skid-mounted modules occupying a space of no more than 8 by 8 by $24 \mathrm{ft}$. Full-scale and firm costs are expected to be available in the next 6 to 9 months. 
It should be noted that the ICRP is fully covered by U.S. patent $4,119,560$. Patents are pending in Europe, and most industrialized countries.

\section{BASIC SYSTEM OPERATION}

The basic operation of the ICRP is shown by the simplified schematic diagram in figure 1. The mass balance and flow rate numbers shown pertain to a typical $120 \mathrm{gph}$ plant. The aqueous wastes (which may contain dissolved salts, suspended resins, and other BWR or PWR residues) are neutralized (if necessary) then evaporated by feeding the wastes into the scale-free evaporator where they are mixed with a very large volume of hot inert carrier. The carrier used for this operation is a liquid silicone that is neither a solvent for nor reactive with any of the materials in the waste. The carrier is heated to a nominal $300^{\circ} \mathrm{F}$ by continuous circulation through the heat exchangers and maintained at a state of high turbulence by the high flow rate and injection process into the evaporator.

The water in the waste is flashed off instantaneously whe: the relatively small feed stream ( $120 \mathrm{gph}$ ) is mixed into the large amount of tubulent hot carrier ( 400 to $500 \mathrm{gal}$ recirculating at $15,000 \mathrm{gph}$ ). The dry slats and other solids in the residue remain as a suspension of fine particles in the silicone. Material balance is maintained by withdrawing a side stream of the suspension so the solids can go through the jet mixer at the same rate as in the entry feed.

The waste is solidified by adding a resin to the side stream of dry suspension as it is passed through a jet mixer. The resin-solids matrix is then sent to a separation column where it falls to the bottom as a separate phase. This phase is withdrawn from the separator and a hardener is added as the stream is passed through a static mixer just before it enters the disposal container. Feed to the drum or cask is regulated by the Moyno pump downstream from the separator. The pump is shut off when a container has been filled and restarted when a new empty container is in place. The separator tolerates a large surge volume of the resin-coated waste product and permits it to accumulate when the time the feed pump is off. 


\section{INERT CARRIER RADWASTE PROCESS}

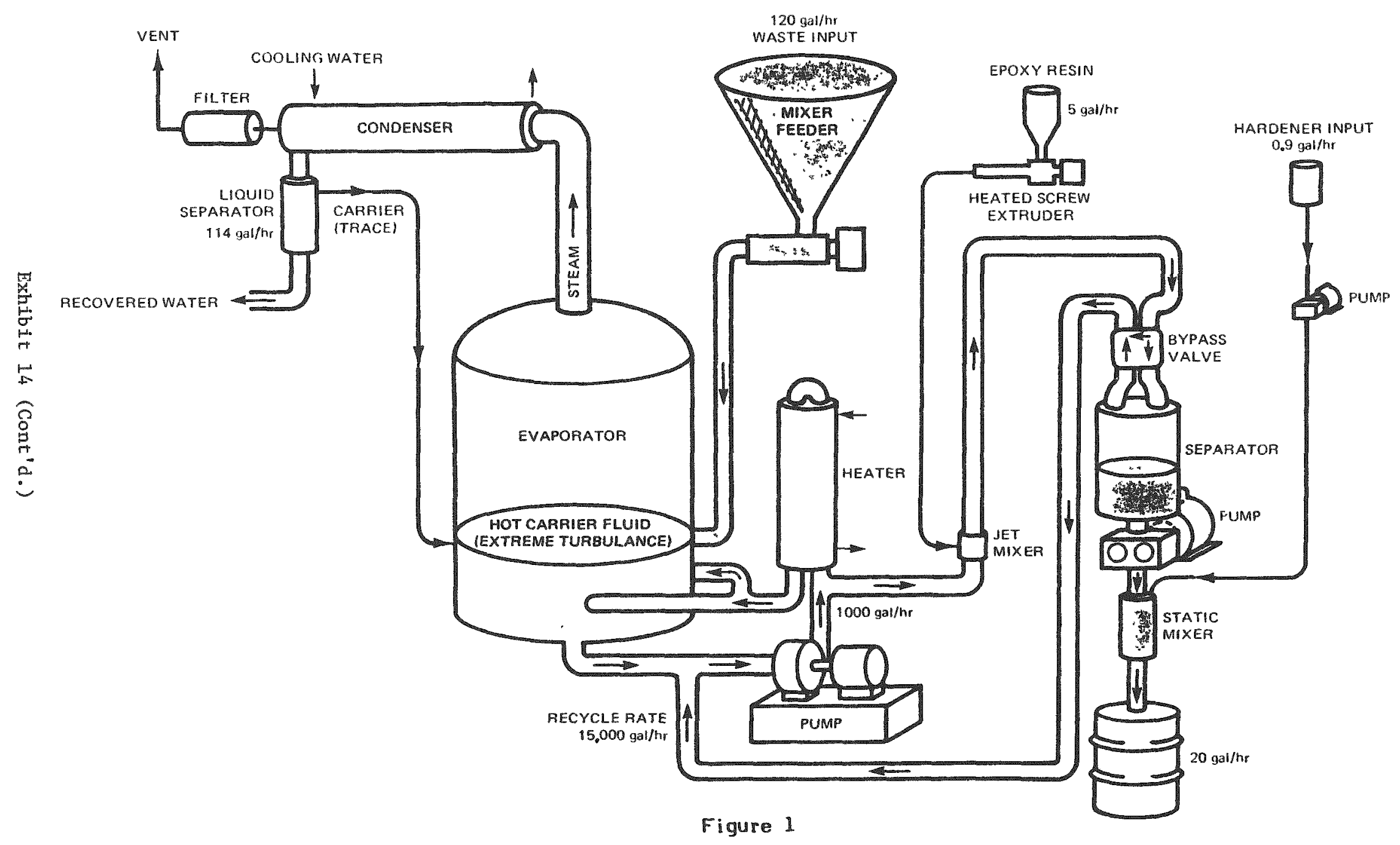


The final product cures in its container in approximately $3 \mathrm{hr}$. The cured product is a nonflammable, rock-like solid with high resistance to fracturing on impact and about $1 \%$ of the leach rate of BWR waste solidified in concrete.

The steam formed by flashing the water off the waste in the evaporator is condensed and fed to a separator. At this point the small amount of steam distilled silicone is separated and returned to the evaporator. The condensed water is either discarded or returned to the plant. If necessary, the trace of silicone oil (less than $50 \mathrm{ppm}$ ) dissolved in the water is removed by filtering through a bed of activated charcoal. Water treated in the manner described should be acceptable for return to the power plant or disposal as uncontaminated waste.

Presently, a nominal 1/10th scale ICRP pilot plant capable of processing 6 to $12 \mathrm{gph}$ of liquid waste has been demonstrated successfully. In the operation of this pilot plant, the waste slurry is fed into a 214-gal tank of a closed system containing approximately 90 gal of silicone fluid maintained at $350^{\circ} \mathrm{F}$. The six month operating experience showed the basic process to be free of operational problems. There were no problems with frothing or carryover in the evaporator, no scaling or corrosion of the heat exchangers, or deposits of epoxy resin or waste accumulated in the system. Also, the current experience with practical use of remote and automated controls shows the ICRP to be fully amenable to entirely remote operation with manual attention required only during startup and shutdown.

\section{ARCHITECTURAL AND ENGINEERING DESIGN}

The present pilot plant is being used to develop engineering data for the final design of a full-scale plant suitable for processing up to $120 \mathrm{gpm}$ of liquid waste together with up to $500 \mathrm{lb} / \mathrm{hr}$ of dry solids. The current design for the planned full scale plant shows the entire operation can be fitted into two 8 by 8 by $12 \mathrm{ft}$ pretested modules as illustrated by figure 2. 


\section{TYPICAL SKID MOUNTED ARRANGEMENT FOR A 120 GPH PLANT}

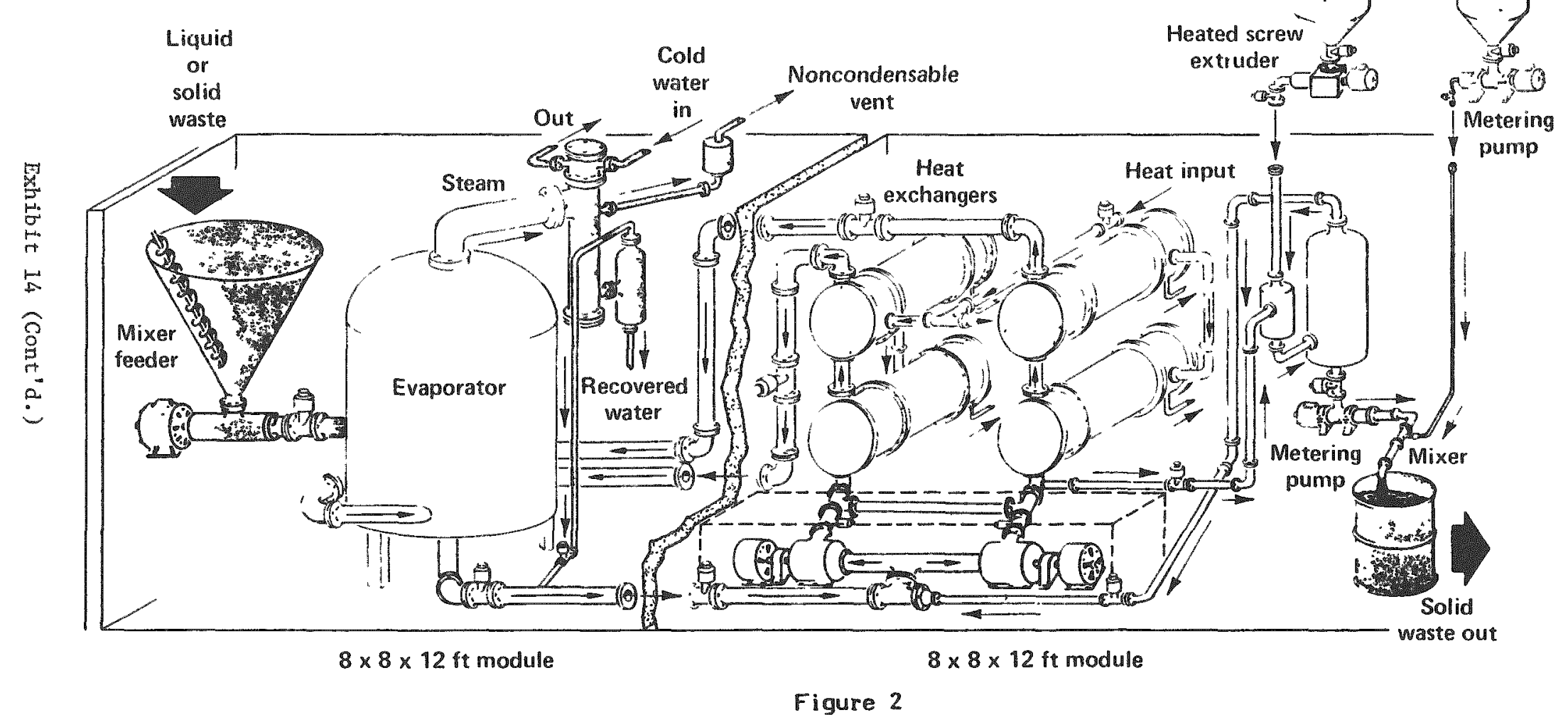


Some of the outstanding features of this design are:

- The plant is built in two readily assembled portable modules on 8 by $12 \mathrm{ft}$ (or smaller) skids

- Each module can be placed in a separate room for shielding

- Components which may require the most maintenance (e.g.g pumps) are shielded separately and arranged for ready access

- The total buiding space requirement (not considering walkways or general access spaces) is no more than 8 by 8 by $824 \mathrm{ft}$.

Inert (nonradioactive) components, such as the resin and hardener supply and the control control console, are designed to be located outside the shielded radioactive area.

The design shown in figure 2 places the two modules end to end in a straight line. In addition to this configuration, the flexibility of the system allows other arrangements of the equipment to fit specific requirements for easier access or more advantageous use of available space. In particular, the modules can be arranged on small skids, (i.e., 6 by $12 \mathrm{ft}$ ) or other configurations as required to fit access doors or available spaces for installation.

The plant is constructed entirely of type 316 stainless steel and uses commercially available valves, pumps, controls, and instrumentation shown to be reliable by extensive operating experience. The principal moving parts in the process equipment are centrifugal and metering pumps or screw feeders. The only other moving parts are the remotely controlled valves.

The overall operation is regulated by liquid level controllers in the evaporator, liquid separator for the waste water, and the separator for the resin coated product. These controllers are set for high and low limits to open or close valves as required to maintain the correct operating levels. Feed rates of the incoming waste, resin, hardener, and outgoing product are controlled by Moyno pumps. All feed rates, pressures, and flow rates are Exhibit 14 (Cont'd.) 
regulated remotely as required from a central control panel. This panel is also equiped with monitoring and recording devices to provide a complete real-time picture of the overall system operation.

The ICRP is designed for operation with electric power for pumps and controls, high pressure steam or separate therminal units for the heaters, and cooling water for the steam condenser. To process $120 \mathrm{gph}$ of $12 \%$ boric acid waste (the greatest evaporator load), it is estimated that $1,840 \mathrm{lb} / \mathrm{hr}$ of 150-psi steam will be needed to provide heat for the evaporator.

Approximately $20 \mathrm{gpm}$ of water wll be required for cooling and $70 \mathrm{~kW}$ of $230.640 \mathrm{~V}$, three-phase, $60-\mathrm{Hz}$ electrical power will be needed for pump operation.

The overall design facilitates the proposed method for supplying the ICRP system, which is to:

- Build the modules to meet specific application requirement

- Assemble and operate the plant before delivery to demonstrate proper functioning in accordance with specifications

- Disassemble the plant into its portable modules and ship to the operating site

- Reassemble the plant at the power plant with a minimum of time and effort.

The equipment to be delivered is planned to include the complete piping, instrumentation, and controls for remote operation. The control console is completely wired and requires no wall mounting.

\section{SYSTEM ECONOMICS}

Analysis of the economics of radwaste processing and disposal shows that major savings result from the volume reduction effect. For example, it is projected that $100 \mathrm{ft}^{3}$ of product from the concentrator bottoms can be disposed of for about $\$ 400$ to $\$ 700$ depending on the type of waste in recurring costs while typical costs for processing by methods currently in 
use (cement or urea-formaldehyde) are in the order of $\$ 3,500$. The main factor in this difference is a reduction of over $10: 1$ in the volume of the final waste product produced by the ICRP.

Starting with $100 \mathrm{ft}^{3}$ of low level aqueous waste, the volume is increased to $150 \mathrm{ft}^{3}$ by adding cement or to $130 \mathrm{ft}^{3}$ by adding ureaformaldehyde resin for solidification. The major advantage of the ICRP is that it removes the water entirely. In addition, the fluid suspension mixing technique permits using the minimum amount of binder. As a result, instead of adding to the volume to accomplish the required solidification $100 \mathrm{ft}^{3}$ of $25 \%$ sodium sulfate is reduced to approximately $15 \mathrm{ft}^{3}$ of final waste. Similarly $100 \mathrm{ft}^{3}$ of $12 \%$ boric acid is reduced to approximately $12 \mathrm{ft}^{3}$.

The principal driver for recurring costs is the volume of the final product which is reflected in all of the disposal costs (containers, shielding, burial, and transportation). In addition, there are costs for materials and labor which differ among the several systems. Operating labor costs, as shown in figure 3, are also expected to be more favorable for the ICRP than

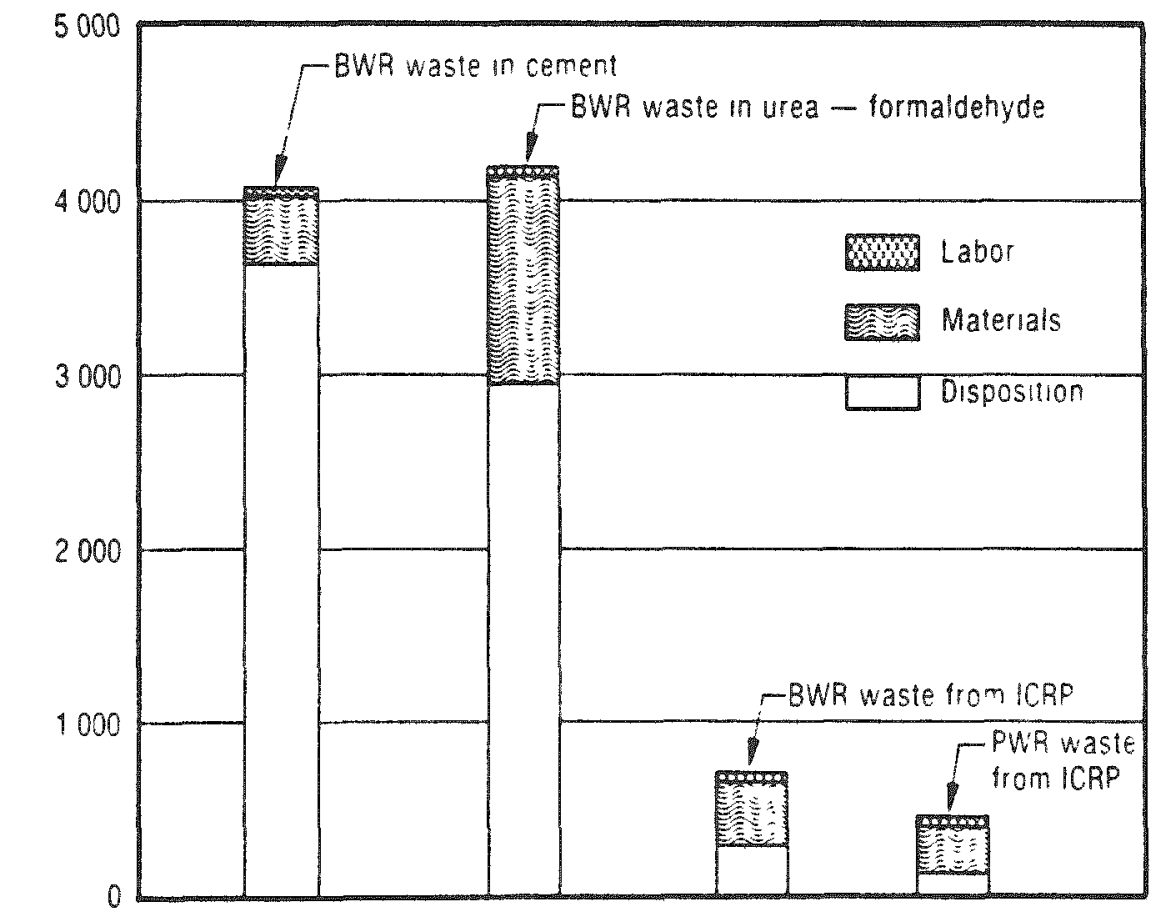

Figure 3. Relative Costs of Waste Processing by Different Methods Exhibit 14 (Cont'd.) 
nonautomated nonreduction processes. One operator can easily run the plant. However, it is assumed that two operators will be required for safety considerations and for managing the drum handling equipment. Again, however, with nominally $1 / 10$ the number of drums (or casks) the labor for this operations also should be substantially reduced. Material costs for the ICRP are somewhat higher than for the cement or urea-formaldehyde processes even with the substantially reduced volume epoxy resin presently used costs $\$ 0.85 / \mathrm{lb}$. It is expected that less pure commercial grades of this material can be obtained and will be entirely satisfactory for large volume orders eventually required. Both of these changes should result in substantial cost reductions for resin and will enhance the ICRP system cost advantage. However, no attempt has been made to show the effect of reduced resin cost in current projections.

A typical volume for cemented wastes produced by a large nuclear power plant can be assumed to be between 30,000 and $60,000 \mathrm{ft}^{3}$ per year. For a plant producing approximately $45,000 \mathrm{ft}^{3}$ of cemented wastes annual savings of $\$ 400,000$ to $\$ 600,000$ using the ICRP volume reduction and solidification process is expected depending on the composition of the waste to be processed. As transportation distances to open burial grounds increase and additional burial surcharges are imposed these cost advantages will similarly increase.

As previously noted, the ICRP will accept waste resins, sludges, and other materials, such as incinerator ash. Since most or all of the water will have normally been removed from these wastes, the economic advantage will result only from the capability to solidify the final product with a minimum quantity of polymer. Therefore, the ultimate economic advantage will depend to a large extent on the proportion of the various types of wastes generated by any particular power plant.

\section{CURRENT STATUS}

The ICRP is currently being subjected to detailed engineering design and process variable sturdies using a pilot plant with a capacity to process 6 to Exhibit 14 (Cont'd.) 
12 gph of aqueous wastes. This study is directed toward generating detailed data needed to prepare optimized designs for $60 \mathrm{gph}$ to $120 \mathrm{gph}$ production plants, determining firm costs for these plants, and developing data on the properties of the final products derived from typical power plant wastes. These pilot plant and detailed design studies are expected to be completed by the end of 1979. Later, the GE/CSD team expects to be in a position to provide ICRP units custom designed to meet waste processing capacity, space availability, and access limitations for specific power plant requirements. In the interim, until the detailed studies have been completed, inquiries are welcomed concerning requirements and specifications for future full-scale installations. 
TRIP REPORT NO. 6

ORNL RADWASTE VOLUME REDUCTION STUDY

AEROJET ENERGY CONVERSTON CO., SACRAMENTO, CALIF./DR. R. GARCIA

SEPTEMBER 6, 1979

Aerojet Energy Conversion Company's (AECC) facility in Sacramento, California was visited to witness testing of AECC's full scale, fluidized bed, dryer/incinerator system. A detailed description, flow diagrams, plant layouts, and photographs of the system are presented in Exhibits 15 through 19. The system consists of two separate fluidized bed vessels - one for processing liquid waste to a dry salt and a second for incinerating combustible material (paper, wood, contaminated oil, etc). The off-gases from both vessels are treated by a common off-gas cleanup system. A scrubber/preconcentrator in the off-gas system uses waste heat in the off-gas to preconcentrate liquid waste to about $28 \mathrm{wt}$. percent solids before it is fed to the dryer. At the same time, the waste feed is used to scrub the off-gas of particulate matter. The dry salt and incinerator ash are collected in a product hopper, which interfaces with whatever type of solidification system that is to be used. Waste to be incinerated is first processed through a three-stage shredder to produce a uniform particle size of $1 / 2$ inch diameter in the feed to the incinerator. The off-gas system for the dryer/incinerator consists of a cyclone type gas/solids separator, scrubber/preconcentrator, vapor condenser, gas heater, HEPA filters, and charcoal adsorber.

In over 500 hours of testing on simulated, nonradioactive power plant waste, the AECC combined dryer/incinerator system has worked very well, with no major problems reported. Very complete combustion is found to occur in the incinerator. Off-gas from the incinerator contains no nitrogen oxides nor $\mathrm{CO}_{2}$. The principle off-gases detected are $\mathrm{SO}_{2}$ and $\mathrm{CO}_{2}$. Most of the $\mathrm{SO}_{2}$ is removed in the off-gas cleanup system. Tests by AECC have shown that 50 percent of the $I-131$ is removed from the dryer vessel with the off-gas. Treating the off-gas for removal of this I-131 has resulted in an overall system DF of $10^{5}$ for I-131. The volume reduction (VR) factor reported for the incinerator is 70 , which is nearly twice that reported for the type of 
incinerator operated by Ontario Hydro. The higher VR factor may be due to two factors - more complete combustion and the use of waste feed that is not as severe a test of the unit's capabilities. For liquid waste, the following VR factors have been achieved:

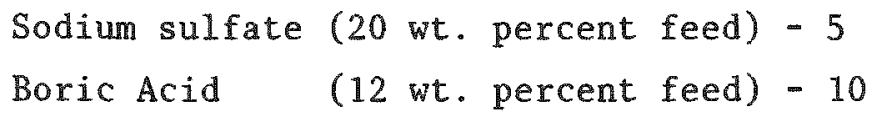

Although the AECC VR system is designed for simultaneous operation of the dryer and incinerator, either can be operated alone. When only the incinerator is operated, a secondary source of water must be used to supply the off-gas scrubber. This water can be supplied from one of the liquid radioactive waste feed tanks, if available.

The starter bed material for the dryer can be sand or the salt in the feed to the dryer. During operation, the bed for the dryer is continuously removed at a rate of about $60 \mathrm{lbs} / \mathrm{hr}$ as liquid waste is added. In the incinerator, the bed, which is inert material such as sand, remains essentially constant in volume. The waste feed to the incinerator leaves the vessel as fly ash in the off-gas. The fly ash is removed from the off-gas in the gas/solids separator at a rate of 1 to $2 \mathrm{lbs} / \mathrm{hr}$. The bed for the dryer is preheated to $850-900^{\circ} \mathrm{F}$ using electric heaters attached to the vessel walls. The bed for the incinerator is preheated to $1,000^{\circ} \mathrm{F}$ with ambient air passed through an external electric preheater. Once waste material is fed to the incinerator, the unit operates at about $1,450^{\circ} \mathrm{F}$.

Materials of construction for the dryer are:

Lower section - Inconel 625

Upper section - 347 Stainless steel

Materials of construction for the incinerator are:

She11 - 347 Stainless steel

Lining - refractory brick 
To avoid chloride stress corrosion, AECC strongly recommends that PVC containing material not be incinerated. Small amounts of chloride in the liquid waste would be removed as sodium chloride in the bed material of the dryer. The lower section of the dryer is Inconel, which should minimize any materials corrosion problems.

The shredder used to pretreat waste feed to the incinerator is a three stage comminutor/macerator type device. Small bits of metal can be handled by the shredder, but a metal detector is provided to remove any large metal objects. The shredder has three separate stages of size reduction cutters to produce a final particle size of $1 / 2$ inch diameter. If the unit should be jammed by such things as an occasional metal object that might get past the metal detector, an overload protective switch will automatically cut off power to the unit drive. The shredder can handle a wide range of materials, including paper, cardboard, rags, $4 \times 4$ wood posts, mop handles, etc. The shredder is manufactured by Disposable Waste Systems of Los Angeles. Manufacturers of similar devices are Saturn Manufacturing of Oregon and Shred-pax of Chicago.

When boric acid is the feed stock for the dryer, the pH is adjusted to 11.5 to obtain the metaborate, which has a solubility of 40 percent at $150^{\circ} \mathrm{F}$. The tetraborate has a pH of 9.5 and a significantly lower solubility at $150^{\circ} \mathrm{F}$. Small amounts of other chemicals, such as acetone, perchlorate, and phosphates, can be handled by the dryer without difficulty. Small amounts (less than 1 percent) of nitrates can be handled, but handling larger amounts would require lower operating temperatures to prevent excessive attrition of the bed.

AECC expects to replace some electric heater elements periodically. Average life of these elements is two to three years. Pump seals and bearings are standard type replacement items. Some cutters in the shredder will have to be replaced yearly. The refractory brick lining of the incinerator may need replacement every 10 to 15 years. The Iife expectancy of this lining is highly dependent on the number of thermal cycles. 


\section{FLUID BED DRYER/INCINERATOR VOLUME REDUCTION SYSTEM}

The Fluid Bed Dryer/Incinerator Volume Reduction System consists of a fluid bed dryer, a fluid bed incinerator, and an off-gas cleanup system as shown below.

Liquids from the radwaste evaporators are preconcentrated and metered to the fluid bed dryer where they are atomized with air and injected into the fluidized bed. As the liquid droplets contact the hot salt particles in the bed, the water is flashevaporated and the salt is deposited on the particles. The fluidized air is supplied by an air blower operating in a semi-closed loop. The air is electrically heated and flows upward through the dryer vessel, fluidizing the bed particles. The dry granular bed particles are discharged from the fluidized bed by the product conveyor to the product storage hopper.

The fluid bed incinerator is a separate vessel designed specifically to incinerate the dry active waste generated in the plant. The dry active wastes consisting of paper, plastic bags, plastic or rubber gloves, boots, laboratory clothing, cardboard, wood, and rags are typically collected in 55-gallon polyethylene bags. These bags containing the waste are passed through a metal detector, shredded, and stored in a dry waste hopper. The dry shredded waste is pneumatically metered into the fluid bed incinerator. The transport air, fluidizing air, and combustion air are supplied by a small separate blower. The bed material is inert and is preheated for startup only by heating the fluidizing air with an electrical preheater. The shredded waste ignites instantly upon introduction into the fluid bed incinerator.

The gas stream leaving the fluid bed dryer and the exhaust gas leaving the incinerator pass through a gas-solids separator where the fines and ash are removed from the gas stream and are discharged to the product storage hopper. The gases leaving the gas-solids separator are subjected to further cleanup in a high energy venturi scrubber. The scrub liquid, which is the input feed, is recirculated through the scrubber system, preconcentrated, and subsequently metered to the fluid bed dryer. The gas stream then passes through a condenser where the water evaporated in the system is condensed by cooling with plant water. The condensate is sent back to the existing plant water treatment system and the air returns to the blower for recompression and recycling. Gaseous effluent equivalent to the combustion air needed for the incineration process is vented from the system and passed via an absolute filter-charcoal adsorber unit to the facility off-gas system.

Dried product, after accumulation in the product storage hopper, is metered to the packaging system for immobilization. 
Aerojet

Energy Conversion

Company

\section{Fluid Bed Dryer/Incinerator Volume Reduction System}

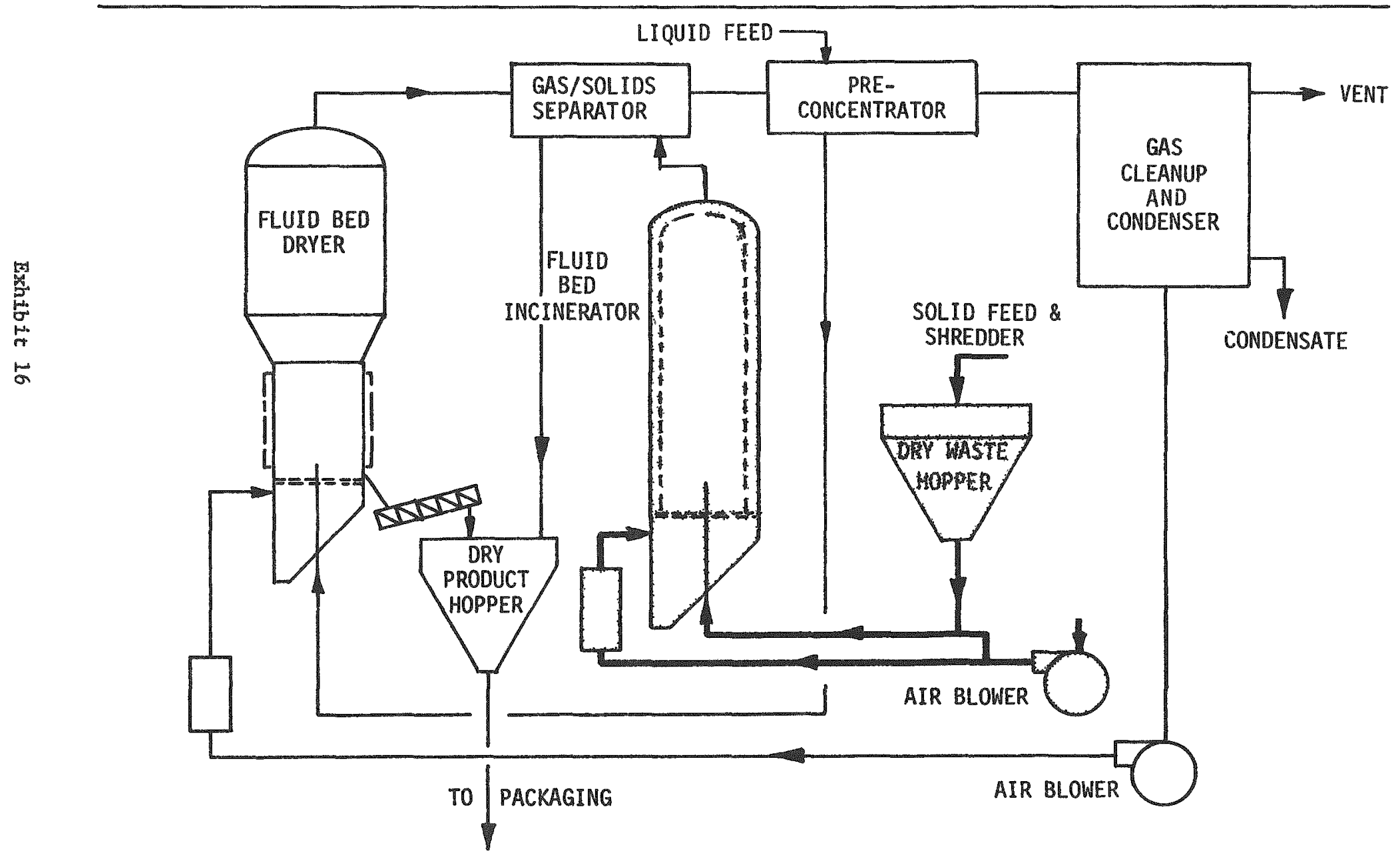




\section{Typical Layout Of Volume Reduction System}

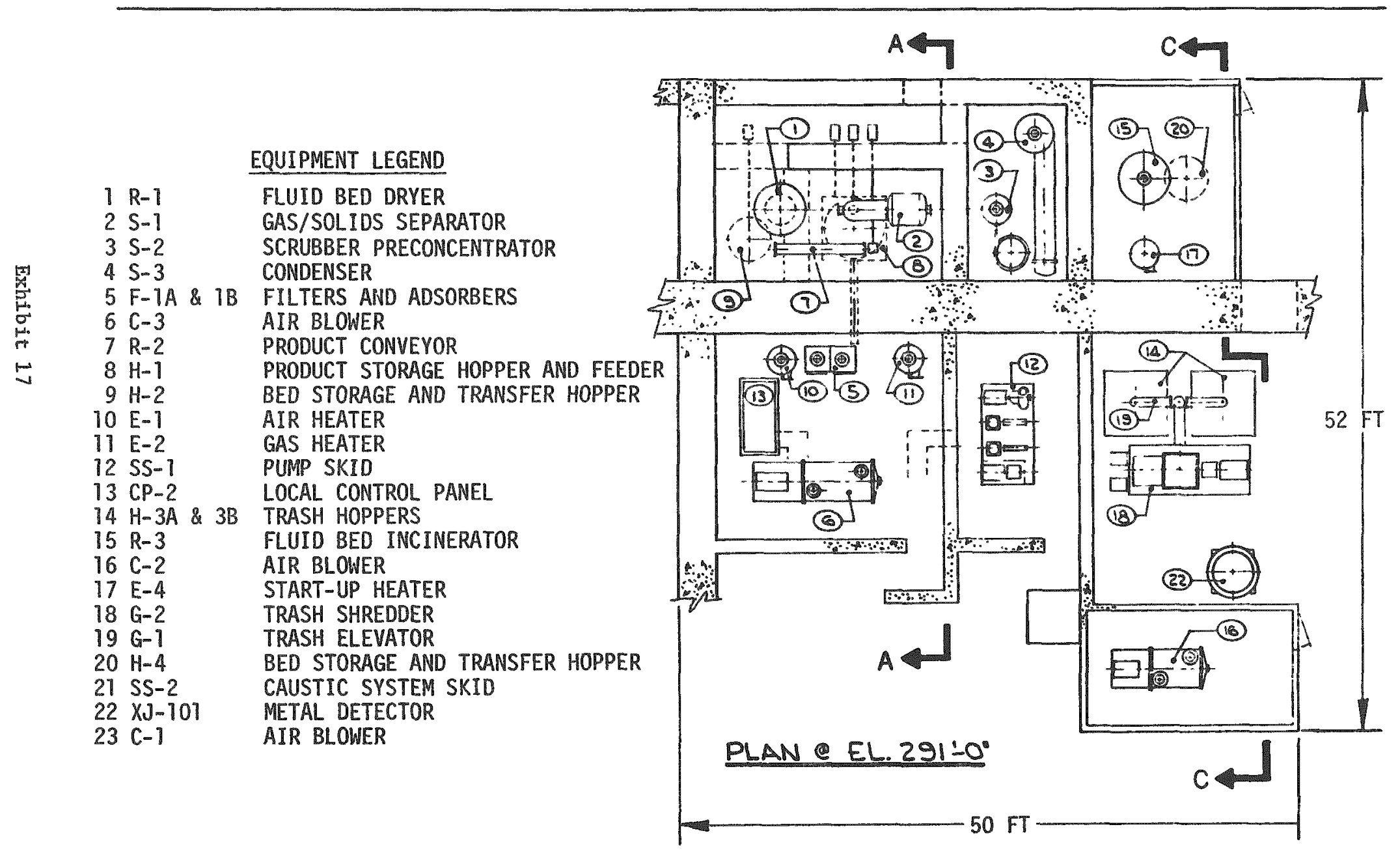


11) $\begin{aligned} & \text { Aerojet } \\ & \text { Energy Conversion } \\ & \text { Company }\end{aligned}$

\section{Typical Layout Of Volume Reduction System}

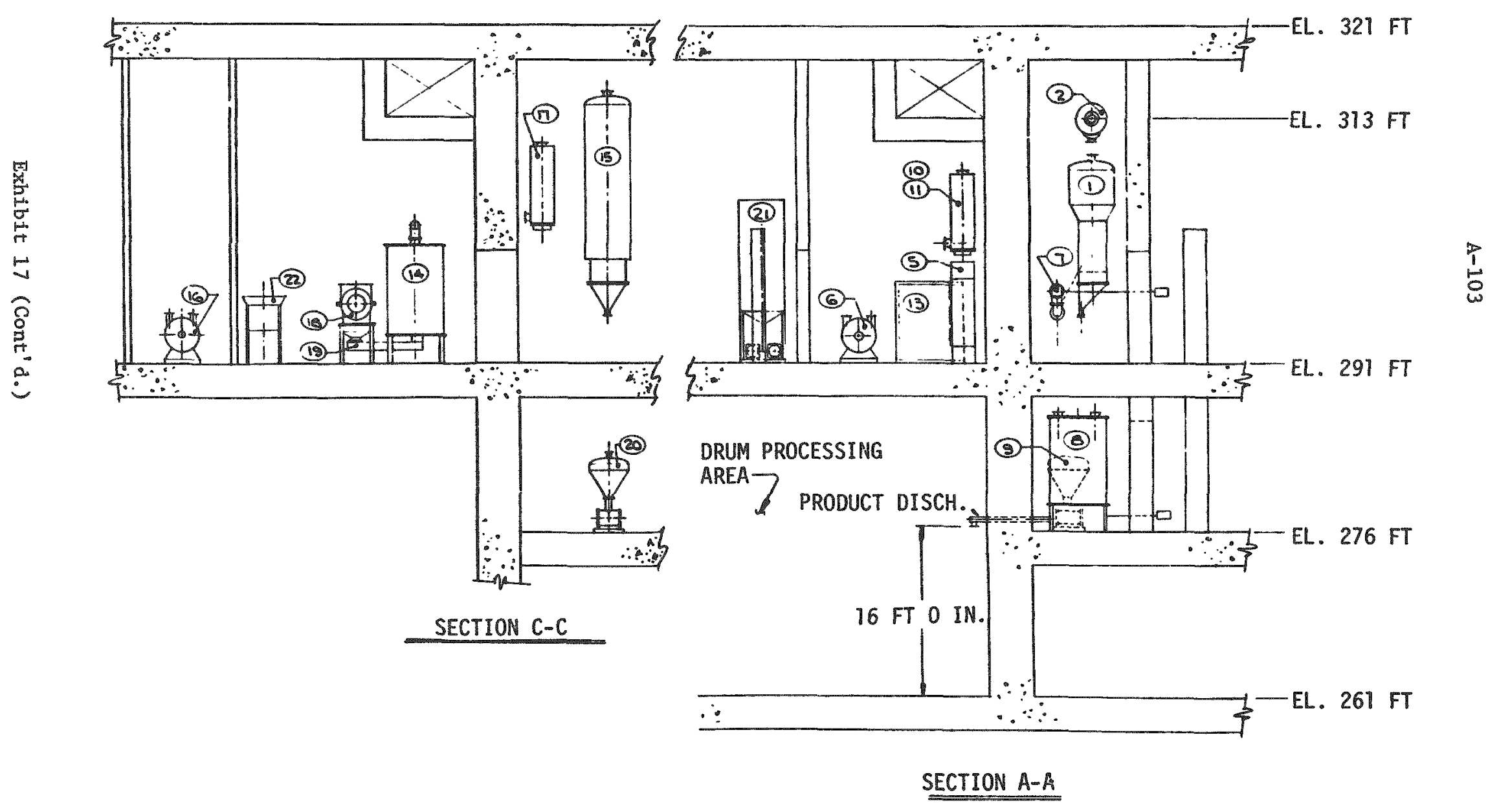


(2)
Energiet Conversion
Company

\section{Radioactive Waste Volume Reduction System}

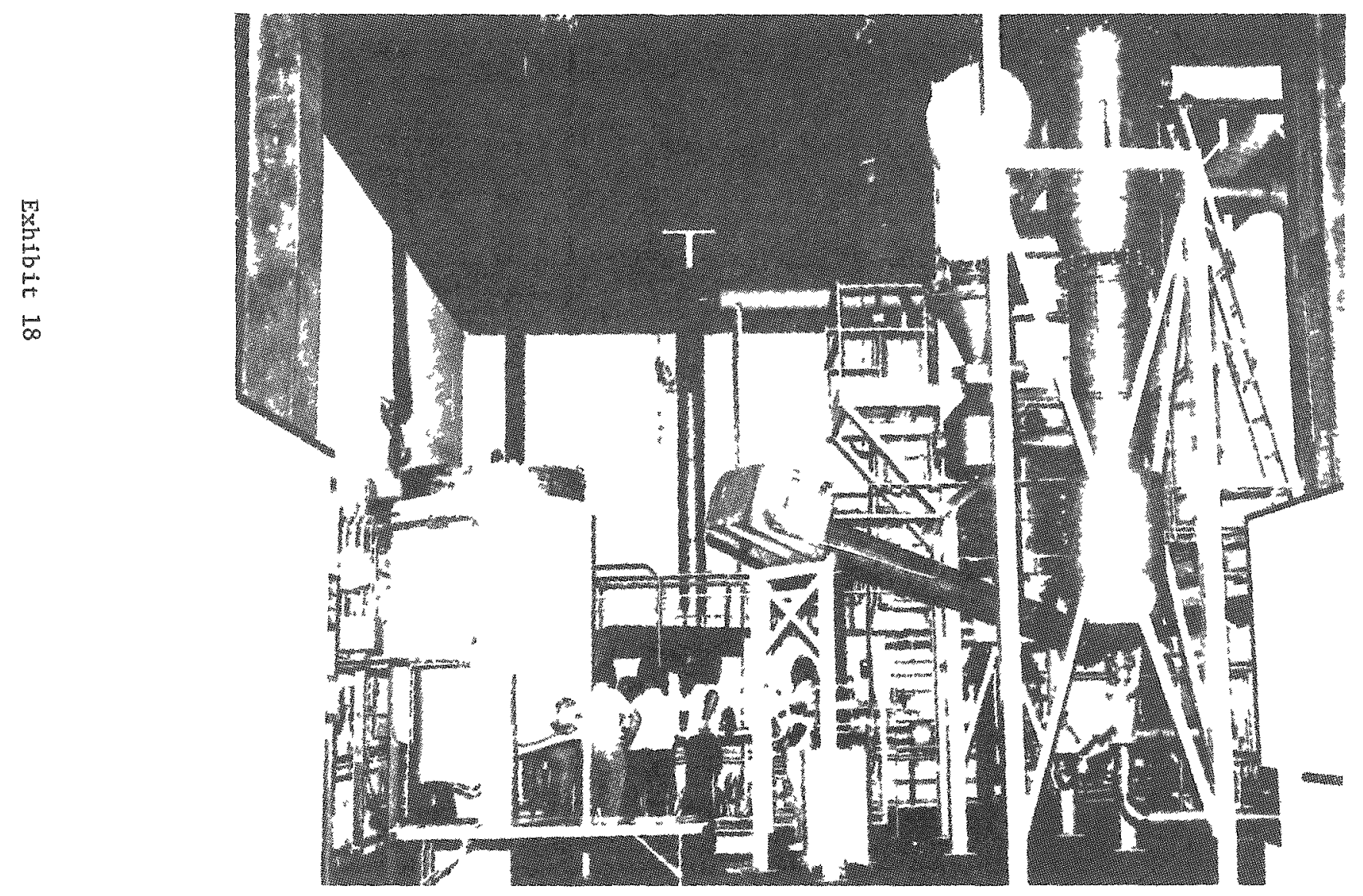




\section{Aerojet Dryer/Incinerator

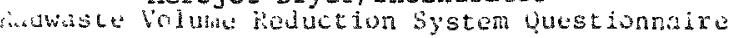

1. brief description of system (please attach layout dwgs. \& PID, if available).

The Aerojet Encrgy Conversion Company (AECC) Radioactive Waste Volume Reduction (VR)

System employs dual fluidized bed vessels and a comnon off-gas cleanup system to process evaporator concentrates to a dry salt and to incinerate dry combustible waste to an ash. The dry salt and ash are accumulated in a product storage hopper which represents the interface with a standard solidification system employing cement or polymer binder for immobilization of the free-flowing product produced by the VR System. The off-gas cleanup syster is used to cleanse the offgas from the fluid bed dryer and the fluid bed incinerator and consists of a gas/ solids separator, yencuri scrubber-preconcentrator, condenser, HEPA filters, and charcoal adsorber. Figure 1 is a process flow schenatic of the System (attached).

2. Feedstock Description:

a) Feedstock Designation

b) Type of Waste

c) Volume per yr. (gal.)

d) Total solids conc. (ppm)

e) Suspended solids (ppm)

f) Conductivity (umho/cm)

g) $\mathrm{pH}$ :

i) Before adjustment

ii) After adjustment

h) Specific gravity

i) Temperature (op)

j) Slurry wastes:

i) Solids conc. (vol. $\%$ )

ii) Interstitial Water

(vol. \%)

iii) Free water above settled sludge (vol.\%)
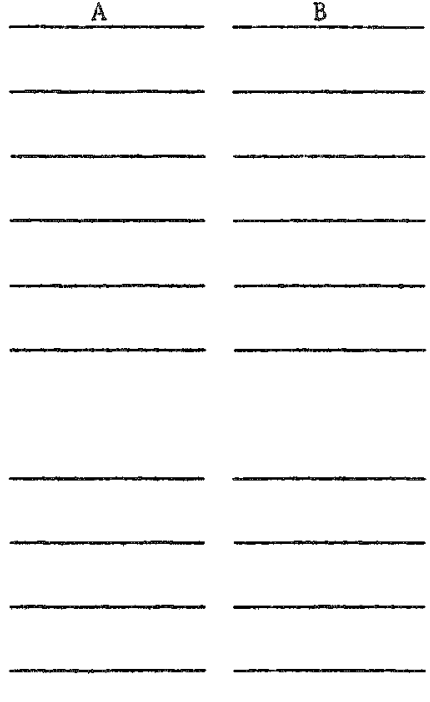
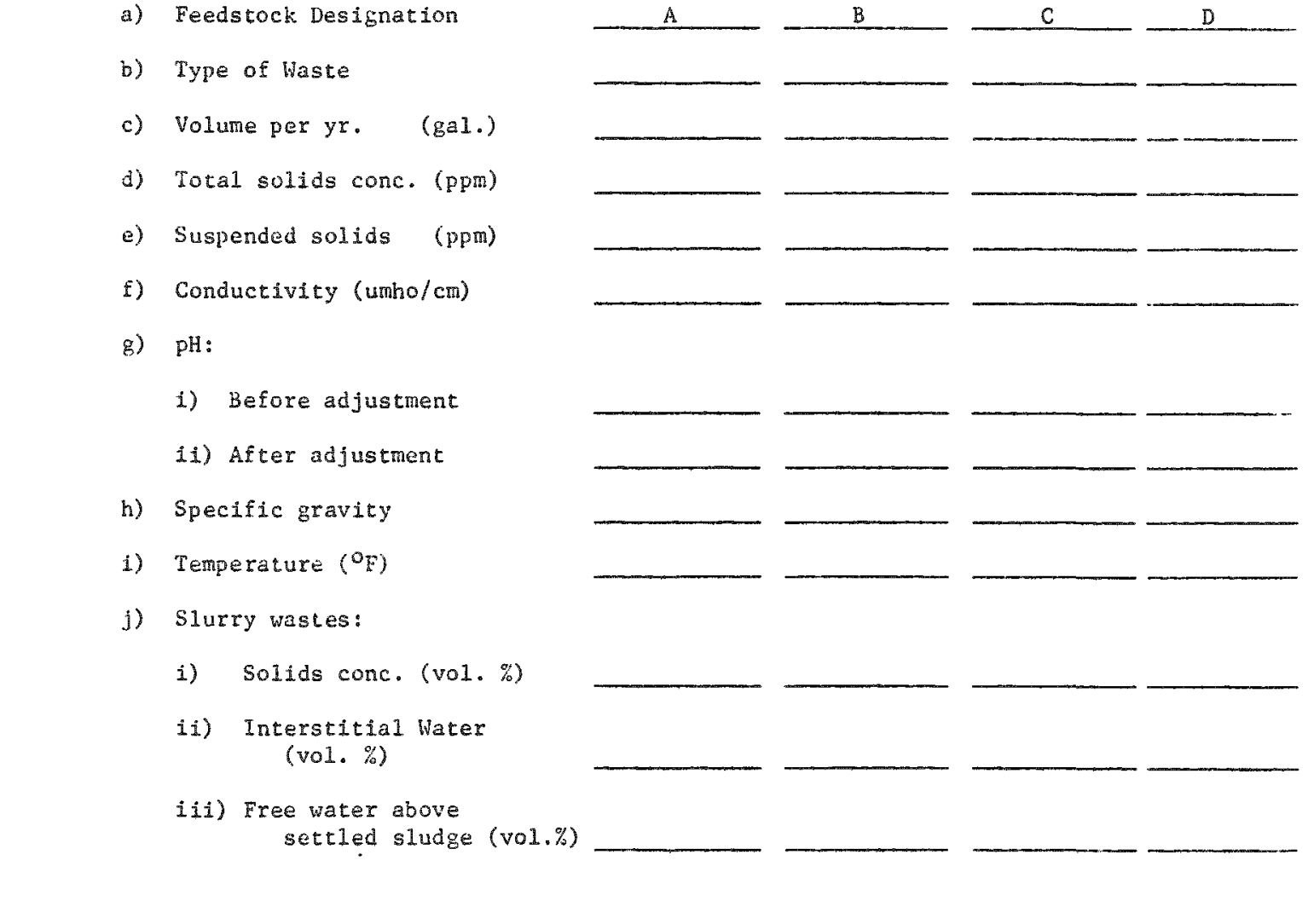

Exhibit 19 


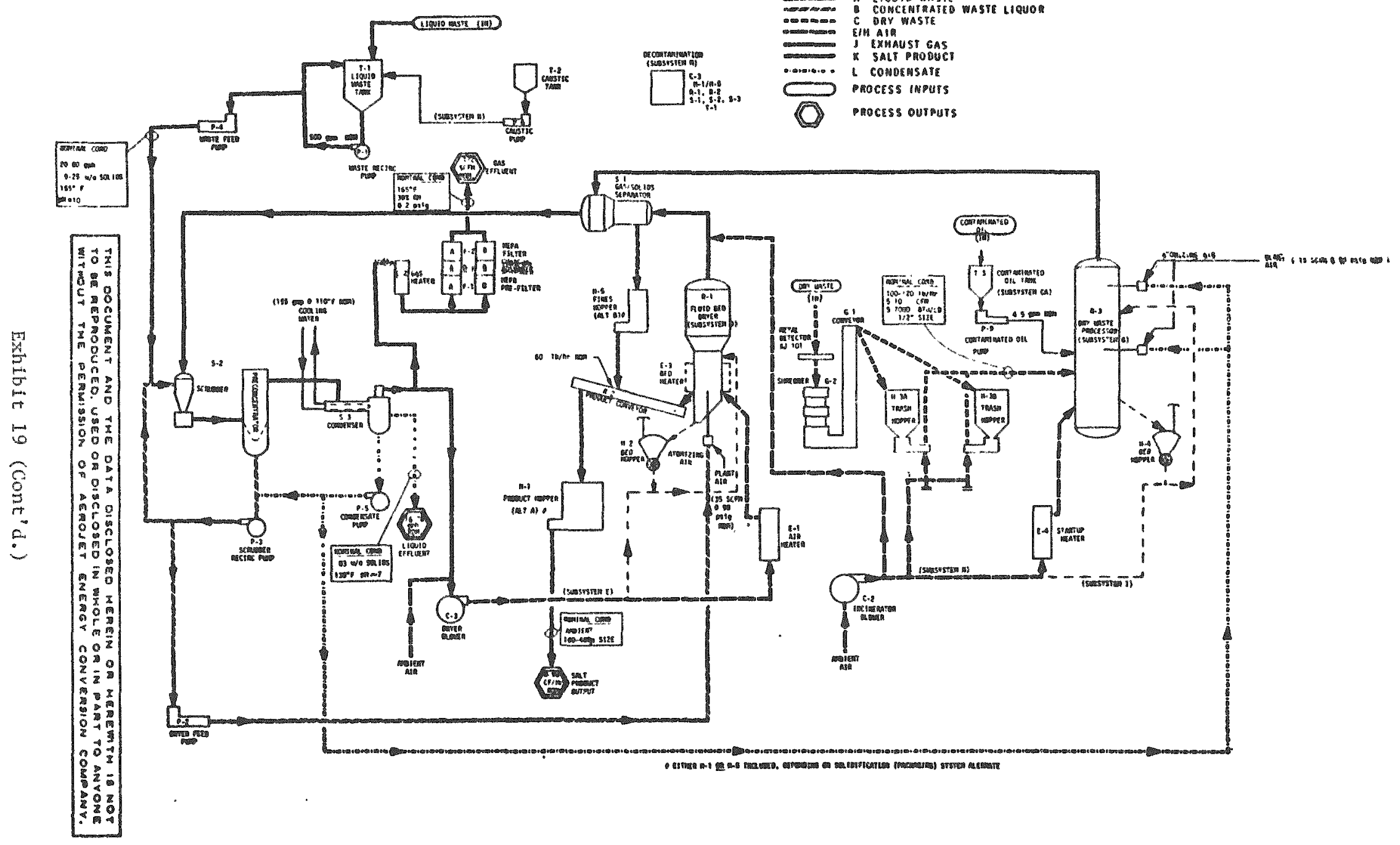

Figure $1 \quad$ AECC Radioactive Waste Volume Reduction System Schematic 
2. The AECC VR System can process (1) evaporator concentrates and (2) dry combustible wastes. The evaporator concentrates may contain 7-25 weight $\%$ solids and consist of sodium sulfate solutions, boric acid solutions, and mixtures of these wastes including small amounts of lubricating oils, detergents, diatomaceous earth, iron oxide, and other crud. The dry combustible wastes consist of the wide variety of combustible trash that is accumulated in the plant which typically consists of paper, cardboard, plastic, cloth, rubber, and wood.

The AECC VR System can process the evaporator concentrates in the fluid bed dryer vessel at a rate which is a function of the Weight \% solids present in the feed stream. Figure 2 shows this characteristic. The fluid bed incinerator vessel can tolerate an energy release of 700,000 Btu/hour. Since the dry combustible waste has a nominal heating value of $7,000 \mathrm{Btu} / 1 \mathrm{bm}$, the nominal feed rate of $\mathrm{dry}$ waste is $1001 \mathrm{bm} / \mathrm{hour}$. 


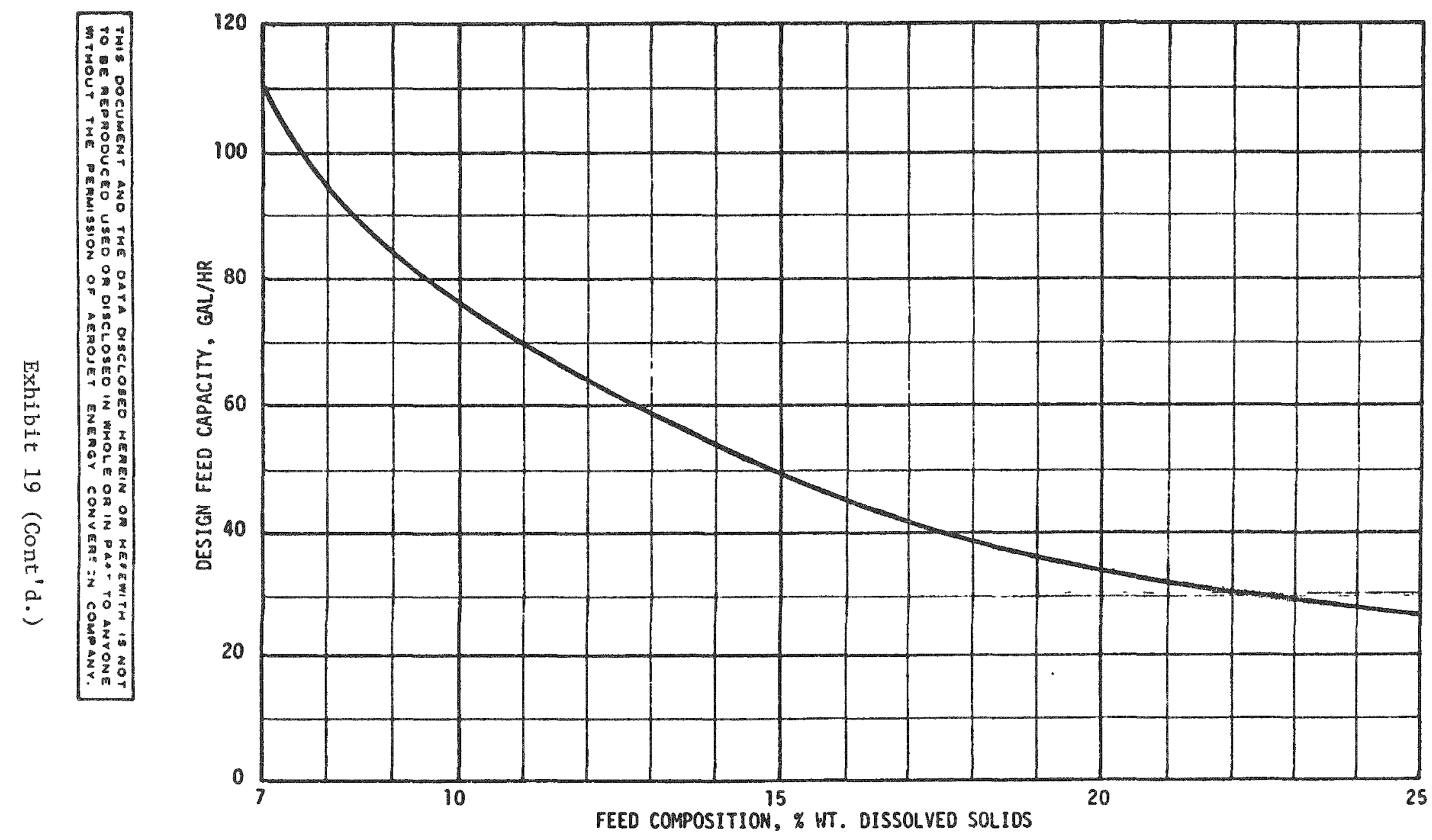

Figure 2 Dryer System Capacits 
k) Radionuclide content by major isotopes ( $\mu \mathrm{Ci} / \mathrm{mI})$ :
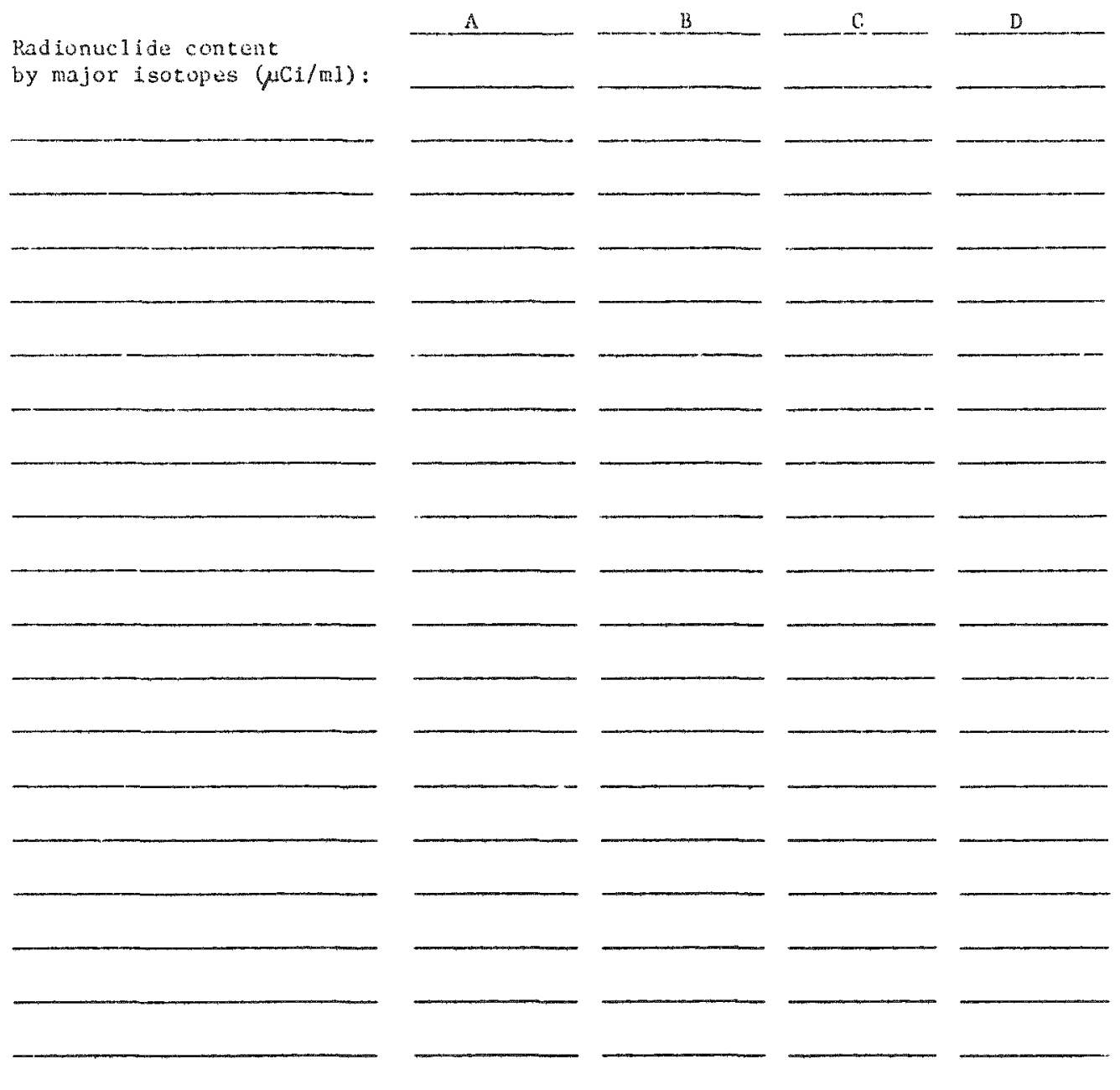

3. Auxiliaries (give pressure, temperature, flow rates, etc.):
a) Stean -
b) Cooling water -
c) Service air -
d) Electric -
e) other

None required

$156 \mathrm{gpm}$ at $90^{\circ} \mathrm{F}$ nomina 1 and $110^{\circ} \mathrm{F}$ maximum (less than 5000 ppm solids)

Plant air required is $58 \mathrm{SCFM}$ at 90 psig. Instrument air required is 33 sCFM at 30 psig $269 \mathrm{~kW}$ (480 VAC, 3 phase, $60 \mathrm{HZ}$ ) and $5.3 \mathrm{KW}$ (120 VAC, single phase, $60 \mathrm{~Hz}$ ) 
4. Operating Data:

a) Feed rate (gpm)

See Figure 2 for Liquid Feed Rate versus beight \% Solids. The dry waste nominal feed rate is 100 lba/hour.

b) Bottoms conc. (wt. \%) AECC VR System produces dry salt

c) Volume reduction factor (vol. feed/vol. bottons)

and ranges from about 5 for 25 Weight \% bottoms to about 11 for 10 weight \% bottons.

d) Decontamination Factors

(ieed to distillate):

i) overall

mately 80

$$
10^{5} \text { for iodine }
$$

ii) major isotopes:
e) Curie content of bottoms $(\mu \mathrm{Ci} / \mathrm{cc})$
f) Radiation level in bottoms (nr/hr):
1) Surface of container -
ii) One foot fron container -

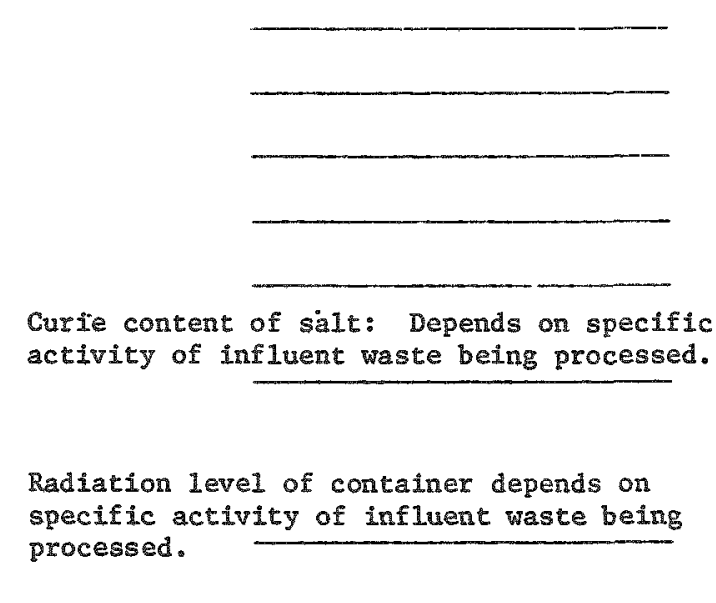

Exhibit 19 (Cont'd.) 
5. Operating distory: -- Prototype System (Ful1-scale) Located in Sacramento, Calif.

a) Date unit installation cumpleted -

Summer, 1974

b) Date unit first operated (with radioactive waste) - Unit first operated in Sumer,

d) Total number of operating hours -

1974 (non-radioactive waste feed)

Approximately 3500 hours on the fluid

bed dryer and 500 hours on the fluid bed

6. Cost Factors:

incinerator.

a) Initial equipnent cost -

$\$ 2.5=3.0 \mathrm{H}$

b) Installation cost

c) Building costs

d) Operating costs ( $\$ / g a l$. of waste feed)

i) Personnel

ii) Auxiliaries

iii) Solidification Agent (if integral part of VR system)

iv) Total

Exhibit 19 (Cont'd.) 
7. Describe any major operating difficulties experienced with the VR system and what measures were taken to correct them.

Some minor difficulties with the shredder initially, but 3-stage approach is working well at this time. 
A-113

- $6-$

8. List all forced outages, including cause of outage (general mantenance, pump failure, etc.) and duration.

Exhibit 19 (Cont'd.) 
TRIP REPORT NO. 7

ORNL RADWASTE VOLUME REDUCTION STUDY

PENBERTHY ELECTROMELT COMPANY, SEATTLE, WASH/MR. LARRY PENBERTHY

SEPTEMBER 7, 1979

Penberthy Electromelt Company's (PEC) manufacturing facility in Seattle, Washington was visited to witness a demonstration of the glass melter incineration process. The electric glass melter is based on the principle, known for many years, that hot molten glass will act as a conductor of electricity. PEC is the holder of numerous patents on improvements in the electromelting process, notably among these is the development of a molybdenum rod electrode system. About four years ago, PEC also provided Hanford with electromelter technology that was used in developing a process for solidifying high level waste in glass.

The electromelter demonstration unit at PEC is a refractory brick lined steel box measuring about $4 \mathrm{ft}$. wide by $8 \mathrm{ft}$. long and $10 \mathrm{ft}$. high. A molten glass bath about $1 \mathrm{ft}$. deep is maintained in the bottom of the unit at a temperature of about $2,300^{\circ} \mathrm{F}$. This temperature is maintained using electrodes immersed in the glass. The glass used to charge the unit is common bottle glass broken into small pieces for easy handling. The lower portion of refractory brick (the portion in contact with or directly above the molten glass) is alumina-zirconium-silica (AZS), which is a non-porous material capable of withstanding the high temperatures involved. The upper portion of the chamber is lined with common fire brick, composed of $60 \%$ alumina and $40 \%$ silica.

The reason for using different materials for the chamber is cost. AZS refractory brick costs about $\$ 400 / \mathrm{cu}$. ft., compared to $\$ 15 / \mathrm{ft}^{3}$ for fire brick. A small door, measuring about - ft. wide by $1 \mathrm{ft}$. high, is situated on one end of the chamber just above the level of molten glass. This door is used for inspection and to feed incinerable waste into the unit. 
The size of the chamber above the molten glass determines how much air is present to burn the waste. Air is drawn out of the chamber by an induced draft fan coupled to the chamber by a circular duct coming from the top of the chamber. Originally, the air chamber was too small to support complete combustion of the waste, resulting in heavy smoke production. The chamber has since been increased in size to solve this problem.

As material is burned in the chamber the majority of the ash produced is absorbed into the molten glass, gradually increasing the liquid level. The molten glass/waste mixture is removed through a gravity drain or simple overflow weir into a collection container where it cools and solidifies. The end product is a glassified waste product with extremely good resistance to leaching.

operation of the glass melter as an incinerator was demonstrated by throwing several pieces of cardboard, work gloves, rubber hose and glass bottles into the melter. All of these items were quickly consumed. In some cases, the ash formed in large pieces that floated out the exhaust duct. This would not occur if the waste was first processed through a shredder to produce a uniform, small diameter feed. The ash that did remain in the melter gradually dissolved into the molten glass. Initially, there was also a great deal of carryover of ash due to excessive air flow. By reducing the flow of air, this problem was corrected.

A furnace designed to handle $2 \mathrm{gpm}$ of liquid radwaste would have a one foot deep bed of molten glass with a surface area of $80 \mathrm{ft}^{2}$. Electric input to this furnace would be $400 \mathrm{~kW}$. If sodium sulfate were injected into the unit as the waste feed, most of the sulfate would be driven off in the off-gas or collect on the glass surface. To accommodate this type of waste, the amount of soda $\left(\mathrm{Na}_{2} \mathrm{O}\right)$ initially used in making the molten glass solution would have to be reduced so that the sodium added by oxidation of the $\mathrm{Na}_{2} \mathrm{SO}_{4}$ would not create a glass with too high of a sodium content. PEC does not recommend processing in the electromelter waste that contains more than about 1 wt percent $\mathrm{Na}_{2} \mathrm{SO}_{4}$. 
If chlorides are present in the liquid waste feed, a maximum concentration of about 2 percent would be absorbed in the glass. Any additional chloride would be carried over in the off-gas.

PEC does not feel there would be much of a contamination problem with the refractory brick. The joints between the bricks will be filled initially with nonradioactive glass, preventing any radioactive material from lodging there. The surface of the AZS brick is a nonporous material that should not absorb much activity. Again, the surface of these bricks will be coated initially with nonradioactive glass.

The life expectancy of the refractory brick lining is 5 years. At the end of this time, the brick could be removed and shipped to a burial site, or the entire furnace could be disposed of as a unit (other than the brick lining, the furnace consists of only a thin gauge steel shell, two electrodes, and residual amounts of glass). The upper section of the chamber could possibly be constructed of material such as Inconel, so that this portion could be reused rather than disposed of. The estimated time to replace the refractory brick lining of an electromelter of the size discussed is about one week.

To date, PEC has done very little developmental work with the electromelter process as a means of radioactive waste disposal. Some preliminary discussions have been conducted with hospitals and research institutions for disposal of their radioactive waste, but a complete test loop with all the necessary off-gas equipment and monitoring devices for temperature, pressures, off-gas carryover, etc. has not been established. At present, PEC is constructing a full scale prototype of the incinerator proposed for commercial use. This unit, which is scheduled for completion in November 1979, will allow PEC to conduct tests to determine VR factors, DF values, etc. Since test loop data must be obtained before a topical report could be developed and submitted to the NRC, it is not expected that an electromelter ill be available for processing radwaste from commercial nuclear power plants for at least several years.

A schematic representation of the system proposed by PEC to process and solidify high level radioactive waste at NFS, West Valley is shown in Exhibit 20. 


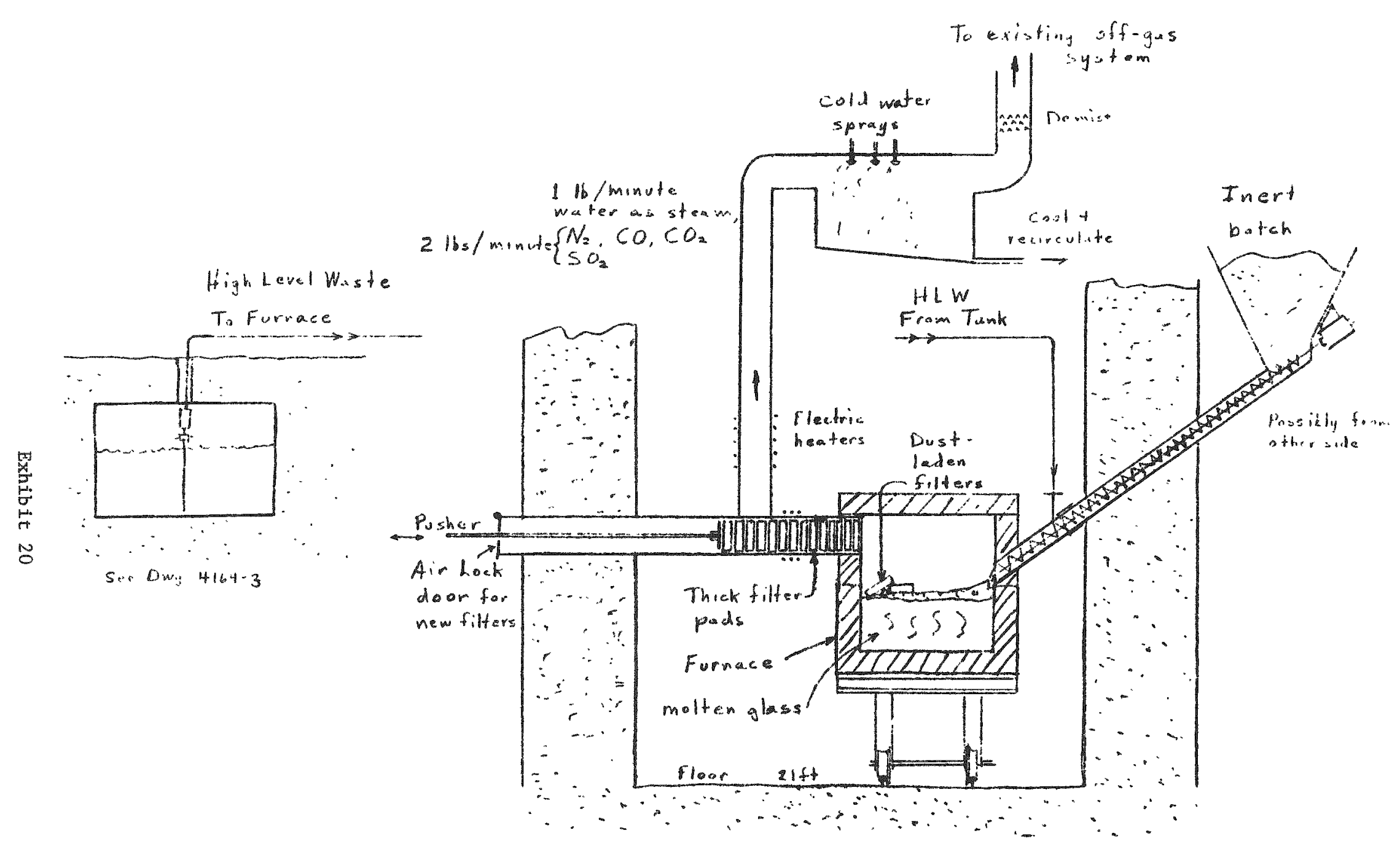




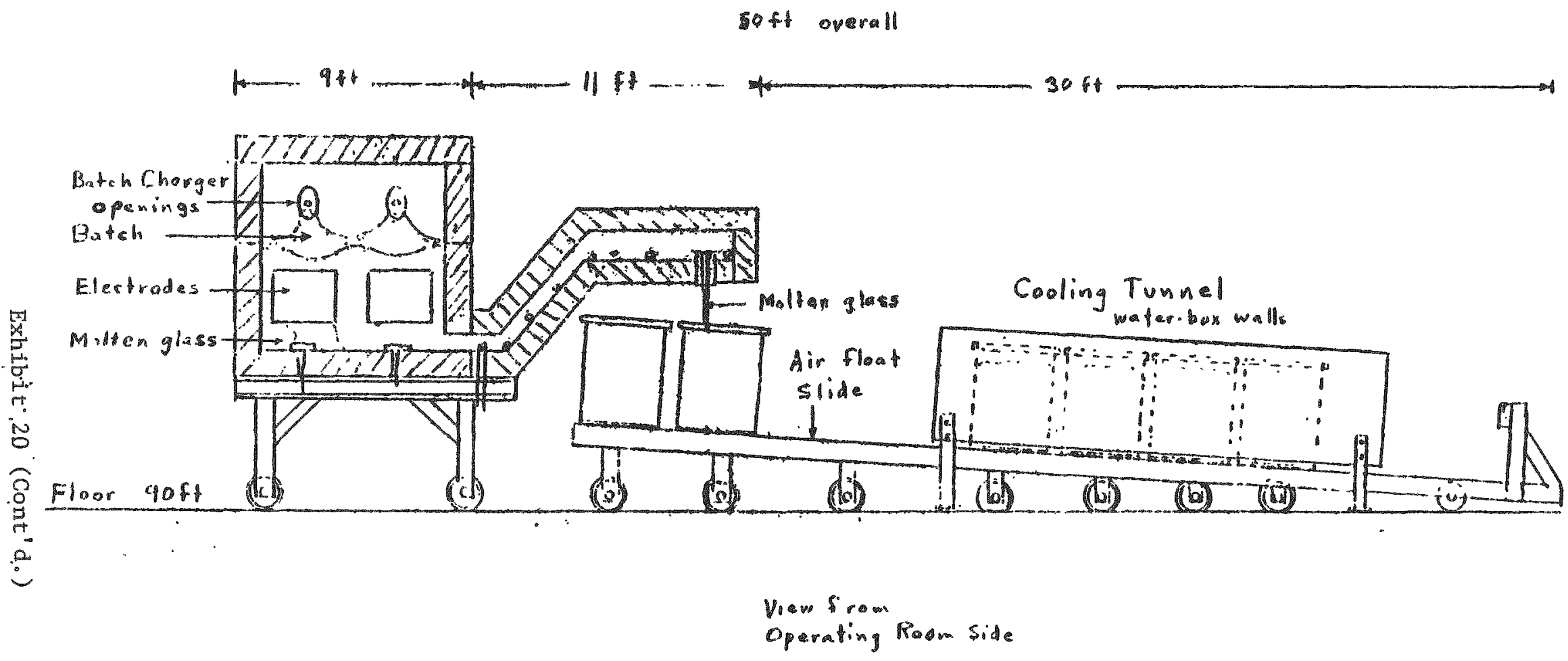

PROPOSED MELTING AND CANISTER FILLING FOR ELECTRIC GLASS FURNACE IN CHEMICAL PROCESSING CELL AT WEST VALLEY SPENT FUEL RECOVERY PLANT 


$$
\text { A-119 }
$$

OTHER SITE SURVEY MATERIAL 
Nine Mile Point Forced Circulation Evaporator

Radwaste Volume Reduction System Questionnaire

1. Brief description of system (please attach layout dwgs. \& P\&ID, if available).

The evaporator currently in service is a (20 GPM) $10,000 \mathrm{lb} / \mathrm{hr}$ unit

designed to process a feed containing $1.5 \% \mathrm{Na}_{2} \mathrm{SO}_{4}$ and misc. Impurities

at $100^{\circ} \mathrm{F}$ to $600 \mathrm{lb} / \mathrm{hr}$. of concentrated liquor with $25 \%$ total solids

at $220^{\circ} \mathrm{F}$. Steam is supplied by a $4.8 \mathrm{Mw}$ resistance type electric boiler.

2. Feedstock Description:

a) Feedstock Designation

b) Type of Waste

c) Volume per yr. (gal.)

d) Total solids conc. (ppm)

e) Suspended solids (ppm)

f) Conductivity (umho/ cm)

g) $\mathrm{pH}$ :

i) Before adjustment

ii) After adjustment

h) Specific gravity

i) Temperature (oF)

j) Slurry wastes: - not input to evaporator

i) Solids conc. (vo1. \%)

ii) Interstitial water (vo1. \%)

iii) Free water above settled sludge (vol.\%)

$4-12$

$6-9$

$1-1.2$$$
70
$$

evaporator

$\frac{\frac{A}{\text { Regen. }}}{\frac{330,000}{\text { NA }}} \frac{\text { NA }}{\text { NA }}$
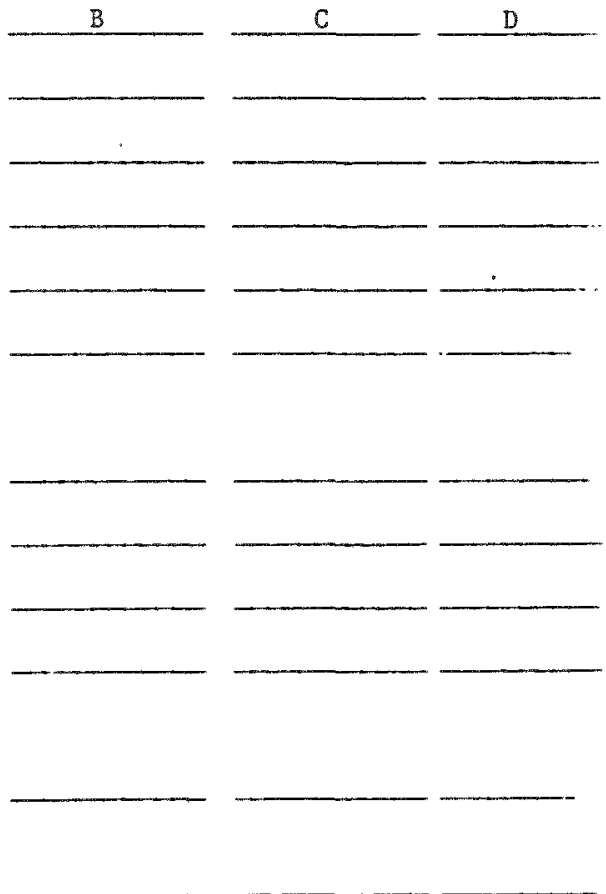

Exhibit 21 
k) Radionuclide content by major isotopes $(\mu \mathrm{C} i / \mathrm{ml})$ :
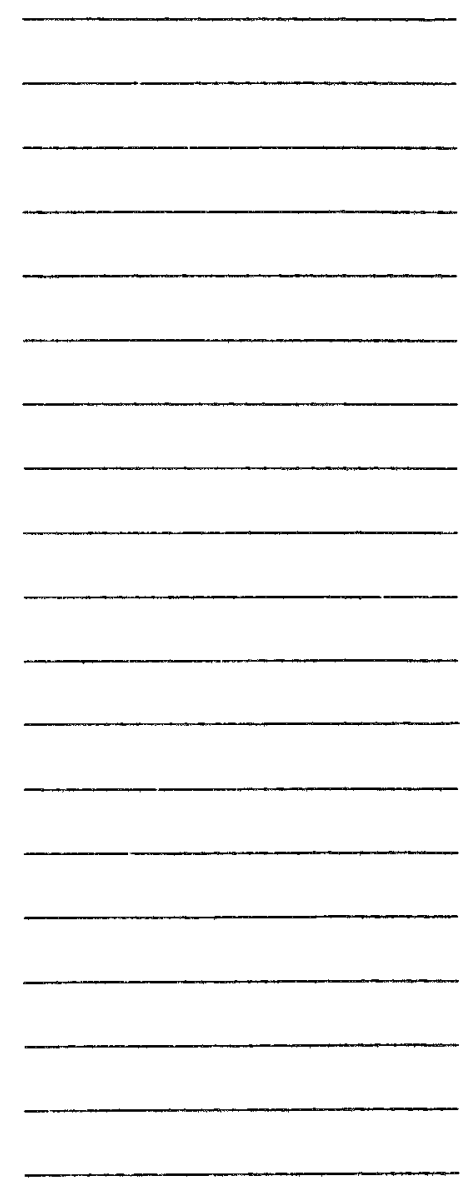

3. Auxiliaries (give pressure, temperature, flow rates, etc.):
a) Steam -
b) Cooling water -
c) Service air -
d) Electric -
e) Other

$-2-$

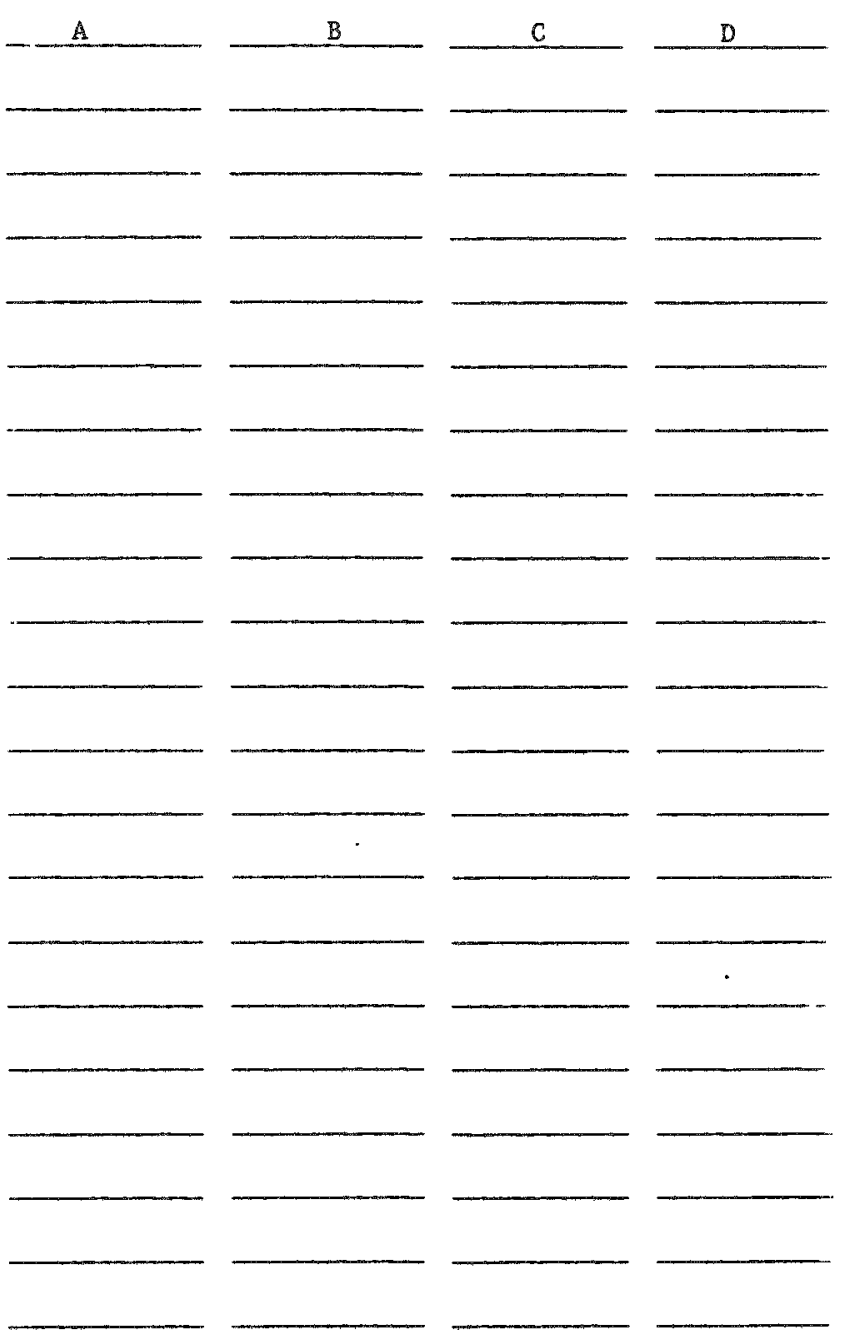


4. Operating Data:
a) Feed rate (gpm)
b) Bottoms conc. (wt. \%)
c) Volume reduction factor (vol. feed/vol. bottoms)
d) Decontamination Factors (feed to distillate):

i) overa11

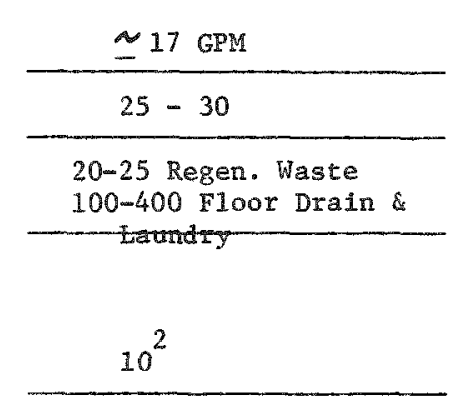

ii) major isotopes:

\begin{tabular}{rr} 
CS-137 & $28.76 \%$ \\
\hline $\operatorname{Cs}-134$ & $7.95 \%$ \\
\hline$M N-54$ & $5.51 \%$ \\
\hline CO-58 & $.88 \%$ \\
\hline CO-60 & $56.90 \%$ \\
\hline
\end{tabular}

e) Curie content of bottoms (uCi/cc)

$4.332 \mu \mathrm{Ci} / \mathrm{Cc}$

E) Radiation level in botcoms $(\mathrm{mr} / \mathrm{hr})$ :
i) Surface of container -
ii) One foot from container -

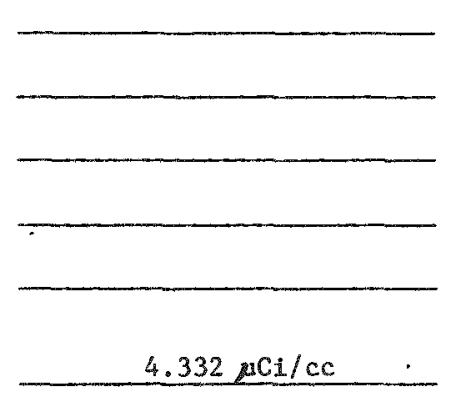

$550 \mathrm{mr} / \mathrm{hr}$ e $3^{\prime \prime}$ top of liner

$30 \mathrm{mr} / \mathrm{hr} @ 6^{\prime}$ top of liner 
5. Operating History:
a) Date unit installation completed -
$5 / 14 / 75$
b) Date unit first operated (with radioactive waste) -
$5 / 21 / 75$
d) Total number of operating hours -
$\sim 22,000$

6. Cost Factors:

a) Initial equipment cost - (including electric boiler) _ $\approx 300,000$

b) Installation cost

c) Building costs

$$
\mathrm{ft}^{3}
$$

d) Operating costs ( $\$$ /rgert. of waste

i) Personnel and Equipment

ii) Auxiliaries (solid. \& burial under contract)

$\frac{\sim \$ 650,000}{\infty} \$ 600,000$

iii) Solidification Agent (if integral part of VR system)

iv) Total

\begin{tabular}{|c|}
\hline$\$ 3.60 / f t^{3}$ \\
\hline$\$ 45.00 / \mathrm{ft}^{3}$ \\
\hline- \\
\hline$\$ 48.60 / \mathrm{ft}^{3}$ \\
\hline
\end{tabular}


7. Describe any major operating difficulties experienced with the VR system and what measures were taken to correct them.

A11 wetted parts were 304 ss except tubes which were $316 \mathrm{~L}$. We currently are in the process of replacing the vapor body, recirc. pump and suction piping with Inconel 625 and Alloy 20 for the Recirc. Pump. The heat exchanger and pump discharge piping was replaced earlier this year. With 625 material, the original unit showed signs of failure at the heat effected areas of the welds. Rebuilt concentrator $\#_{12} 2$ will Tave a separate entrainment separator rather than having it in the vapor body as was the original unit. 
$-6-$

8. List all forced outages, including cause of outage (general maintenance, pump failure, etc.) and duration.

See Item 7. 
CONCENTRATOR ANALYSIS DATA

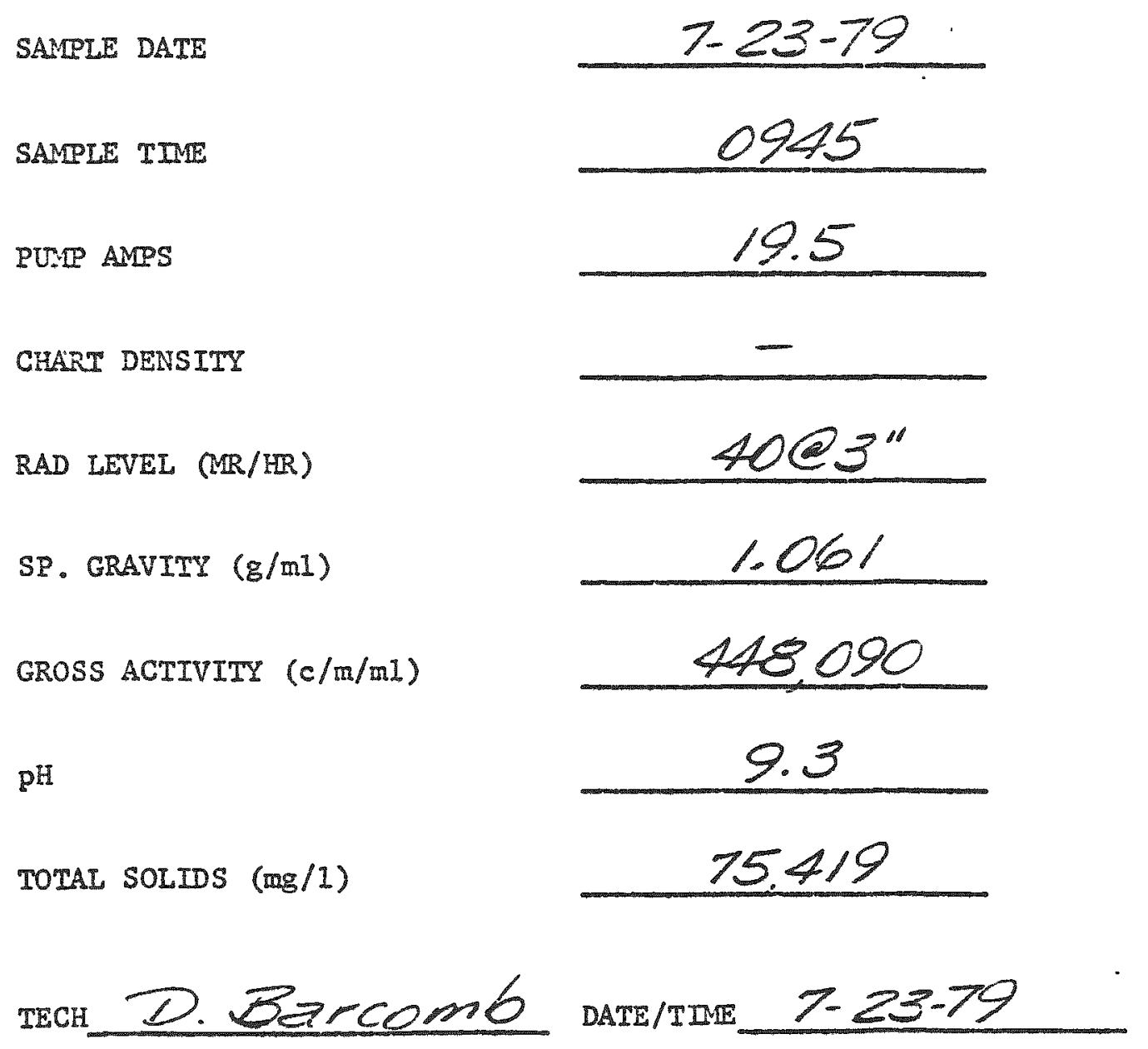


CONCENTRATOR ANAIYSIS DATA

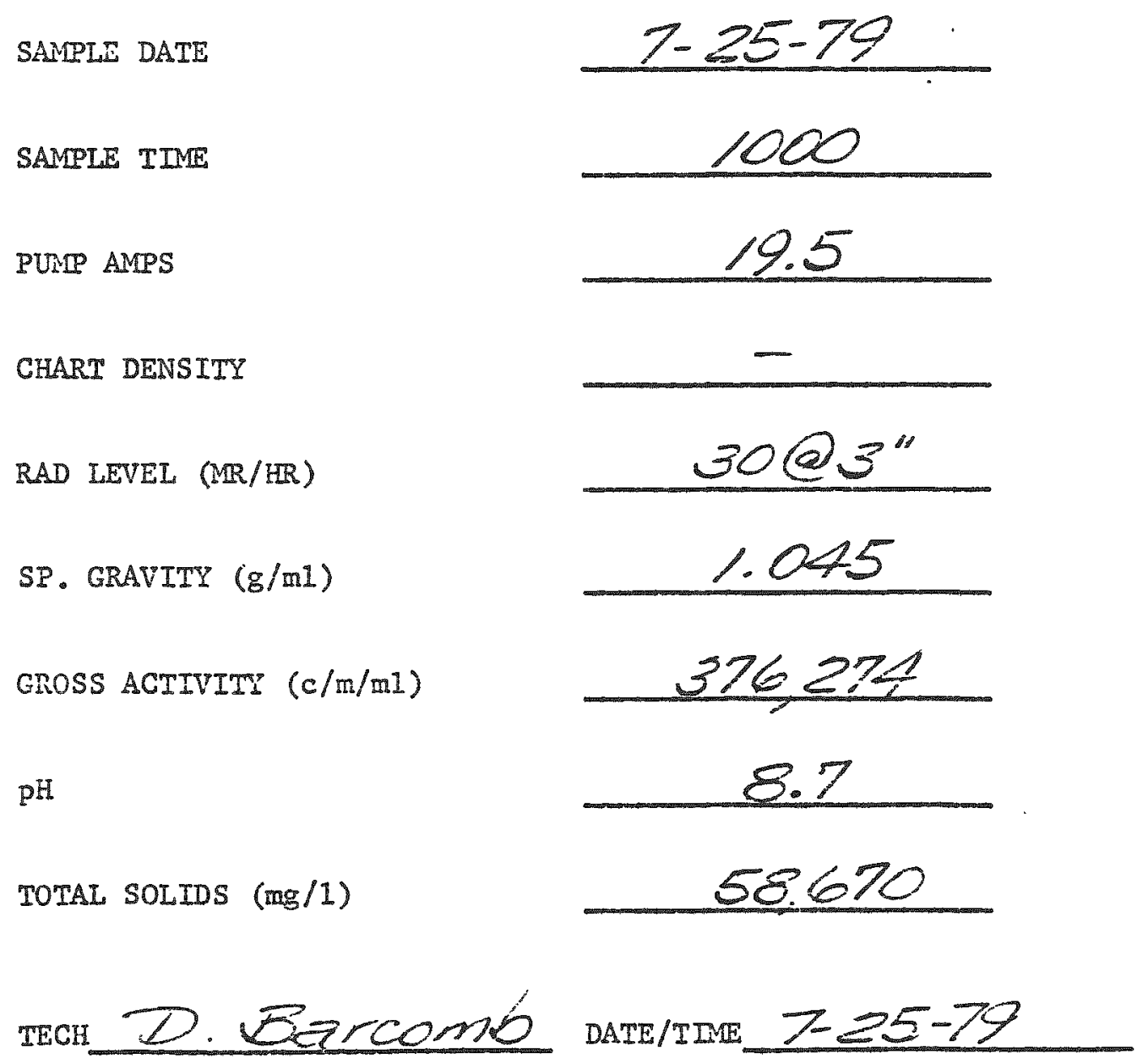

Exhibit 22 (Cont'd.) 
CONCENTRATOR ANALYSIS DATA

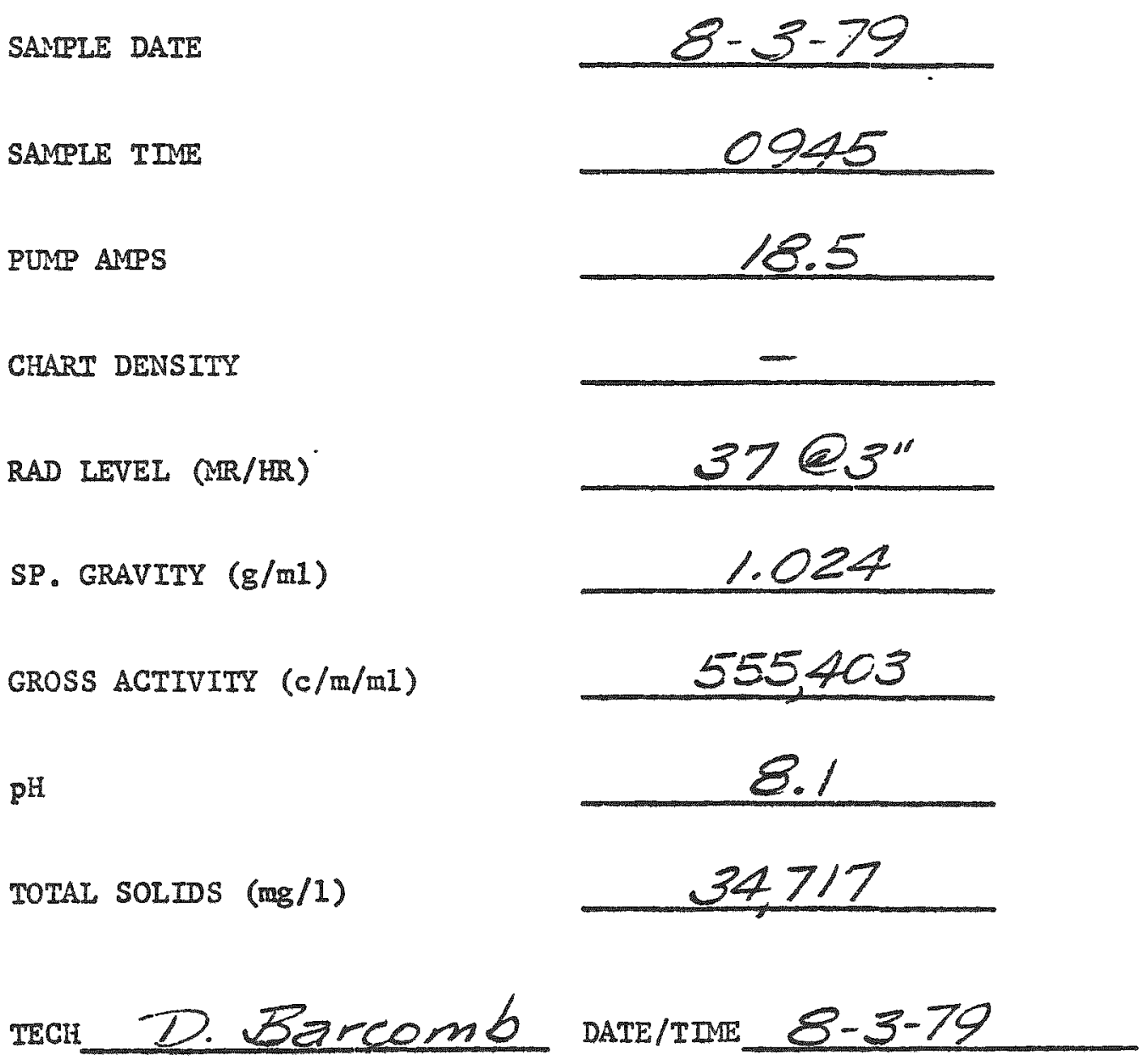

Exhibit 22 (Cont'd.) 
CO.VCENIRATOR ANALYSIS DATA

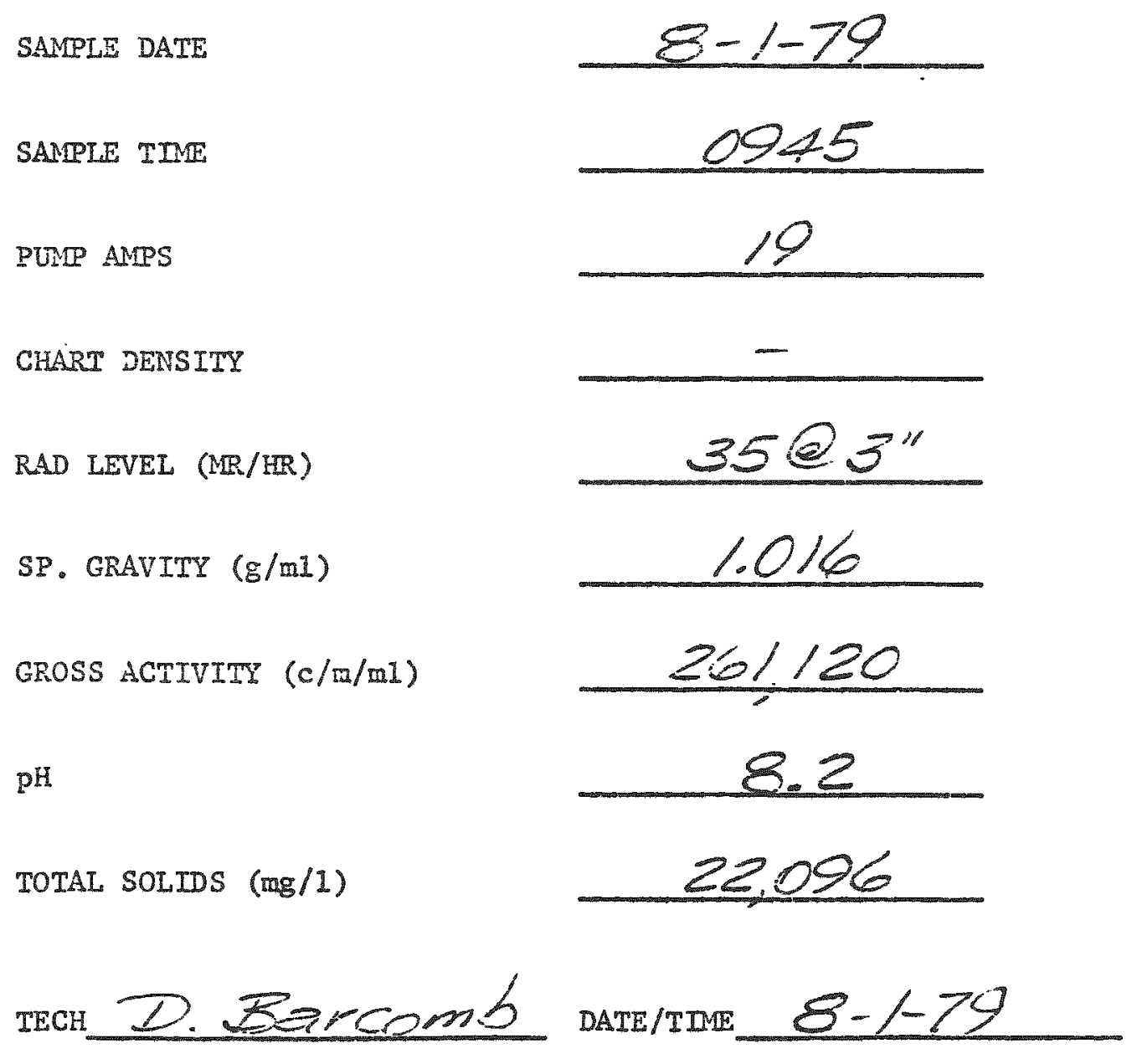

Exhibit 22 (Cont'd.) 
CONCEITRATOR ANALYSIS DATA

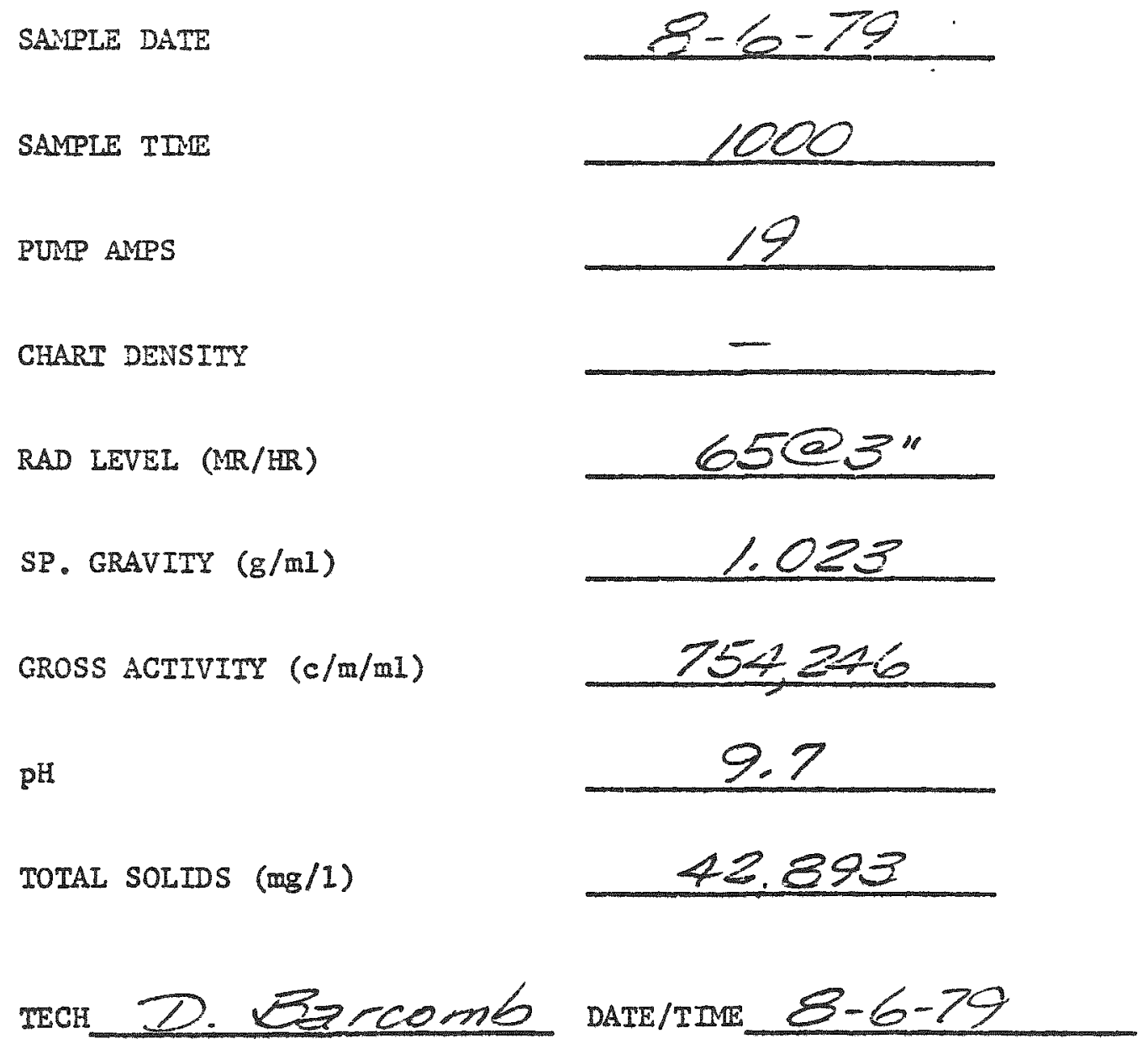

Exhibit 22 (Cont'd.) 


\section{CONCENTRATOR ANALYSIS DATA}

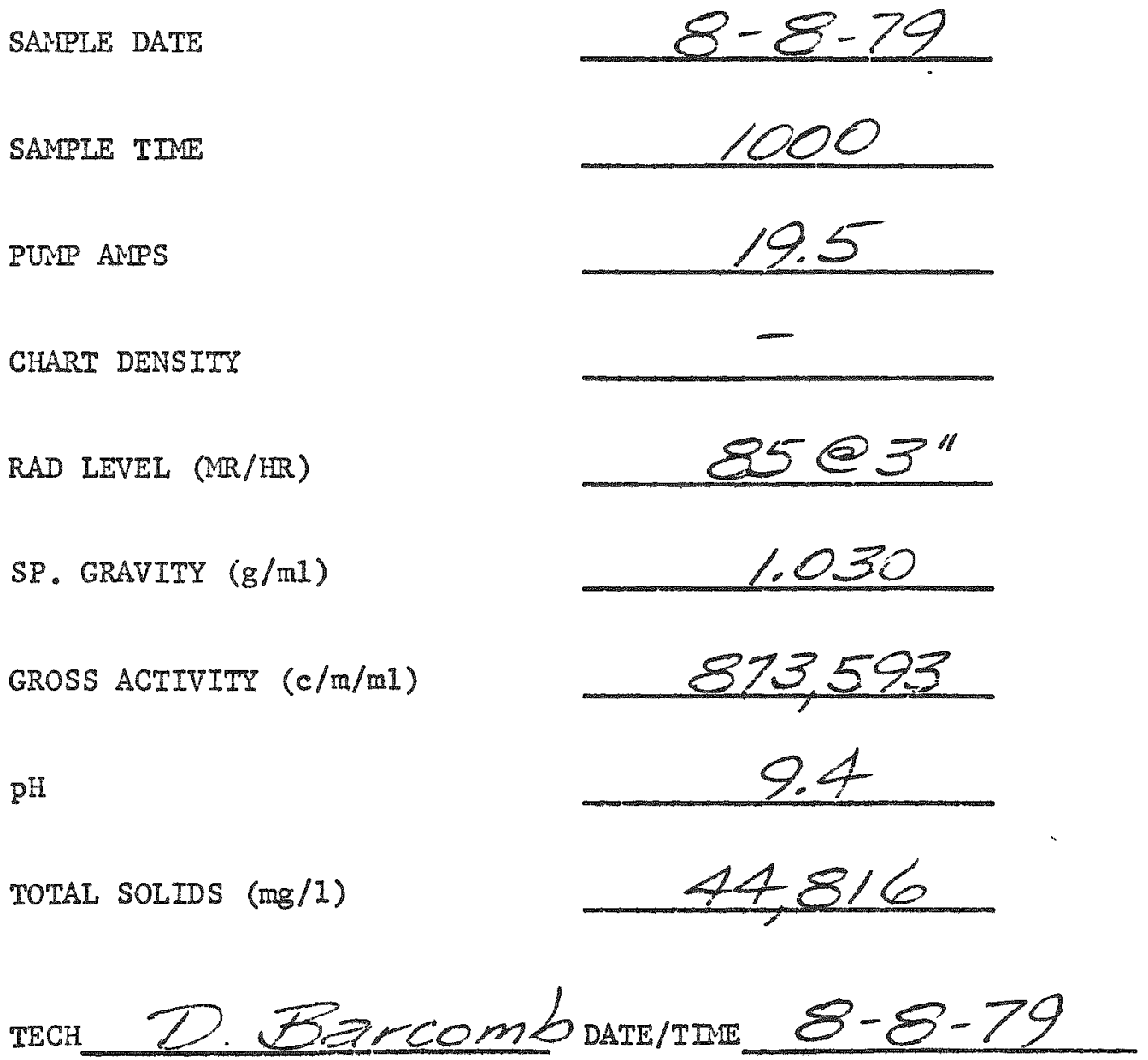

Exhibit 22 (Cont'd.) 
CONCENTRATOR ANALYSIS DATA

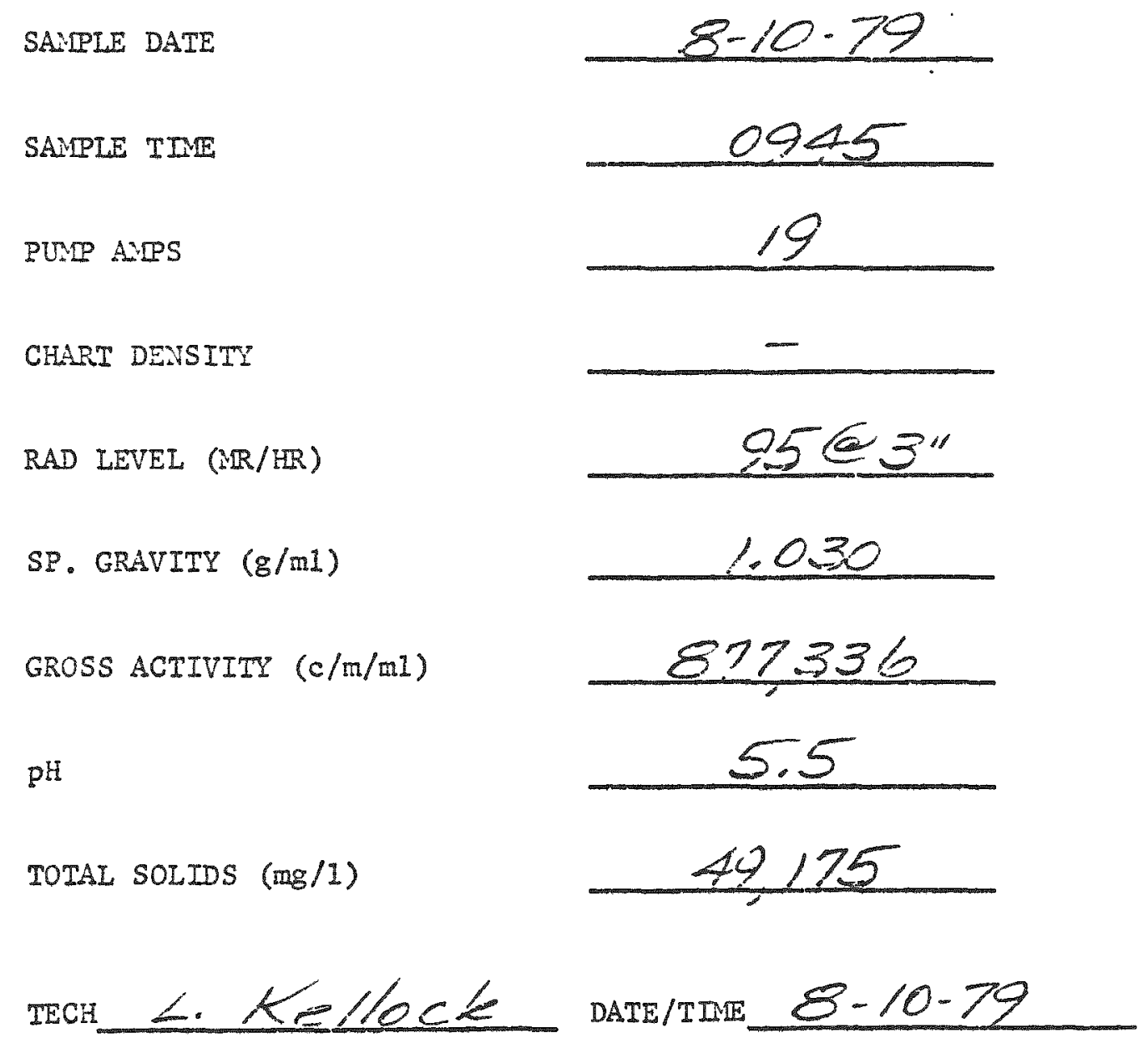




\section{CONCENTRATOR ANALISIS DATA}

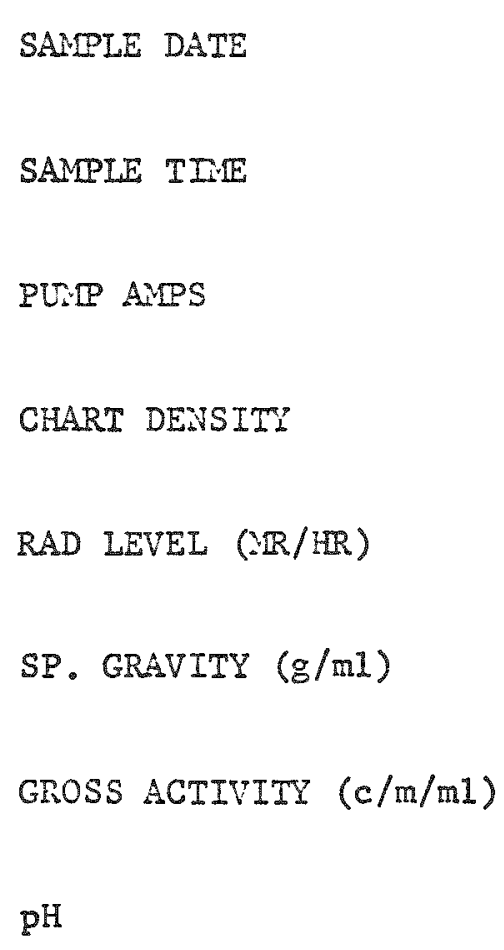

TOTAL SOLIDS (mg/1)
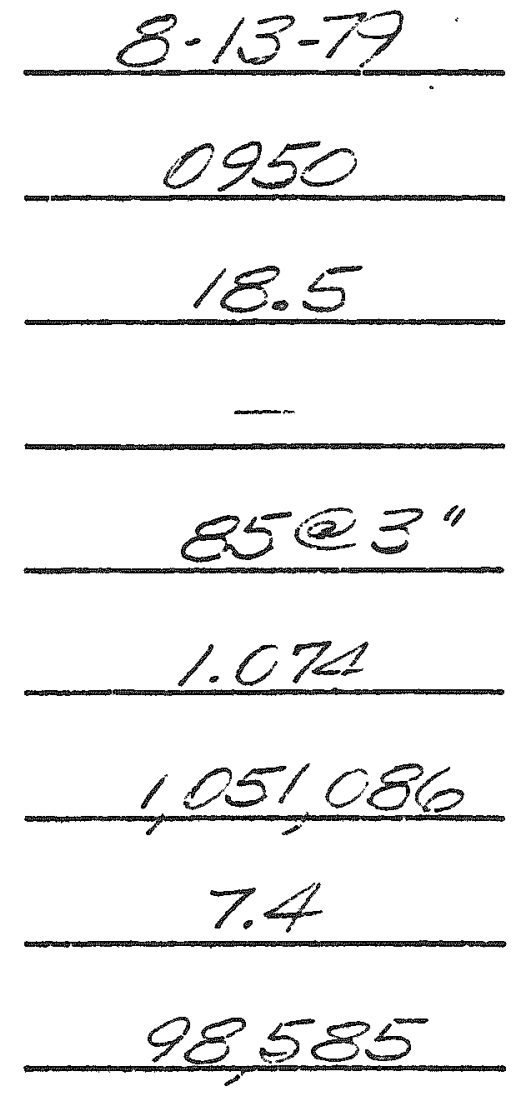

TECH 20.Zircomb DATE/TIE 8-13-79 


\section{$A-134$}

\section{CONCENTRATOR ANALYSIS DATA}

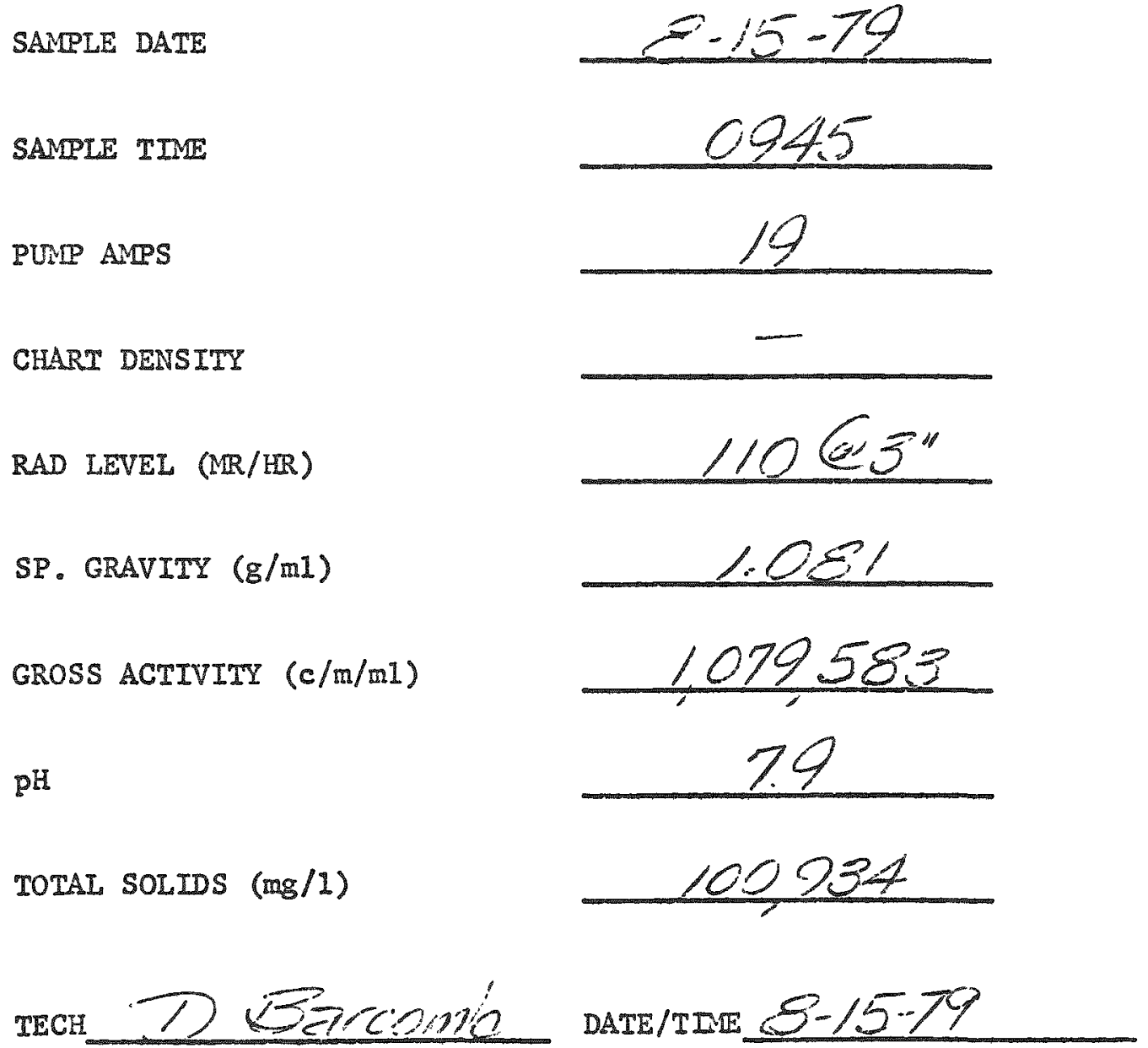

Exhibit 22 (Cont ${ }^{\prime} \mathrm{d}$.) 


\section{CONCENTRATOR ANALYSIS DATA}
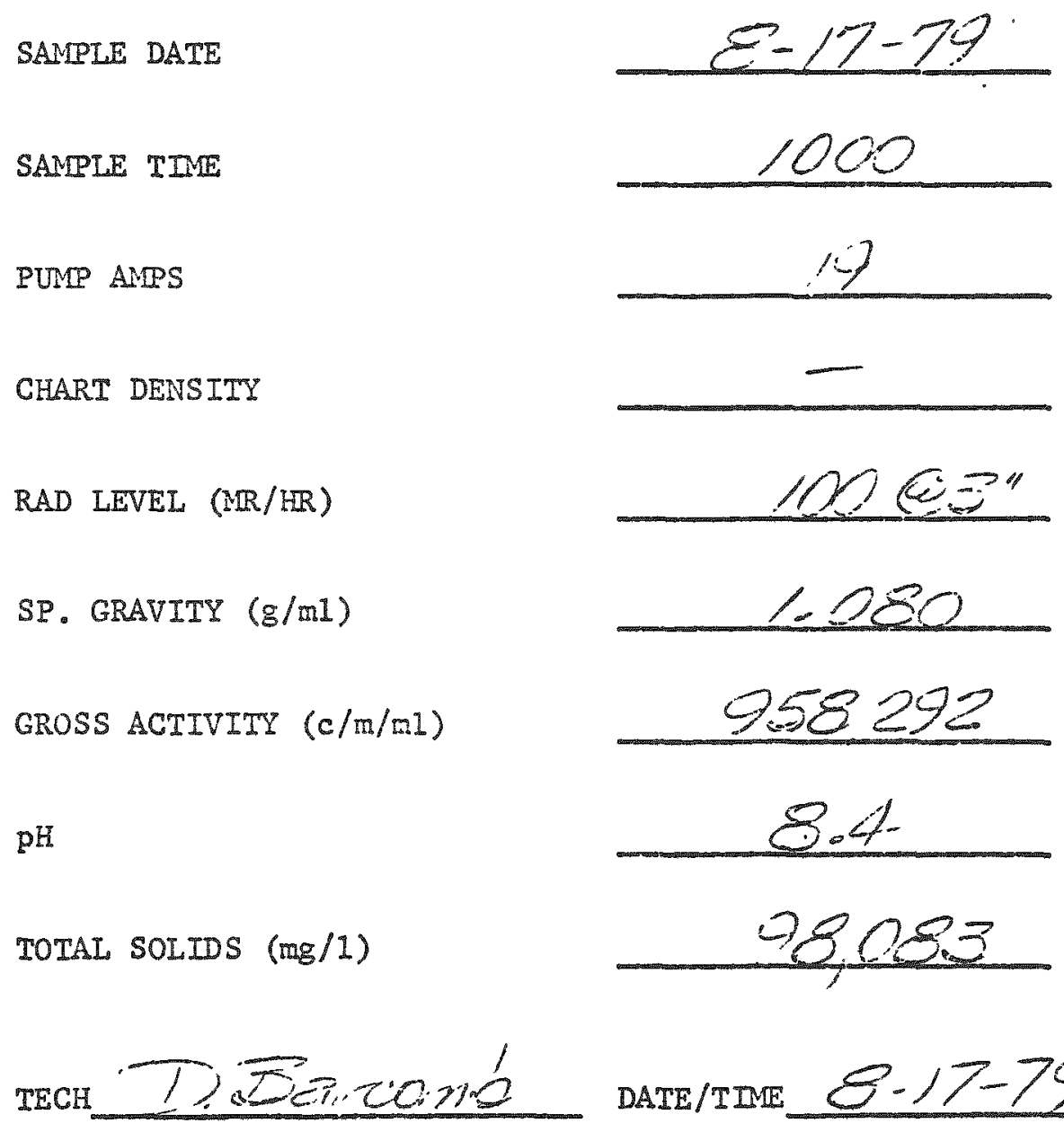

DATE/TIME $8-17-79$

Exhibit 22 (Cont'd.) 


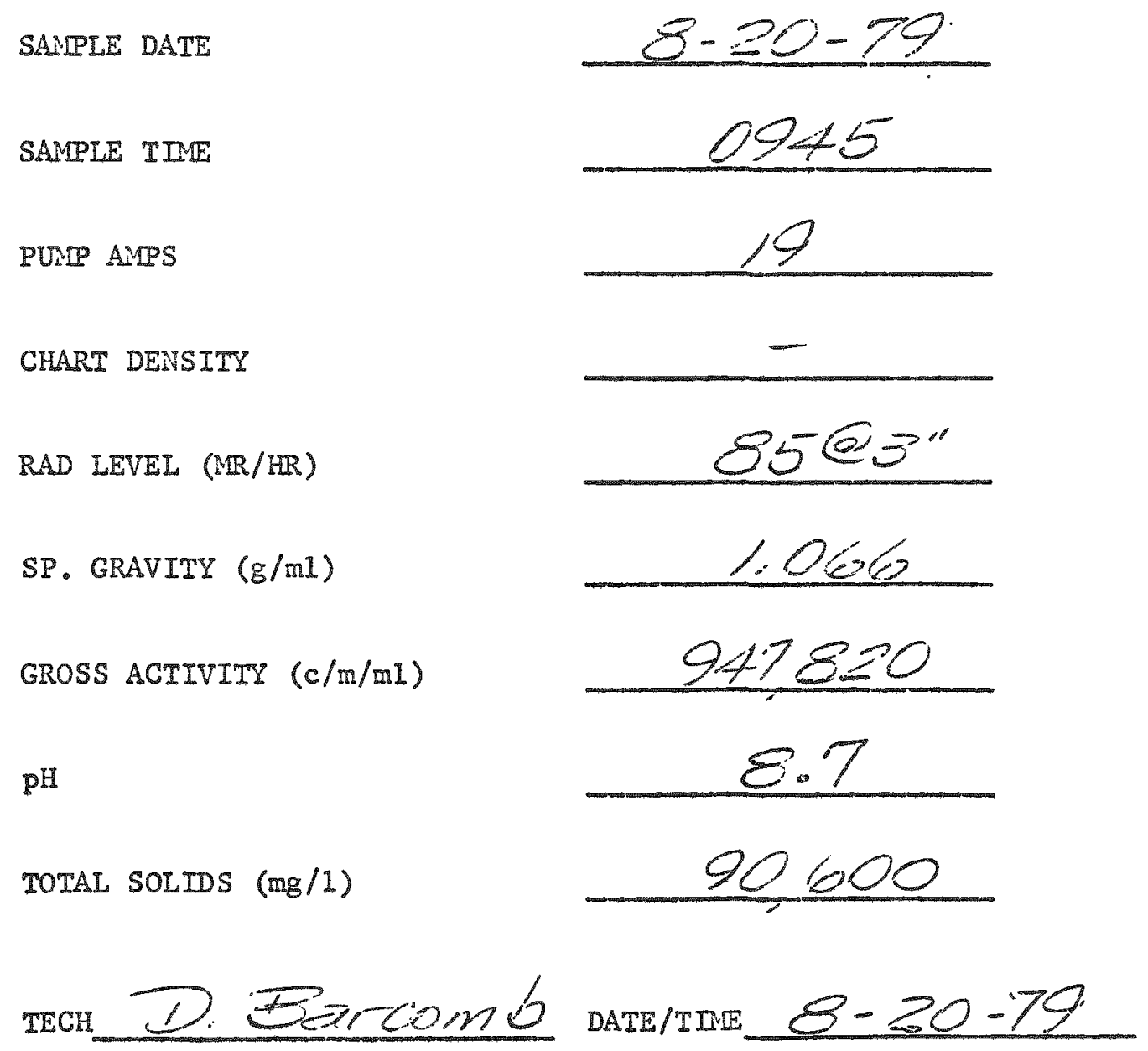

Exhibit 22 (Cont'd.) 


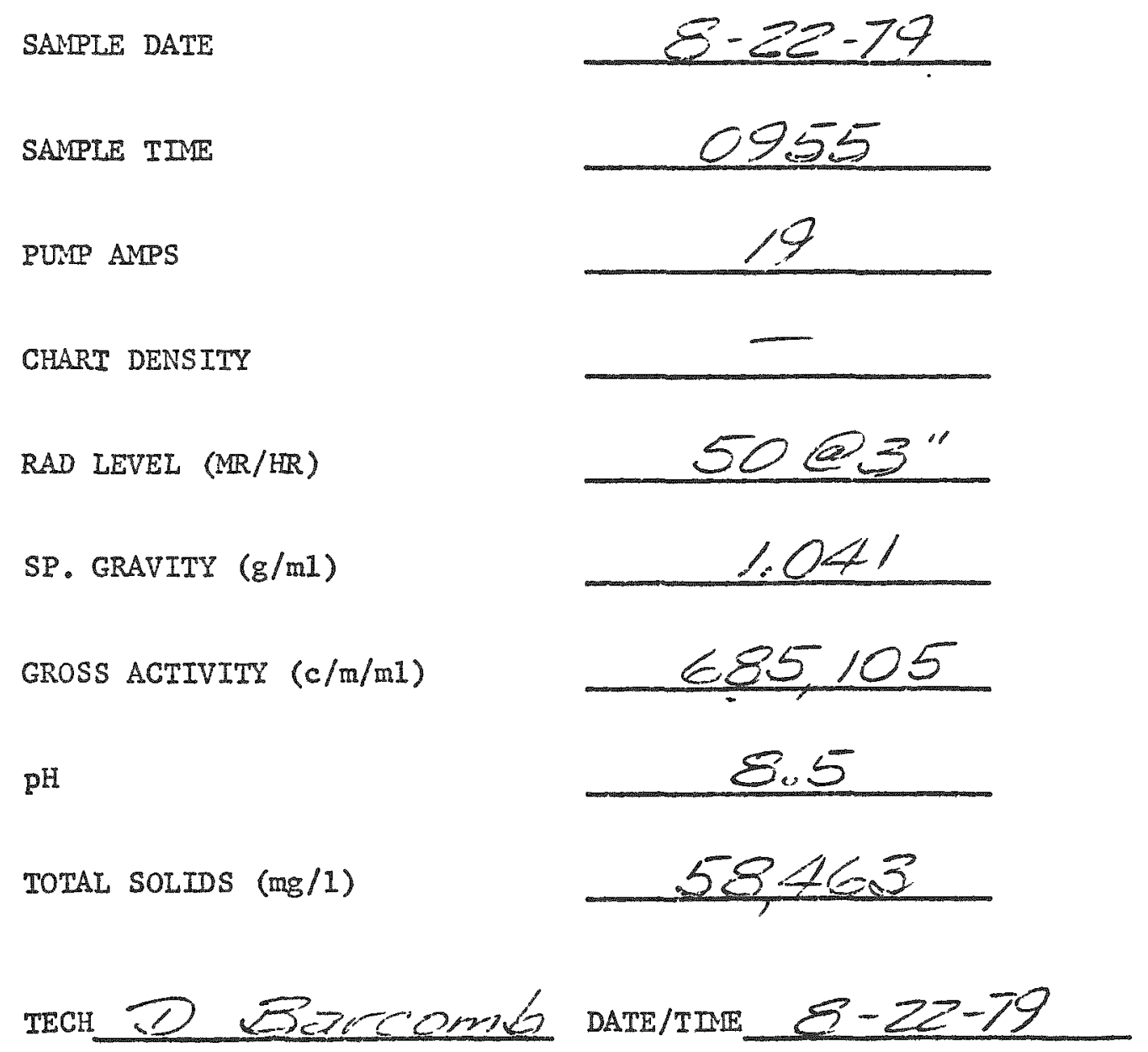

Exhibit 22 (Cont'd.) 


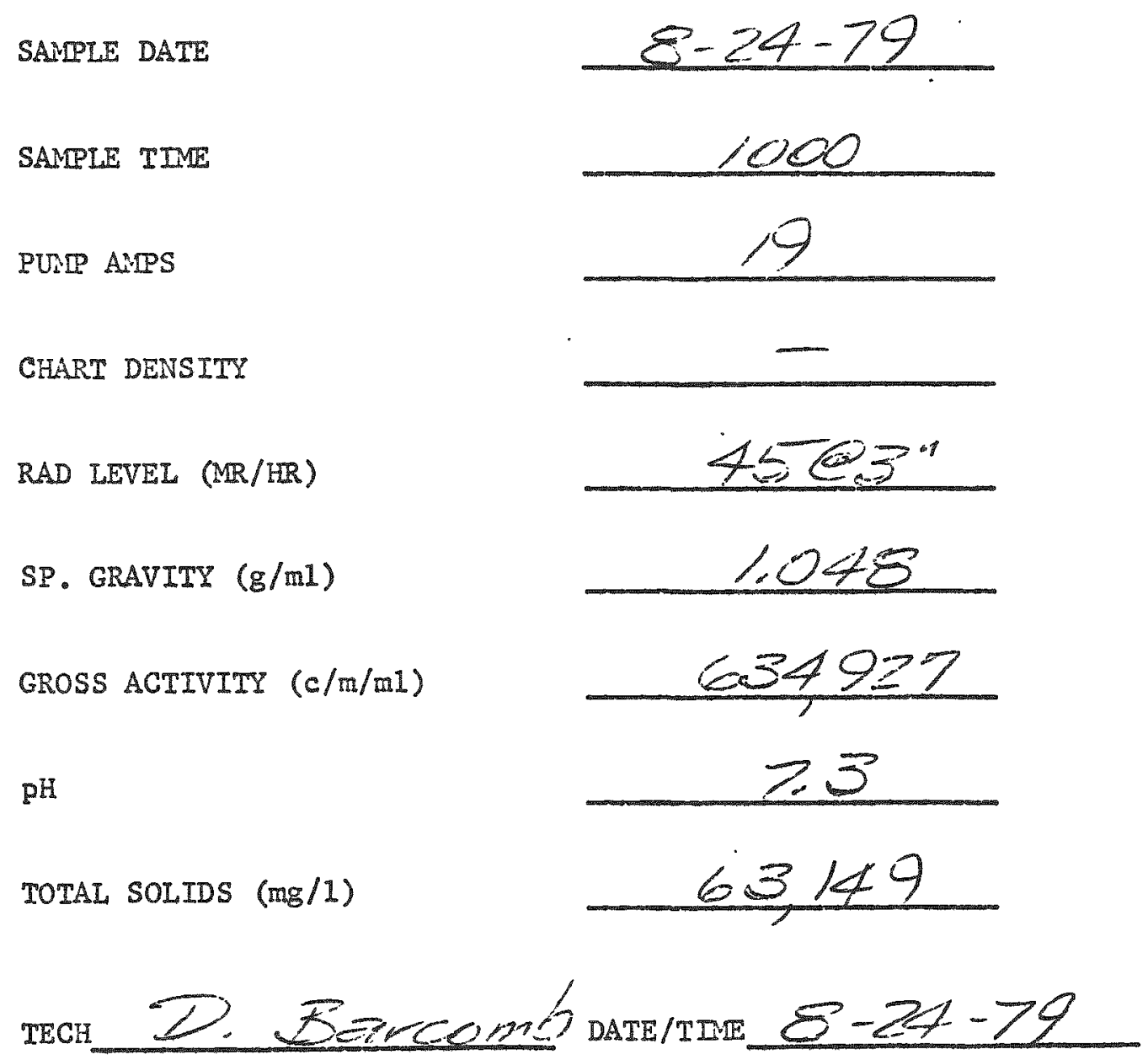

Exhibit 22 (Cont'd.) 


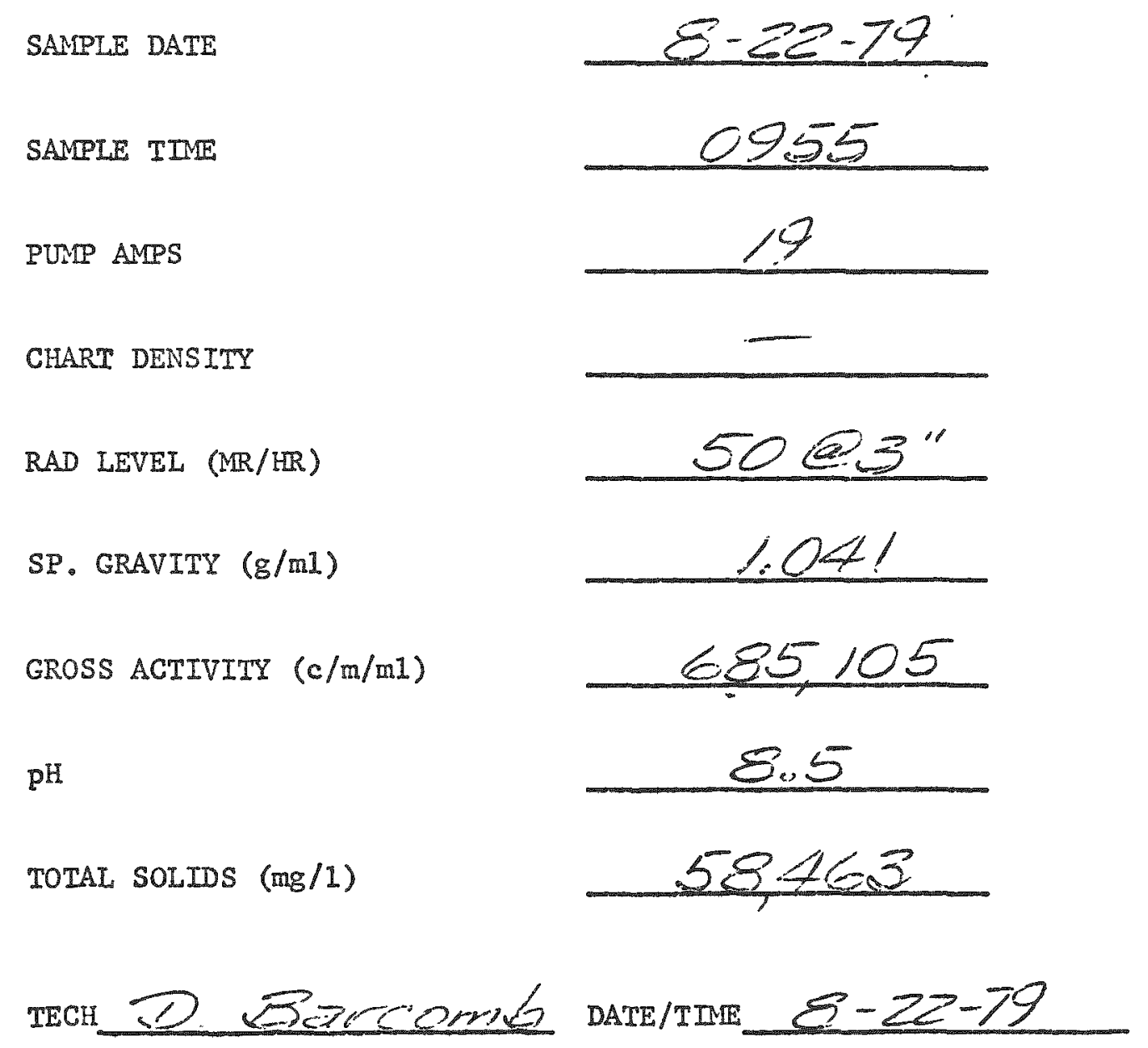

Exhibit 22 (Cont'd.) 
CONCENTRATOR ANALYSIS DATA

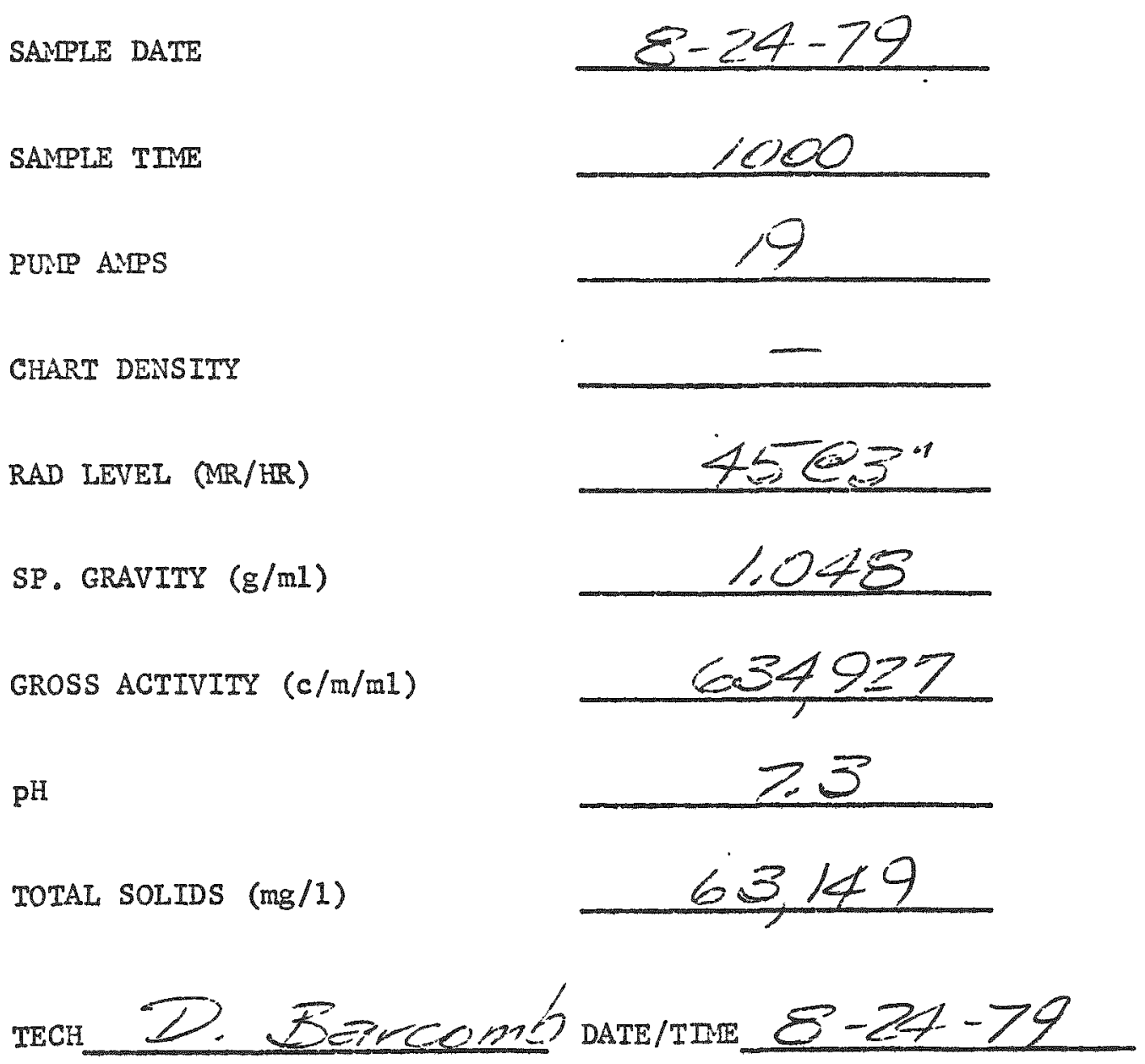

Exhibit 22 (Cont'd.) 
CONCENTRATOR ANALYSIS DATA

SAIPLE DATE

SAIPIE TIME

PU.P A.PS

CHART DENSITY

RAD LEVEL (MR/HR)

SP. GRAVITY $(\mathrm{g} / \mathrm{mI})$

GROSS ACTIVITY $(\mathrm{c} / \mathrm{m} / \mathrm{mI})$

$\mathrm{pH}$

TOTAL SOLIDS (mg/1)

$\mathrm{TECH} \perp \angle E C O C K$
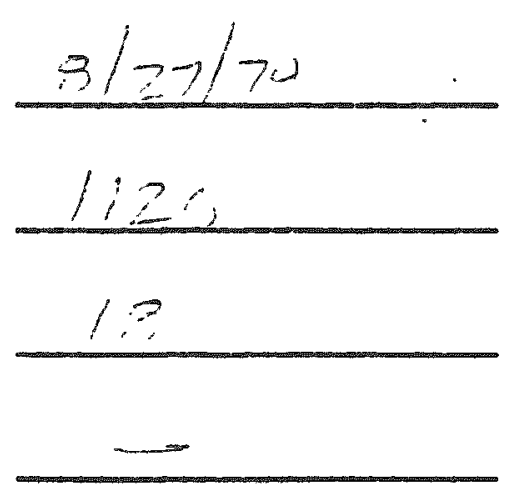

$100.3^{\prime \prime}$

1.012

132,209

0.9

18,537

DATE/TIME_ $8 / 27 / 79 \quad 1320$ 
ORNL EVAPORATOR QUESTIONNAIRE FOR NINE MILE POINT - UNIT 1 FORCED CIRCULATION EVAPORATOR

1. What type evaporator (pot, etc.; Iong or short tube; internal or external heater; vertical or horizontal heater; natural or forced. circulation; wiped film, etc.) is used? What is the size of the heating element or calandria? Of the flash chamber or vapor head? What materials of construction are used? What is the design capacity (gpm)?

2. Who manufactured the evaporator? Condenser? Awxiliary equipment? Is the equipment that originally installed or a replacenent?

3. What mode (batch, semi-batch or semi-continuous, continuous) of operation is used? For a batch operation, what size batch is added to the evaporator? For a semi-batch (or semi-continuous) or a continuous operation, what are the minimum, maximum, and average feed rates? How does the maximum capacity that can be achieved compare (ratio) with the design value? Is the feed degassed? How? Is the feed prefiltered?

4. What portion of the time is the evaporator operated (days/year)? Maxirnum? Minimum? Average? What are the heat-up and cool-dom times? What loss of capacity do these times represent?

5. What is the boil-ofi rate? How is the heat supplied (e.g., gas-irired bojler)? At what pressure or vacuun does the evaporator operate?

6. How is the evaporator (Iiquid level, solids content, steam pressure, etc.) controlled? Which controls are manual? Automatic? How is the evaporator feed (condensate, thick liquor) sampled? Frequency?

7. What is the usual chemical (and radiochemical) composition of the feed to the evaporator? Range of deviation? Is the chloride concentration ( $\mathrm{mg} / \mathrm{ml}$ ) a problem? Are chemical additives other than antifoam agents used to improve periornance? What is purpose of each additive? Are antifoam agents added to the evaporator? Kind? Where? Rate?

8. What is the measured volume reduction factor (feed to thick liquor) achieved? Maximum? Minimum? Average? What is the design volume reduction factor? What storage capacity is provided for thick liquor? How is the thick liquor transferred (pump, gravity, etc.) from the evaporator? Is further volume reduction of the thick liquor carried out or contemplated? How (thin-film evaporator, calciner, etc.)?

9. Are defoaming devices (jets, heaters, etc.) built into the evaporator? Where? Are demisting devices (wire mesh, electrostatic precipitators, plates or trays, etc.) built into or external to the evaporator? Size? Decontamination factor? 
10. What are the equipment decontamination factor (thick liquor to condensate) and system decontamination factor (ieed to condensate) obtained for gross activity and for each specific nuclide checked, in particular, jodine? Average? Range? What methods are used to measure activities?

11. How do the measured decontamination factors compare with the design values? Ratio of design to measured?

12. Is the condensate treated (e.g., ion exchange) further? Kind of unit? Size of unit? Decontamination Iactor? Is the condensate recycled? To what system? Is the condensate discharged? Where?

13. How is the evaporator thick liquor treated (e.g., cenent, urea formaldehyde, etc.) before disposal? Weight and volume shipped. (annually)?

14. How long has the evaporator been in service?

15. Have you experienced any recurring operational problems (thick liquor solidifying, poor condensate quality, low capacity, etc.)? Remedy?

16. Have you experienced any corrosion problems? Where? Corrective measures?

17. Has decontamination of the unit been necessary? Why? How was decontamination accomplished? Has the heat transfer surface of the unit been cleaned? Method?

18. Are the components of the evaporator easily accessible for decontamination and maintenance? Are they separated? Skid mounted? Has dose rate from the unit posed a problem during routine operation, abnormal operation, or maintenance? What is the average dose rate $(\mathrm{mr} / \mathrm{hr})$ in the area during each of these kinds of operation?

19. Has the evaporator in general operated at, above, or below design specirications? What has been the average maintenance time (hr/year)? Does the evapoxator require excessive operator attention to perform satisfactorily?

20. Are changes or modifications to, or replacement of, the evaporator system planned to improve performance? What kind? When? 
Evaporator

1. The evaporator at Nine Mile Point has an external 2 pass horizontal heat exchanger with forced circulation. The heat exchanger is $3^{\prime} 2^{\prime \prime}$ in diameter and $16^{\prime} 6^{\prime \prime}$ in overall length. There are 154-2" ODx14BWG (average wa11) $\times 12^{\prime}$ long $316 \mathrm{~L}$ stainless steel tubes. The vapor body is $6^{\prime}$ in diametex and $18^{\prime} 6^{\prime \prime}$ in overall height. The unit is constructed of 304 stainless steel. The design capacity is $20 \mathrm{gpm}$.

2. The unit is an H.P.D. with a Morris $16^{\prime \prime}$ HoGV axial flow pump. The concentrator feed pump, concentrator waste transfer pump and the concentrated waste pump are Goulds $1 \times 2-10$.

3. Semi-continuous

Feed rates 5 to $20 \mathrm{gpm}$ - average feed rate is $15 \mathrm{gpm}$. The unit will operate at the full design flow of $20 \mathrm{gpm}$. The feed is not degassed. The feed from the floor drain sample tank is not filtered. The feed from the waste neut. tank is not riltered. The floor drain is filtered thru a septum filter precoated with DE (Celite 545).

4. Concentrator is operated 9.5 hrs a day to process floor drain water. When a waste neut. tank requires processing it can be processed in $16.5 \mathrm{hrs}$, this is at the average feed rate of 15 gpm. We average 1 waste neut. tank every $11 / 2$ weeks. Taking actual operating times from the stean flow recorder, yields a minimum operating time of $7 \mathrm{hr}$ per day. Average operating time of 14 hrs per day. Maximum operating time of 36 hrs. Many times steam flow is reduced to keep the concentrator on line while another feed tank is being prepared.

Unless concentrator has been emptied, the nomal idle temp of liquor is about $200^{\circ} \mathrm{F}$. Then we can bring unit on line in about $45 \mathrm{~min}$ at full capacity. Cool down for entering the concentrator for inspection is not a problem. We have entered the vapor body within 12 hours after shutting down. If any maintenance work such as polishing had to be done a longer cooling time would be necessary. To date we have not experienced any appreciable loss of capacity due to heat up and cool down.

5. The boil off rate is $20 \mathrm{gpm}$, a $11,850 \mathrm{ibs} / \mathrm{hr}$. Stean is supplied from a $4800 \mathrm{KW}$ resistance element electric boiler, which is rated at $16,000 \mathrm{lbs} / \mathrm{hr}$ e $65 \mathrm{PSIG}$. The boiler is operated at approx. 27 psig which gives us about $245^{\circ} \mathrm{F}$ at steam inlet to heat exchanger. This of course is to prevent a high $\Delta T$ across the heat exchanger tubes. The concentrator operates at or slightly above 14.7 psia.

Exhibit 23 (Cont'd.) 
6. The evaporator level is controlled by adjusting feed flow automatically to maintain a fixed level in the evaporator. The level is sensed with a bubbler type of level sensor. The level signal is density compensated. The heat exchanger steam pressure is a function of steam flow. At the present time the demister wash is mamul and bottoms withdrawal is manual. Startup and shutdown are manual operations, selection of distillate flow path is automatic.* We have installed a circuit to shut off steam flow on a recirc. pump trip and a pump trip on low low level. Stean flow and level are automatic functions. The tanks that are to be concentrated are sampled and checked for $\mathrm{Ph}$. and chlorides. Evap bottoms are sampled twice each week minimum, by drawing off a 1 liter sample fron the waste transfer punp recirc loop.

* With manual override.

Concentrator Feed Solutions (Estimates)

7. W. Neut.

- $2 \% \mathrm{Na}_{2} \mathrm{SO}_{4}$ and varying concs. of soluable and insoluable iron, calcium, magnesium and silica compounds as carbonates, sulfates, chlorides, phosphates and oxides. Also includes varying concs. of resin fines (anion-cation). $\mathrm{pH}=6-9$ activity is generally $-10^{-1} \mu \mathrm{c} / \mathrm{ml}$.

Floor Drains

ppm concentrations of $\mathrm{Na}_{2} \mathrm{SO}_{4}$ and varying concs. of soluble and insol materials as above. $\mathrm{pH}$ is adjusted to 6.0-9.0 range. Activity $=-10^{-3} \mu \mathrm{c} / \mathrm{ml}$. Chloride control is accomplished by adding isodium phosphate. Dow antifoam " $B$ " is used for foam control. I liter of antifoamant is added directly to concentrator or it is added to the feed tank, depending on amount of foam in concentrator.

8. A volume reduction of 400 on floor drain tanks and 15 on waste neutralizer tanks. The design is 20 . Liquor storage capacity is 8000 gals. Liquor is transferred by a centrifugal pump from the low point on the concentrator (circulator pump discharge pipe) to the top of the concentrated waste tank. Further volume reduction is planned using the Newport News RWR-1 sjatem which we are planning to install.

9. No defoaming devices in this unit. A stainless steel demister pad 3 feet in diameter and 1 foot thick mounted interna1. The Demister D.F. is $10^{2}$.

10. Equipment $D F=2.7 \times 10^{4}$, regen $D F$ (feed to distillate) $=2 \times 10^{2}$, Floor drain $10^{2}$, no further information is available.

11. Design Equip DF $10^{5}$ (Bottoms/Distillate) Design DF $-2 \times 10^{4}$ (Feed/Distillate) 
12. The distillate nomally is routed to the waste building equipment sump which is pumped to the waste coll. tank. The waste collector water is filtered and then passed thru the waste demineralizer (deep bed). (See Ion Exchange Questionnaire.) Condensate is returned to condensate storage. Condensate has been discharged to Lake Ontario when we have had excess. This is infrequent.

13. Evaporator bottoms are currently solidified using a U.F. system. Liquid waste is stored in an $8000 \mathrm{gal}$. tank in a heated room. Prior to pumping to the solidification an air sparger is turned on to mix up tank. $280 \mathrm{M}^{3}$ including solidification agent annual voluse of evaporator bottoms.

14. 19 months.

15. We have had high conductivity in the distillate which is caused by the anion resin which is a quaternary mathyl amine with a diviny 1 benzene polystyrene copolymer base breaking down to form a quaternary methyl amine vapor. By running the vapor condenser at $210^{\circ} \mathrm{F}$ we remove the volitol via the vent system. We have also had problems pumping the liquor fxom the concentrator to the storage tank. We are currently contemplating installing a different pump.

16. We have had no corrosion problems at this time. We have had test coupons installed of $304,316 \mathrm{~L}, 304$ welded with $316-\mathrm{L}$ rod these are all stainless steel. Also an Incoloy 825 coupon welded with Incoloy $625 \mathrm{rod}$, and Incoloy 825 coupon and a Hastalloy $G$ coupon. These coupons are typical $U$ bend prestressed style. The 304 coupon is being checked for any sign of stress corrosion cracking since they are prestressed, any cracking should take place on the coupon before it effects the vessel. The other materials are installed to test other types of alloys for future evaporators.

17. Evaporator has been cleaned out for inspection and demister pad replacement. Both times after the liquor was pumped out and the cvaporator was filled with condensate and circulated for an hour or so and then drained. The cover and denister were removed with maintenance personnel wearing full face breathing air masks. Airborne particulate survey with concentrator open was $37 \%$ GPC. The demister pad was $550 \mathrm{MRAD} / \mathrm{hr}$ at $3^{\prime \prime}$. The total exposure for the job-8 maintenance personnel $67 \mathrm{mr}, 1 \mathrm{rad}$ protection tech $5 \mathrm{mr}$. The heat exchanger has not been cleaned other than boil outs with condensate about every 4 months.

18. The evaporator is sectionalized with the vapor body in a shielded room, the recirc. pump in another, the heat exchanger in another along with the distillate cooler. The vapor condenser and vent cooler is not shielded. The transfer punp and the concentrated waste pump each have their own shielded cubicle. Dose rate in the various rooms has not posed any operating problens. For maintenance radiation levels see question 17. Normal operating radiation levels can run as high as $1 \mathrm{r} / \mathrm{hr}$ depending in liquor activity although we generally limit the activity to $2 \times 10^{6}$ counts per min/ML, average dose rate is about $200 \mathrm{mr} / \mathrm{hr}$.

Exhibit 23 (Cont'd.) 
19. The evaporator has in general operated according to specs. We have not found it necessary to operate at the full rate of $20 \mathrm{gpm}$. 15 to $17 \mathrm{gpm}$ seems to satisfy our needs. We have had to repack and clean out the concentrator waste transfer pump several times the other pumps have had to be repacked several times. Actual maintenance time is not available at this time. Once the unit is on the line and stable only casual operator attention is needed.

20. We are currently in the process of preparing to remove our original natural circulator concentrator and replace it with a current "state of the art" unit. On the HPD unit we are modifying level instrumentation, we have installed larger volume and wider angle demister sprays. We are contomplating installing the demister in a separate vessel, replacing transfer pump and installing a flushing system for flushing out pusp and piping after each use. We are also modifying bubbler type density instrumentation so it will be more accurate. We are plotting recirc pump amps versus density as a backup for the density instrumentation. A timed demister wash cycle will be added. Automatic routing of distillate depending on conductivity. These changes are contemplated over the next year. 


\section{HPD Incorporated}

\section{DETERGENT TEST}

One source of radwaste evaporator feed is the nuclear laundry. Presently plants are either discharging this laundry stream, sending their laundry off site for processing, or have purchased a drycleaning system to eliminate the laundry waste. HPD investigated detergent usage at existing plant sites and found that processing of these detergents through the evaporator often caused foaming and thus was not an acceptable operating procedure. HPD conducted bench scale foaming tests on all detergents presently being used in the nuclear industry, together with all antifoams typically used in the nuclear system. We found that there was a definite need for a low foaming detergent capable of good decontamination capabilities yet can be easily processed in the evaporator without the addition of antifoam agents. HPD conducted $a$ pilot demonstration for a number of utilities to demonstrate the non-foaming soap being processed in our evaporator. Figure 2 shows the "Nuclear News Magazine" writeup from the detergent demonstration.

HPD markets this detergent as a service to our clients. Samples of the detergent are available upon request for actual inplant testing.

In conjunction with our detergent test program HPD determined that the anti-foam agents presently used in nuclear power plants are ineffective. We have found that a number Exhibit 24 (Cont'd.) 


\section{HPD Incorporated}

of commercially available formulations, not used in operating plants to date, are much more effective and reliable for evaporator operation. HPD evaporator crystallizer systems often do not need anti-foam additions. It is wise to have available an anti-foam system and proper anti-foam chemicals so that should a waste stream create foaming problems, the evaporator does not become the limiting component.

\section{ENTRAIMMENT SEPARATOR TESTS}

Based on inplant experiences, HPD pioneered the use of a separate entrainment separator. We have used our pilot plant system to determine the effectiveness of valve trays, mesh pads and packing. The HPD pilot plant system is equipped with both valve trays and mesh pads with the ability to recycle distillate on a continuous or intermittent basis. From our test work we have determined that mesh pads as, provided in the HPD design, are capable of offering high quality distillate when concentrating typical BWR waste streams with non-volatile components. PWR secondary liquid waste streams operated under a low $\mathrm{pH}$ condition can also be processed using mesh pad separators. We have also determined the need for valve trays when processing boric acid due to boric acids operating characteristics and slight volatility. Based on data determined by pilot plant operation we can also determine proper reflux rates, wash 


\section{HPD Incorporated}

requirements for pads, and optimum entrainment separator velocities.

\section{DENSITY INSTRUMTENTATION}

HPD utilizes some very unique instrumentation in our radwaste system. The use of the Dynatrol density meter and critical angle refractometer have required special development. We have installed in our pilot plant system a Dynatrol unit to check and calibrate the instrument based on typical nuclear plant waste streams. HPD will also be conducting surveys of actual inplant operations of both density devices as data becomes available. This data will be checked with the information gained in our pilot testing program. Present developments have already led to proper flushing and mounting details for the density instruments.

SODIUM SULFATE CONCENTRATION

Concentration of sodium sulfate to 50 percent total solids requires operation of the HPD evaporator crystallizer in the crystallizing mode. Figure 3 provides a solubility diagram for sodium sulfate and sodium sulfate decahycrate. This phase diagram will change slightly based on impurities such as floor drains and other waste input in the power plant. HPD has operated our pilot plant crystallizer at 50 percent solids with sodium sulfate as this represents 


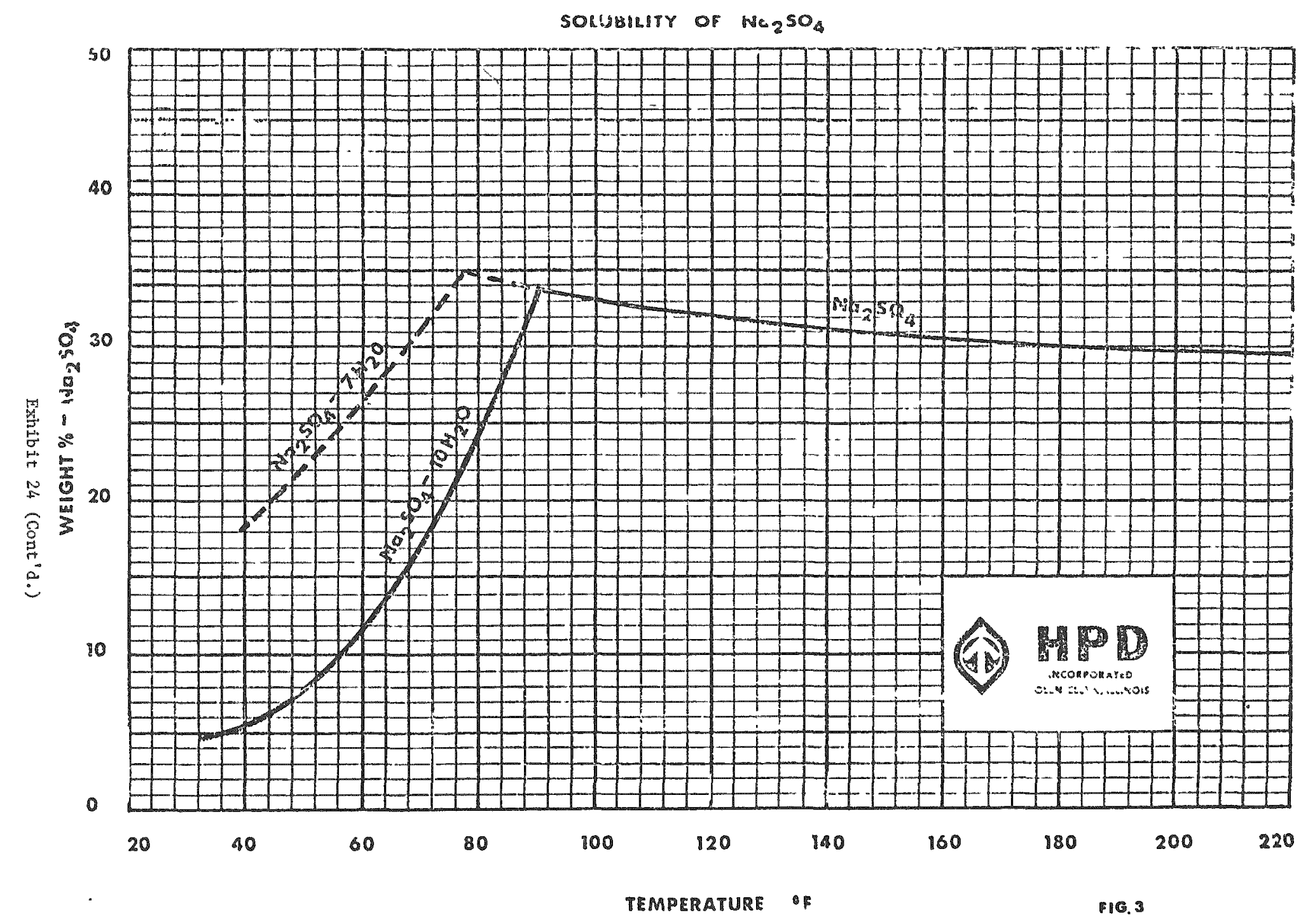




\section{HPD Incorporated}

the highest slurry concentration one might expect in a radwaste system due to sodium sulfate's limited solubility. Although HPD has a number of operating installations processing this type of waste as well as a good deal of experience in the chemical industry we used our pilot system to determine the effects of (a) power failure causing the recirculation pump to stop (b) the effectiveness of polished surfaces (c) increased reliability due to $2^{\prime \prime}$ diameter tubes (d) effects of impurities on the solubility diagram of sodium sulfate (e) ability of different types of valves such as plug valves to perform in service.

BORIC ACID OPERATION

When concentrating boric acid it has been determined that neutralization of the boric acid feed stream prior to concentration is definitely recommended. Neutralization offers the plant operators the highest volume reduction with minimum operating difficulties. Concentrating boric acid to 50 percent total solids without neutralization requires substantial interface considerations. It has been demonstrated based on past pilot runs with unneutralized boric acid that (a) heat tracing of all instrument lines and flanges are required (b) insulation must be properly designed for the overall system (c) feed inlet modifications are required. The above requirements are 


\section{HPD Incorporaled}

necessary when processing boric acid to 25 weight per cent and are mandatory if processing unneutralized boric acid to 50 percent total solids.

It is possible to concentrate unneutralized boric acid with the HPD crystallizer to 50 weight per cent as has been demonstrated in past tests with pilot plant system but due to the rigorous operating procedures required, HPD felt it was necessary to develop a bettex operating procedure. Refer to Figure 4. As one can see by this diagram the solubility of boric acid is definitely a function of $\mathrm{pH}$. Therefore, by neutralizing the boric acid solution prior to concentration one can achieve the highest solids concentration possible with minimum operating problems. It must be pointed out that it is not recommended to operate near the saturation point when concentrating any solution. By proper neutralization of the boric acid one can concentrate to 50 per cent equivalent boric acid yet still remain in solution.

As discussed earlier, boric acid exhibits a slight volatility and thus requires the use of valve trays and distillate reflux system to provide high quality distillate.. AMMONIUM SULFATE SODIUM SULFATE

Volatile treatment programs utilized by all major steam generator suppliers for protection of secondary side 


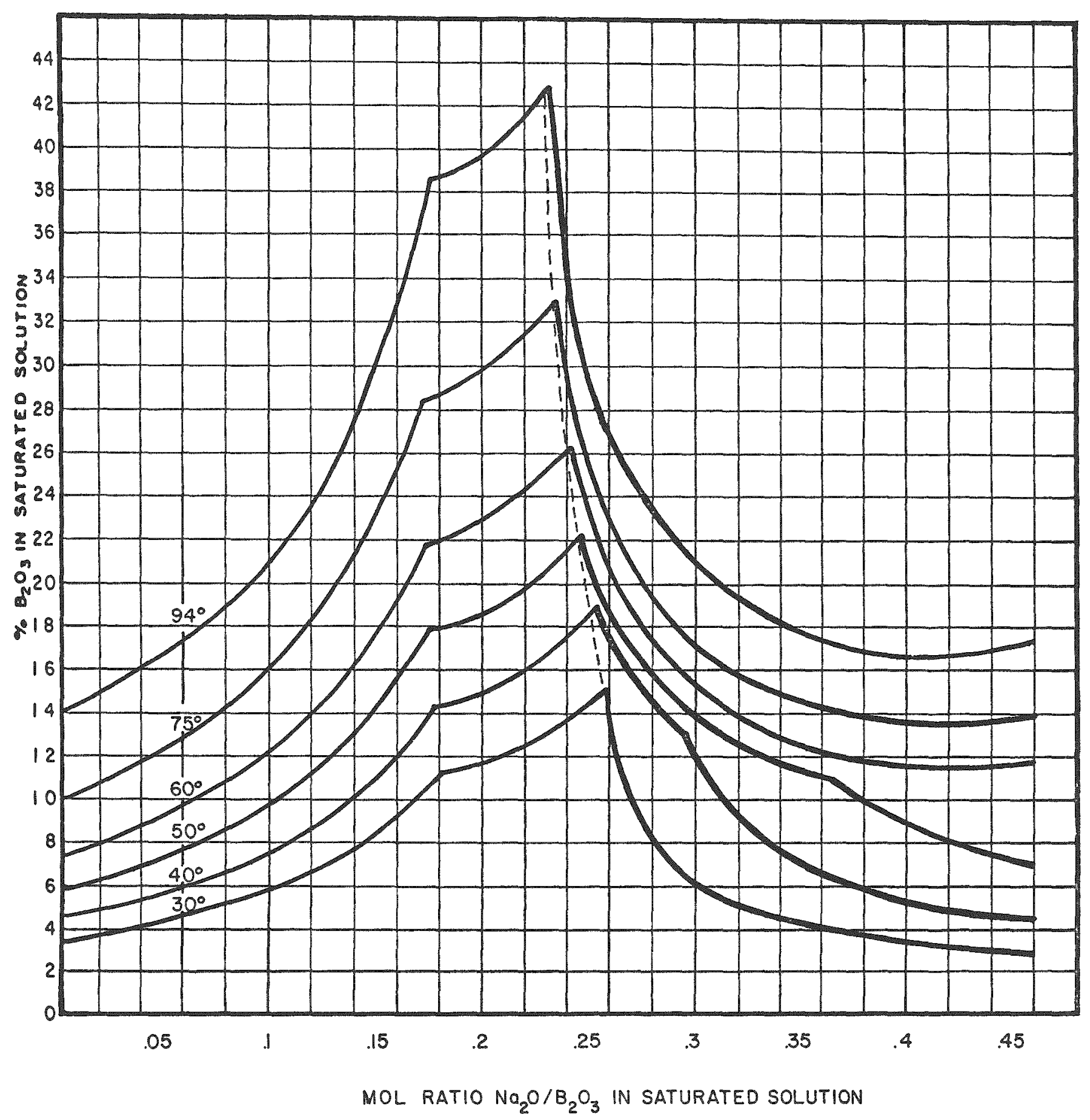

SOLUBILITY ISOTHERMS IN NEUTRALIZED BORIC ACID SOLUTIONS 


\section{HPD Incorporated}

equipment utilizes hydrazene or ammonia. The ammonia is collected on the demineralizers. If a regenerative type demineralizer is utilized the resultant regeneration waste contains ammonium sulfate and sodium sulfate. Ammonium sulfate has a definite volatility which will release a substantial amount of ammonia in resulting evaporator distillates and vent lines unless the proper $\mathrm{pH}$ of the feed to the evaporator is established. Figure 5 provides some typical data for the amount of ammonia which is evolved in ppm based on a solution typical of a PWR regenerant. It is evident from the data that one must either operate at low $\mathrm{pH}$ in the evaporator system to keep all ammonia in solution or to remove the ammonia prior to evaporation. Stripping the ammonia from the distillate would be the most difficult as it would be hard to control the evaporator concentrate at a constant $\mathrm{pH}$ condition as the ammonia is evolving off in the evaporator. HPD recommends either removing the ammonia from the feed or keeping the ammonia in solution via low $\mathrm{pH}$ operation.

HPD has recently developed a new system which requires minimum capital cost for removal of the ammonia from the feed. This system is proprietary and details are available upon specific request.

Exhibit 24 (Cont'd.) 


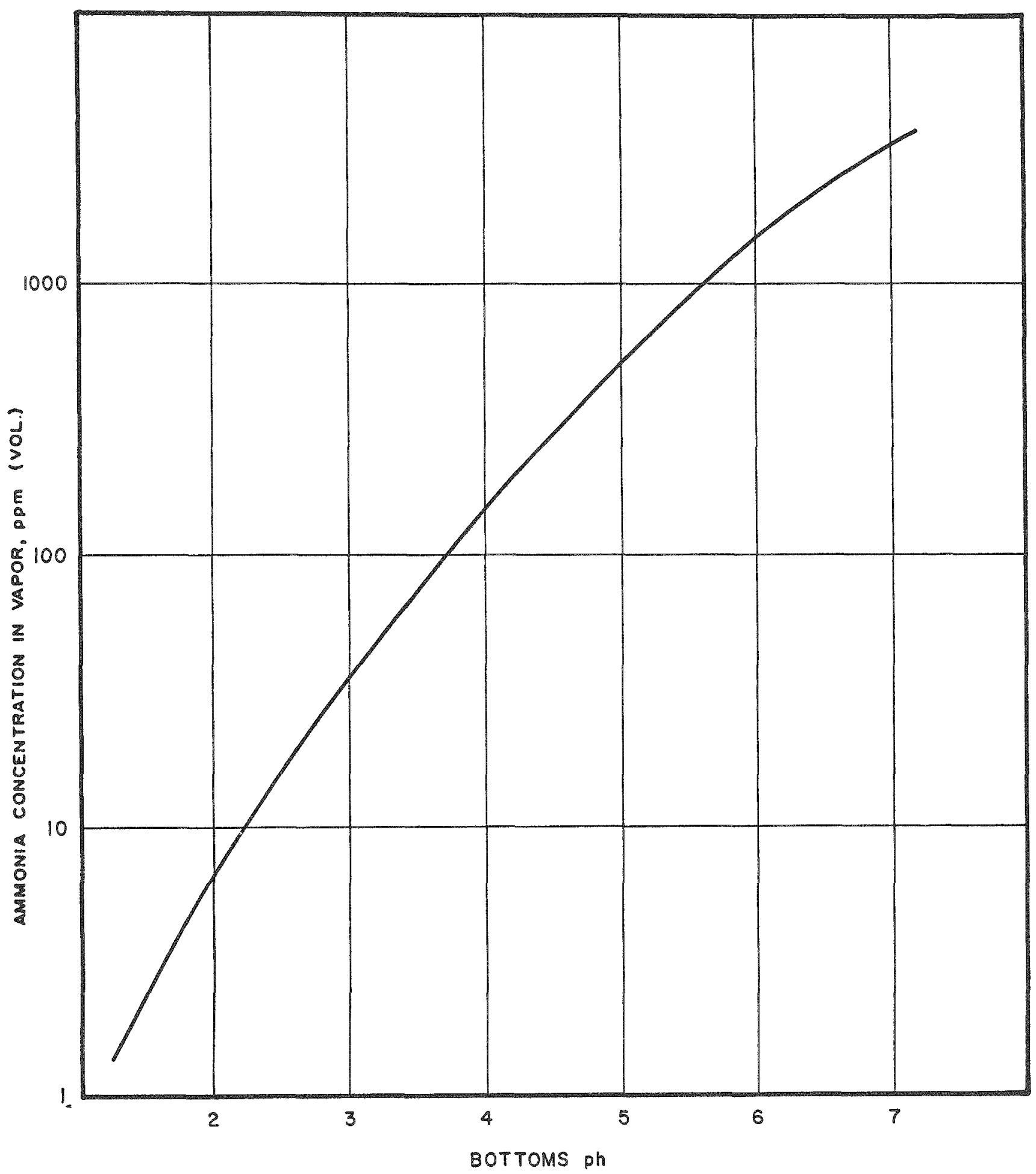

EQUILIBRIUM CONCENTRATION INVAPOR ABOVE BOILING, CONCENTRATED ION EXCHANGER REGENERATION WASTES.

Exhibit 24 (Cont'd.) 


\section{HPD Incorporated}

HPD has also developed phase diagrams for the ammonium sulfate, sodium sulfate impurities solution typical of the PWR regenerant. This phase diagram is also quite proprietary as it is not available, to our knowledge, except from experimental test work. HPD provides such information to our clients to enable them to properly design interface equipment. Solubility of the ammonium sulfate, sodium sulfate mixture is higher than the typical sodium sulfate stream concentrated in the boiling water reactor. It is possible to concentrate PWR regenerant solutions to higher than 50 percent total solids in HPD crystallizer systems. 
Newport News Fluidized Bed Incinerator

Radwasce Volume Reduction System Questionnaire

1. Brief description of system (please attach layout dwgs. \& $P \& I D$, if available). See Attached

2. Feedstock Description:

a) Feedstock Designation (1)

b) Type of Waste

c) Volume per yr.

d) Total solids conc. (ppm)

e) Suspended solids (ppm)

f) Conductivity (umho/cm)

g) $\mathrm{pH}$ :

i) Before adjustment

ii) After adjustment

h) Specific gravity

i) Temperature $\left({ }^{\circ} \mathrm{F}\right)$

j) Slurry wastes:

i) Solids conc. (vol. \%)

ii) Interstitial Water (vol. \%)

iii) Free water above settled sludge (vol.\%)
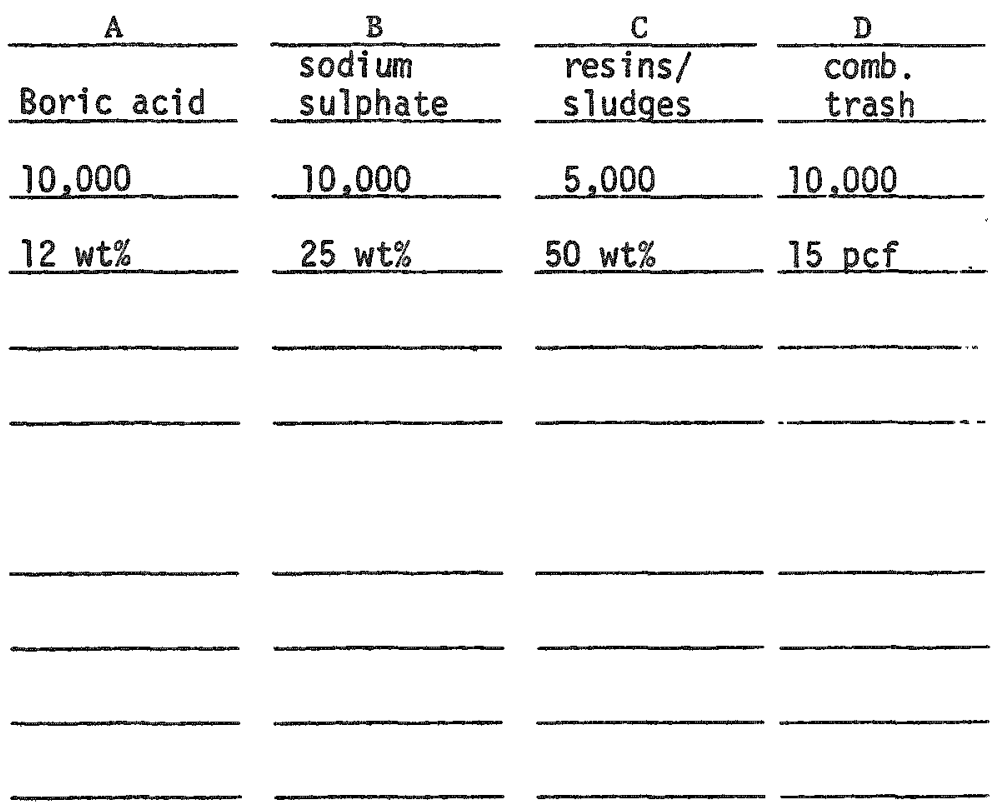

(1) Feedstock $A$ or $B$, in combination with $C$ and $D$, depending upon PWR or BWR.

Exhibit 25 
k) Radionuclide content

by major isotopes $(\mu \mathrm{Ci} / \mathrm{mI})$ :
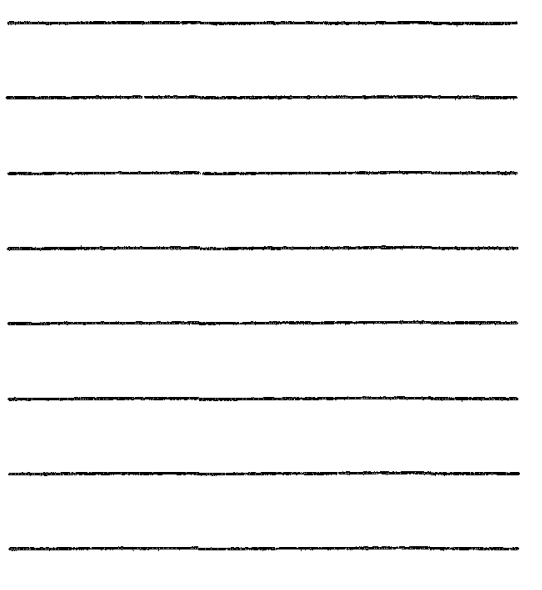

3. Auxiliaries (give pressure, temperature, flow rates, etc.):
a) Steam -
b) Cooling water -
c) Service air -
d) Electric -
e) Other

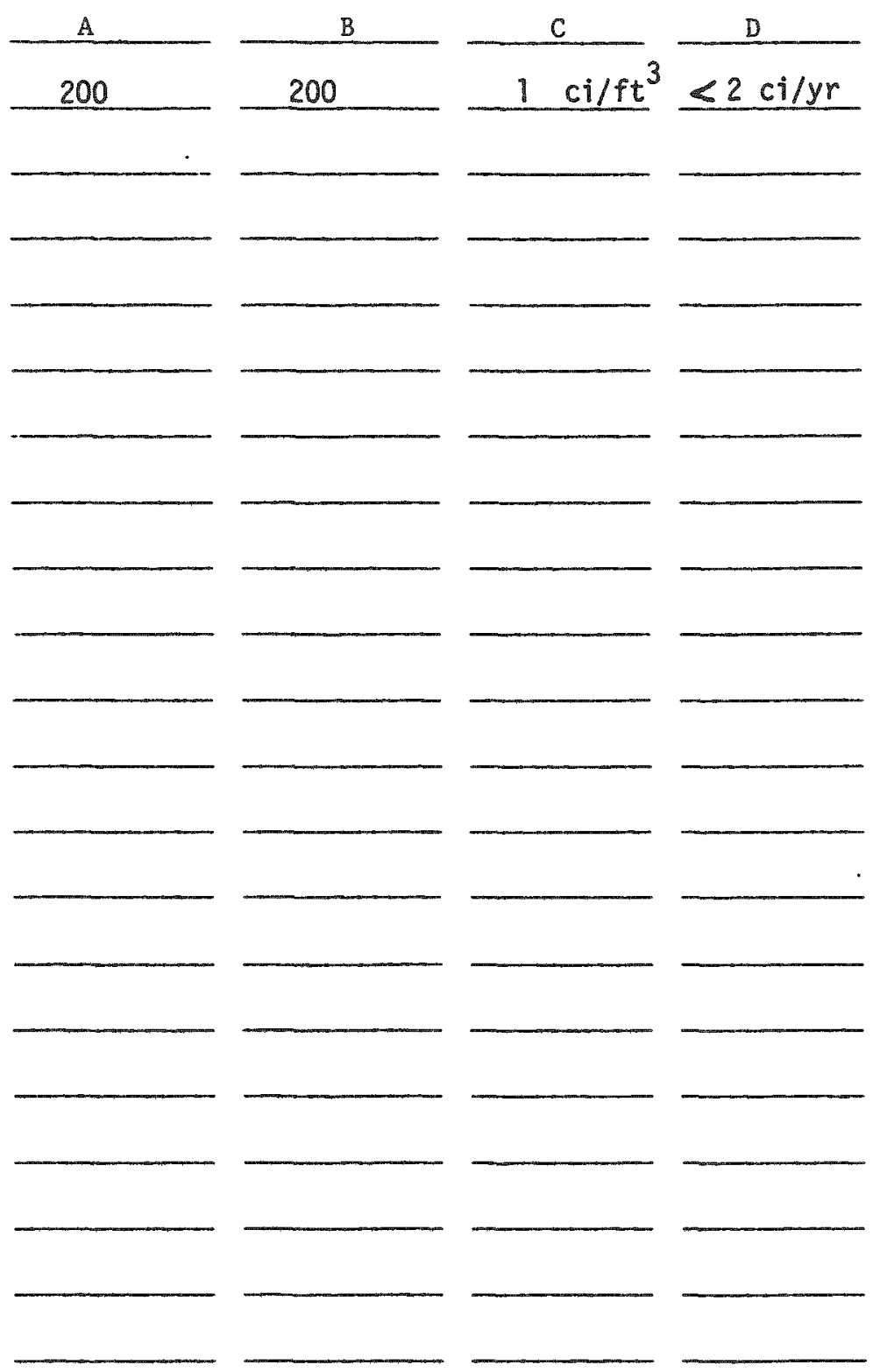

None

$200 \mathrm{GPM}$ \& 100 PSIG O $90^{\circ} \mathrm{F}$

$1000 \mathrm{scfm}$

$400 \mathrm{~kW}$

Exhibit 25 (Cont'd.) 
4. Operating Data:
a) Feed rate (gpm)
b) Bottoms conc. (wt. \%)
c) Volume reduction factor
d) Decontamination Factors (feed to distillate):

i) overal1

ii) major isotopes:

e) Curie content of bottoms $(\mu \mathrm{C} 1 / \mathrm{cc})$

f) Radiation level in bottoms (mr/hr):

i) Surface of container -

ii) One foot from container -

(1) Nominal Feed Rates

- Evaporator Bottoms:

- Resins/s ludges:

- Trash:

$41 \mathrm{gph}$
$200 \mathrm{Ibs} / \mathrm{hr}$
$140 \mathrm{Tbs} / \mathrm{hr}$

(2) Average Volume Reduction Factors

- Evaporator bottoms:

- Resins/STudges:

- Combustible Trash:
See (1) below

see (2) below

$10^{6}$ Particulates

$10^{4}$ Iodine 
5. Operating History: (Full Scale Pilot Plant)
a) Date unit installation completed -
b) Date unit first operated (with radioactive waste) -
d) Total number of operating hours July 1977

\begin{tabular}{l} 
Julv 1977 \\
October 1978 \\
4000 hrs \\
\hline
\end{tabular}

6. Cost Factors:
a) Initial equipment cost -
b) Installation cost
c) Building costs (e $\$ 250$ per sq. ft.)
d) Operating costs ( $\$ / g a l$. of waste feed)

$\$ 2.5-\$ 3.5$ million

approx. $\$ 700,000$

i) Personnel (@ \$15 per hr)

$\$ 90,000$ yr

ii) Auxiliaries

$\$ 25,000$ yr
iii) Solidification Agent (if integral part of VR system)

$\$ 115,000 / \mathrm{yr}$

iv) Total 
7. Describe any major operating difficulties experienced with the VR system and what measures were taken to correct them.

$n / a$ 


\section{$A-163$}

$-6-$

8. List all forced outages, including cause of outage (general maintenance, pump failure, etc.) and duration.

$n / a$ 


\section{DESCRIPTION OF NEWPORT NEWS \\ FLUIDIZED BED CALCINER/INCINERATOR}

\section{Process Description}

\section{Genera}

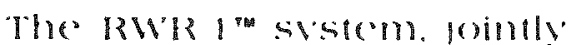
ceveloged by Newent News inctustrial comporation and linerge incomongated.

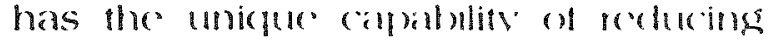
both licpuct and solut fartwasto in int anhyefrous gramular sobet the recluchom of licluels foaleination) amel soldels fincinerationt is arecomplished in a single chamber process vossin wheh contains the lludized bed lhis proprictary lludized hed asesh allows the system to mo'the independent of Waste strenm chemistry. $\alpha$ variety ot fuclscan bx" 140 ol toprovirloprocessheat:

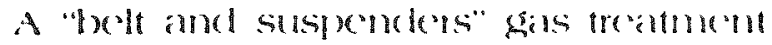
dosign assure "s that molouctive materals are remoxed trom the otf gas prior lo its release to the plant stark.

\section{Miscellaneous Combustible Solids}

Miscollano(n) comblistiblo"

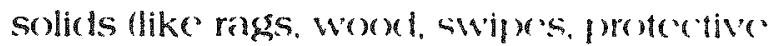
clothing and plastic bassi which are generated fluring the mommal dably plant operation-and seneratted in larse quan

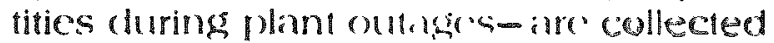
in a hopper (6). A shedder buill ind the hopper shrels the matellal into stpall piccos. The shudded praces are thented into the process ressel fol by moans ot scre $W$ freder. Tho shredred nialelial is then incinerated and reduced to small quantity of nomeombusable suld pite. rial.

\section{Or?-Gas}

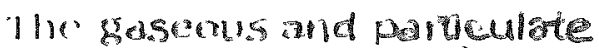
products of the calcinoth and inciner.

\section{Ligฺ̣ îd}

comcentrated licund waste is

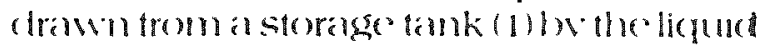
waste pumple (2) and injerted ante the primany poressvessel (9). The heated

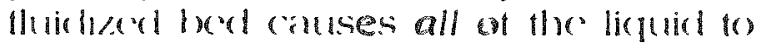
evapolate, thus convertme the inpult waste stream 10 a small quanthy of an hy drous solid material

\section{Spentresins piltor Siudges}

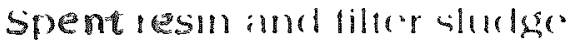

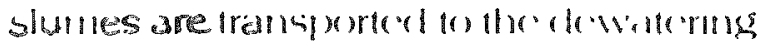
tank (4). The liquid is remosed $x^{\circ}$ tho dew tenng pump (25). The "dry" soliots are then fed into the primary process vessol (9) where the are incimeraterland redueed to a smbull fllantity of nom. combustible solid material

ationpm csses leave the primary process vessel (9) and pass through a dry cyclone (10) where particulates are removed. The oftegas then passes through a quench ank (12) where the temperature is re ducad by contact with a scrub solution spray. The gas then passes through a venturi scrubber $(13)$, i) wet cyclone $(14)$ a a condenser (15) and a mist elininator (16). Particulates carried over from the dry cychane are captured in the scrub uhlution aryd rewned to the scrub solution timk and then the mist elimindor; the ras pasyes hrough an inilial HEPA filter( 17 . an rodine adsmber $(18)$ a find HEPA filter (19), and blower (20) betore discharge 10 the plank stack 


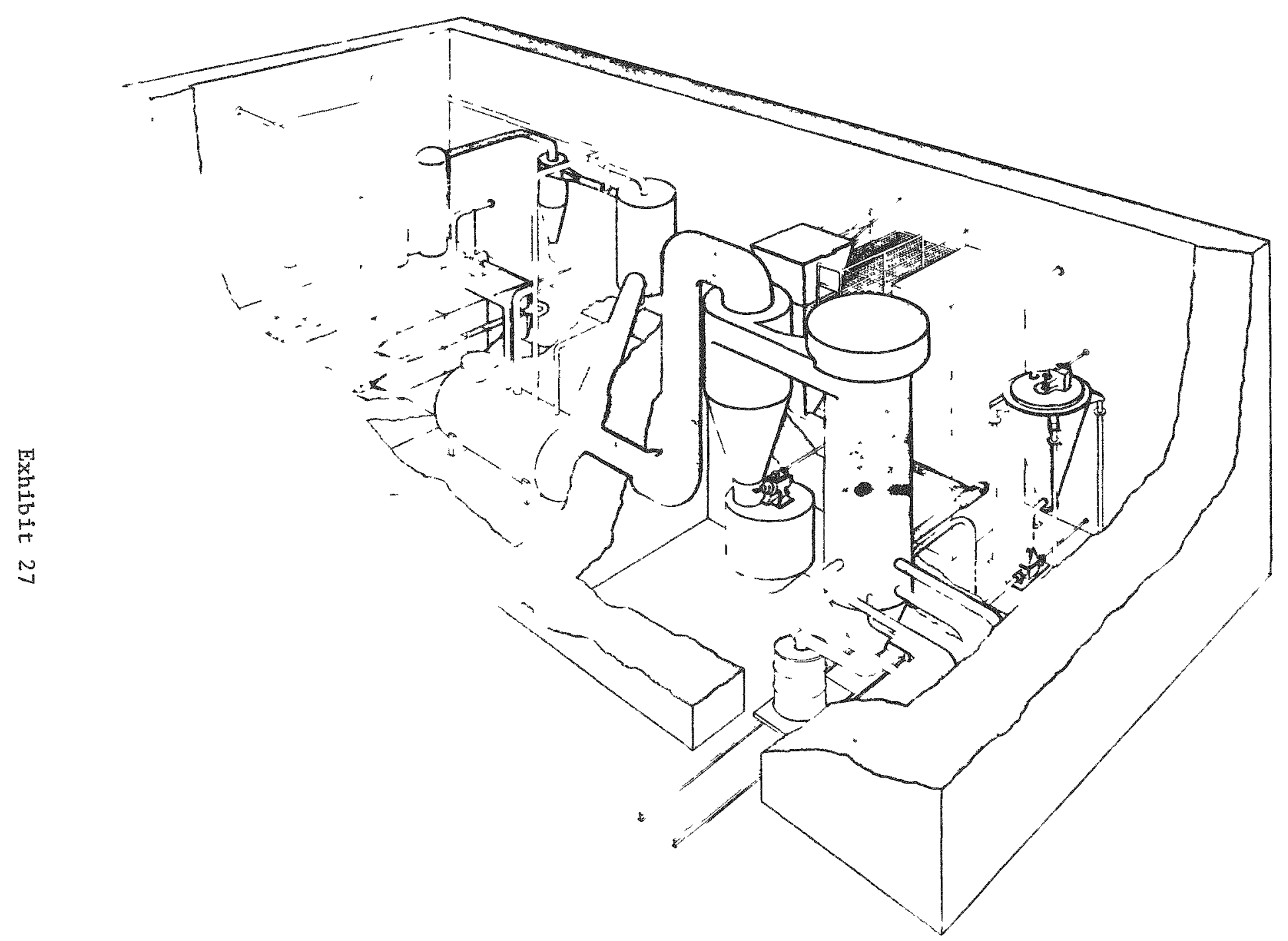

菑

MATT HANT - NEWPORT NEWS RWS-1 FLLIDIZED BED DRYER/TNCINERATOR 


\section{BIBL IOGRAPHY}

\section{A. Filtration}

1. Brooks, N.S. and Chow, E.R., Cartridge Filtration in Pressurized Water Reactors, presented at AIChE/Filtration Society Annual Meeting, Houston, Texas, March 1975.

2. Gischel, E.H., "Radioactive Fluid Filtration Systems, presented at ASME Winter Annual Meeting, New York, N.Y., November 1974, 74-WA/NE-4.

3. Kibbey, A.H. and Godbee, H.W., The Use of Filtration to Treat Radioactive Liquids in Light-Water-Cooled Nuclear Reactor Power Plants, ORNL/NUREG-41, September, 1978.

4. Kurihara, Y., Oda, M., Okugaw, K., Sunaoka, Y., Kleper, M.H., Markind, J., Goldsmith, R.L., and Ryan, J.M., "Treatment of Equipment Drain Wastes in a Nuclear Power Plant With an Electro Magnetic Filter and Ultrafiltration System", presented at

International Water Conference, Pittsburgh, Pa., November, 1978, IWC-78-16.

5. Parks, C.S., "Operating Experience With Two New Filter Precoat Materials", presented at International Water Conference, Pittsburgh, $\mathrm{Pa}$., November, 1978, IWC-78-36.

6. Pottier, P.E., Chemical Treatment of Radioactive Wastes, IAEA Technical Reports Series No. 89, STI/DOC/10/891968.

7. Tracy, R.L., "BWR Radwaste Filtration Pilot Plant Study Comparison", presented at International Water Conference, Pittsburgh, Pa., November, 1979, IWC-79-9.

8. Wedig, C.P., and Coplan, B.V., "Selection of Filters for Radioactive Liquids", presented at ASME-IEEE Joint Power Generation Conference, Buffalo, N.Y., September, 1976, 76-JPGC-NE-7.

B. Ion Exchange

1. Applebaum, S.B., Demineralization by Ion Exchange, Academic, New York, 1968.

2. Ames, L.L., Jr., Knoll, K.C., Loading and Elution Characteristics of Some Natural and Synthetic Zeolites, USAEC Rep. HW-74009 (1962).

3. Baetsle, L., Study of the Fixation and Migration of Radioactive Cations in a Natural Ion Exchanger, USAEC Transl. AEC-TR-3949 (1959).

4. Benson, D.W., Mineral Adsorption of Radionuclides in Reactor Effluent, USAEC Rep. HW-69225 (1961). 
B. Ion Exchange (Continued)

5. Burns, R.H., Clarke, J.H., Wright, T.D., "Filtration and ion-exchange plants in use at the Atomic Energy Research Establishment, Harwell", Practices in the Treatment of Low- and Intermediate-Level Radioactive Wastes (Proc. IAEA-ENEA Symp. Vienna, 1965), IAEA, Vienna (1966) 223-54.

6. Clarke, J.H., et al., Investigation into the Use of Ion Exchange Resins for the Decontamination of Radioactive Effluent, UKAE Rep. AERE-R-4905 (1965).

7. Demier, W.V., Fixation of Radioactive Fission Products on Inorganic Ion Exchange Media, USAEC Rep. HW-SA-3233 (1963).

8. Emelity, L.A., Operation and Control of Ion-Exchange Processes for Treatment of Radioactive Wastes, IAEA Technical Report Series No. 78, 1967.

9. Fletcher, W.D., Ion Exchange in Boric Acid Solutions with Radioactive Decay, USAEC report WCAP-3716 (November 1962).

10. Haden, W.H., Jr., The Use of Inorganic Exchange Materials for Radioactive Waste Treatment, TID-7644 (1962).

11. Hancher, C.W., A Comparison of Fixed and Moving Bed Ion-Exchange,

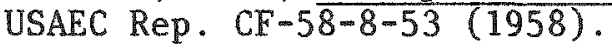

12. Higgins, I.R., Phillippi, G.C., Jones, J.D., Development of a Process for Continuous Phenolic Ion Exchange Treatment of Alkaline Intermediate Radioactive-Level Waste, USAEC Rep. ORO-604 (1963).

13. Holcomb, R.R., Roberts, J.T., Low-Level Waste Treatment by Ion Exchange. II. Use of a Weak-Acid, Carboxylic-Phenolic Ion-Exchange Resin, USAEC Rep. ORNL-TM-5 (1961).

14. Holcomb, R.R., Roberts, J.T., A Phenolic Resin Ion Exchange Process for Decontaminating Low-Radioactive-Level Process Water Wastes, USAEC Rep. ORNL-3036 (1961).

15. Jamison, D.K., et al., The Use of Organic Exchange Materials for Radioactive Waste Treatment, USAEC Rep. TID-7644 (1963).

16. Kadoya, S., Horioka, M., "Decontamination of Radioactive Water with Domestic Clay Minerals", 2nd Rad. Res. Mtg. in Science and Engng (1965).

17. King, L.J., Ichikawa, M., Pilot Plant Demonstration of the Decontamination of Low-Level Process Wastes by a Recycle Scavenging-Precipitation Ion-Exchange Process, USAEC Rep. TID-4500 (46th Ed.) (ORNL-3863) (1965).

18. Lin, K.H., Use of Ion Exchange for the Treatment of Liquids in Nuclear Power Plants, ORNL-4792, Dec. 1973. 
B. Ion Exchange (Continued)

19. Lindsay, W.T., Abrams, C.S., Ion Exchange Removal of Fission Products from High Purity Water. Development Work Associated with the PWR Radioactive Waste Disposal System, USAEC Rep. WAPD-PWR-CP-2636 (1957).

20. Mercer, B.W., Adsorption of Trace Ions From Intermediate Level Radioactive Waste by Ion Exchange, USAEC Rep. BNWL-180 (1966).

21. Mercer, B.W., Storage of Long-Lived Fission Products on Alumino-Silicate Zeolites, USAEC Rep. RL-SA-58 (1965).

22. Michael, N., Bel1, M., Evaluation of Ion Exchange Resins for Use in the Yankee Reactor, USAEC Rep. YAEC-115 (1959).

23. Nater, K.A., Irradiation Damage in Ion Exchange Materials, NP-9805 (1959).

24. Nelson, J.L., Ames, L.L., Mercer, B.W., Characterization and Application of Zeolites for Radioactive Waste Treatment, USAEC Rep. HW-SA-3333 (1964).

25. Permutit Co., LTD., Investigations Into the Use of Ion Exchange Resins for the Decontamination of Radioactive Effluent. Part I. Laboratory Trails, UKAEA Rep. AERE-R-3496 (1960).

26. Rhodes, D.W., Wilding, M.W., Decontamination of Radioactive Effluent with Clinoptilolite, USAEC Rep. IDO-14657 (1965).

27. Rimshaw, S.J., Winkley, D.C., Removal of ${ }^{137} \mathrm{Cs},{ }^{90} \mathrm{Sr}$, and ${ }^{106} \mathrm{Ru}$ from ORNL Plant Wastes by Sorption of Various Minerals, USAEC Rep. CF-60-4-17 $(1960)$.

28. Roberts, J.T., Development in Continuous Ion Exchange Equipment for AEC Applications, ORNL-2504 (1958).

29. Roberts, J.T., and Holcomb, R.R., A Phenolic Ion Exchange Process for Decontaminating Low-Radioactivity-Level Process Water Wastes, USAEC report ORNL-3036 (May 1961).

30. Sisson, A.B., Scott, J.S., and Selby, K.A., "Resin Evaluation for Removal of Radionuclides from PWR Steam Generator Blowdowns," paper presented at International Water Conference, Pittsburgh, $\mathrm{Pa}$. , November 1971 .

31. Sonnen, M.B., Ray, A.D., A Report on Sma11-Scale Decontamination of Radioactive Waters by Ion Exchange, Vanderbilt Univ., USA (1963).

32. Swope, H.G., "Treatment of Radioactive Wastes", Chapter 17, Ion Exchange Technology, Academic Press, Inc., New York (1956).

33. Wilding, M.W., Rhodes, D.W., Removal of Radioisotopes from Solution by Earth Materials from Eastern Idaho, USAEC Rep. IDO-14624 (1963). 


\section{Evaporation}

1. Bidwel1, G.P., "Technical Trade-offs in Designing Evaporators for Nuclear Power Stations," presented at ASME Winter Annual Meeting, New York, N.Y., Nov. 1974, 74-WA/NE-7.

2. Godbee, H.W., Use of Evaporation for the Treatment of Liquids in the Nuclear Industry, ORNL-4790, 1973.

3. Mende, H., and Freeze, H.L., "Evolution of Radwaste Evaporator in West Germany", presented at ASME-IEEE Joint Power Generation Conference, Long Beach, California, 1977, 77-JPGC-NE-13.

4. Yamomoto, Y., Mitsuishi, N., and Kadoya, S., Design and Operation of Evaporation for Radioactive Wastes, IAEA Technical Report Series No. 87, STI/DOC/10/87, 1968.

D. Reverse Osmosis

1. Crowson, F.R. "Role of Reverse Osmosis in Zero Release from a BWR", presented at International Water Conference, Pittsburgh, $\mathrm{Pa}$., 1974.

2. Kaup, E.C., "Design Factors in Reverse Osmosis", Chemical Engineering, Vol. 80, 46-50, April 1973.

3. Kikuchi, M., Sugimoto, Y., Yusa, H., Ebara, K., and Takeshima, M., "Development of a Laundry Waste Treatment System", Nuclear Engineering Design, Vol. 44, No. 3 pp. 413-420, Dec. 1977.

4. Kniazewycz, B.G., "The Treatment of Liquid Radwaste by Reverse Osmosis, Conception to Operation," presented at ASME-IEEE Joint Power Generation Conference, Portland, Oregon, September, 1975, $75-P W R-27$.

5. Lacey, R.E., "Membrane Separation Process," Chemical Engineering, Vol. 79, pp. 56-74, September, 1972.

6. Markind, J., and Tran, T.V., A Study of Reverse Osmosis Applicability to Light Water Reactor Radwaste Processing, NUREG/CR-0724.

7. Minard, P.G., et. al., "Two Year's Experience with a Reverse Osmosis Radioactive Laundry Waste Concentrator," presented at 2nd National Conference on Complete Water Reuse, Chicago, Illinois, May, 1975.

\section{E. Forced Circulation Evaporation}

1. Anthony, D., and Kallfisch, K., "Evaporator/Crystallizers for Radwaste Service," presented at Symposium on Management of Low-Level Radioactive Waste, Georgia Institute of Technology, Atlanta, Ga., May, 1977. 
E. Forced Circulation Evaporation (Continued)

2. Cheng, P.J., and Karoby J.A., "Evaporators and Crystallizers - Process Links," Proceedings of the 3rd National Conference on Complete Water Reuse, Cincinnati, Ohio, June 1976.

3. Cheng, P.J., "Crystallization for Radwaste Service," presented at ORNL sponsored Reactor Radwaste Management Workshop, New Orleans, La., January, 1977.

4. Cheng, P.J., "Operating Experience with Radwaste Evaporator," presented at ASME-IEEE Joint Power Generation Conference, September, 1977.

5. Karolyn, J.A., and Oshen, S., "Effect of Equipment Size on Performance of Large Scale Crystallizers," presented at 79 th National Meeting of AIChE, March, 1975.

6. Malacarne, 0.J., and Washburn, A.M., "Crystallization of Sodium Sulfate for Effluent Abatement," presented at 79th National Meeting of AIChE, March, 1975.

7. Tanaka, K.H., "Vacuum Evaporator-Crystallizer Process Development for Hanford Defense Waste", presented at ASME Conference on Power Generation, Dallas, Texas, September, 1978, Report No. RHO-SA-38.

F. Fluidized Bed Drying/Incineration/Calcination

1. Anderson, F.H., Bringham, G.E., Buckham, J.A., Dickey, B.R., Slansky, C.M., and Wheeler, B.R., "Design Criteria for the New Waste Calcining Facility at the Idaho Chemical Processing Plant," presented at IAEA Symposium on the Management of Radioactive Waste, Vienna, Austrai, March, 1976, CONF-76031-7.

2. Bingham, G.E., and Wheeler, B.R., "Remote Design Criteria and Philosophy of the New Waste Calciner Facility, "Transactions of the American Nuclear Society, Vol. 30, pg. 784, 1978.

3. Bonder, S.S., Effect of Feed Atomization and Vessel Configuration on Fires Formation and Entrainment from Fluidized-Bed Calciners, Allied Chemical Corp., Idaho Falls, Idaho, Nov. 1978, Report No. ICP-1175.

4. Bonner, W.F., Blair, H.T., and Romero, L.S., "Spray Calcination of Nuclear Wastes," presented at 78th Annual Meeting of the American Ceramic Society, Cincinnati, Ohio, May 1976, Battelle Nortwest Laboratories Report No. BNWL-SA-5764.

5. Freeby, W.A., Off-Gas Cleanup System Considerations for Fluidized-Bed Radioactive Waste Calcination at the ICPP, Allied Chemical Corp., Idaho Falls, Idaho, August, 1978, Report No. ICP-1162. 
F. Fluidized Bed Drying/Incineration/Calcination (Continued)

6. Grimmett, E.S. and Murger, D.H., Product Removal and Solids Transport from Fluidized-Bed Calciners, Allied Chemical Corp., September, 1978, Report No. ICP-1161.

7. Johnson, J.E., and Bradford, D.J., Decontamination of the Waste Calcining Facility: A Histrocial Review, Allied Chemical Corp., Idaho Falls, Idaho, December, 1978, Report No. ICP-1173.

8. May, J.R., "Radioactive Waste Volume Reduction," Power Engineering, Vo1. 82, No. 10, pp. 68-71, October 1978.

9. May, J.R., Thompson, T.K., and McConnel1, J.W., "Fluidized Bed Radioactive Waste Volume Reduction System," Management of Low-Level Radioactive Waste, Volume 1, pp. 287-294, Pergamon Press, Elmsford, N.Y., 1979.

10. McElroy, J.L., Bonner, W.F., Blair, H.T., Bjorklund, W.J., Chapman, C.C., Dierks, R.D., and Romero, L.S., "Recent Calcination and Vitrification Process Accomplishments," presented at IAEA Symposium on the Management of Radioactibe Waste, Vienna, Austria, March 1976, Report No. BNWL-SA-5542.

11. Mikols, W.J., Romero, L.S., and Bonner, W.F., "Recent Advances in Spray Calcination of Nuclear Wastes," presented at ANS Annual Meeting, San Diego, California, June, 1978, Battelle Pacific Northwest Labs. Report No. PNL-SA-6719.

12. Particle Growth and Control During Calcination, Allied Chemical Corp., July 1978, Report No. ICP-1158.

13. Removal of Particulate Solids from the Off-Gas of the WCF and NWCF, Allied Chemical Corp., Idaho Falls, Idaho, June 1978, Report No. ICP-1157.

14. Topical Report - Fluid Bed Dryer, prepared for USNRC by Aerojet Energy Conversion Co., February, 1975, Report No. AECC-1-A.

15. Ziegler, D.L., and Johnson, A.J., "Fluidized Bed Incineration of Transuranic Contaminated Waste," presented at Technical Seminar on the Treatment, Conditioning and Storage of Solid Alpha-Bearing Waste and Cladding Hulk, Paris, France, December, 1977, CONF-771208.

16. Ziegler, D.L., and Johnson, A.J., "Disposal of HEPA Filters by Fluidized Bed Incineration," presented at 15th Annual Nuclear Air Cleaning Conference, Boston, Mass., August, 1978, CONF-780819-4. 
G. Thin-Film Evaporation

1. Chino, K., Kikuchi, M., Yusa, H., and Horiuchi, S., "Analysis of Concentrating and Drying Processes in a Thin-Film Evaporator", Transactions of American Nuclear Society, Vol. 28, pp. 358-359, June, 1978.

2. Fischer, R., "Agitated Thin-Film Evaporators: Part 3 - Process Applications", Chemical Engineering, September, 1965.

3. Freese, H.L., and Gregory, W.T., "Volume Reduction of Liquid Radioactive Wastes Using Mechanically Agitated Thin-Film Evaporators", presented at 85 th National Meeting of AIChE, Philadelphia, Pa., June, 1978.

4. Goodlett, C.B., "Concentration of Aqueous Radioactive Waste with Wiped-Film Evaporators," Radioactive Waste from the Nuclear Fuel Cycle, AlChE Symposium Series, Vol. 72, No. 154, pp. III-122.

5. Goodlett, C.G., "Wiped Film Evaporators for Evaporating Alkaline LWR Radioactive Wastes," Nuclear Technology, Vol. 43, pp. 259-267, April, 1979.

6. Mutzenberg, A.B., "Agitated Thin-Film Evaporators, Part 1, Thin-Film Technology," Chemical Engineering, September, 1965.

7. Parker, N., "Agitated Thin-Film Evaporator, Part 2, Equipment and Economics," Chemical Engineering, September, 1965.

8. Recay, W.H., "Recent Advances in Thin-Film Evaporation," The Industrial Chemist, Vol. 39, No. 6, pp. 293-297, June, 1963.

9. Rupinskas, R.L., and Vogt, P.M., "Thin-Film Evaporators for Processing BWR Liquid Radwaste," presented at ASME Winter Annual Meeting,

New York, N.Y., December, 1976, 76-WA/NE-4.

10. Segawa, T., Yamamoto, M., Miyao, H., and Iwasaki, T., "Development of Bituminization Process for Radioactive Wastes Test by Bench-Scale Plant," Semi-Annual Progress Report of Power Reactor and Nuclear Fuel Development Corp., Tokai Works, pp. 38-45, Apri1, 1973, Report No. PNCT-831-73-01.

11. Thieme, A., Goff, D.L., and Blone, E.W., "A Radioactive Liquid Waste Treatment Facility Utilizing a Wiped-Film Evaporator," Ballistics Research Laboratories, Report No. 1538, Aberdeen Proving Ground, Maryland, AD-726-901, March, 1971.

H. Extrusion/Evaporation

1. Bituminization of Radioactive Wastes, IAEA Technical Report Series No. 116, July 1970 .

2. Bourns, W.T., Buckley, L.P., and Burrill, K.A., Development of Techniques for Radwaste Systems in CANDU Power Stations, Atomic Energy of Canada Limited, Chalk River Nuclear Laboratories, April, 1979, Report No. AECL-6534. 
H. Extrusion/Evaporation (Continued)

3. Stewart, J.E., and Herter, R., "Solid Radwaste Experience in Europe Using Asphalt," presented at ASME-IEEE Joint Power Generation Conference, Portland, Oregon, September, 1975, 75-PWR-21.

4. Topical Report - Radwaste Volume Reduction and Solidification System, prepared for USNRC by Werner and Pfleiderer Corp., November, 1976, Report No. WPC-VRS-001.

I. Incineration

1. Baehr, W., Hempelmann, W., and Krause, H., "Incineration Plant for Radioactive Waste at the Nuclear Research Center Karlsruhe", presented at ASME-IEEE Joint Power Generation Conference, Buffalo, N.Y., September, 1976.

2. Campbe11, A.B., Kohout, R., Sligl, V.R., Jelinski, E.F., Seabrook, A.M., "Volume Reduction of Low Level Radioactive Solid Waste in Ontario Hydro," presented at 9th Biennial Topical Conference on Reactor Operating Experience, Arlington, Texas, August, 1979.

3. Choi, E.C., Drolet, T.S., Stewart, W.B., and Campbe11, A.V., "Operation of Low-Level Radioactive Waste Incinerator," Proceedings of the $15 \mathrm{th}$ DOE Nuclear Air Cleaning Conference, Boston, Mass., 1978.

4. Corbit, C.D., Incineration, Compaction, Segregation and Burial of Solid Radioactive Wastes, Douglas United Nuclear, Inc., Richland, Washington, February, 1979, Report No. DUN-6748.

5. Drolet, T.S., and Skova, J.A., An Incinerator for Power Reactor Low-Leve1 Radioactive Waste, in Proceedings of the 14th ERDA Air Cleaning Conference, Sun Valley, Idaho, August, 1976, CONF-760822.

6. Franioni, W.M., Pilot Incineration Plant for Solid, Combustible, and Low-Level Wastes, May 1976, ORNL-TR-4510.

7. Jordan, H.S., "Problems in the Incineration of Radioactive Wastes," Proceedings of Health Physics Society, pp. 152-158, June 1956.

8. McQuade, D.W., "ORNL Active Waste Incinerator," Atomic Energy of Canada Limited, AECL-2248, 1965.

9. Perkins, B.L., Incineration Facilities for Treatment of Radioactive Waste: A Review, LA-6252, July 1976.

10. Rudnick, S.N., Leith, D. and First, M.W., "Particulate Collection in a Low-Level Radioactive Waste Incinerator," Proceedings of $14 \mathrm{th}$ ERDA Air Cleaning Conference, Sun Valley, Idaho, August, 1976. 


\section{INTERNAL DISTRIBUTION}

1. S. I. Auerbach
2. R. E. Blanco
3. J. H. Coobs
4. N. H. Cutsha11
5. E. J. Frederick
6. D. E. Fergus on
7. R. B. Fitts
8. H. W. Godbee
9. W. J. Lackey
10. R. E. Leuze
11. A. L. Lotts
12. R. S. Lowrie

1. S. I. Auerbach

2. R. E. Blanco

3. J. H. Coobs

4. N. H. Cutsha1I

5. E. J. Frederick

6. D. E. Fergus on

7. R. B. Fitts

8. H. W. Godbee

9. W. J. Lackey

11. A. L. Lotts

12. R. S. Lowrie
13. J. G. Moore

14. M. S. Moran

15. K. J. Notz

16. W. W. Pitt

17. R. A. Robinson

18. T. Tamura

19. D. B. Trauger

20. J. E. Vath

21. N. D. Vaughan

22-25. Laboratory Records

26. Laboratory Records - RC

27. Patent office

EXTERNAL DISTRIBUTION

28. L. Andrews, Chem Nuclear, P. O. Box 1866, Bellevue, WA 98009

29. E. L. Albenesius, Savannah River Laboratory, Aiken, SC 29801

30. T. Bergstrom, University of Michigan, Ann Arbor, MI 48109

31. L. Bradley, 2726 Country Club Drive, Olympia, WA 98502

32. R. L. Brodzinski, Battelle Northwest, 329 Bldg., 300 Area, Richland, WA 99352

33. R. Broseus, National Institute of Health, 9000 Rockville Pike, Bethes da, MD 20205

34. H. Brown, National Govemors Association, 444 North Capital, Washington, DC 20555

35. P. Colombo, Brookhaven National Laboratory, B1dg. 830, Upton, NY 11973

36. P. Costello, Office of the Governor, Statehouse, Boise, ID 83702

37. T. Deboer, Empire State Plaza, Albany, NY 12223

38. J. L. Deichman, Rockwe11 Hanford Operation, 2750 E. B1dg., 200 E. Area, P. O. Box 800, Richland, WA 99352

39. W. Dornseife, Pennsylvania Bureau of Radiation Protection, P. 0. Box 2063, Harrisburg, PA 17120

40. I. Dressen, Division of Waste Products, B 107, Washington, DC 20545

41. J. P. Duguid, Battelle Project Management Division, 505 King Ave., Columbus, OH 43201

42. L. Franks, Bureau of Consumer Health Protection, 505 King Street, Carson City, Nevada 89701

43. E. Fray, EG\&G Idaho, P. O. Box 1625, Idaho Falls, ID 83401

44. G. Frieling, Wisconsin Electric Power Co., Milwaukee, WI 53201

45. R. H. Galbraith, 322 N. Lauderdale, Memphis, TN 38101

46. P. J. Gillis, Stone \& Webster, P. O. Box 2325, Boston, MA 02107 
47. E. Held, Office of Nuclear Regulatory Research, Mail Stop 1130-SS, Washington, DC 20555

48. D. Jacobs, Evaluation Research Corporation, Oak Ridge, TN 37830

49. J. L. Johnson, Los Alamos Scientific Laboratory, P. O. Box 1663, Los Alamos, NM 87545

50-59. D. E. Large, Oak Ridge Operations, DOE, Oak Ridge, TN 37830

60. W. W. Larson, 81 Highland Circle, Wayland, MA 01788

61. D. Lavine, Deadhil1 Road, Durham, CT 06422

62. J. A. Lenhard, Oak Ridge Operations, DOE, Oak Ridge, IN 37830

63-82. G. B. Levin, EG\&G Idaho, P. O. Box 1625, Idaho Falls, ID 83401

83. T. McLaughlin, EPA, $401 \mathrm{M}$ Street, SW, Washington, DC 20460

84. G. L. Meyer, EPA, 401 M Street, SW, Washington, DC 20460

85. G. Derte1, Director, Division of Waste Products, Office of Waste Management, DOE, Washington, DC 20545

86. J. Pee1, Idaho Operations, DOE, 550 Second Street, Idaho Fal1s, ID 83401

87. R. W. Peterson, ONWI, Battelle Columbus Laboratory, Columbus, $\mathrm{OH} 43201$

88. S. J. Phillips, Pacific Northwest Laboratory, Richland, WA 99352

89. R. Pope, Sandia Laboratories, P. O. Box 5800, Albuquerque, NM 87185

90. P. Psomas, Division of Waste Management, NRC, Washington, DC 20555

91. R. Raw1, Department of Transportation, Washington, DC 20460

92. J. R. Robertson, USGS, National Center MS 410, Reston, VA 22092

93. E. M. Romney, UCLA, 900 Veteran Ave., Los Angeles, CA 90024

94. H. Shealey, Bureau of Radiological Health, 2600 Bull Street, Columbia, SC 29201

95. D. Smith, Division of Waste Management, NRC, Washington, DC 20555

96. J. G. Steger, Los Alamos Scientific Laboratory, P. O. Box 1663, Los Alamos, NM 87545

97. J. Watson, University of North Carolina, Chapel Hi11, NC 27514

98. J. B. Whitsett, Idaho Operations, DOE 550 second Street, Idaho Falls, ID 83401

99. T. Wolff, Envi ronmental Improvement Division, P. O. Box 968 , Santa Fe, NM 97503

100. G. Yuan, Natural Resources Defense Council, 25 Kearney, San Francisco, CA 94108

101-127. Technical Information Center, DOE, Oak Ridge, TN 37830 